\title{
IDENTIFICATION, EVALUATION, AND CLASSIFICATION OF BUILDING FAILURES
}

by

William Alexander Porteous

A thesis

submitted to the Victoria University of Wellington in partial fulfilment of the requirements for the degree of Doctor of Philosophy in Architecture

Victoria University of Wellington

1992 


\section{ABSTRACT}

The origin of this thesis was a long-standing interest in the performance of buildings in the years after completion, when the designers and builders have all moved onto the next new work. That interest grew as a result of conducting building surveys in the course of professional practice. The surveys often revealed incipient or actual building failures which required careful diagnosis to discover the cause, so that the failure could be prevented in future.

For the knowledge gained from investigation and diagnosis to benefit the wider community, rather than merely the individuals concerned with one building, it became obvious that some system of objective and anonymous recording of the circumstances of each building failure was necessary.

This thesis proposes a basis for identifying and evaluating building failures. Building failure is defined from the viewpoint of both the producer of the building and the user to ensure that it is the expectations of both that are considered when a building failure is being identified and evaluated.

Identifying and evaluating building failures is a precursor to diagnosing the cause or causes of that failure. It is argued here that any evaluation of the causes of building failures must acknowledge the part played by natural causes as well as the part sometimes played by human error. It is also argued that placing emphasis on blame, and hence on legal liability, encourages universal denial of fault and works against the search for the truth.

A system for classification of building failures by their causes is proposed as a means by which the knowledge gained from diagnosis of individual building failure events can be aggregated to reveal the pattern of failures in a sample of buildings. The results from applying the system of identifying, evaluating, and classifying building failures in a sample of New Zealand dwellings are presented.

The main conclusion drawn from the work is that because natural causes are so difficult an influence to regulate, the best prospect for reducing the incidence of building failures is the avoidance of human error. Because human error can never be entirely discounted insurance against the risk of error is only wise.

A second conclusion reached is that the proposed system of identifying, evaluating, and classifying building failures has been shown to produce useful results, even when the system has had only a written record from which to work. 


\section{ACKNOWLEDGEMENTS}

I consider myself fortunate to have been supervised by David Kernohan whose patience, rigour and encouragement combined to sustain me through the otherwise rather lonely process of writing a thesis.

It would not have been possible to complete my research without the willing assistance of the following organisations, for which I record my gratitude:

Management and staff of the New Zealand Building Performance Guarantee Corporation. (BPGC) Management and staff of the MBS Group of Loss-Adjusters in Auckland, Wellington, Christchurch and Dunedin.

The Board and officials of the New Zealand Architects Co-operative Society Ltd, especially Mr A.G. Kofoed.

Management and staff of the Building Research Association of New Zealand (BRANZ).

Special thanks are gratefully offered to my colleagues in the Victoria University of Wellington. In particular the assiduous work of the librarians Kathryn Bolland, Julie Howarth and Elizabeth Russell must be acknowledged, but I am equally grateful for the many gestures of support received from my friends at the School of Architecture. Amongst these I must include an eminent source of inspiration and encouragement, Gerd Block, Professor Emeritus and founder Professor of the School of Architecture, and the late Tom Jarman and Wendy Light. In the same spirit I thank Professor Helen Tippett whose collaborative research with me in 1980 was one of the experiences which hardened my determination to investigate building failures.

Inspiration and encouragement cannot be mentioned here without a sincere expression of thanks to my parents and to my partner in life Francine for their sustained support.

I am pleased to take this opportunity to acknowledge a debt of gratitude to Olga Vincent, Diana Braithwaite, Elizabeth McKelvey, Trish Blair, Val Laybourn and especially Tracey Edmonds for their patience and exemplary skills in typing, word-processing and lay-out, and to Nigel Isaacs for sharing his enthusiasm and his computing skills.

Finally I must emphasise that, notwithstanding all the help I have received, all errors and omissions are entirely my responsibility. 


\section{CONTENTS}

\section{PAGE}

Abstract

Acknowledgements

Contents

List of Figures

List of Tables

\section{CHAPTER 1 GENESIS OF THE STUDY}

1.0

1.1

1.1.1

1.1.2

1.1.3

1.2

1.2.1

1.2 .2

1.3

1.3.1

1.3 .2

1.3 .3

1.4

1.4.1

1.4.2

1.5

1.5.1 INTRODUCTION

THE CASE FOR RESEARCHING FAILURES

A starting point

The initial search for failure data

Why the cause is important

INDICATIONS THAT FAILURES MIGHT MATTER

Diversion of funds to repair instead of new work

Significance of the proportion of cost of fixing failure

GOVERNING IN IGNORANCE

Building Control system

Building Control system and building failure

New Building Act 1991

\section{LAW AND BUILDING FAILURE}

Reluctance to make written records

Consequences of universal denial of fault

\section{LIKELY BENEFITS FROM THE RESEARCH}

Discovery of what data exits

Design of a procedure for objective identification, evaluation, and subsequent classification of failures and their causes

Analysis of existing data

Improvement of building procedures to reduce the incidence of building failures

\section{DIRECTIONS FOR RESEARCH}

Deciding on a basis for identifying and evaluating each failure event

Defining a building failure

Establishing the causes of building failure

Finding some facts about failures

Finding facts about a suitable sample of failures 

1.7
SUMMARY
1.8
REFERENCES

CHAPTER 2 EVALUATING FAILURE

INTRODUCTION

2.1

BUILDINGS AND CONSUMERS

2.1.1

Buildings as products

2.1.2

Variable tolerance of defects

2.1.3

Variable perception of defects

2.1.4

Taking account of variable tolerance and perception

2.2 AN INITIAL MODEL OF BUILDING FAILURE

2.2.1

Making allowance for individual tolerance and perception

2.3 FINDING A SUITABLE SAMPLE

2.3.1

Searching for a well-recorded sample

2.3.2

Definition of a dwelling

2.4

EVALUATING

2.4.1

Evaluating buildings

2.4 .2

Elements of performance

2.4.3.

Evaluation of simple versus complex buildings

2.4 .4

Evaluation without measurable criteria

2.5 CURRENT AND PARTIAL EVALUATION PRACTICE

2.5.1 Buildings currently evaluated

2.5 .2 Partial evaluation in connection with building failure DOING THE EVALUATION

2.6.1 Applying evaluation practice to dwellings

2.6.2 Objective expert evaluator

2.6.3 Dwelling evaluation team

2.6 .4

A limited evaluation of a dwelling

2.6.5 Evaluation at "arms length"

2.6.6 Barriers to objectivity in evaluation

2.7 SUMMARY

2.8 REFERENCES

CHAPTER 3 DEFINITION OF BUILDING FAILURE

3.0

3.1

3.1.1

\section{INTRODUCTION}

\section{DEFINING BUILDING FAILURE}

Why a definition is necessary 
3.2.1 Obtaining the experts' definition

3.2.2 Limiting the use of the term 'Building failure'

3.2.3 Catastrophes and failures

3.2.4 Experts' definition stated

3.3 USERS' DEFINITION

3.3.1 Obtaining the users' definition

3.3.2 Necessary stages in definition

3.3.3 Users' definition stated

3.4 COINCIDENCE OF DEFINITIONS

3.4.1 Comparison of perceived characteristics of building failure

3.4.2 Degree of coincidence of perceived characteristics

3.4.3 Coincident perceptions and coincident definitions

3.4.4 Significance of the coincident definitions

3.5 SUMMARY

3.6 REFERENCES

CHAPTER 4 CAUSES OF BUILDING FAILURE

4.0

4.1

4.1.1

4.2

4.2.1

4.2.2

4.3

4.3.1

4.3.2

4.3.3

4.3.4

4.3.5

4.4

4.4.1

4.4.2

4.4 .3

4.4.4

4.4.5

4.4.6
INTRODUCTION

TWO GENERIC CAUSES

The case founded on empirical evidence

NATURE'S APPARENT MALEVOLENCE TOWARDS BUILDING

Ashes to ashes, dust to dust

Tabulating natural causes

MISTAKES PEOPLE MAKE

Errors and negligence

Limitations of the word "negligence"

Investigating human errors in building failures

Importance of the survey

Who makes the errors?

AMPLIFICATION OF THE TYPES OF HUMAN ERROR

Defective materials

Overlooked site conditions

Ignorance

Over-emphasis on first cost

Defective documentation

Unanticipated consequences of change 
4.4.7 Specialist contractors' lack of knowledge

4.4.8 Design too difficult to build well

4.4.9 Dereliction or negligence.

4.4.10 Poor communication

4.5

4.5 .1 CLASSIFYING FAILURES BY CAUSE(S)

4.5.2 Benefits from using the classification system

4.6 SUMMARY

4.7 REFERENCES

CHAPTER 5 NEW ZEALAND BUILDING FAILURES DATA

5.0

5.1

5.1 .1

5.2

5.2 .1

5.2 .2

5.2 .3

5.2.4

5.3

5.3.1

5.3.2

5.3 .3

5.3 .4

5.4.1

5.4 .2

INTRODUCTION

\section{SELECTING DATA}

Ideal data source

BUILDING PERFORMANCE GUARANTEE CORPORATION OF NEW ZEALAND (BPGC)

Functions of the corporation

BPGC claim procedure

Analysis of BPGC claims data

5.2.3.1 Distribution by locality

5.2.3.2 Examination of claims to identify cause(s)

5.2.3.3 Time interval from completion to claim

5.2.3.4 Claim cost as \% of contract price

5.2.3.5 Claim sums

Contract prices of BPGC sample houses

NEW ZEALAND ARCHITECTS CO-OPERATIVE SOCIETY LTD (NZACS)

Access to the NZACS claim files

NZACS claim procedure

NZACS claim data categories

Analysis of NZACS claims data

5.3.4.1 Distribution by locality

5.3.4.2 Examination of claims to identify cause(s)

5.3.4.3 Time interval from completion to claim

5.3.4.4 Claim sums

\subsection{INSURANCE LOSS-ADJUSTERS}

Function of loss-adjusters

Impartiality and skilled judgment 
5.4.3 Building failures as a proportion of all claims

5.5 SUMMARY

5.6 REFERENCES

CHAPTER 6 PATTERNS FROM THE FAILURE DATA

6.0 INTRODUCTION

6.1 THE VARIED USEFULNESS OF THE DATA

6.1.1 Variation in data-collection habits

6.1.2 Drawbacks and possible gains from variety of data sources

6.2 THE PATTERN OF CLAIMS

6.2.1 Time lapse between completion and claim

6.2.2 The cost of claims as a \% of contract price

6.2.3 The cost of claims in dollar terms

6.2.4 The loss adjusters data

6.2.5 The incidence of building failures in dwellings

6.3 SUMMARY

CHAPTER 7 WIDER APPLICATIONS

7.0 INTRODUCTION

7.1 POTENTIAL DATA REQUIREMENTS

7.1.1 Ideal data source

7.2 BUILDING INDUSTRY

7.2.1 Nature of the industry

7.2.2 Repository for failure reports

7.2.3 Failure reporting

7.2.4 Benefits

7.3 INSURANCE INDUSTRY

7.3.1 Nature of the industry

7.3.2 Repository for failure reports

7.3.3 Failure reporting

7.3.4 Benefits

7.4 RESEARCH ISSUES

7.4.1 Confidentiality

7.4.2 Ownership of data

7.4.3 Method of data storage

7.4.4 Beyond the simple database

7.4.5 Standard of diagnosis 


\section{SUMMARY}

\section{REFERENCES}

CHAPTER 8 SUMMARY AND CONCLUSIONS

8.0 INTRODUCTION

8.1 METHODOLOGY

8.1.1 Evaluation, identification, and classification combined

8.1 .2 Method of building evaluation

8.1.3 Method of identification Method of classification TESTING THE METHODOLOGY

Limitations of the data

Low incidence of failures

8.4.2 Inevitability of some failures

8.4.3 Management of risk

Causes are proven

8.6.1 Dealing with the causes of failure

8.6.2 Dealing with the risk of building failure

8.6.3 Evaluation "at arms length" 


\section{LIST OF FIGURES}

FIGURE

$\begin{array}{lll}2.1 & \text { A defect is the origin of a failure. } & 19\end{array}$

2.2 Perception and tolerance in the defect/failure connection. 19

2.3 Model of POE process using the Performance Concept (After 24 Preiser).

4.1 Model of building failure perception, incorporating the 'sources' of 59 natural causes (after Addleson) and human error.

5.1 BPGC. Claims by location. 92

5.2 BPGC. Causes of failure. 93

$\begin{array}{lll}5.3 & B P G C . & \text { Incidence of types of human error. }\end{array}$

$\begin{array}{lll}5.4 & \text { BPGC. Natural causes. } & 94\end{array}$

5.5 BPGC. Cause 'dampness' analysed by source. 95

5.6 BPGC. Cause 'chemical/biological change' analysed by source. 95

5.7 BPGC. Cause 'movement' analysed by source. 95

5.8 BPGC. Completion to claim time (years). (All natural causes). 96

5.9 BPGC. Completion to claim time (years). (Natural causes 97 separately).

5.10 BPGC. Completion to claim time (months). (Natural causes only). 98

5.11 BPGC. Completion to claim time (months). (Natural causes 98 separately).

5.12 BPGC. Completion to claim time (years). (Human error alone and 99 natural causes separately).

5.13 BPGC. Completion to claim time (months). (Human error alone 100 and natural causes separately).

5.14 BPGC. Completion to claim time (years). (Human error alone and 101 natural causes summed).

5.15 BPGC. Completion to claim time (months). (Human error alone 101 and natural causes summed).

5.16 BPGC. Claim as \% of contract price. (All natural causes). 102

5.17 BPGC. Claim as \% of contract price. (For each natural cause). 103

5.18 BPGC. Claim as \% of contract price. (Human error alone and 104 natural causes).

5.19 BPGC. Claim as \% of contract price. (Cause 'dampness'). 105

5.20 BPGC. Claim as \% of contract price. (Cause 'dampness' analysed 105 by source).

5.21 BPGC. Claim as \% of contract price. (Cause 106 'chemical/biological'). 

analysed by source).

5.23 BPGC. Claim as \% of contract price. (Cause 'movement'). 107

5.24 BPGC. Claim as \% of contract price. (Cause 'movement' analysed 107 by source).

5.25 BPGC. Claim sums (\$1000s). (Human error alone). 108

5.26 BPGC. Claim sums $(\$ 1000 \mathrm{~s})$. (Natural causes summed). 108

$\begin{array}{lll}5.27 & B P G C . & \\ & \end{array}$

5.28 BPGC. Claim sums (\$1000s). (Cause 'dampness'). 109

5.29 BPGC. Claim sums ( $\$ 1000$ s). (Cause 'dampness' analysed by 110 source).

5.30 BPGC. Claim sums (\$1000s). (Cause 'chemical/biological'). 110

5.31 BPGC. Claim sums (\$1000s). (Cause 'chemical/biological' 111 analysed by source).

5.32 BPGC. Claim sums (\$1000s). (Cause 'movement'). 111

5.33 BPGC. Claim sums ( $\$ 1000 \mathrm{~s})$. (Cause 'movement' analysed by 112 source).

5.34 BPGC. Wellington. (Average prices of dwellings). 113

$\begin{array}{lll}5.35 & \text { BPGC. Auckland. (Average price of dwellings). } & 114\end{array}$

5.36 BPGC. Hamilton. (Average price of dwellings). 114

$\begin{array}{lll}5.37 & B P G C \text {. Christchurch. (Average price of dwellings). } & 115\end{array}$

$\begin{array}{lll}5.38 & B P G C . & 115\end{array}$

$\begin{array}{ll}5.39 & 119\end{array}$

$\begin{array}{ll}5.40 & 121\end{array}$

5.41 NZACS. Analysis of claims by number of classes of human error 124 per claim.

5.42 NZACS. Incidence of types of human error. 125

$\begin{array}{ll}5.43 & 127\end{array}$

$\begin{array}{ll}5.44 & \text { NZACS. Natural cause 'dampness' analysed by source. } \\ \end{array}$

$\begin{array}{ll}5.45 & \text { NZACS. Natural cause 'chemical/biological' analysed by source. } 127\end{array}$

$\begin{array}{ll}5.46 & 128\end{array}$

5.47 NZACS. Completion to claim time (years). (All causes). 128

5.48 NZACS. Completion to claim time (months). (All causes). 129

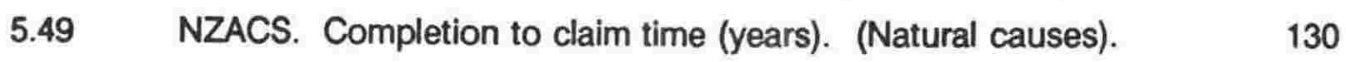

5.50 NZACS. Completion to claim time (months). (Natural causes). 130

$5.51 \quad$ NZACS. Completion to claim time (years). (Human error only). 131

5.52 NZACS. Completion to claim time (months). (Human error only). 131

$5.53 \quad$ NZACS. Claim sums $(\$ 1000 s)$. (All causes). 132 

causes).

5.55 MBS. Proportion of building failures, Auckland and Wellington.

5.56 MBS. Proportion of building failures, Christchurch and Dunedin.

5.57 MBS. Failure by fire and water, Auckland and Wellington.

5.58 MBS. Failure by fire and water, Christchurch and Dunedin.

5.59 MBS. Failures and accidents in Auckland and Wellington (1982).

5.60 MBS. Failures and accidents in Christchurch (1983) and Dunedin (1982).

5.61 MBS. Fires and accidents in Wellington in 1982 and 1983.

6.1 Completion to claim time lapse (years) for BPGC claims from all causes

6.2 Completion to claim time lapse (years) for BPGC claims from 'natural causes'.

6.3 Completion to claim time lapse (years) for NZACS claims from all causes.

6.4 Comparison of completion to claim time lapse (years) for BPGC and NZACS claims from all causes.

6.5 Completion to claim time lapse (years) for NZACS claims from 'natural causes'.

6.6 Completion to claim time lapse (months) for BPGC claims from human error alone and 'natural causes'.

6.7 Completion to claim time lapse (months) for BPGC claims from 'natural causes'.

6.8 Completion to claim time lapse (months) NZACS claims.

6.9 Completion to claim time lapse (months) NZACS claims from 'natural causes'.

6.10 Comparison of completion to claim time lapse (months) for BPGC and NZACS claims for all causes.

6.11 Claim as \% of contract price for BPGC claims from all causes.

6.12 Claim as \% of contract price for BPGC claims from 'natural causes'.

6.13 Claim as \% of contract price for BPGC claims caused by movement, showing sources.

6.14 Claim as \% of contract price for BPGC claims caused by chemical/biological change, showing sources.

6.15 Claim as \% of contract price for BPGC claims caused by dampness, showing sources.

6.16 Claim sums (\$1000s) for NZACS and BPGC claims.

6.17 Claim sums ( $\$ 1000 \mathrm{~s}$ ) for BPGC claims by 'natural causes'. 158

6.18 Claim sums $(\$ 1000 \mathrm{~s})$ for BPGC claims by 'natural causes' and 159 'human error alone'. 

6.19 Claim sums $(\$ 1000$ s) for all BPGC claims in period $1978 / 80$,
$1980 / 82$ and $1982 / 84$.

6.20 Dwelling annual completions and annual BPGC claims.

161 


\section{LIST OF TABLES}

TABLE

3.1 Characteristics of failure by source of opinion.

43

3.2 Characteristics of Failure by source of opinion (including the BPGC

49 opinion expressed under statutory authority.

4.1 Sources and Causes ('Natural Causes') of building failure (after Addleson, L, 1977).

4.2 Numbers of references to various human errors as causes of failure, by year of publication of the reference, and the totals for each type of human error.

5.1 BPGC indemnities issued as a percentage of new permits.

$5.2 \quad$ NZACS. Analysis of claims by locality.

5.3 NZACS. List of claims showing 'natural' cause and classification of human error.

5.4 NZACS. Analysis of claims by class of human error.

5.5 NZACS. Analysis of Causes by Sources. 


\section{CHAPTER 1}

\section{GENESIS OF THE STUDY}

This chapter explains how the research sprang from perception of a clear need, revealed during earlier research, to obtain data about the way buildings perform so that decisions about the controls to be imposed on the building industry could be based on researched fact rather than on conservative theory or expert belief. The reason for concentrating on building failures is explained, and the range of investigations of failures, and aspects of failure, is surveyed briefly.

Indications that building failures do matter are discussed. The apparent inability of the Building Control system to affect the incidence of building failures and the stifling effect of the adversarial legal system on the search for truth uncoloured by considerations of blame are outlined.

The benefits which might be expected to flow from a better understanding of building failures, their causes and effects, are considered. These are short, medium, and long-term in nature and promise economic as well as less tangible gains.

Finally the chapter concludes with a summary of the directions in which research must proceed if the phenomenon of building failure is to be properly understood and the benefits of that understanding obtained. 


\subsubsection{A starting point}

The impetus to carry out research into building failures originated from the findings of research carried out in 1980 into the cost impact of New Zealand Standards (Tippett, 1980). The findings revealed it was possible for a mandatory building code (the NZ Standard under examination) to be modified on hearsay evidence to become so stringent that compliance became demonstrably impossible. Examination of the process by which such an absurd situation could arise soon showed that much of the detailed requirements of building codes relied more on theory and opinion than on any researched proof of the need for those requirements. Thus it was possible for the fastening requirements for suspended ceiling tiles to be made more onerous, on the grounds that there had been accidents in New Zealand arising from tiles falling in earthquakes, when research revealed not one record of such an event.

This discovery seemed to suggest not only that there were few data about building failures in New Zealand but also that, in the absence of such data, the building codes were possibly being written on the basis of undue caution. While caution has its place in building, unjustified caution was shown by Tippett to contribute to the cost of building.

\subsubsection{The initial search for failure data}

The search for failure data was based on empirical evidence that building failures are more likely to be recorded than building successes. A building which performs satisfactorily attracts much less notice from its users than one which exhibits failure of some sort. Similarly, the cause of sound buildings is less likely to attract notice than the cause of building failures. 
Early enquiries (Porteous, 1982) revealed that there has been no national agency in New Zealand collecting data about each building failure event. Instead the available data has consisted of written queries or complaints made to such organisations as the Building Research Association of New Zealand (BRANZ) or the Consumers Institute, or in the case of building contracts indemnified by the Building Performance Guarantee Corporation, to the Corporation. Complaints made to local branches of the Master Builders Association have not been recorded in any systematic way.

The inevitable result of such a dispersed and incomplete system of gathering building failure data is that no one in New Zealand has known, even roughly, how many failures occurred in a year, where they occurred, why they occurred, their nature and extent, approximate cost, or any other significant detail which might provide an insight to ways of reducing the incidence and/or severity of failures.

Internationally the problem is the same. Data is incomplete because of erratic or inconsistent reporting. Buildings are not constructed in laboratories where they may be studied in a controlled setting, but are, like the people studied in medical research, spread randomly across countries.

Despite these difficulties interested organisations in some countries have attempted to collect failure data on a nation-wide scale. Amongst these attempts are those of the National House Builders Registration Council (NHBRC) in the United Kingdom (National House Building Registration Council, 1979), and the Nippon Telegraph and Telephone Corporation (NTT) in Japan (Morishita et al, 1989). The first of these records the work of a researcher employed to analyse the reports of NHBRC inspectors investigating defects in a block sample of 1028 complaint cases. The second records a method for 
diagnosing deterioration and appropriate repair techniques for NTT's portfolio of more than 30,000 buildings.

As examination of the Bibliography will show, there has been considerable international interest in the subject of building failures, but a search of the literature over a period of ten years to the present time has failed to discover any on-going nation-wide system for the recording of building failure data. Like the British National House Building Registration Council and the Japanese NTT Corporation, other individuals and organisations have researched and reported on aspects of building failures, but usually with an emphasis on legal liability (Cecil, 1983, 1984), structural failure (Di Pasquale, 1982), cost of failure (Drury, 1981), design (Harper, 1974) or some other specialised viewpoint which either disregards cause, or ascribes all failures to negligence. AEPIC (Architecture and Engineering Performance Information Centre) at the University of Maryland, USA (Allen, 1983) is another organisation collecting data nationwide, largely from professional liability insurers. It attributes cause to broad headings such as 'architectural services' and 'management problems', but does not appear to examine or classify the nature of human errors.

\subsubsection{Why the cause is important}

It is important to find the causes of building failures because until the causes are known their eradication or reduction will be, at best, difficult to achieve. The controls which our society imposes on facilities which may be built are intended to ensure that building is carried out "in a manner which will not put at risk the health safety and well-being of the public." (Department of the Environment, UK, 1980). If it is argued that building failures are detrimental to the well-being of the public, then their evaluation or reduction will accord with the intent of the building controls. 
More importantly, finding the causes of building failures enables the appropriate instruments to be used to prevent or reduce those failures. It may be discovered, for example, that the cause of frequent plumbing failures lies with the inadequacy of the crimping tool supplied to plumbers and not with a defect in the plastics materials. A building control ban on the use of plastics plumbing materials would clearly be draconian and possibly add to the cost of the building by forcing the use of more expensive materials, whereas improving the crimping tool would solve the failure problem without adding to the cost of all future plumbing.

It is tempting to think that lack of building failure data matters little in New Zealand given that the building industry in this country is small by international standards. To do so is to ignore economic data (NZ's Dept of Statistics, 1991) which shows that construction made a contribution of NZ\$2215 million to New Zealand's Gross Domestic Product in 1989, an amount which is not insignificant when it is realized that agriculture for which New Zealand is well-known in international markets, contributed \$NZ4281 million in the same year. The building industry in New Zealand is not small seen in that context. Also often overlooked is the fact that it is not the cost of making good the failures that matters so much as it is the proportion of building industry resources diverted away from new building and expended on the execution of premature repairs and modifications following building failure.

In the Architects' Journal (Rabeneck, 1981) it was reported: 
'The GLC for example, spent £12 million * last year and has allocated the same this year for what it calls 'major technical problems'. It is not alone; many other local authorities and private owners face large bills for remedying defects. The National House Builders' Council (NHBC) is also paying out $£ 4$ million a year on defects under its insurance scheme. Most people were shocked at press predictions that the bill for remedial works to local authority housing could exceed £200 million, (a figure I would judge conservative) or that the London Borough of Hillingdon had to find £8.5 million for remedial works to its Bison Wallframe housing'.

For the year ended 31 March 1990 the value of all notified building of dwellings in New Zealand was NZ\$2553.6 million of which NZ\$383.1 million (15\%) was described as additions and alterations.

\subsubsection{Significance of the proportion of expenditure on fixing failure}

Those cost figures, while certainly not inconsequential, mean little unless put into perspective against the United Kingdom expenditure on the whole building industry. For that reason it is salutary to note a report in New Scientist (Marsh, 1978) which stated (with reference to the intended lifespan of buildings):

'Some maintenance is, of course, to be expected - just as humans need a dose of medical care once in a while - but repairs and improvement nowadays account for about £3.5 billion of the industry's annual output of $£ 12$ billion...'.

costs are pounds sterling, but it is the relative amount, not the absolute value that matters. 
It is possible that the proportion of monies spent on repairs and improvements in New Zealand has been just as high, but without the necessary evidence being collected this cannot be substantiated or refuted. For the year ended 31 March 1990 the value of all notified building work carried out in New Zealand was NZ\$3885.3 million of which NZ\$935.5 million (24\%) was described as 'additions and alterations'. How much of the 'additions and alterations' was actually remedial work is not known.

The building industry in new Zealand as in most developed countries has been governed by various acts and regulations imposed on it by central government, by codes imposed by government departments, by bylaws imposed by local authorities and by its own internal networks of professional and trade organisations, and teaching training, and research institutions and systems.

While some parts of the governance system are largely self-imposed to ensure that certain work can only be done by certain trades and professions and may be seen to be not unconnected with the profit motive, other parts, especially those imposed by law, are intended to protect public health and safety and, to some extent, amenity. The imposed system is commonly called the 'Building Control system', a title which implies that the system controls all aspects of building. In fact it does not. It is highly selective as to which aspects of the design, construction, use and maintenance of buildings it controls, and to what extent that control is justified by research. That part of the system intended to protect public health and safety in the event of earthquake, for example, has been the subject of almost continuous 
modification in the light of the latest research theory and knowledge to the point where the industry began to question whether the cost of compliance could be justified, or even whether compliance was possible (Tippett, 1980).

Other parts of the system, also ostensibly concerned with the preservation of public health and safety, remained unaltered despite advancing knowledge proving them to be redundant. For example, two local authorities continued to require interceptor traps in domestic soil drains long after most others had removed such traps from bylaw requirements. Interceptor traps add cost to the drainage installation and do not allow a blockage-clearing cleaning rod to pass through. Their retention simply imposed additional installation cost and possibly greater maintenance cost on the house-owner. Anecdotal reports tell of similar conservatism being encountered by the designers of a new hotel who wished to install a single-stack drainage system at a considerable cost saving compared with previously used dual-stack systems. The designers found the local authority to be ignorant of the research evidence that the proposed system was sound.

The inconsistent application of new knowledge to building control requirements is the inevitable result of a 'prescriptive' system, which prescribes what must be installed, being used instead of a 'performance' system which specifies how the installation should perform. Unless prescriptive building control systems are frequently updated to take account of the latest knowledge they cause the building process to be governed in ignorance.

By its very nature, a prescriptive system is far more vulnerable to the influence of powerful lobby groups (such as a fire-fighter organisation) than a performance system is likely to be. That is because a prescriptive system relies upon more or less informed opinion as to 
what is desirable while a performance system specifies more or less precisely measurable criteria.

There are types of building failure which do threaten public health and safety. Failures causing fire are one obvious type, but that most wellknown and obvious failure, the water leak, is another. Living or working in perpetually or even spasmodically damp conditions is not conducive to good health (Platt et al, 1989), yet, in the past, the Building Control system offered little prospect of preventing the building-owner suffering from this class of building failure. The requirements for fire safety on the other hand are far more rigidly imposed and enforced, involving annual inspections in some cases.

The Building Control system cannot, with certainty, prevent or reduce the incidence of building failures because there is, at present, insufficient information to show how it might be done, or whether it is possible for the incidence of building failures to be affected in any way by a building control system. The exception to this general statement is that class of failures which might be classed as catastrophic. The Building Control system has much to say about structural strength to resist wind, earthquake, dead and live loads, and it is likely that new and complying drainage and electrical installations will not spread disease or cause electrocution, but the system has nothing effective to say about more common, less drastic shortcomings in buildings. How can it when only catastrophic events draw attention, just as the squeaky wheel receives the oil?

\subsubsection{New Building Act 1991}

The new Building Act, recently passed in New Zealand (and replacing more than 30 earlier Acts) paves the way for a performance based 
system in place of the old prescriptive one. The passage of time will show what improvements this will bring to the Building Control system, but, by itself, the Act is unlikely to affect directly the incidence of building failures. The regulations to be made under the new Act will include the New Zealand Building Code (NZBC) which will render obsolete over 50 old regulations and 213 local government bylaws. The simplicity of the NZBC and its performance - specifying nature may be expected to assist in the definition of building failures. As discussed in Chapter 3 such definition is no simple matter.

The Building Industry Authority (BIA), which will administer the NZBC and approve documents, building systems and materials shown to comply with the code requirements, may become a repository for reports on investigation of cases in which failures to comply have occurred. Such a centralised collection of data would offer enormous potential for research into building failures.

\subsection{LAW AND BUILDING FAILURE}

\subsubsection{Reluctance to make written records}

The adversarial system of law in New Zealand, a system which is shared with the United Kingdom, Australia and other Commonwealth countries has encouraged certain conventions in the behaviour of disputants. Chief amongst these is the convention that no fault is to be admitted. This leads to the curious situation in which two or more parties to a dispute over a defective building will all deny liability even when it is obvious that one or more of them must be at least partly responsible for the error. Because the lawyers for each party may seek to obtain copies of any reports written by an investigator, and seek to use them in court, some investigating organisations record only a few sparse facts and report verbally and privately to their 
clients. This situation changes if the case goes to court and the investigator is nominated as an expert witness. An expert witness (Webb, 1989) is a servant of the court and may be obliged to provide an expert opinion as to the attribution of blame.

\subsubsection{Consequences of universal denial of fault}

The chief consequence of the convention of denial of fault is to encourage the complainant to seek compensation from the party most likely to be well insured against such claims. Architects sometimes find themselves the subject of a professional negligence claim which the owner has commenced only because the building contractor has no resources and no insurance from which to meet such a claim (Caulfield, 1991). In other words the convention of denial of fault may lead to legal disputes (and decisions) which have less to do with the complexity of the cause(s) of the building defect (see Chapter 4) than they do with whether the only (or best) insured party can be made to pay.

From the outset, this research has sought to examine the nature of the human errors that contributed to building failures in the belief that to do so would reveal much about the causes of building failures that the use of the legal catch-all label 'negligence' seems only to conceal. The only purpose served by delving into the mistakes of the past has been a constructive one, much more concerned with reducing the incidence of failures in the future, than with apportioning blame for those in the past. 


\subsubsection{Discovery of what data exists}

As no data-base on building failures in New Zealand existed before the research began, one obvious benefit to building research is the establishment of a database comprising whatever data can be gleaned from existing sources. Once a database is established the current and future incidence of failures can be compared with it.

1.5.2 Design of a procedure for objective identification, evaluation, and subsequent classification of building failures and their causes

The need for the ideal database to contain data objectively identified, evaluated, and classified, is evident. The design of a procedure which makes such a database possible, and which offers the further real benefit of permitting data to be aggregated to obtain general results, is an essential product of the research. The ability to identify, evaluate and classify failures makes possible the medium and long-term benefit of monitoring the incidence of failures of various types (see 1.5.4).

\subsubsection{Analysis of existing data}

The analysis of existing data, no matter that the data may be imperfect or incomplete, will provide rare (and possibly the first) indicative information about the cause, cost and other aspects of building failure in New Zealand. This is a realizable short-term benefit. Given more and better recorded data there is also the prospect of a sustained benefit, as the analysis assists the long-term benefit outlined in 1.5.4. 

building failures

When the causes of building failures are known with some certainty the resources devoted to the control of quality in building can be concentrated on those aspects of building most prone to errors or to the most expensive errors. This is a medium to long-term benefit which will flow more strongly as more evidence about the causes of building failure is accumulated. event

The number and geographic distribution of the buildings within New Zealand was seen as likely to affect the ability of a researcher to visit all the failure sites, even if it was otherwise possible to do so before the failures were fixed and thus concealed. Therefore, although it would be less than ideal, a system for identifying and evaluating the failures away from the sites would have to be devised. This system would suffice for obtaining indicative research results, although it would fall short of the ideal system in which every site would be visited while the building failure still existed.

In Chapter 2 the proposed method of identification and evaluation is shown to be an adaptation of well established techniques used successfully all over the world. 


\subsubsection{Defining a building failure}

Earlier reference to catastrophic and smaller building failures (see 1.3.2) made it clear that some definition would be needed if the term 'building failure' was to be used with any precision. The question of definition is pursued in Chapter 3.

\subsubsection{Establishing the causes of building failure}

It was not certain that any new cause of building failure, previously unknown to the arts and science of building, would be found. Nonetheless, in Chapter 4 a fresh view of the complexity of the cause of some failures involving both natural causes and human error is discussed, drawing on the literature and represented in a model of the process of failure.

\subsubsection{Finding some facts about failures}

As none of the most likely industry organisations in New Zealand, such as the Building Research Association of New Zealand (BRANZ) or the Masters Builders Associations, had maintained collections of data about building failure it was necessary to look further afield. As it turned out, some of the organisations that insure buildings eventually proved to be the most useful sources of factual information.

In the light of the legal conventions discussed in 1.4.1 and 1.4.2 the search for facts about building failures was given a sharper focus by the need to find a source of data which contained information freely recorded without regard for acceptance or denial of fault. 
Assuming that it would not be possible for a solo researcher even to find, let alone read, every failure record in New Zealand, it was obvious that the selection of a sample of failure records would be necessary. The selection might have to be by building type, location, cost, age or similar factors, or a combination of these. The other possibility was that the sample might be dictated by the desirability of using the most complete and consistently assembled data available.

\section{SUMMARY}

This chapter began by explaining the genesis of the study. It went on to point out that building failures, while attracting little attention in New Zealand, are a matter of considerable interest internationally.

The chapter argued that building failures may be a matter for concern which cannot be regulated simply by a building control system. It made reference to the short, medium and long-term benefit which might flow from a better understanding of building failures, their causes and effects.

Finally the chapter concluded with a summary of the directions in which research must progress if the phenomenon of building failure is to be properly understood and the benefits of that understanding obtained. The first of these directions is followed in the next chapter. The second (defining a building failure) is pursued in Chapter 3 , the third (establishing causes of failure) in Chapter 4, while the fourth and fifth, concerned with obtaining a sample of usable data, are the basis of Chapter 5. 


\subsection{REFERENCES}

Allen, D.E. AEPIC Computerised Database on Failures. Personal Communication with Division of Building Research, National Research Council of Canada, Ottawa, December 1983.

Caulfield, Robert. Surviving the Recession - Minimising Claims. Paper presented to New Zealand Institute of Architects International Conference, Auckland, November 1991.

Cecil, Raymond. Raymond Cecil on liability in Royal Institute of British Architects (RIBA) Journal, September 1983 p 43, October 1983 p 39, November 1983 p 43, November 1983 p 27, January 1984 p 35, February 1984 p 41, April 1984 p 44, May 1984 p 42, June 1084 p 42, September 1984 p 42, October 1984 p 41.

Department of the Environment, UK. The future of building control in England and Wales. Consultation papers prepared for circulation to local authorities and interested parties in England and Wales, June 1980.

Di Pasquale, R.A. Bridging catastrophe: understanding why failures occur. Concrete Construction, USA, April 1982. pp 345-348.

Drury, C.A. The Effects on Investment of Major Defects, Chartered Surveyor, (Supplement) April 1981, pp 10-11.

Harper, D. The Designer's Viewpoint. in Proceedings of joint Building Research Establishment/Institute of Building Seminar on building defects and failures. 29 November, -1974, IOB, Ascot, Berks, U.K. November 1974.

Marsh, P. Why do Britain's Builders Bungle the Job?, New Scientist, London, vol 78, no 1104, May 1978, pp 523-525. 
Morishita, K., Sato, Y., Fuse, T. Deterioration Diagnosis and Repair Techniques for NTT Buildings in Proceedings of CIB ' 89 11th International Congress, Paris, June 1989. Theme III vol 1. pp 167-176.

National House Builders Registration Council. The incidence, causes, and prevention of defects in private and public sector housing. NHBRC, London, June 1979.

Platt, S.D, Martin, C.J, Hunt, S.M, Lewis, C.W. Damp Housing, Mould Growth and Symptomatic Health State, British Medical Journal, vol 298, 1989, p 1673.

Porteous, W.A. Building Failures, The Chartered Builder (Journal of the Australian Institute of Building), vol 35, 1982, pp 53-56.

Rabeneck, A. Facing Up to Failure. Diagnosing and preventing defects, Architects Journal, vol 173, no 15, 15 April 1981, pp 715-718.

Tippett, $\mathrm{H}$ and Porteous W. Cost Impact of New Zealand Standards - A pilot study of methodology using NZS4203:1976 Clauses 3.6.5 Suspended ceilings. Report prepared for Ministry of Works and Development. Victoria University of Wellington. November 1980.

Webb, Chris. Working as an Expert Witness, Architects Journal, vol 190, no 21,22 November 1989, p 127. 


\section{CHAPTER 2}

\section{EVALUATING FAILURE}

\subsection{INTRODUCTION}

The previous chapter listed the directions in which the research would need to move to advance the study of building failure. First amongst these was the establishment of a basis for identifying and evaluating each failure event. Such a basis was necessary so that each investigated or reported failure could be treated consistently. While the ideal identification and evaluation procedure would be one carried out on the site immediately after the failure was notified, for the purposes of the research that was not possible (see 1.6.1) and recourse was had, instead, to the written records of the failures.

As mentioned in Chapter 1 (see 1.1.2) it was easier to write about written records of failure than it was to find some. In the chapter the successful search to find a well-recorded suitable sample of buildings on which to apply an identification and evaluation technique is described. Although the evaluation procedure proposed is applicable to all types of occupied buildings, the only suitable sample of failure records located was in a collection of claim files in the Building Performance Guarantee Corporation of New Zealand, an organisation which dealt with dwellings.

The chapter begins with a commentary on the variable tolerance and perception displayed by people towards defects or shortcomings in products. In this context it is argued that buildings are products in which defects will be regarded with similar variability by their owners and occupiers. 
The chapter goes on to set out the basis of the evaluation procedure as it can be applied to simple and to complex buildings. The rationale behind a partial evaluation of a building, limited to evaluation of the technical aspects of the building is explained, noting that building failures, as defined in Chapter 3, represent a shortfall on the technical performance of the building.

Finally the practical aspects of carrying out an evaluation are described. The procedure can be carried out on site or 'at arm's length - that is, remote from the site and reliant on the observations and records of others. This latter application of the procedure will always be necessary in cases where issues of confidentiality or legal liability prevent investigators of building failure from gaining access to the failure site. For the purpose of the research it was the only practicable course to follow.

\section{$2.1 \quad$ BUILDINGS AND CONSUMERS}

\subsubsection{Buildings as products}

A building is a product, the consequence of a series of processes involving material and human resources. Not all products are perfect in every aspect while others are unacceptably defective.

\subsubsection{Variable tolerance of defects}

Sometimes the trade-off of price and quality implicit in buying factory 'seconds' is acceptable, but some products are not regarded as good enough to sell at all. The individual's personal tolerance of imperfection in buildings and consequent willingness to allow a strength to compensate for a weakness is implicit in the way a steep or awkward access to a building site is sometimes accepted as the price to be paid for superb views, all-day sun, or the convenience of inner-city living. 
If the imperfection is in a dwelling owned and occupied by an individual, then the tolerance of imperfection may be affected by the extent of that individual's ability to fix the imperfection or to pay someone to fix it. The less affluent may tolerate imperfection not from natural inclination but of necessity, while the well-off can afford to be intolerant, "to have high standards", because they can pay for the achievement of perfection.

When people group together in a business entity there may be a low tolerance of imperfections which might discourage business clients or customers but it is observably common for commercial enterprises to tolerate the inconvenience of less than ideal buildings, albeit sometimes renovated, in return for gaining advantages such as association with a landmark building or proximity to streets with high pedestrian counts.

On the other hand individuals working for a business may be less tolerant of imperfections in the building in which they work because they know the cost of fixing the imperfection will fall not on them but on the firm.

An observer of the way in which people adapt to less than ideal spaces in commercial and industrial buildings or appear to be able to live happily by choice in houses, flats and motels will require no convincing that people are the most flexible elements in a building.

Whether the building users are thinking and behaving as individuals or as a corporate entity there is also likely to be present the "newer is better" and "brand-new is faultless" factors which much persuasive advertising works assiduously to keep raised in our society's collective sub-conscious. These may cause building users to expect a new building to be better than an old one, and will almost certainly reinforce their belief that a new building should be faultless at the time of delivery, an expectation most people have about any new purchase, and one to which the plethora of guarantees and warranties offered to purchasers is obviously geared. 


\subsubsection{Variable perception of defects}

While individuals may have differing degrees of tolerance of building imperfections for various reasons including those just discussed, they may also have differing perceptions of what constitutes an imperfection. Someone who has spent a life-time in a succession of skilfully designed, well-crafted, and meticulously maintained buildings will be irritated by squeaking hinges and erratic lifts to a greater extent than someone accustomed to living in ramshackle poorly maintained buildings in which doors that still swing on their hinges and windows that are glazed represent a high point in amenity.

\subsubsection{Taking account of variable tolerance and perception}

The variable tolerance and perception of individual building users are unique to those individuals and may not be matched by the tolerance and perception of the individual builder - the producer of the product. This variability and possible (even likely) mismatch needs to be borne in mind when evaluation of buildings is discussed. Aggregation of the viewpoints of many individual building users and producers makes it possible to obtain the general viewpoint of each group by revealing the common aspects of those viewpoints. 


\subsubsection{Making allowance for individual tolerance and perception}

It is axiomatic that for a building failure to be perceived there must be some real or perceived defect in the building. The relationship can be graphically represented thus:

Real or perceived building defect

leads to Perceived building failure

Fig 2.1. A defect is the origin of a failure

An illustration of this simple relationship would be an instance where untreated timber is used for house piles and the resulting premature decay causes the building to settle unevenly, leading to serious cracking of wall linings, jamming doors and undulating floors.

The situation is more complicated where there is less certainty about whether there really is a defect, or, if the defect is indisputable, whether there really is a building failure as a consequence. As discussed in 2.1.2 and 2.1.3 different people may have different tolerances and perceptions of defects and therefore of failures. Modifying the model to allow for these factors leads to the following:

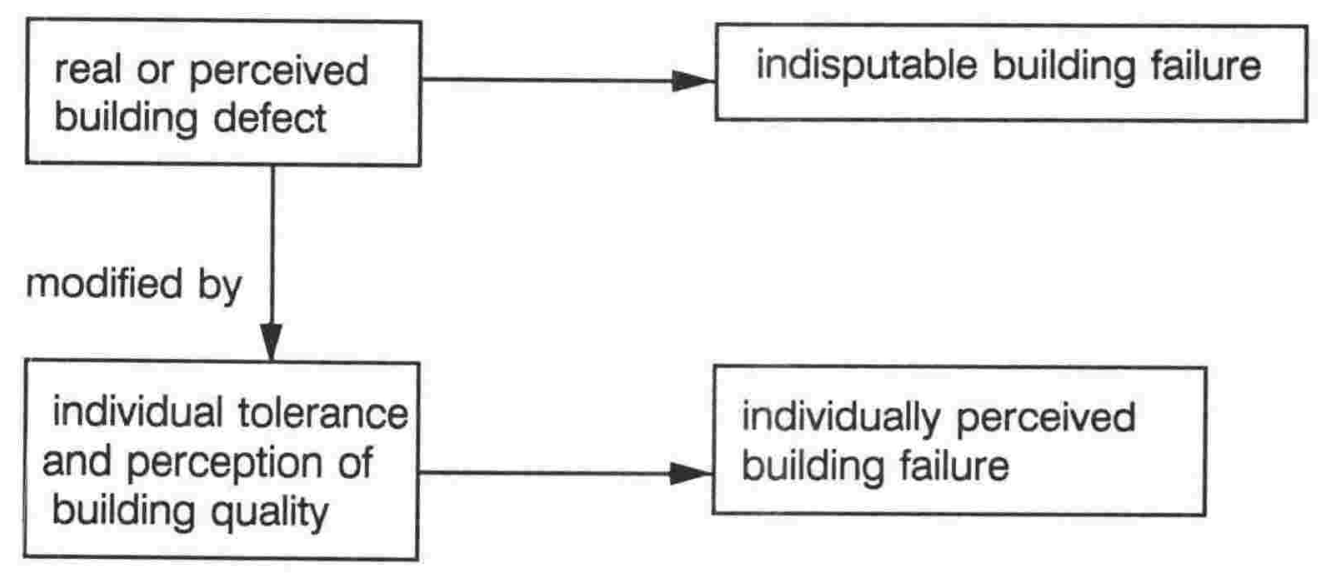

Fig. 2.2 Perception and tolerance in the defect/failure connection. 
In Chapter 3 the definition of a building failure is explored from the point of view of both the lay user of a dwelling (the owner/occupier) and of building industry related experts. The purpose of such an exploration is to discover more about the personal perceptions of defects and failures which lay users and industry experts bring to bear when they are identifying and evaluating building failures.

\subsection{FINDING A SUITABLE SAMPLE}

\subsubsection{Searching for a well-recorded sample}

Before evaluation of building failures could be carried out, it was necessary to locate a suitably sized sample of comparable buildings, since aggregation of the findings of the individual evaluations was contemplated as the best means of drawing out the trends indicated by the evidence of the evaluations. As the evaluation was to be done from existing records made by others, it was also desirable that the records being examined for each evaluation should have been made in much the same fashion, and for the same purpose in each case.

In the course of earlier research into building failures in New Zealand dwellings (Porteous, 1986) it was discovered that there did exist a sample of dwellings for which the records met these requirements. The Building Performance Guarantee Corporation (BPGC), then a subsidiary of the statefunded Housing Corporation had, for some years, been offering a form of guarantee to new house-owners at the commencement of construction. It provided protection against builder insolvency and various classes of defect arising for a period of up to six years after completion. Claims were lodged with the BPGC who engaged independent assessors from the Housing Corporation to inspect and report on the circumstances and validity of each claim. In essence the inspectors acted in the same impartial way that loss- 
adjustors act in the general insurance industry and can be considered to be the 'objective expert evaluators' described in 2.6.2.

The BPGC scheme was open to all-comers and there was no restriction on which builder the client could elect to employ. It will be shown in Chapter 5 that housing contracts both above and below the average value in the various regions of New Zealand were protected by the Corporation. In these circumstances it was clear that the BPGC claim files would contain a sample of new houses being built all over the country. In the event all claims over a period of 6 years were investigated in order to include some dwellings which had reached the age at which the BPGC protection lapsed and to allow the pattern of time lapse between construction and a claim (if any claim was made) to be revealed in the aggregated data.

As discussed in Chapter 5 other sources of building failure data related to dwellings were located, but these tended to be less complete or in other ways less useful for evaluation purposes.

Quite apart from the availability of the BPGC claim data, the use of a sample of dwellings has other advantages for an experimental evaluation procedure.

In particular it was noted that:

1 Dwellings are the most numerous buildings to be erected in any given year in New Zealand. This means that even in a trough in the level of activity in the construction industry there will always be a range of new dwellings being constructed in most climatic regions in the country.

2 Dwellings tend to be relatively simple buildings with few, if any, mechanical services, and the same range of common utility services. 
They are consequently sufficiently similar to be considered comparable and for aggregation of data to be valid.

3 Dwellings are generally occupied day and night and thus exposed to the maximum possible period of use and consequent scrutiny by the users.

4 Dwellings tend to be purchased with personal rather that corporate funds. This is likely to increase the acuity of the owner's interest in the performance of the building.

\subsubsection{Definition of a dwelling}

For the purpose of this experimental evaluation a 'dwelling' is taken to have its common meaning of 'place of residence' or 'house' (Concise Oxford Dictionary, 1976). This definition excludes buildings which are houses but which are not predominantly used as a place of residence. A place of residence can be a house (detached or otherwise), a town house, apartment, or flat. In the sample under consideration all the dwellings were owner-occupied and it was the owner who lodged the complaint of building failure in each case.

\subsection{EVALUATING}

\subsubsection{Evaluating buildings}

In a recent publication on building evaluation (Preiser, 1989) developments in both the theoretical and practical aspects of building evaluation are cogently summarised. Also summarised is the case for incorporating the building performance concept into the performance evaluation process generally known as evaluation of a building in use, or as Post Occupancy 
Evaluation (POE). This case largely relies on the argument that evaluation of a completed building in use will produce the most useful results if that evaluation can compare actual performance with explicitly stated performance criteria. It is argued that ideally the planning for a POE should begin with the earliest planning of the building so that clearly stated and measurable performance criteria can be deliberately declared as objectives for the new building before construction commences. A rigorous POE will reveal which criteria were met and which were not. In accordance with POE theory the results of the evaluation can be made available to designers so that the experience of one building will help to achieve an even better match between intended and actual performance in the next and subsequent buildings. Improvement of the evaluated building may also be an outcome. Fig 2.3 depicts a model of the POE process.

Whether or not the evaluation incorporates the building performance concept, modern developments in the evaluation field recognise the differences in outlook and requirements between the building providers and the users. Very recent work (Kernohan, Gray, Daish, with Joiner 1992) refers to the two cultures of users and providers which "rarely make contact and often conflict or would if it were not for the fact that one side tends to avoid expressing discontent while the other avoids acknowledging it". Building evaluation practice strives to bring together these two cultures by stressing the commonality of their ultimate interest in improving the quality of the existing and future buildings they may all have to occupy. 


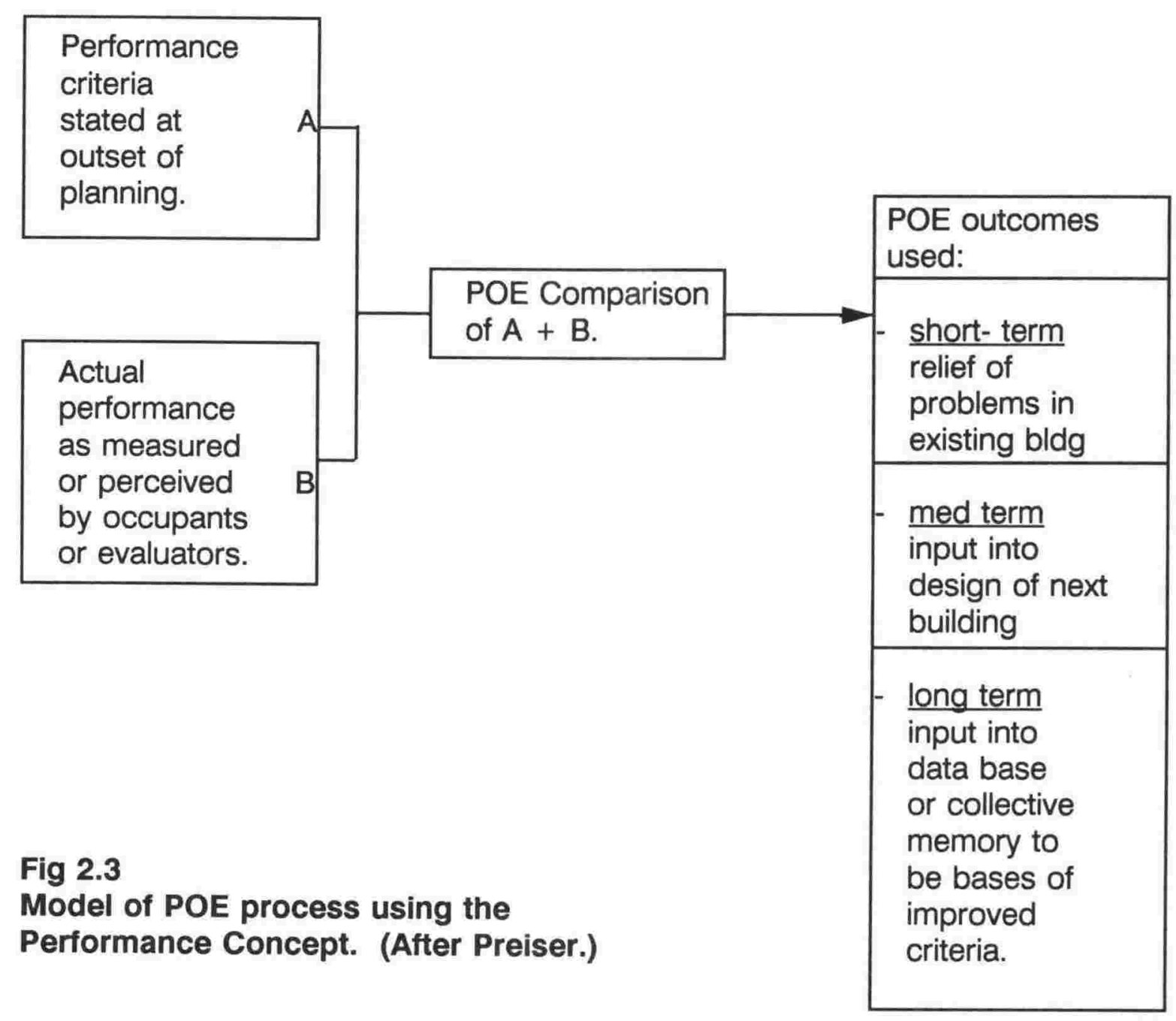

\title{
2.4.2 Elements of Performance
}

Three major elements of performance that POEs attempt to measure, evaluate and use to improve buildings are said (Preiser, 1989) to be:

\author{
technical \\ functional \\ behavioral
}

and it is argued that while there are others, (such as location and economics) these three are the most important. Of these three, it is the technical element alone which bears on building failures as they are defined in Chapter 3. POE focuses on the requirements and performance 
of building occupants' needs, and therefore, the technical performance is considered only in so far as it affects the occupants of the buildings. Building failures, being a shortfall in the expected technical performance of a building experienced by the occupants can obviously be said to have affected the occupants in that way.

This theoretical basis for evaluation of building underpins the practice of post occupancy evaluation which has been carried on since the 1960's. (Rabinowitz, 1989). POE has developed from an academic pursuit to a process shown to be practicable in a range of building types, and productive of useful outcomes. These range from immediate improvements for the providers and users to long-term benefits in the form of greater knowledge to apply to the design and construction of future buildings.

\subsubsection{Evaluation of simple versus complex buildings}

It must be observed that POE as commonly described and practised is rendered easier to do when there are explicit criteria by which to evaluate the completed building. The explicit criteria are more easily educed when the process of planning and designing the building is very well documented. This is more likely to be the case with larger buildings than with smaller ones. At opposite extremes are multi-storey and/or multifunctional buildings for which an extensive array of briefing documents are likely to be amassed prior to the production of a detailed specification and detailed drawings, and the builder designed and built house for which the only documentation is often limited to an annotated drawing and a very general specification promising compliance with standards and by-laws. Evaluation of such a dwelling by a provider, which has been described (Kernohan et al, 1992) as including the producer and the maintainer of the building, is unlikely to be possible once the dwelling is occupied and the 30-90 day maintenance period has elapsed, partly because the producer will feel that any further evaluation may result in the exposure of further 
work (unpaid) to be done on the dwelling, but mainly because there is little probability of the producer and user ever coming into a contractual relationship again in the future. There is, in other words, no financial incentive to encourage the producer back to a completed dwelling, except perhaps in the comparatively rare case in which an architect is involved, when the owner may use the settlement of the final instalment of fees as such an incentive.

In the case of commercial buildings and corporate clients there is often not only the financial incentive of substantial final instalments of fees and contract sums to be collected, but also the hope that future work will come from a satisfied owner.

\subsubsection{Evaluation without measurable criteria}

If no measurable performance criteria could be used in the POE of a dwelling then the evaluations must fall back on the building's actual performance as perceived by the building's occupants and any other evaluators. This evaluation will not be a comparison of clearly documented target performance with actual performance as in the model of the ideal POE but will be a subjective evaluation, by the producers and users (and any other specialist evaluators), of the extent to which the building's performance matches the expectations of the producer and user. To that evaluation will be brought all or any previous experience of dwelling performance. Other non-occupant evaluators may bring more comparative experience to the evaluation because, for example, they habitually evaluate more dwellings, but if such an evaluator is not a provider of the dwelling the evaluation will not be able to take account of anything more than a guess (possibly a well-informed guess) at the performance expected of the building. When there are no measurable criteria for evaluation the counterbalancing effect of the users' evaluation becomes even more important in the overall evaluation. 


\subsection{CURRENT AND PARTIAL EVALUATION PRACTICE}

\subsubsection{Buildings currently evaluated}

POE is increasingly being used not only as a tool for producing the shortterm relief depicted in the model (Fig 2.3), but as an automatic process to be followed within an organisation once a newly procured building has been in use for a short period. It appears (Bechtel 1989) that the bulk of POE work has shifted from academic settings to government agencies and private industry. These organisations both motivate and pay for POEs in their own buildings. This means that government funded dwellings may be subjected to POE along with larger departmental buildings, while private industry carries out POEs on buildings housing commercial operations.

Owner-occupied dwellings appear to fall outside the usual ambit of the POE practitioners, yet who can say that dwellings as a class of buildings are not likely to benefit from the POE process? While some POEs of larger buildings are carried out in response to dissatisfaction with the building in use, with the cost of the evaluators' time borne by the building owners, there is no equivalent to this pattern in the case of dwellings.

Of course the users of large commercial buildings are likely to see value in a POE which may well improve staff morale, productivity, and the general well-being of the organisation. The owner-occupier of a dwelling may see only the cost of POE and reason that given the subjective nature of an evaluation which is not based on measurable criteria, the outcome will not be worth the expense. Nonetheless, if a POE has the potential to provide short, medium and long-term information useful for the betterment of one class of buildings it should be able to do the same for other classes. This leaves open the question of how to bring dwellings into the evaluators' orbit. 


\subsubsection{Partial evaluation in connection with building failure}

Even if the users of buildings do not elect to have formal evaluations of those buildings carried out at their own expense, that need not prevent the carrying out of some evaluation. An invitation to evaluate the building or access to the records of a suitable evaluator who has been so invited are all that may be necessary to allow the technical element of an evaluation to be pursued. Such records are, for example, made by people who are called in by insurers to investigate the owner-occupier's claim of defective building performance leading to some loss to the user. The motivation for the evaluation comes from the users who seek an immediate short-term benefit - the fixing of a poorly performing building, and who would not be expected to have much interest in any long-term benefits for the building industry, or even for building users as an interest group.

\subsection{DOING THE EVALUATION}

\subsubsection{Applying evaluation practice to dwellings}

Consider, then, how well the theory and the practice of POE can contribute to the evaluation and improvement of owner-occupied dwellings, products of the scanty documentation already described in 2.4.3. It would be difficult if not impossible to use the concept of building performance to generate measurable performance criteria since no measurable performance targets were set for the dwellings at the outset. There will be no target measures for lighting levels, acoustic performance, interior temperature, or other measurable quantities.

Identification of users of dwellings is straightforward. Recent work (Kernohan et al, 1992) describes users of buildings as generally comprising the occupants, the owners, and visitors. In the case of owner occupied 
dwellings the occupant and the owners obviously fuse into one category of users with visitors being another. Because the occupiers are the owners it can be supposed that whatever influence the owner was able to extend on the selection and design of a new dwelling will be known to the occupiers.

\subsubsection{Objective expert evaluator}

If evaluation of a dwelling is to be more than an expression of the users' views the producer (ie the builder) must be represented in some way. (As explained in 2.4.3, by the time evaluation of a dwelling is sought the producer is unlikely to have any further interest in the building). The provider's representative cannot hope to represent all the nuances of the behaviour, attitudes and performance of the 'real' producer, but could at least represent the level of technical competence, and the aspirations to building performance, of the ordinary builder. This representative of the producers would exercise expert or informed judgement as the 'most knowledgable person' (Daish et al, 1980) best qualified to make such judgments.

Where a dwelling is evaluated only by the user and one expert evaluator the scope of the evaluation must be circumscribed by the breadth or narrowness of expertise of both parties. If the expert evaluator is expert only in respect of the technical element, for example, the evaluation must not purport to be wider than that.

\subsubsection{Dwelling evaluation team:}

Whereas a large and complex building, or assembly of buildings, may be evaluated by a team of people representing the various designers, builders, users and owners, the evaluation of the technical element of a dwelling requires a very small number of people. In more than $90 \%$ of cases in New 
Zealand there will have been no architect involved in the design of the dwelling, (NZIA, 1991), the design instead being a standard plan from a catalogue or a magazine modified by the owner and builder to fit the site and the budget and possibly to accommodate some of the owner's express wishes for layout and features. In such cases the person most familiar with the intended performance of the dwelling and best able to compare it with the actual performance, is the owner. The builder may also be well equipped to make such a comparison but unless the intended performance is well documented (which is most unlikely) the owner and the builder may well have entirely different expectations of building performance, the former based on experience of living in dwellings and the latter based on experience of building them.

Despite their almost inevitable individual differences in expectations of building performance most dwelling builders attempt to match the owner's expectations by the end of the 30-90 day maintenance period which follows hand-over to the owner. By the time a building-in-use evaluation can first sensibly be done the builder will normally be long gone from the site for several weeks or months, and become engrossed in another building contract.

Evaluation by the owner-occupier alone is difficult to defend against the charge of lack of neutrality and, in most cases, lack of technical competence. If the evaluation was conducted by both the owner-occupier (as the repository of knowledge of the intended performance and the person most competent to compare the intended with the actual performance) and by a technically competent evaluator experienced in evaluation of dwellings (described in 2.5.2), then it could be argued that the evaluations will stand the scrutiny of both parties, each anxious that the process should be fair. 


\subsubsection{A limited evaluation of a dwelling}

In 2.4.1, reference is made to three major elements of performance technical

functional

behavioral

An evaluation does not have to include all three elements and indeed cannot do so when the evaluation team does not include the necessary expertise. The process of evaluation could still be followed but the evaluation outcomes would of necessity be limited.

It is the possibility of carrying out an evaluation limited in scope but still in theory holding out the promise of useful results that led to the adoption of an evaluation approach to the investigation of causes and implications of building failure patterns in New Zealand dwellings.

Central to the investigation is the thesis that enfranchising the dwelling users by involving them in the evaluation of apparent building failure, along with so-called expert independent evaluators, would yield immediate benefits to the users and long-term benefits to the house-building industry and those who regulate it. The short term benefits were expected to be the making good of the defective dwelling, while the long-term benefits were expected to include an understanding of the short-comings if any, in the processes that produced the building.

\subsubsection{Evaluation 'at arms length'}

This report records the application of building evaluation practice to the assessment of technical deficiencies in a sample of owner-occupied dwellings, and the findings which resulted from aggregation of those evaluations are described. In every case the evaluations were carried out 
as a result of the owner-occupier complaining of a shortfall in the dwellings' performance. Further, the evaluations were carried out at "arms length" from the dwelling concerned and relied on the written record of the expert evaluator and of the user.

Because the evaluation of the owner-occupied dwelling was to be carried out using only the written evidence on an insurance claim file, recording the owner-occupier's complaint and an independent assessor's report, it was conducted in an atmosphere free of any bitterness or rancour between the owner and the builder. Free of those emotional overtones the evaluation could, in theory, be totally dispassionate and completely neutral.

\subsubsection{Barriers to objectivity in evaluation}

While the process of evaluation of building failures (where building failure is a generic term to describe a short-fall in technical performance) could be made an objective and dispassionate one in theory, the practice of evaluation of building failures is fraught with complications which can inhibit the evaluator on the one hand or lead to misleading distortions of the truth on the other.

These complications arise from

(a) vague or varying definitions of the term 'building failure'

(b) a poor understanding of why building failures happen, leading to

(c) a tendency for our society to attribute inappropriate blame in order to bring the force of the law to bear in support of claims for compensation. 
In Chapter 3 the difficulty in defining building failure is illustrated, and a working definition which was used in the evaluation of the dwelling sample is presented.

The complications in (b) and (c) above are considered in Chapter 4 in which a model of the building failure process, first introduced in 2.2 is further developed. The model demonstrates how complex the mechanism can be and how inappropriate it can be to lay all or any of the blame for a building failure on one person or even on any human agency.

\subsection{SUMMARY}

This chapter began by discussing buildings as products and noting that individuals' perception and tolerance of defects in products varies. A simple model was proposed (Fig 2.2). From this variable evaluation by individuals the chapter moved to current theories of evaluation of buildings.

Because the study is centred on building failures it was explained that the proposed evaluation procedure would constitute a partial evaluation from the view point of practitioners of post-occupancy evaluation.

The requirement to obtain objectively-recorded evidence of past building failures, free of legal considerations of blame, was alluded to in 1.4, and in this chapter it was explained how a sample of dwellings, which met this requirement, was located.

This chapter described how it was proposed to evaluate the sample of dwellings failures using the written records of the New Zealand Building Performance Guarantee Corporation. These records were described as containing the evaluation of the building user and the objective expert evaluator engaged by the Corporation to investigate the claim of failure. 
The status of the objective expert evaluator as the equivalent, in behaviour, attitudes and performance, of the actual builder (producer) of each dwelling was explained.

The chapter concluded with discussion about the barriers to objectivity in evaluation. These include varying definitions of the term building failures happen. The latter problem, it was argued, leads to a tendency in our society to attribute in appropriate blame in order to bring the force of law to bear on claims for compensation.

In Chapter 3 the problem of defining building failure is approached, while in Chapter 4 the causes of building failures are investigated.

\subsection{REFERENCES.}

Bechtel, Robert B. Advances in POE Methods: An Overview, in Building evaluation. Preiser W.F.E (Ed). Plenum Press, New York 1989, p 202.

Daish J, Gray J, and Kernohan D. Post-Occupancy Evaluation of Government Buildings, Victoria University of Wellington. 1980.

Kernohan D, Gray J, and Daish J, with Joiner D. User Participation in Building Design and Management. Butterworth Architecture, Butterworth-Heinemann, London, 1992.

New Zealand Institute of Architects (NZIA) Members Play Leading Role in House of the Year Awards, NZIA Detail, Wellington, October 1991.

Oxford University Press. The Concise Oxford Dictionary of Current English. 6th Edition O.U.P. 1976. 
Porteous, W.A. Form and Failure, in Proceedings of the Australian and New Zealand Architectural Science Association (ANZASCA) Conference, Auckland, August 1986.

Preiser, Wolfgang F.E. Towards a Performance-Based Conceptual Framework for Systematic POES, in Building Evaluation Preiser W.F.E. (Ed). Plenum Press, New York, 1989, pp 1-7.

Rabinowitz, Harvey Z. The Uses and Boundaries of Post-Occupancy Evaluation: An Overview, in Building Evaluation, Preiser W.F.E. (Ed) Plenum Press, New York, 1989, p 10.

Weeks, J. Planning for Growth and Change, Architects Journal, 7 July 1960. 


\section{CHAPTER 3}

\section{DEFINITION OF BUILDING FAILURE}

\subsection{INTRODUCTION}

In Chapter 2 an approach to the technical evaluation of buildings was described. That approach was founded on the developments which have taken place in recent years in whole-building evaluation and focused partevaluation of buildings. How a selection of dwellings was chosen for the purpose of testing the evaluation procedure was explained.

Also explained was the acceptability of carrying out the technical evaluation of the sample buildings using existing written records, rather than visits to the sites, since access to all the sites was not practicable.

Evaluation whether on site, or by examination of the records, requires some degree of precision both to give the evaluation some communicable meaning and to cater for the variable tolerance and perception people have of building failures.

Evaluation of building failure can only begin after the failures have been identified. Identification of building failures implies some means of defining or describing a building failure. This chapter deals with the issue of defining building failure, a task first identified in Chapter 1 . 


\subsection{DEFINING BUILDING FAILURE}

\subsubsection{Why a definition is necessary}

In Chapter 2 it was explained how at least one school of thought about building evaluation believes the evaluation process should start, prior to construction, with the setting down of measurable performance targets which the building is intended to reach (2.2.1). It was also explained that such pre-set targets, desirable as they may be, are seldom found in practice. Evaluations must then fall back on the buildings' actual performance as perceived by the users and other evaluators. Evaluation of building failure, like any other part of a total building evaluation must therefore take account of what the users and producers of buildings perceive to be a building failure. For a definition of building failure to be useful to the building evaluator it must fairly reflect the perceptions of the users and producers, through whose eyes the building is being evaluated.

Once a satisfactory definition of building failure is agreed upon, it becomes possible to evaluate buildings for the presence or absence of building failure in a consistent and realistic way.

This chapter describes how the producers' and the users' perceptions of building failure were gauged and considers the extent to which the perceptions of the two groups tend to coincide.

\subsection{EXPERTS' OR PRODUCERS' DEFINITION}

\subsubsection{Obtaining the experts' definition}

As explained in Chapter 2 it was not practicable to survey the builders of the dwellings in the sample since by the time the dwellings generated a claim and thus entered the claims record of the Building Performance Guarantee 
Corporation the builder was generally long gone from the site. Even if it had been practicable it is difficult to believe that the builders' stated perception of building failure would not be affected by any minor or major disputes between builder and owner over work which the owner required to be done during the so-called maintenance period after practical completion but before the final payment to the builder.

To obtain a range of views as to what a building failure is, a literature survey was conducted (Porteous, 1985). The opinions sought were those of people professionally involved in the designing, building, maintenance and management of buildings as well as those of people who contribute to research and education in the building industry or to the legal and financial matters which arise from procuring and dealing in buildings. The views may not all be impartial, in fact each must be coloured by a sector view point, but in combination it was expected that the views would approximate to those of a building producer with a level of technical competence and aspirations to building performance appropriate to an 'ordinary builder.' It was argued in 2.5.2 that the perceptions of building failure held by such persons would equip them to be the objective expert evaluators required to take the place of the real producers of the dwellings in the sample.

\subsubsection{Limiting the use of the term 'building failure'}

In searching the literature for references to building failure the decision was made to limit the use of the epithet 'building failure' to shortfalls in building performance which did not amount to total collapse of the building. There was a reason for this limitation. The literature survey was intended to reveal the perceptions of well-informed people as to what constituted building failure. To extend the use of the term to include total collapse, was considered unhelpful since such an extreme event at the upper limit of the scale of failure would be unsusceptible to varied perception. Further more, total collapse of buildings is usually the result of structural failure of a type described in 1.3.2 as 'catastrophic'. Such events are rare in countries with 
an enforced building control system because the codes are usually copiously supplied with structural requirements which are checked at the design and construction phases for safety reasons. As argued in 1.3.2, building control systems are less certain in their effect on building failures.

\subsubsection{Catastrophes and failures}

As it turned out in the course of the survey, there appears to be a commonsense view point, shared by informed observers, that catastrophic events in buildings are something separate from building failure. In most cases the forces necessary to cause such events are of a much higher order of magnitude than those which cause what most observers would call a building failure. (Causes of building failure are fully discussed in Chapter 4). Generally the literature survey found no opposition to the idea that catastrophic malfunction or collapse of a building caused by forces so unusual, so dreadful and so powerfully malevolent that they are sometimes described as Acts of God, should be excluded from the otherwise widelyembracing term 'building failure'.

\subsubsection{Experts' definition stated}

The following table, (Table 3.1) lists some characteristics of building failure as reported in the literature by the various sources listed. Also shown is an indication of the year in which the opinion was reported. The list of sources does not pretend to be exhaustive but it is representative of a cross-section of people connected with the building industry, as the key to the sources shows.

A notable feature of the list of sources is the absence of references to the literature of the U.S.A. This is because the words 'building failure' as used by North American commentators, such as Di Pasquale (1982), Feld (1968), Janney (1979), Kaminetzky (1981), McKaig (1962), and Richardson (1980), tend be reserved for failures of a structural nature. Such failures are more 
in the nature of the catastrophic events deliberately distinguished from building failure in the sense in which it is used in this study (see 3.2.2 and 3.2.3).

From this list of perceived characteristics of building failure can be drawn a practicable working definition of building failure, sufficiently wide to embrace a range of views while still supportable by good authority. That experts' definition says that a building failure is a shortfall in performance which exhibits one or more of the characteristics in Table 3.1.

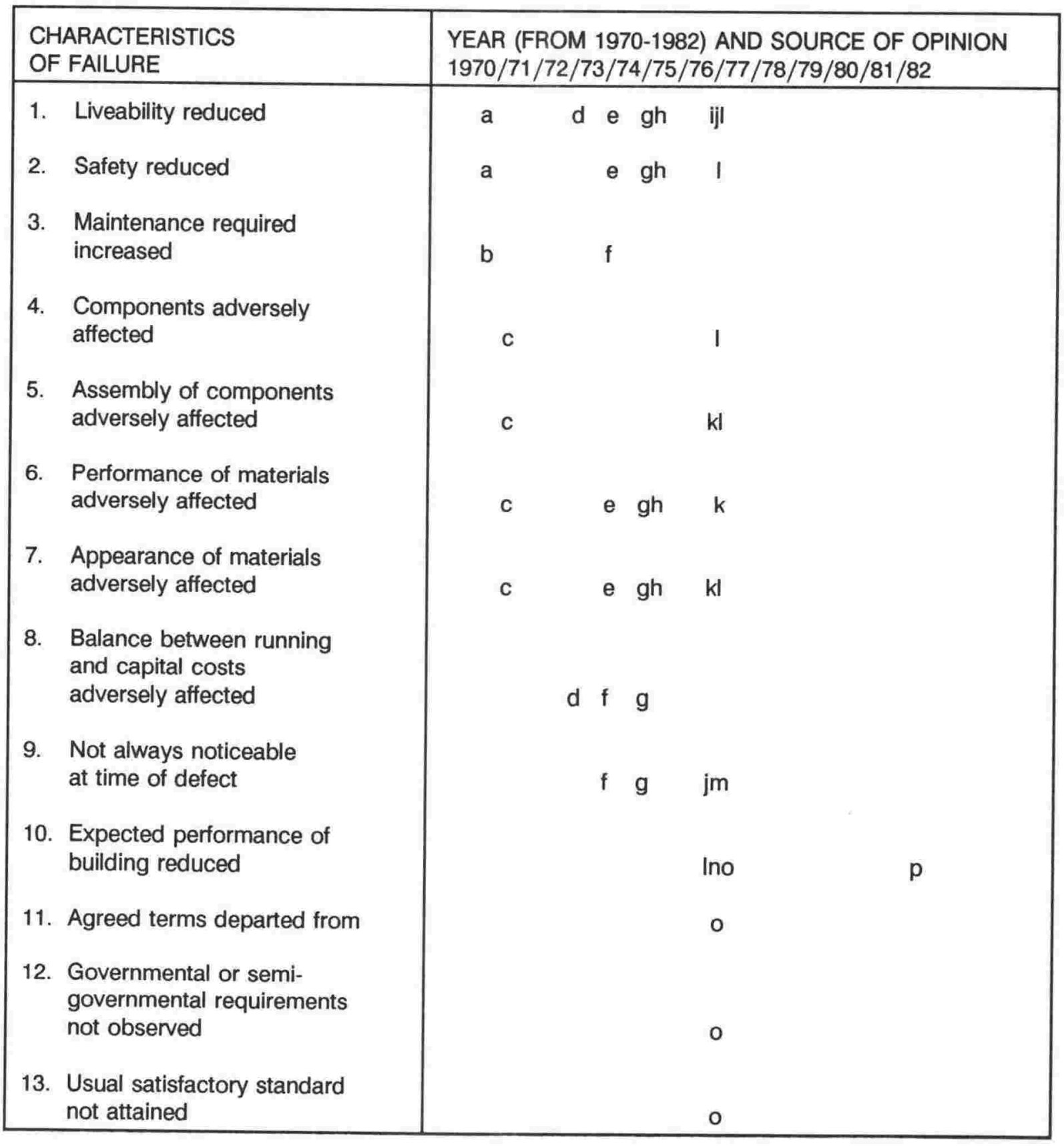

TABLE 3.1: CHARACTERISTICS OF FAILURE BY SOURCE OF OPINION: 


\section{Key to sources of opinion:}

(a) NHBRC is the National House-Builders Registration Council which was reported in 1970 to have conducted a computer analysis of 6000-7000 defects in 1000 defective houses in England and Wales.

(b) G E Stringer was solicitor to the Royal Institute of British Architects (RIBA) and addressed a conference on Quality Control in London in 1970.

(c) Bickerdike Allen Rich and Partners are architects who, along with Turlogh O'Brien, structural engineer, as materials consultant, published a series of information sheets in Building in 1971.

(d) D W Cheetham was a lecturer at the Lanchester Polytechnic who wrote a series of articles about building defects in Building.

(e) I L Freeman was a researcher at the Building Research Establishment (BRE) who spoke on failure patterns and implications at a BRE:IOB (Institute of Building) seminar on building failures.

(f) Karl Fantl was Director of the Austrian Institute for Building Research.

(g) GLC (Greater London Council) produced a series of Technical Information Papers for its staff.

(h) BRE (Building Research Establishment) published findings of building failures and research in its Digest 176.

(i) Dr Knud Nielsen was Chief Engineer at the Copenhagen Technological Institute which instigated building failures research in that country. 
(j) Adam Neville was Professor of Civil Engineering at the University of Leeds and later Vice-Chancellor at the University of Dundee. He cited Professor E M Brown of London University.

(k) W W Abbott was Principal lecturer in the Department of Civil Engineering and Building at Lanchester Polytechnic, Coventry.

(I) J Nelson worked in the BRE Advisory Division.

(m) D Little was an architect speaking at a conference on defects in buildings organised by the Building Science Forum (New South Wales Division).

(n) B Freedman was a consulting engineer at the same conferences as D Littlemore.

(o) A Mclnnes was a Sydney barrister speaking at the same conference.

(p) HW Harrison was a researcher at BRE, speaking at CIB Symposium at the University of Strathclyde.

\subsection{USERS' DEFINITION}

\subsubsection{Obtaining the users' definition}

While the literature is rich in definitions of building failure from the view-point of industry-related professionals (ie from the producers' viewpoint) a search for definitions from the user view-point proved fruitless. In the absence of a user definition there was little option but to resort to that expression of society's expectations in so many fields, statute law, for whatever help it might offer. 
The only statute law which might be considered to be written with the user of a defective building in mind was found to be a New Zealand Act, the Building Performance Guarantee Corporation Act 1977, which empowered the Corporation, inter alia, to issue an Indemnity Agreement to its clients. The Act and Agreement are of interest here because they are the documents which declare that the Building Performance Guarantee Corporation of New Zealand (BPGC) offers a system of indemnity to building owners designed to indemnify the owner (subject to various conditions, exclusions, modification and inclusions) against any loss or damage suffered by the owner out of:

(a) Any failure by the building contractor to erect or construct the building or to carry out any works in connection with the erection or construction of the building in accordance with the building contract.

(b) Any failure by a builder to erect or construct any works in accordance with the standards to be expected of a competent and diligent builder.

(c) Any significant inherent defect in any materials that are incorporated in the building in the course of erection or construction of the building.

Unfortunately neither the Indemnity Agreement published in 1980, nor the empowering Act (Building Performance Guarantee Corporation Act 1977) attempts to define 'the standards to be expected of a competent and diligent builder' or meaning of the words 'significant inherent defect'.

The First Schedule to the Building Performance Guarantee Corporation Indemnity Agreement contains a definition of a 'minor defect':

"'Minor construction defect' means any defect in the building arising from poor workmanship or from defective materials used in the erection or construction of the building but which does not render the building 
unsafe, uninhabitable or unusable for the purposes for which the building was designed or intended."

but only because the General Exclusions section of the Indemnity Agreement includes a paragraph (para. 4.4) which reads:

"(The Corporation shall not be liable under this indemnity for or in respect of any loss or damage arising out of) any minor construction defect in the building, unless the defect arises within a period of 12 months from the date upon which the building is completed or the date upon which the building is first occupied...".

It could be deduced from the BPGC definition of a 'minor construction defect' that an average or major defect means 'any defect in the building arising from poor workmanship or from defective materials used in the erection or construction of the building which does render the building unsafe, uninhabitable or unusable for the purposes for which the building was designed or intended', but the BPGC itself acting with the authority given by the New Zealand Parliament, and no doubt conscious of the difficulties of interpretation, avoids making any such definition in its published documents.

\subsubsection{Necessary stages in definition}

It is obvious that if a user lodges a claim with BPGC for reasons other than non-completion, then the claimant perceives a building failure to exist. That is after all what (b) and (c) (above) attempt to describe.

If the first stage of the test for user perception of building failure is the lodging of a claim, then the second stage must be the acceptance by the BPGC that the claim is valid, since acceptance of the claim signifies that it falls inside the statute-based definition of failure. It should be noted that the 
BPGC is neither a producer nor a user but is obliged to interpret its contract with the client (user) claimant in an impartial way. (An examination of all claims over a 6 year period revealed a sustained high degree of impartiality).

\subsubsection{Users' definition stated}

For the purposes of evaluating the sample of dwellings described in 2.4.1 it can be argued that the users' definition of a building failure is a shortfall in performance which motivates the user to lodge with the BPGC a claim which is subsequently accepted by the Corporation.

In the case of dwellings not indemnified by the BPGC, and of other classes of buildings, the users' definition of a building failure cannot, of course, be verified by acceptance by the BPGC. Instead verification could be carried out by the objective expert evaluator (described in 2.5.2) who, by definition would be familiar with "the standards to be expected of a competent and diligent builder" and to know what the words "significant inherent defect" mean.

\subsection{COINCIDENCE OF DEFINITIONS}

\subsubsection{Comparison of perceived characteristics of building failure}

The comparison can be made by examining Table 3.2, which reproduces all the contents of Table 3.1 and includes, in addition, the characteristics of building failure as the BPGC (and therefore the New Zealand legislature) appears to perceive them. (' $q$ ' denotes a BPGC perceived characteristic).

It is immediately apparent (see characteristics 1,2,10,11, and 13) that 5 out of the 13 characteristics of building failure identified by a cross section of expert persons professionally associated with the building industry are 
clearly identified in the BPGC's own view of building failure. Of the other 8 characteristics, none are contradicted by the BPGC Indemnity Agreement or by the empowering Act while most if not all are implicit in the Indemnity Agreement.

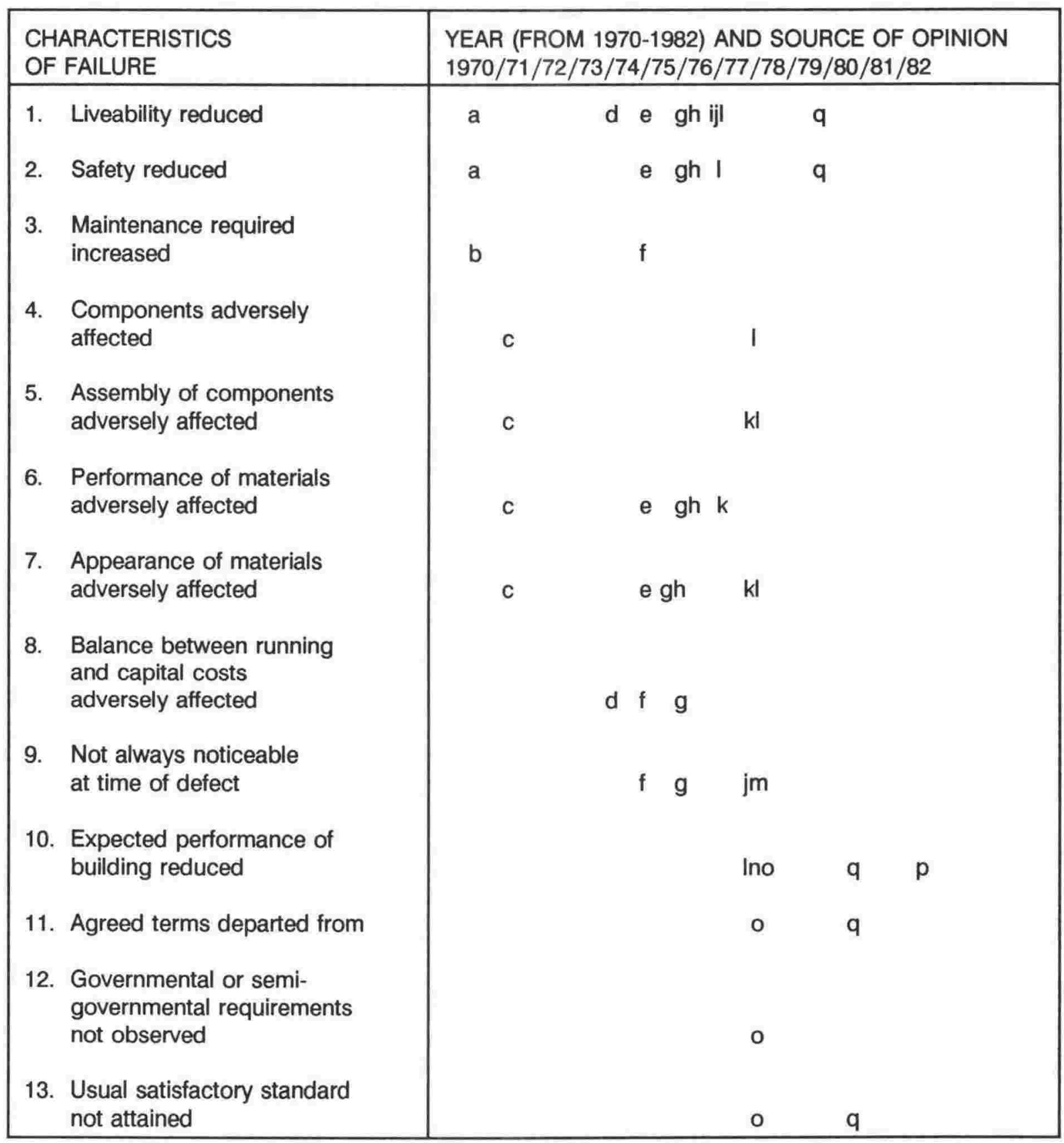

Table 3.2 Characteristics of failure by source of opinion (including the BPGC opinion expressed under statutory authority). 
Consider these 8 characteristics in order:

\section{Characteristic No}

3 Maintenance required increased.

4 Components adversely affected.

\section{Comments}

This characteristic is implicit in the BPGC Indemnity Agreement reference to "any significant inherent defect in any materials."

This characteristic is implicit in the BPGC Indemnity Agreement reference to "any significant inherent defect in any materials" - it is evident from the claim files that BPGC does not distinguish between materials and components.

This characteristic is implicit in the BPGC Indemnity Agreement reference to "any significant inherent defect in any materials."

This characteristic is implicit in the BPGC Indemnity Agreement reference to "any significant inherent defect in any materials."

Not excluded by the wording of the indemnity agreement but not specifically included either. 
8. Balance between running and capital costs adversely affected.

9. Not always noticeable at time of defect.
Not excluded by the wording of the indemnity agreement but not specifically included either.

The Indemnity Agreement specifies a period of 12 months from data completion (or first occupation) in which the defect may arise, clearly recognising this characteristic by implication.

12. Governmental or semi- The Indemnity Agreement refers to governmental requirements not observed. failure to erect or construct the building "in accordance with the building contract". As a matter of course the BPGC (and any mortgagee) would insist that the dwelling complies with local authority permit requirements and therefore with the requirements of characteristic 12.

\subsubsection{Degree of coincidence of perceived characteristics}

The conclusion to be drawn from this comparison of characteristics is that the BPGC's stated perception of building failure is quite comparable with that of a qualified cross-section of professional people associated with the building industry. In 5 out of 13 characteristics of building failure the coincidence is explicit, while in another 7 (viz. characteristics $3,4,5,6,8,9$, and 12) it is implicit. Only in the case of the appearance of materials (characteristic 7) is the coincidence not apparent. 


\subsubsection{Coincident perceptions and coincident definitions}

The high level of coincidence between the BPGC's perception of characteristics of building failure and those of the industry experts in general is strong evidence that their definitions of building failure are also coincidental. That this should be the case is not surprising. The BPGC was established to operate effectively with the building industry and with the industry's consumers (the users). It would, at the very least, be difficult for the BPGC to indemnify house-owners against a shortfall in standards different from those which the building industry itself considered fair and appropriate.

It, was argued in 3.3.3 that the users' definition of a building failure is a shortfall in performance which motivates the user to lodge a claim with the BPGC which is subsequently accepted by the Corporation. In such a claim the BPGC definition of a building failure is coincident with that of the claimant user. If, as has now been argued, the BPGC definition of building failure is coincident with that of industry experts, then it can be asserted that for the dwelling sample under examination the users' definition of building failure and that of the producers coincides.

\subsubsection{Significance of the coincident definitions}

In Chapter 2 a method of evaluation of a sample of dwellings "at arms length" using written records was suggested (2.5.5). The evaluation process was carried out remotely from the dwellings concerned and relied on the written record of the users' complaint and the expert evaluator's report following investigation of the complaint. The 'objective expert evaluator' (2.5.2) was defined as someone competent to represent the house-building industry's normally acceptable standards and therefore to be representative of the producers of dwellings. 
The apparent coincidence of the users' and producers' definition of building failure greatly strengthens the argument that an 'at arms length' evaluation is likely to have validity. If both user and provider are looking through the same eyes at a building problem their collective evaluation must be better based than if each is measuring the problem against a different standard. If an 'at arm's length' evaluation is likely to have validity, then an evaluation carried out on site and involving users' and producers' evaluators together must have an even greater prospect of validity and potential benefit.

\subsection{SUMMARY}

This chapter examined how users and producers of buildings tend to define building failure. It showed how the definitions tended to coincide to a very large extent and pointed out that this coincidence of definitions gives considerable assurance that the proposed definition of building failure would have credibility with everyone concerned with buildings.

Equipped with a workable definition of building failure it is now possible to identify building failures consistently. Before these failures can be evaluated in a way which might ultimately lead to a reduction in their incidence, the causes of building failures must be identified in an equally consistent way. Chapter 4 sets out to achieve that.

\subsection{REFERENCES}

Abbott, W.W. Quality Costs in Building, The Quantity Surveyor. June 1977, pp 193-195.

Atkinson, G. $\quad$ Attention to Details, Building vol 240, 8 May 1981, pp 60-61. 
Bickerdike, Allen, Rich and Partners in association with Turlogh O'Brien. Building Failures, Building. 24 September 1971, p 107.

Building. National House-builders Registration Council Research into Preventing Defects in New Houses, 28 August 1970, p59.

Building Performance Guarantee Corporation of New Zealand. Indemnity Agreement. Published by the Corporation, Wellington, 1980.

Building Research Establishment. (BRE) Failure Patterns and Implications. Digest 176. HMSO, April 1975.

Cheetham, D.W. Defects in Modern Buildings, Building. Part 1 vol 225 no 6805, 2 November 1973, pp 91-94. Part 2, vol 225 no 6807, 16 November 1973, pp 175-176, 179-180, 182, 187-188.

Di Pasquale, R.A. Bridging Catastrophe: Understanding Why Failures Occur, Concrete Construction. April 1982, pp345-348.

Fantl, K.

Building Defects: The Role of Building Research, Building Research and Practice. Jan/Feb 1974, pp23-26.

Feld, J. $\quad$ Construction failure. Wiley, New York, 1968.

Freedman, B. Engineering Services: Environment for Productivity - Who Needs It? Building Research and Practice, Jan/Feb 1974.

Freeman, I.L. Failure Patterns and Implications in Proceedings of a joint BRE:IOB Seminar on Building Defects and Failures. 29 November 1974. IOB, Ascot, Berks. UK, 1974. 
Harrison. H.W. Practical Problems in Estimating Effective Service Life of Components and Elements in Housing - paper presented to C.I.B. Seminar W60 (The Performance Concept) University of Strathclyde, Glasgow, June 1982.

Janney, J.R. Guide to investigation of structural failures. Report from ASCE Research Council on Performance of Structures. American Society of Civil Engineers, 1979.

Kaminetzky, Dov. Failures During and After Construction, Concrete Construction, August, 1981, pp 641, 643, 645, 647, 649.

Littlemore, David. Building Defects - Who Dunnit? in Proceedings of the 29th Conference of NSW Division of the Building Science Forum of Australia. Published by the BSFA NSW Division, Sydney, November 1977.

Mclnnes, A. Who Pays if the Roof Falls In? in Proceedings of the 29th Conference of NSW Division of the Building Science Forum of Australia. Published by the BSFA NSW Division, Sydney, November 1977.

McKaig, T.H. Building failures. Case Studies in Construction and Design, McGraw-Hill, New York, 1962.

Nelson, J. The Nature of Common Defects in Building, SAAT News. Society of Architects and Architectural Technicians, London, 28 August 1977, pp 7-8.

Neville, Adam and Evans R.W. Rethinking the Professional Role, Building vol 232 no 6972, 11 February 1977, pp 83-85, 87. 
New Zealand Government. Building Performance Guarantee Corporation Act, N.Z Government Printer, Wellington, 1977.

Porteous, W.A. Perceived Characteristics of Building Failure - a Survey of the recent literature, Architectural Science Review, vol 28, no 2, June 1985, pp30-40.

Richardson, Barry A. Remedial treatment of buildings. Construction Press, New York, 1980.

SAAT (Society of Architectural and Associated Technicians) News. Avoidance of Building Failures. (Extracts from Parts 4 and 5 from the Greater London Council's Materials and Information Bulletins No's 79 and 80, reprinted with permission, July 1975 pp 16-19.

Stringer, G.E. What is Quality Worth? in Quality Control 1970, Report on a two day conference held during the International Building Exhibition, Olympia, 1969. HMSO, 1970, pp 63-76. 


\section{CHAPTER 4}

\section{CAUSES OF BUILDING FAILURE}

\subsection{INTRODUCTION}

In Chapter 1 the task of establishing the causes of building failure was noted as being essential to the productive study of building failure events. Other tasks included deciding on a basis for evaluation of such events, and defining a building failure. These latter tasks were carried out in Chapter 2 and 3. Prepared by the completion of those two tasks this chapter sets out to describe the causes of building failures in a way which will permit any failure event to be classified by cause. This is important because unless such a system of classification of building failures is available to be used by investigators of such failures, the detection of trends or patterns in building failure causes would be impossible, except possibly on a subjective 'gut feeling' level. It is by discovering the cause(s) of failure that progress may be made in reducing or controlling the incidence of building failures in the future.

\subsection{TWO GENERIC CAUSES}

\subsubsection{The case founded on empirical evidence}

In the previous chapter building failure was defined as a shortfall in the technical performance of the building, sufficient to convince both the user and an objective expert evaluator that the building is defective.

Empirical evidence alone makes it obvious to any perceptive observer that all buildings develop building failures eventually if they are left standing long enough. The development of failure may be delayed by processes of 
maintenance, or forestalled by demolition, but if the building is simply left alone without attention it will fail. Further, this failure is inevitable even if the building remains unoccupied from the date of completion. Clearly this phenomenon is not a consequence of human behaviour but is the result of natural influences which continually operate to degrade and disorganise the universe. These influences, operating independently of any human agency, may be given a generic title 'natural causes'. In passing it must be observed that 'natural causes' generally tend to support the cycle of life on this planet. They are less benevolent to inanimate objects such as buildings.

Different empirical evidence tells the observer that on occasions building failures occur not because of 'natural causes' but because a human being made a mistake. In such cases the term 'human error' describes the generic cause.

As might be expected there are also occasions when the empirical evidence is that the cause of the failure is a combination of the 'natural causes' and 'human error'. The two generic causes are now discussed in more detail.

\subsection{NATURE'S APPARENT MALEVOLENCE TOWARDS BUILDINGS}

\subsubsection{Ashes to ashes, dust to dust}

The fact of continual renewal of life on earth requires no proof. Every day brings birth, death, ageing and decay to every living species on earth. This continual cycle is now known to occur in the inanimate parts of creation as well. Mountains are thrust up by geological mechanisms and worn down by erosion, continents are slowly washed into the oceans while new land is formed by volcanic eruption. If all this can happen to mountains and continents, it is hardly surprising that it happens to buildings too. The only 
difference is that nature does not arrange for the replacement of buildings it wears away. The Pyramids are worn away by the eroding power of windblown sand, limestone buildings are slowly dissolved by rain and atmospheric carbon dioxide, but nature does not push up replacement construction.

As a consequence people study building science and attempt to construct buildings which will resist the effects of the 'natural causes'. To design and construct such buildings it is necessary to identify and describe the causes and understand how they exert their sometimes malign influence on buildings.

\subsubsection{Tabulating natural causes}

Addleson (March 1977) published a most useful tabulation of 'natural causes'. A distinction is made between 'cause' and 'source' (see Table 4.1) which enables the 3 'causes' (dampness, movements, chemical/biological change) to be listed alongside the much larger number of possible 'sources' of each cause. This distinction is useful because, as will become clear later in this chapter, some building failures can be prevented by removing the 'source' so that the 'cause' cannot operate. It is also useful because awareness that a 'cause' may have several possible 'sources' encourages systematic investigation of a 'cause'.

Addleson's Table is faithfully reproduced, but with the addition of 'insect attack' under the 'sources' of chemical/biological changes, since attack by insects is a significant contributor to building failure in some parts of the world. 


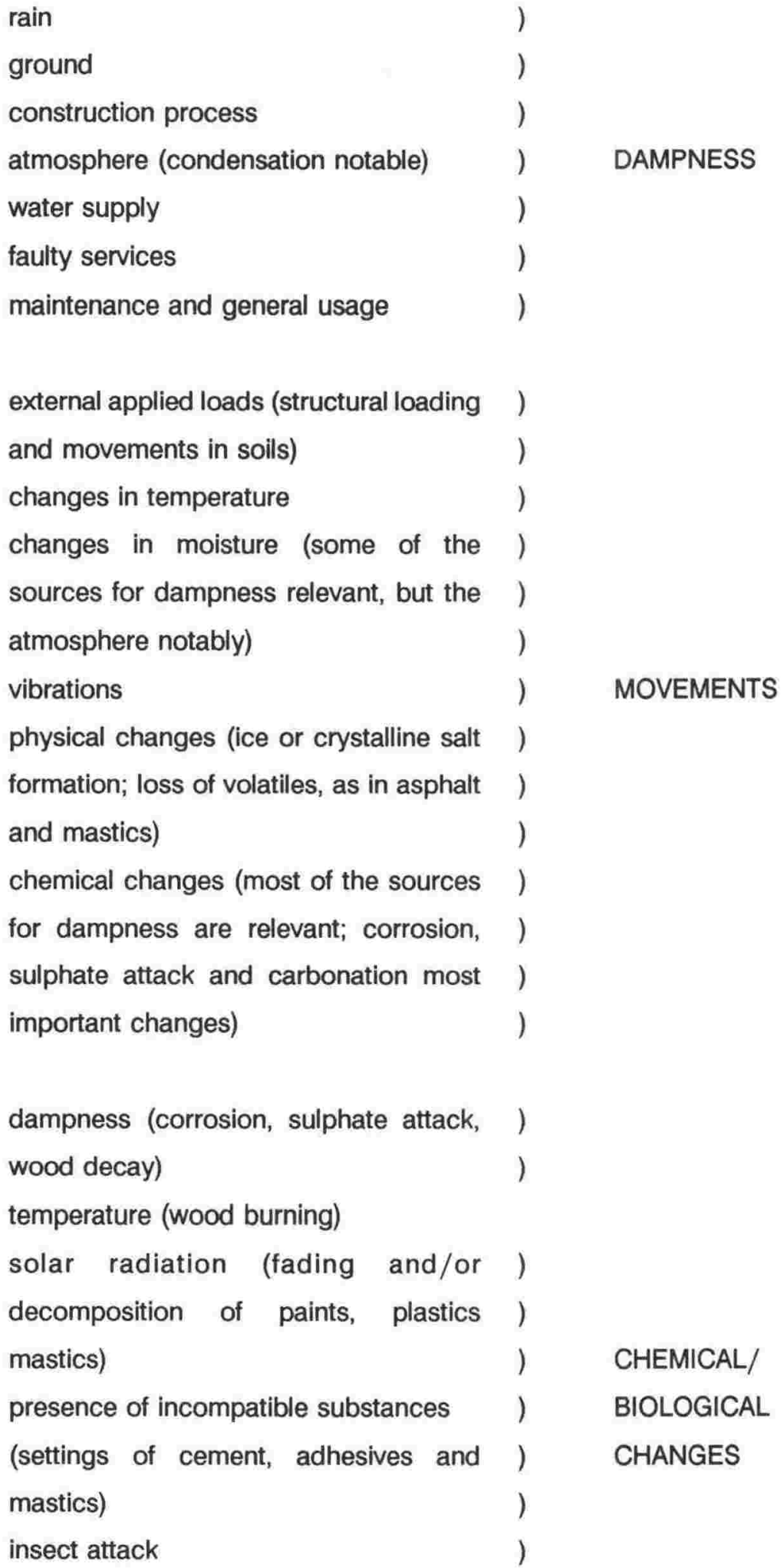

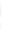

Table 4.1 Sources and Causes ('Natural Causes') of building failure (after Addleson, 1977) 
As Addleson points out, building defects may have up to three natural causes, and there may be multiple sources of causes.

In 2.2.1 an initial model of building failure was proposed. It was graphically represented thus:

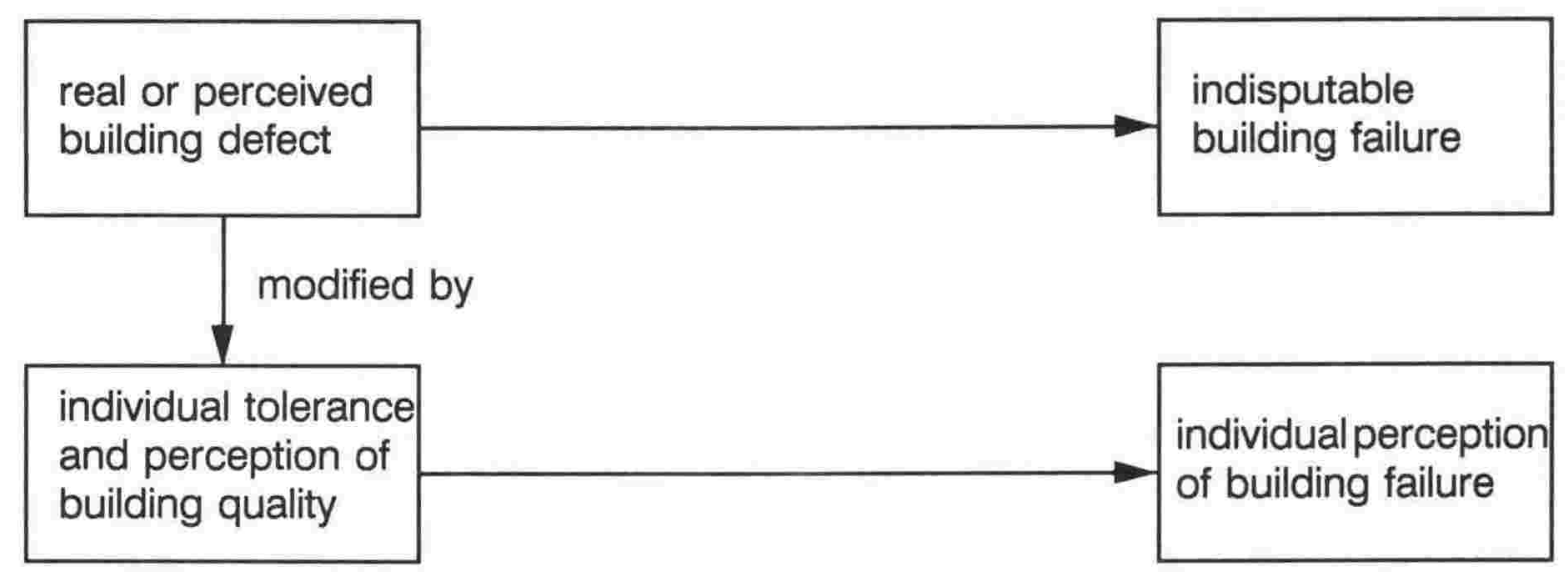

Incorporating Addleson's 'sources' and 'causes' the model can be modified and represented as in Fig 4.1.

\subsection{MISTAKES PEOPLE MAKE}

\subsubsection{Errors and negligence}

It was asserted in 4.1.1 that there is empirical evidence to show that some building failures result solely from human error and others from a combination of natural causes and human error. This phenomenon is illustrated in Fig 4.1, which models graphically the sequence of events or accidents which must occur before a building failure can be said to have happened. 


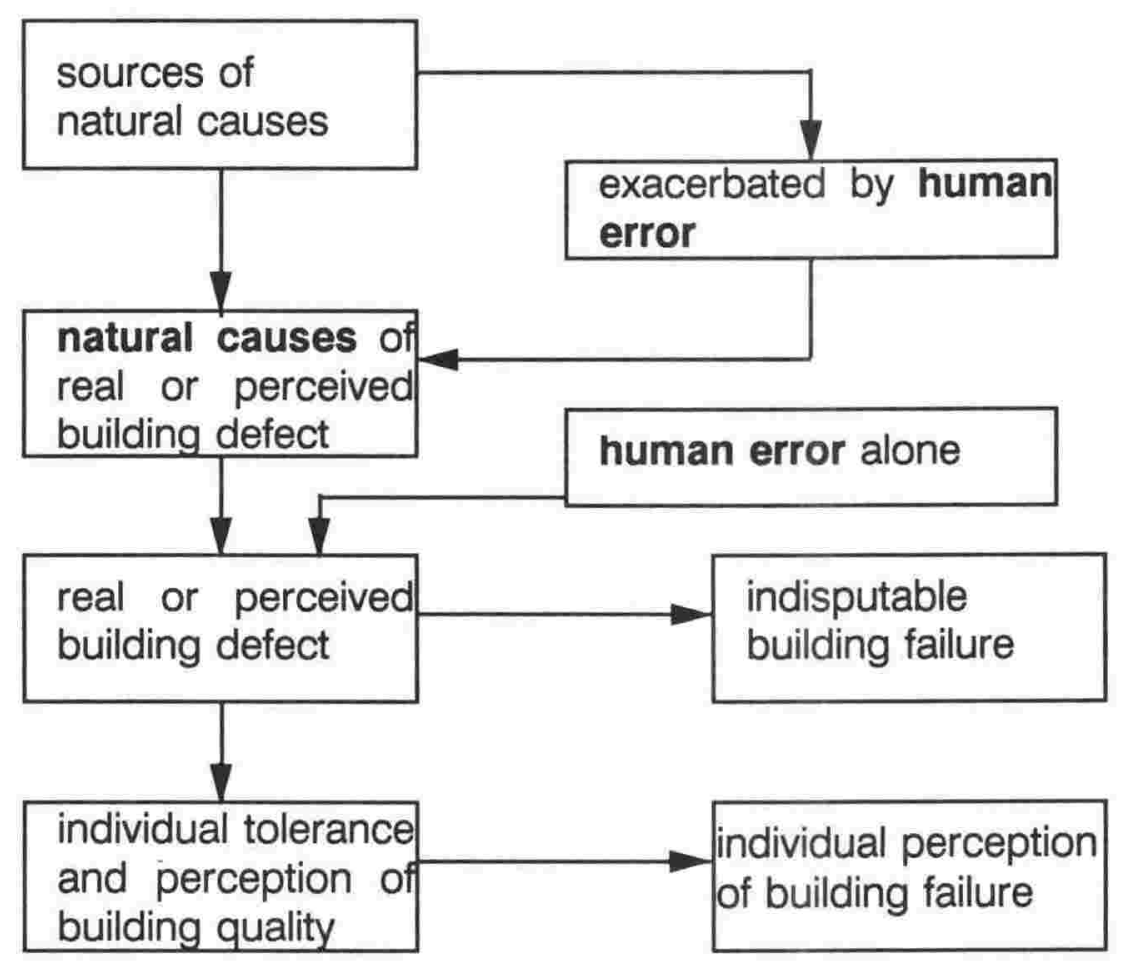

Fig 4.1 Model of building failure perception, incorporating the 'sources' of natural causes (after Addleson) and human error.

The model shows how the natural causes may sometimes be exacerbated in their effect by a human error. For example rain (a source) may gain entry to a building and give rise to dampness (a natural cause of building failure) only because, as a result of human error, an important roof flashing has not been fitted. Without that error rain might have to await the gradual decay of the roof, possibly for decades, before entry became possible.

Legal processes can do little about the natural causes (dampness, movement and chemical/biological change) in Table 4.1. When failures arise in buildings and the owner or user is seeking compensation for the cost of remedial work and losses suffered, the natural causes are difficult to engage in litigation. That is why the processes of the law concentrate so much on the human error aspect of building failure. There is a well 
established line of precedent in the law of negligence, which is generally the law applied to error, so that the legal avenue is the one most commonly entered by seekers of compensation.

\subsubsection{Limitations of the word 'negligence'}

Negligence is defined as 'lack of proper care or attention, carelessness' (Concise Oxford Dictionary) and is a handy general description for a whole range of human errors. Like most general descriptors it is convenient to use when a more specific or detailed description is not considered necessary, but much detail may be lost when such words are used. For example the descriptor 'crime' embraces armed robbery and murder but does little to describe these two totally different activities. So it is with 'negligence', a word which embraces a variety of human errors.

\subsubsection{Investigating human errors in building failures}

In Chapter 3 is described a survey of the literature carried out to obtain informed opinions on the definition of building failure. A preliminary search of the literature (Porteous, 1982) revealed considerable diversity in the "human error" causes of building failure as perceived by the various commentators. This indicated the necessity for a more comprehensive literature survey which was undertaken to shed light on the extent to which the commentators agreed or disagreed about the causes of building failure (Porteous, 1984 - an unpublished paper incorporated in this thesis as Appendix A). From the survey was derived a list of different types of human error based as closely as possible on a literal interpretation of the words actually used by the various authorities in the literature. As anticipated the word 'negligence' was found to be used quite frequently, in which case that was the word recorded in the survey. Other types of human error were also mentioned and recorded in the list which is reproduced in Table 4.2. Also shown are the number of references to each type of error found in the 
literature in a given year. The table thus also gives some impression of the frequency with which the various types of error were mentioned in the literature over a period of years.

The absence of literature references from the USA in the list assembled during the literature survey is not the result of any deliberate policy. The survey attempted to cast a wide net, but the USA references caught by that net, such as Di Pasquale (1982), Feld (1968), Janney (1979), Kaminetzky (1981), McKaig (1962), and Richardson (1980) tended to concentrate on structural failure, often of the catastrophic type mentioned in 3.2.3, rather than on the range of failures considered by this study.

HUMAN ERROR

YEAR: '69-73 $74 \quad 75 \quad 76 \quad 77 \quad 78 \quad 79 \quad 80 \quad 81 \quad 82 \quad 83$ Total

Defective materials

Overlooked site condition

Ignorance

Over-emphasis on first cost

Defective documentation

Unanticipated consequence of change

Specialist contractor's lack of knowledge

Design too difficult to build well

Dereliction or negligence

Poor communication

\begin{tabular}{|c|c|c|c|c|c|c|c|c|c|}
\hline 1 & 2 & & 1 & & 2 & & 1 & 2 & \\
\hline 3 & & 1 & 2 & & 1 & & 1 & 1 & \\
\hline 3 & 1 & & 5 & & & 1 & & & \\
\hline 2 & & 1 & 3 & & & 1 & 2 & 1 & \\
\hline 4 & & & 3 & 1 & & 1 & 2 & & \\
\hline 1 & 2 & & 4 & 1 & 2 & 4 & 2 & 1 & \\
\hline 5 & 1 & & 7 & 1 & 2 & & 3 & 1 & \\
\hline 3 & 6 & & 3 & 1 & 3 & 3 & 1 & 2 & \\
\hline 3 & 6 & & 4 & 2 & 2 & 3 & 3 & 2 & \\
\hline 4 & 1 & & 6 & 3 & 1 & 4 & 4 & 1 & 1 \\
\hline
\end{tabular}

Table 4.2 Number of references to various human errors as causes of failure, by year of publication of the reference, and the totals for each type of human error.

It is quite possible that when the various commentators used the word 'negligence' they were using it in a generic sense to describe a variety of carelessness or lack of proper care or attention (see 4.3.2) which would embrace all the other types of error listed in Table 4.2 but it remains unproven. The author argues that 'negligence' is a handy general 
description for a whole rage of human errors but that it does little to assist understanding of the type of mistake made. From that point of view it is argued that many references to negligence in the literature are really references to the commentator's familiarity with a variety of human errors including all those listed in Table 4.2.

\subsubsection{Importance of the survey}

The importance of the survey is that it penetrated beyond the general terms 'human error' and 'negligence' to expose some details about the sorts of mistakes people make when designing and constructing buildings. By focusing attention on the notion of human errors as mistakes which contribute to building failures rather than on the legal concept of negligence, two benefits are gained.

The first benefit is that once the emphasis on blame is removed the maker of the mistake, along with any other witnesses or evaluators, is much more likely to acknowledge the mistake and to discuss it frankly.

The second benefit is that a list of types of human error is a useful reminder to building evaluators that human error takes many forms and should not be summarily dismissed as 'negligence' every time it is uncovered.

Table 4.2 is not proposed as an immutable list of all possible human errors, but as a useful working instrument which may well be refined and augmented as further knowledge is gained. It accords with the observations of commentators in the literature surveyed.

\subsubsection{Who makes the errors?}

It is important to realise that the various types of human error may be made by any or all members of the building production team. Poor 
communication may occur between any or all of them on site and in the associated offices. Defective documentation may not be the result of an error by the architect but by the contractor who produced them for an offsite fabricator. Site conditions can just as easily be overlooked by an engineer new to the area as by a contractor who has worked in the locality for years but has never built a particular form of foundation before.

An illustration of this latter was provided in the course of an interview with a technical field advisor from BRANZ. He told the author about a wellregarded builder whom he happened to meet on site just prior to the pouring of a reinforced concrete floor slab to be cast on prepared ground. The BRANZ advisor queried the absence of a water proof membrane between the hard-fill base and the slab. The builder was totally nonplussed, and it transpired that he had never used such a membrane in twenty years of on-ground slab construction and did not know he had been ignoring an important, even elementary, principle of construction. Fortunately all the sites he has built on were raised above surrounding land so that the water table was always well below the unprotected concrete slab. That explained the absence of any reports of dampness from his many clients.

The circumstances which led to some of the building failures investigated in the course of research suggest that it may be fairer to refer to 'accident' rather that 'negligence' when ascribing cause to some failures. Where omissions are made by a contractor whose workmanship and attention to detail are otherwise exemplary, but who was interrupted in the work by an urgent call to another site, it seems unnecessarily pejorative to use the word 'negligence'.

A case typical of the 'accidental' class of building failure was one in which a bath was installed complete with chromium-plated waste outlet but with no waste pipe connected. For some months of daily use the bath water was 
discharged partly down through the hole in the floor through which the nonexistent pipe should have run, and partly over the surface of the floor. Visible water damage to the floor coverings adjacent to the boxed-in bath finally alerted the owners to the problem. The fact that a hole in the floor had been prepared for the waste pipe suggests that the plumber had every intention of connecting a waste-pipe, knew the necessity for doing so, but was so distracted by some event that completion of the job was forgotten.

\subsection{AMPLIFICATION OF THE TYPES OF HUMAN ERROR}

\subsubsection{Defective materials}

Materials may be defective when used in one circumstance but adequate in another. When a building failure is attributed to defective materials there is an implication that the material or the choice of that material was defective in the circumstances in which the material was to be used.

Modern sealants can illustrate the point. A silicone sealant containing acetic acid may be an excellent product for many jobs but if used in contact with galvanised steel roofing in which it may induce corrosion it becomes a defective material. Of course it is possible for a material to be defective for all or any purposes. Poorly stored paint, partially hydrated cement and untreated timber all come into that category.

In the literature survey (Porteous, 1984) references to defective materials as a cause of building failure made by Kimber (1973), Eldridge (1974), Freeman (1974), The Architects Journal (May 1977), Marsh (1979), a report in Building Design (1979), Drury (1981), Roberts (1982) and Harrison (1982) were found. 


\subsubsection{Overlooked site conditions}

In New Zealand, site conditions may be taken to include not only the bearing capacity and other soil conditions but also such factors as wind exposure, earthquake risk and rainfall, since these may vary with distance from the coast, altitude, proximity to earthquake faults and position relative to mountain ranges. A builder accustomed to building in sheltered inland locations may find that good building practices found to be reliable there are quite inadequate when building on a ridge-top high above Wellington and on the edge of the Cook Strait weather zone.

Anyone can overlook site conditions through carelessness or inexperience, or because the conditions are deceptive, fluctuating or even concealed.

There is another category of site conditions, also easily overlooked, and that is the category of site conditions which exists during and/or after construction. Such site conditions may include congestion, shortage of flat ground, or lack of covered storage, for example, so that it proves impossible to store aluminium joinery in conditions in which it is supported against distortion and protected from concrete spatter which could damage both glass and aluminium.

In the course of the literature survey (Porteous, 1984) references to overlooked site conditions made by Stringer (1970), O'Brien (1970), Cheetham (1973), Wigglesworth (1976), Nelson (1977), Bessey (1977), Marsh (1979), Rabeneck (1981) and Harrison (1982) were found.

\subsubsection{Ignorance}

At first glance 'ignorance' is a highly pejorative term, yet everyone is ignorant of something and the rapid growth of applied technology and complexity in building makes participants in the industry likely sufferers from 
some sort of knowledge-gap. It is therefore with a degree of humility that the word ignorance is used. In itself ignorance is not a vice, and the only harm ignorance can cause arises when the ignorance is of some matter vital to the success of human enterprise and is resident in a person crucial to that success. Thus ignorance of the significance of concrete shrinkage causes no harm if that ignorance resides in a glazier, but a glazier ignorant of the effects of thermal expansion on large sheets of glass may be a liability if employed to glaze a building with large sheets of glass.

The extent to which reliance is placed on the absence of ignorance is evident in the frequent use of the phrase 'in accordance with good trade practice' as the indicator of the standard of work expected. Such a phrase presupposes that all the work will be done by people fully trained in 'trade practice' and flies in the face of common knowledge that much building work is carried out by apprentices and casual labour with varying degrees and standards of skill, experience and supervision.

Ignorance in the building industry, as elsewhere, may exist as two types. The first is ignorance of what to do, and the second is ignorance of why a particular practice is normally carried out in certain way. Of the two the second may be the more potentially harmful.

An example to illustrate this point concerns the case of a stainless steel shower base installed on the floor directly over a basement garage. The installer knew that the shower waste fitting must be fitted with a large brass back-nut which is threaded on to the shaft of the waste-fitting and tightened with a wrench. Knowing this, the installer cut a hole on the particle-board floor through which the shower-waste fitted snugly, protruding into the basement. The installer went down to the basement and fitted the backnut, tightening it with a wrench. The waste pipe was then fitted. 
What the installer had not understood was that the function of the backnut is to squeeze the waste-fitting down tightly over a bead of waterproof bedding compound so that the junction of the waste-fitting to the shower base is permanently water-tight. The procedure followed by the installer did not achieve this purpose. When the back-nut was tightened against the under-side of the floor it was not securing a water tight joint but merely pulling the centre of the shower-base down towards the floor a little. When the shower came to be used the weight of the person showering caused the shower-base to sag a little further towards the floor at which point the shower-waste was no longer bedded tightly into place, and leaking through the shower-waste to shower-base junction began. Had the installer known why the back-nut is used the mistake would not have been made. This easily understood domestic-scale error has its many equivalents in commercial-scale building.

In the course of the literature survey (Porteous, 1984) ignorance was found to be cited as a cause of building failure by O'Brien (1970), a report in The Architect and Surveyor (1973), Cheetham (1973), Eldridge (1974), Addleson (1977), Nelson (1977), McDonald (1977), Littlemore (1977), Smith (1977) and Croome (1980).

\subsubsection{Over-emphasis on first cost}

When the post-completion period during which the contractor is required to make good any short-comings is as short as the very common 30 days, there must be little incentive to use materials and techniques which will last much longer. In practice, of course, considerations of personal reputation, honesty, and professional integrity tend to make designers, builders, and suppliers aim for greater longevity.

Real pressure to limit the first cost may come as much from the actual or potential owner as from those who design, supply, and build. It is not 
necessarily wrong to attempt to lower the first cost. Lower cost building may perform quite satisfactorily over the years using less expensive but still durable materials and undoubtedly meets a crucial need. There is an important distinction to be made between lowering the first cost by using cheaper, equally durable, but perhaps less attractive or fashionable material, and lowering first cost by using a second-grade material which appears to be what it is not. The 'specials' offered by some timber suppliers can come into this latter category. The timber may be offered for sale at a lower price because it is poorly graded and prone to warping and cupping. Such material may be fairly priced for what it is and well suited to some temporary or rustic forms of construction but it is bound to show poorer appearance and earlier degradation than a more appropriate quality of material. In such cases the lower first cost may be heavily out-weighed by the cost and worry of premature re-cladding made necessary not by aesthetic considerations but by the need to maintain a building in a basic watertight condition.

In the course of the literature survey (Porteous, 1984) references to the phenomenon of over-emphasis on first cost made by CIRIA (1973), the Architect and Surveyor (1973), Wigglesworth (1976), Addleson (1977), Graham (1977), Bessey (1977), Holland (1980), the Chartered Surveyor (1981), Rabeneck (1981) and Harrison (1982) were found.

\subsubsection{Defective documentation}

Documentation may be defective by reason of the inaccuracy of the information it contains or because information essential to the building process is not included. Where the information is inaccurate the building may be constructed incorrectly, especially if no-one suspects the inaccuracy of the information.

In the case where the information is inadequate or missing, the way is left clear for the contractor to follow, for better or for worse, the course of action 
dictated by whatever previous experience has been had. In some cases no harm will be done because the necessary information has, as it were, been provided by the contractor sufficiently and correctly enough for the job to be done well.

Other cases may not turn out so well. If the construction involves unusual processes, materials or components, the well of contractor experience may not be deep enough to supply missing information with enough accuracy and completeness to enable the work to be done properly. Material requiring special surface preparation or special temperature conditions before application are a case in point. There is, as another example, no point in a cryptic note in a specification stating 'all external walls to be foil insulated' unless the location of the foil in the wall cavity is also specified. No benefit is gained and much harm may be done if the foil is put in the wrong place in the cavity.

In the course of the literature survey (Porteous, 1984) reference to defective documentation as a cause of building failure made by O'Brien (1970), the Architect and Surveyor (1973), Kimber (1973), Cheetham (1973), Addleson (1977), Abbott (1977), Smith (1977), Bampton (1978), Croome (1980), Rabeneck (1981) and Bentley (1981) were found.

\subsubsection{Unanticipated Consequences of change}

Changes may be made to building materials, components, fittings, fixtures, assembly techniques and processes, as well as to the size, cost or other characteristics of the finished building. The number of variation orders issued in the building industry bears testimony to the many changes that are an inevitable part of the process of designing and constructing a building.

The interdependence, apparent or otherwise, of so many aspects of building is what can make changes so fraught with risk. It is in the nature of the 
business that changes are often made quickly in order not to delay the work or to reduce the amount of work which must be redone. It is that very haste that can lead to the making of changes which have undesirable and unanticipated 'knock-on' effects. A good example of this effect may happen when the decision is made, after the wall-frames are up, to change from a light steel roof, to a heavy concrete tile roof. The increased weight will have consequences for the strength of the existing frames in walls and roof (which will require retro-fitted strengthening) and for the construction details at roof penetrations, eaves, and gutters. If those consequences are not foreseen a sagging ridge line is going to be but one of the most obvious consequences.

Changes may, of course, by made at a much more detailed level. A decision to change the exterior cladding of a building from glass-reinforced concrete (GRC) panels to pressed steel ones will require a complete revision of the wall penetration and jointing details to maintain weather-tightness, and careful selection of fastening systems to avoid electro-chemical corrosion effects. The relationship of the modular spacing of the steel panels to the GRC ones has to be considered in the midst of these other consequences.

In the course of the literature survey (Porteous, 1984) references to the effect of unanticipated consequences of change by the Architects Journal (1971), Hardy (1974), the Development and Material Bulletin of GLC (1974), Addleson (1977), Nelson (1977), Bessey (1977), Newlove (1978), Beck (1979), Marsh (1979), Roxburgh (1980), Palmer (1980), Downey (1980), Nice (1980), Ransom (1981), Rabeneck (1981), Building Technology and Management (1982), and Mclnnes (1977) were found.

\subsubsection{Specialist contractors' lack of knowledge}

The increasing complexity of building has given rise, as it has in other occupations such as electronics or mechanics, to the tendency for some 
aspects of construction to divide into the province of specialists. Well established are specialist applicators of roofing membrane materials, but more recently the market has seen the arrival of specialist contractors offering to install security systems, specialised coatings for walls, roofs, and ceilings, vacuum cleaning systems, telephones and intercoms and satellite TV aerial dishes. The burgeoning range of floor finishes is also fertile ground for the specialist contractor.

There is much to be said for the specialist contractor who knows the product well and has been expertly trained in the best techniques of preparation, installation, finishing and testing of the product. Reputable specialists can offer a warranty backed by the specialist installer and often by the maker of the product itself. Where the advantage of the specialist contractor becomes lost is where that contractor is represented on site by a poorly trained employee unfamiliar with the special requirements of the makers' installation advice. The warranty may offer some protection against the consequences of the specialist contractor's lack of knowledge but if the job has been botched from the start no amount of remedial work (which may be all the warranty, or the manufacturer is prepared to cover) is going to produce a satisfactory job with the life-expectancy normally to be expected.

In the course of the literature survey (Porteous, 1984) references to this cause of building failure by O'Brien (1970), Powell (1971), CIRIA (1973), the Architect and Surveyor (1973), Cheetham (1973), Development Material Bulletin of the GLC (1975), Allen (1977), Addleson (1977), the Architects Journal (May 1977), Nelson (1977), Abbott (1977), Smith (1977), Bessey (1977), Bampton (1978), Beck (1979), NHBC (1979), Ransom (1981), the Chartered Surveyor (1981), Rabeneck (1981) and Donaldson (1982) were found. 


\subsubsection{Design too difficult to build well}

Architects and other building designers are sometimes accused by builders of designing with insufficient regard to the practicalities of construction. Like some accusations it presupposes a degree of absolute certainty which may not be supportable by the facts. It is certainly true that some construction details are more difficult to build well than others, but the extent to which that is so will depend on the experience of the builder, the quality and extent of the plant available, and possibly on the availability of appropriate materials. If every building site had the facilities of a modern metal and wood-working shop and skilled operators to work it, then construction drawings could call for details of almost Swiss precision and they could be built. The reality of life is that few sites for any building other than extraordinary national or corporate symbols like the Hong Kong and Shanghai Bank in Hong Kong, with virtually unlimited budgets, have such resources.

The solution is therefore to design construction details which are buildable given the likely level of workshop facilities and personal skills to be found on the site (or in the supplier's fabrication plants). Failure to design with regard to those constraints leaves the way open not only for bitter arguments surrounding the cost for re-doing non-complying work but also for expensive delays.

In the course of the literature survey (Porteous, 1984) difficult design was found to have been mentioned in the following references: O'Brien (1970), Powell (1971), Kimber (1973), Fantl (1974), Higby (1974), Hardy (1974), Eldridge (1974), Freeman (1974), Development and Material Bulletin of GLC (1974), The Architects Journal (May 1977), Graham (1977), Downey (1977), Bampton (1978), Beck (1979), Marsh (1979), Building Design (1979),

Bonshor (1980), Palmer (1980), Downey (1980), Drury (1981), Roberts (1982) and Harrison (1982). 
4.4.9 Dereliction or negligence 
assumes knowledge or experience in the other party and therefore fails to draw the necessary detail or to specify the material in writing. Another cause of poor communication occurs when the information is written down or drawn, but is incomplete. A window specification, for example, may appear to the contractor to be complete but still fail to communicate fully because it lacks a warning that the window installation is to be exposed to exceptionally high winds and rain. The incomplete communication may result in a competent contractor selecting a window system that is entirely satisfactory for most sites, but fails on the exposed one.

In the course of the literature survey (Porteous, 1984) references to poor communication as a cause of building failure made by the Architects Journal (1971), CIRIA (1973), the Architect and Surveyor (1973), Kimber (1973), Harper (1974), Addleson (1977), Nelson (1977), Downey (1977), McDonald (1977), Smith (1977), McDowell (1977), Hughes (1978), Bampton (1978), Marsh (1978, Beck (1979), Croome (1980), Bonshor (1980), Holland (1980), Roxburgh (1980), Ransom (1981), Rabeneck (1981), Atkinson (1981), Bentley (1981), Building Technology and Management (1982) and Duell (1983) were found.

\subsection{CLASSIFYING FAILURES BY CAUSE(S)}

\subsubsection{Applying knowledge of the two generic causes}

Using the knowledge drawn from the tabulation of natural causes in Table 4.1 and from the literature survey findings about human error in Table 4.2 it is possible to systematically classify a building failure according to:

(a) which of the 3 natural causes' (if any) contributed to the failure, and what the sources of those causes were in each case, and 
(b) which of the list of 10 types of human error (if any) contributed to the failure.

\subsubsection{Benefits from using the classification system}

Application of the classification system to one or more building failures enables the failure(s) to be evaluated in a way which may yield an immediate short-term benefit by encouraging objective analysis of the evidence to determine cause, not blame. Remedying the cause will certainly prevent repetition of the failure, even if it does not make good the damage already caused. Attributing blame does not, by itself, remedy anything.

The classification system also enables the evaluation to feed-back single case or aggregated data to produce medium and long-term benefits to builders, and designers and ultimately to the users of buildings. It does this by encouraging a methodical diagnosis of the underlying causes of failure in a way which allows for consistent written records to be made and manipulated for research purposes. From the research will flow findings about those aspects of the process of designing and constructing buildings which give rise to building failures. It is in concentrating efforts for improvements on the weaknesses exposed by such research that the best prospect for containing and minimising the incidence of building failures lies.

Just as branches of science such as chemistry and zoology trace their most dramatic progress from the development of systems of classification of their subject matter, so may the study of the causes of building failures be advanced by the development of a classification system. 


\subsection{SUMMARY}

This chapter presented a new approach to identifying the cause(s) of building failure. It did that firstly by considering the often over-looked contribution to failures made by natural causes and secondly by considering, in tandem with those natural causes, the many forms of human error which occur in the production of buildings. This new approach avoids involvement with issues of blame by eschewing the term 'negligence' in favour of 'human error' or 'mistake'.

The extent to which this system of classification is helpful in understanding and learning from building failures is demonstrated in the next two chapters.

\subsection{REFERENCES}

Abbott, W.W. Managing for Quality in Building, National Builder, September 1977, p 349.

Addleson, L. $\quad$ Technical study 3. Diagnosis: Principles and Procedures, AJ Guide to Building Failures, Architects Journal, vol 165, 2 March 1977, pp 415-419.

Addleson, L. Technical study 1 - Introduction AJ Guide to Building Failures, Architects Journal, vol 165, 16 February 1977, p 323-325.

Allen, W. Letter to the Editor, in Building, vol 232, no 6974, 25 February $1977, \mathrm{p} 81$.

Atkinson, G. Attention to details, in Building, vol 240, 8 May 1981, pp 6061. 
Bampton, E, Bowyer, J.T., and Armstrong, R.W. Building Better Buildings Maintenance at the Design Stage, three contributions in Institute of Building Maintenance Information Service, no 3, IOB, Ascot, Berks, UK, 1978, pp 1-3.

Beck, V.R. Failures of Wall Claddings and Finishes - A Survey. Technical Record 448. Experimental Building Station, Dept Housing and Construction. New South Wales, February 1979.

Bentley, M.J.C. Quality control on Building Sites. Current Paper CP 7/81. Building Research Establishment, Garston, UK, 1981.

Bessey, G.E. Avoiding Faults and Failures in Building, in Overseas Building Notes, No.177. Building Research Establishment, Overseas Division, December 1977.

Bonshor, R. Low Rise Housing Design and Construction Architects Journal, vol 171, no 18. April 1980, pp 881-885.

Building Failures Architects Journal, vol 154, no 30, 28 July 1971, pp 187-188.

Building Failures Building Technology and Management, vol 20, no 4, April 1982.

Can We Master Technology? Architects Journal, vol 165, no 19, May 1977.

Cheetham, D.W. Defects in modern building Building, Part 1, vol 225, no. 6805, 2 November 1973. pp 91-94 Part 2, vol 225, no. 6807, 16 November 1973, pp 175-176, 179-180, 182, 187-188. 
Construction Industry Research and Information Association (CIRIA). Serviceability of Buildings in Development and Materials Bulletin of Greater London Council, vol. 63, March 1973, pp 2/1-2/8.

Croome, Derek J. The Role of Feedback in Building Design, Building Services Engineering Research and Technology, vol. 1, no. 1, 1980 pp $1-9$.

Di Pasquale, R.A. Bridging catastrophe: understanding why failures occur. Concrete Construction (USA). April 1982. pp 345-348.

Donaldson, R. Construction Faults in Housing located in a Mining Town in North West Australia, Architectural Science Review, vol 25, no 2, June 1982, pp 29-36.

Downey, E. Building Defects, Construction News, vol 3, no 9, October 1977, pp 72-73.

Downey, E. Weathertightness and Water Penetration of Buildings. Seminar Paper. Paisley College of Technology, 5 November 1980.

Drury, C.A. The Effects on Investment of Major Defects. Chartered Surveyor. (Supplement) London, April 1981, pp 10-11.

Duell, J.

Variations on a Theme, Architects Journal, Vol 177, no 1, 5 January 1983, p 32.

Eldridge, H.J. Common Defects and Their Diagnosis. in Proceedings of Joint Building Research Establishment:Institute of Building Seminar on Building Defects and Failures, IOB, Ascot, Berks, UK, November 1974. 
Fantl, K. Building defects: The client's viewpoint Building Research and Practice, Jan/Feb 1974, pp 23-26.

Faults in New Buildings A Report in Architectural Surveyor, Vol 18, May/June 1973.

Feld, J. $\quad$ Construction failure. Wiley, New York. 1968.

Freeman, I.L. Failure Patterns and Implications in Proceedings of Joint Building Research Establishment:Institute of Building Seminar on building defects and failures. 29 November 1974. JOB, Ascot, Berks, UK, November 1974.

Graham, H. Eliminating the Defects of the 1970's Municipal Building Management, vol 4, 1977, pp 31-32.

Greater London Council (GLC). Development and Materials Bulletin. Vol 79, October/November 1974.

Greater London Council (GLC). Development and Materials Bulletin. Vol 81, January 1975.

Hardy, A.C. Opening Address to Symposium on Design Failures in Buildings, Building, 24 May 1974, p 63.

Harper, D. The Designers' Viewpoint in Proceedings of Joint Building Research Establishment:Institute of Building Seminar on building defects and failures. IOB, Ascot, UK, November 1974.

Harrison, H.W. Avoiding Faults in Traditional Housing. BRE News 58, Winter 1982. 
Harrison, H.W. Practical problems in Estimating Effective Service Life of Components and Elements in Housing - Paper presented to C.I.B Seminar W60 (The Performance Concept) University of Strathclyde, Glasgow June 1982.

Higby, H.C.

Defects in building: The client's viewpoint Chartered Surveyor: BQS Quarterly, vol 2, March 1974, pp 52-54.

Holland, G.

Misuse of Building Material - Design. in Proceedings of 36th Conference of N.S.W Division of the Building Science Forum of Australia. Published by the BSFA N.S.W Division Sydney June 1980.

Hughes, T.

Failures and Remedial Work in New Buildings, Construction no 25, P.S.A London, March 1978, pp 8-10.

Janney, J.R.

Guide to investigation of structural failures. Report from ASCE Research Council on Performance of Structures, American Society of Civil Engineers, New York, 1979.

Kaminetzky, Dov. Failures during and After Construction in Concrete Construction, vol 26, August 1981, pp 641, 643, 645, 647, 649.

Kimber, K.G. Pathology of Building. Contract Journal, vol 225, no 4912, 25 October 1973, pp 38-39.

Littlemore, David. Building Defects, - who dunnit? in Proceedings of the 29th Conference of the N.S.W Division of the Building Science Forum of Australia. Published by the BSFA, N.S.W Division, Sydney, November 1977. 
McDonald, B. Defects - Who's to Blame? Developer, Architect, Governments? Or? in Proceedings of 29th Conference of the N.S.W Division of the Building Science Forum of Australia. Published by the BSFA, NSW Division, Sydney, November 1977.

McDowell, I. Defects in Buildings - Feedback or Foul-ups. in Proceedings of 29th Conference of the N.S.W Division of the Building Science Forum of Australia. Published by the BSFA, NSW Division, Sydney, November 1977.

Mclnnes, A.

Who Pays if the Roof Falls In? in Proceedings of the 29th Conference of the N.S.W Division of the Building Science Forum of Australia. Published by the BSFA, N.S.W Division, Sydney, November 1977.

McKaig, T.H. Building failures. Case studies in construction and design, McGraw-Hill, New York, 1962.

Marsh, Paul. Whither the Buck? An Analysis of Blame, Concrete. vol. 3, no. 5, May 1979, pp 12-14.

Marsh, Peter. Why do Britain's Builders bungle the job? in New Scientist, vol 78, no 1104, May 1978, pp 523-525.

National House Builders Council (UK). The incidence, causes and prevention of defects in private and public sector housing. NHBC, London, June 1979.

Nelson, J. The nature of common defects in building SAAT News Society of Architects and Architectural Technicians, London, 28 August 1977. 
Newlove, J.

The Achievement of Quality in Construction, Building Technology and Management, vol 16, no 1, 1978 pp 6-10.

Nice, P.H. Building Problems and Failures, Building Technology and Management, vol 18, no 10, November 1980, pp 27-28.

O'Brien, T.P. Quality Control on Site in Quality Control. 1970 Report on a Conference organised by U.K. Ministry of Public Buildings and Works. H.M Stationery Office, 1970.

Oxford University Press. Concise Oxford Dictionary of current English. 6th Edition 1976.

Palmer, J. Education in Use or Misuse of Building Materials. in Proceedings of 36 th Conference of the N.S.W Division of the Building Science Forum of Australia. Published by the BSFA N.S.W Division, Sydney, June 1980.

Porteous, W.A. $\quad$ Perceived causes of building failure. Unpublished paper, 1984. $47 \mathrm{pp}$.

Porteous, W.A Building Failures, The Chartered Builder (Journal of the Australian Institute of Building) vol 135, 1982, pp 53-56.

Powell, M.

The Incidence, Cause and Prevention of Defects in the Construction of New Houses. The Housing Research Foundation, U.K 1971.

Rabeneck, A. Facing up to failure. Diagnosing and preventing defects Architects Journal, vol. 173, no 15, 15 April 1981, pp 715-718. 
Ransom, W.H. Building Failures: Diagnosis and Avoidance, E \& F.N. Spon Ltd, London 1981.

Richardson, Barry A. Remedial Treatment of Buildings. Construction Press, New York, 1980.

Roberts, W.G. Innovation in Materials and Technology Makes a Major Contribution to Defects and Failures in Buildings, Building Technology and Management, vol 20, no 5, May 1982, pp 1619.

Roxburgh, R.D. Use or Misuse of Material. in Proceedings of 36 th Conference of the N.S.W Division of the BSFA of Australia. Published by the BSFA N.S.W Division, Sydney, June 1980.

Scandal of New Failures, Building Design, no 473, 23 November 1979.

Smith, A.C. Defects in Building - A Builder's Bane. in Proceedings of 29th Conference of the N.S.W Division of the BSFA of Australia. Published by the BSFA N.S.W Division, Sydney November 1977.

Stringer, G.E. What is Quality Worth? in Quality Control. Report on a conference organised by U.K Ministry of Public Buildings and Works. H.M Stationery Office. 1970.

When will We Ever Learn? Chartered Surveyor. (Supplement) London, April 1981.

Wigglesworth, G. Building Defects - Who is Guilty, Architects Journal, vol 164, no 32, 11 August 1976, pp 252-253. 


\section{CHAPTER 5}

\section{NEW ZEALAND BUILDING FAILURES DATA}

In the previous chapter the causes of building failures including the two generic causes 'natural causes' and 'human error' were explained and amplified as necessary. The chapter concluded by suggesting the benefits that would result from the ability to classify building failures by their cause or combination of causes.

This chapter begins by discussing the features of an ideal data source for the investigator of building failures, and by pointing out that, despite an extensive search, no such ideal data source was located for the study.

The chapter then goes on to report the results of an analysis of those data sources which were located and found to be useful to varying degrees. Closest to the ideal was the data in the claim files of the Building Performance Guarantee Corporation (BPGC), but two other sources, which provided less detail, are reported.

These two sources are the New Zealand Architects Co-operative Society Ltd (NZACS) and the MBS (NZ) Ltd firm of insurance lossadjusters. 


\subsubsection{Ideal data source}

In earlier chapters the meaning of the term 'building failure' was defined, and the causes of building failures were set out.

With the benefit of that preparatory work a systematic examination of reported building failures in New Zealand became possible. Building failures could be identified and classified as to source and cause and the extent to which human error had contributed to the failure.

The major difficulty still remaining was to find some reports of building failures containing sufficient detail recorded systematically enough to make identification and classification both possible and useful. It was not enough that the reports, once located, should contain sufficient information to enable the building failure to be identified and classified; it was also important that the credentials and the legal position of the recorder should be known. For accurate and objective findings to flow from an analysis of building failure reports it was essential that the reports themselves should be as accurate and objective as possible. This combined requirement of accuracy and objectivity narrowed the range of sources of useful failure reports. For example, it precluded consideration of reports written by the builders who erected the affected buildings, not because the builders were not expert in describing the failure, but because economic and legal considerations might have affected their objectivity. Similarly, reports written by lay people without experience of building technology are precluded on the grounds that the accuracy of the information must be suspect.

The ideal source of building failure reports for this research could therefore be defined as one where people with the necessary knowledge of building technology were engaged to write objective reports containing enough detail to enable the nature of the failure to be identified and understood, and the cause to be made clear. An 
ideal source would contain records written with the needs of the building failures researcher in mind.

Such ideal sources do not exist. Sources which provided accurate and objective reports were found, but none of those sources was written with the researcher in mind. As a consequence the details were not always complete or clear, and some qualified interpretation of the reports was sometimes necessary.

The sources of building failure data discovered in the course of the research are discussed in the following pages.

\subsection{BUILDING PERFORMANCE GUARANTEE CORPORATION OF NEW ZEALAND (BPGC)}

\subsubsection{Functions of the Corporation}

Of the various sources of records of building failures investigated in the study, the source which most closely approximated the ideal described in 5.1.1 was the Building Performance Guarantee Corporation of New Zealand which since April 1st 1978 had been issuing indemnities protecting and indemnifying the owners of residential buildings against loss or damage to, defects in, or deterioration of those residential buildings. The Corporation has also been involved in the making good of such damage, defects and deterioration.

Offices of the Housing Corporation of New Zealand (HCNZ) acted as agents for the Building Performance Guarantee Corporation (BPGC), issuing Indemnity Application forms to would-be home-owners wishing to indemnify themselves against the risks previously described, as work commenced on their new houses. 


\subsubsection{BPGC claim procedure}

Interest in the BPGC scheme was aroused by awareness of the claim process which occurs when the house-owner detects something going wrong. In such a case officers of the HCNZ inspect the defect and, using a specially designed form, produce an impartial report on the nature of the defect and the apparent reason for it, together with an estimate of the cost of the remedy and the actions to be taken to affect the remedy. It will be seen at once that this reporting procedure by people acting neutrally between the client and the builder was likely to produce a gradually increasing supply of data about building failure in newly built dwellings in New Zealand. The indemnity provided protection against faulty workmanship and materials for up to 6 years for the starting date of the Indemnity (which was the date on which the BPGC executed the indemnity, or the subsequent construction start date). Although a distinction was made between "minor defects" (for which the indemnity period was limited to 18 months) and "major" and material defects, in practice the corporation, exercising something of a consumer protection function, tended not to invoke the "minor defect" definition rigidly in cases where the claimant could reasonably be given the benefit of the doubt as to the timing of the defect or the extent to which it had become obvious to a lay person. This reasonable approach to claims in no way reduced the objectivity of the claim data recorded by the HCNZ inspector since all claims are investigated on notification unless obviously well out of time. With these few exceptions, decisions to admit or refuse a claim were made after the inspector's report had been made.

From the BPGC claim files it was possible to glean, inter alia, the location of the dwelling, the year of the claim, the date of completion, the class of human error (using Table 4.2) and the natural source and cause of failure (using Table 4.1). The files from which data was extracted included all those claims in which building failure was evident and which were lodged after the inception of the scheme on 1st April 1978 and before 31 December 1984.

A total of 198 of the claims made to the BPGC in that period were identified as claims relating to building failures as defined in Chapter 3 . 


\subsubsection{Analysis of BPGC claims data}

Analysis of all BPGC claims received over the period 1st April 1978 (when the BPGC first issued indemnities) until 31 December 1984 revealed that of 446 claims received 198 involved building failure as defined in this report. (The bulk of the 'non-failure' claims were for non-completion of contract.)

The total number of building failure claims (198) should be seen in the context of the 25,000 indemnities issued by the Corporation over that period. It must also be appreciated that the Corporation indemnified only a small proportion of all the new dwellings erected in that time. The Corporation's own figures (BPGC Annual Reports) show a varying penetration of the potential market for indemnities, as shown in Table 5.1.

\begin{tabular}{|l|c|c|c|c|c|}
\hline $\begin{array}{l}\text { NZ New House } \\
\text { Permit Numbers }\end{array}$ & 21761 & 20266 & $\begin{array}{c}1983 \\
15999\end{array}$ & $\begin{array}{c}1982 \\
19006\end{array}$ & $\begin{array}{c}1981 \\
14442\end{array}$ \\
\hline $\begin{array}{l}\text { BPGC Share } \\
\text { of Market }\end{array}$ & $21.8 \%$ & $17.5 \%$ & $15.5 \%$ & $18.9 \%$ & $27.8 \%$ \\
\hline
\end{tabular}

Table 5.1: BPGC indemnities issued as a percentage of new permits. Source : Building Performance Guarantee Corporation

\subsubsection{Distribution by locality}

The indemnity scheme was open to all-comers and there was no policy of selection against particular builders so it may be assumed that the houses indemnified by the Corporation represented a fair sample of new housing of the period. As will be demonstrated later in this chapter, the dwellings which became the subject of claims were not only distributed all over the country (see Fig 5.1) but were also distributed both above and below the average dwelling construction cost for the time and location. 


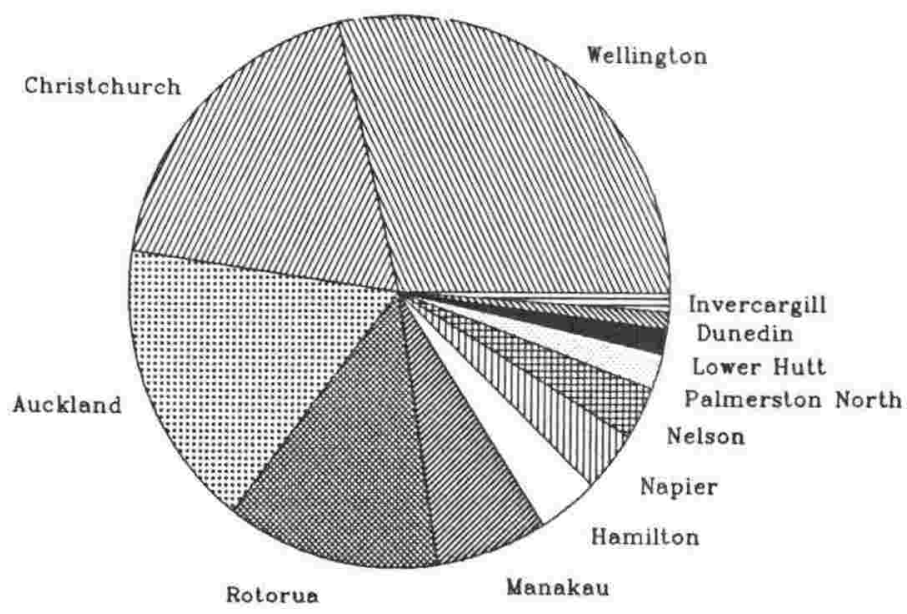

Fig 5.1 BPGC Claims by location.

\subsubsection{Examination of claims to identify cause(s)}

Analysis of the 198 building failure claims to identify the cause or causes was carried out using the list of causes identified in Chapter 4 in Tables 4.1 and 4.2.

dampness

movements

) natural causes (Table 4.1)

chemical/biological change

)

and

human error (Table 4.2)

It must be remembered that more than one cause may operate to create a building failure. Fig 5.2 shows the relative frequency with which the given cause was found to have been a factor. 


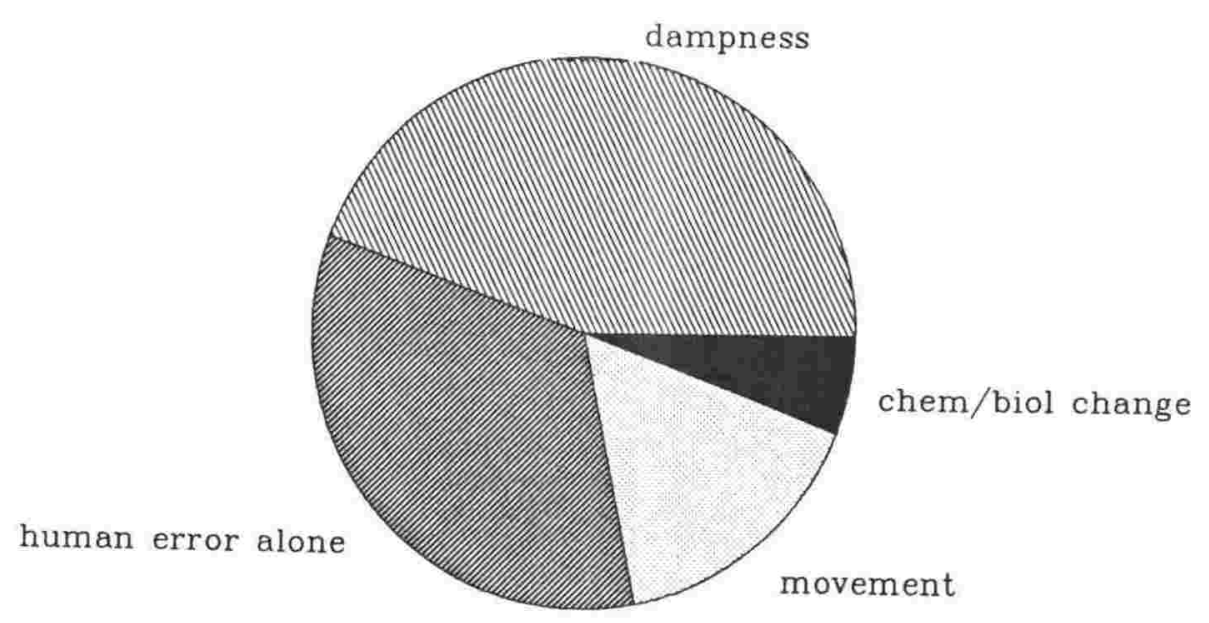

Fig $5.2 \quad$ BPGC. Causes of failure

It should be noted that human error alone makes a significant contribution to the number of building failures, as does the cause 'dampness'. Of course it is common for a building failure to result from the effects of more than one cause.

Further analysis of the cause 'human error', using the list of types of human error discussed in Chapter 4 and reproduced below, reveals that the relative incidence of the various types of human error is as illustrated in Fig 5.3. 


\section{Key to type of human error:}

\begin{tabular}{|c|c|}
\hline & Defective materials \\
\hline & $\begin{array}{l}\text { Overlooked site } \\
\text { conditions }\end{array}$ \\
\hline & Ignorance \\
\hline & $\begin{array}{l}\text { Overemphasis } \\
\text { on first cost }\end{array}$ \\
\hline & $\begin{array}{l}\text { Defective } \\
\text { documentation }\end{array}$ \\
\hline & $\begin{array}{l}\text { Unanticipated } \\
\text { consequence of change }\end{array}$ \\
\hline & $\begin{array}{l}\text { Specialist contractors } \\
\text { lack of knowledge }\end{array}$ \\
\hline & $\begin{array}{l}\text { Design too difficult } \\
\text { to build well }\end{array}$ \\
\hline & $\begin{array}{l}\text { Dereliction or negligence } \\
\text { Poor communication }\end{array}$ \\
\hline
\end{tabular}

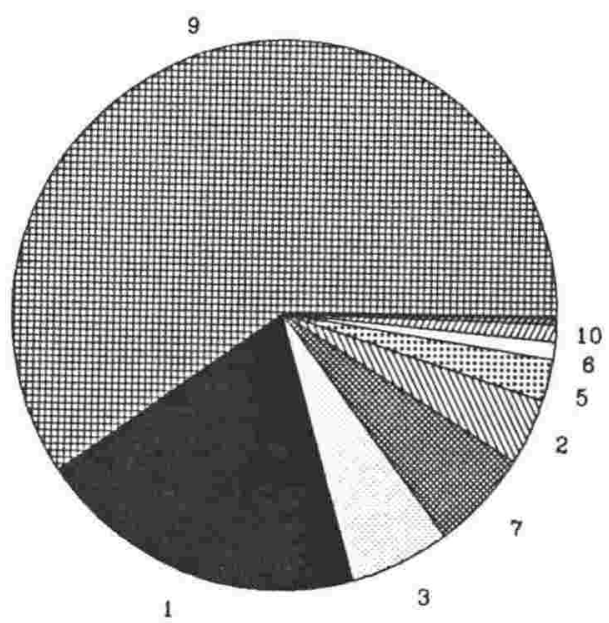

Fig 5.3 BPGC Incidence of types of human error.

The preponderance of the human error type "negligence" (type No. 9) is obvious and is discussed in Chapter 6 . Suffice to say at this point that the word 'negligence' is used liberally if not intelligently in building failure reports.

Figure 5.2 illustrates the relative incidence of failure causes including both 'natural causes' and 'human error'. Fig 5.4 shows the relative incidence of 'natural causes' only.

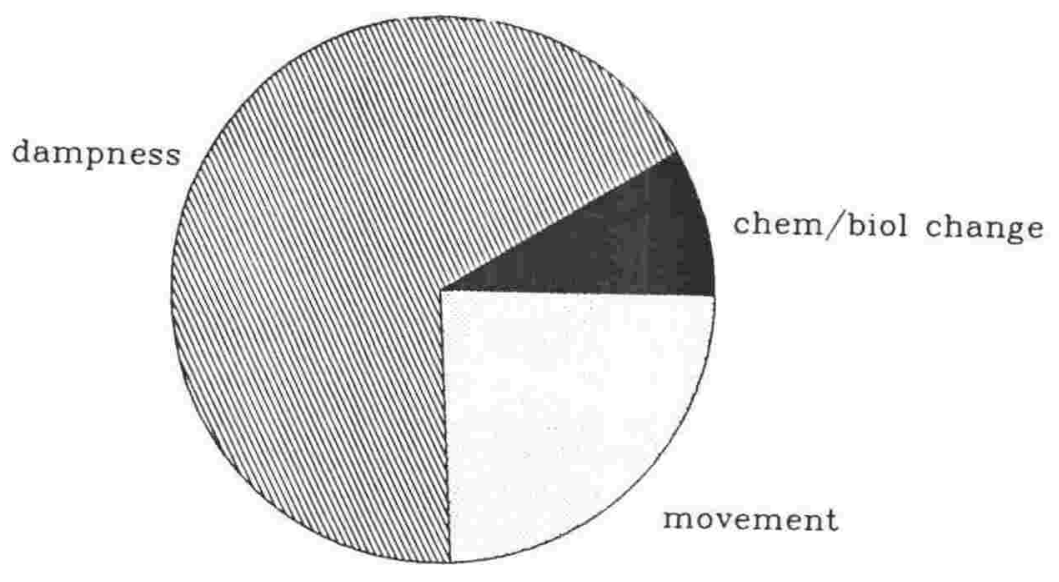

Fig 5.4 BPGC. Natural Causes 
When each of the three 'natural causes' is analysed to reveal the sources of that cause, the results are as shown in Figs 5.5 and 5.6 and 5.7 following:

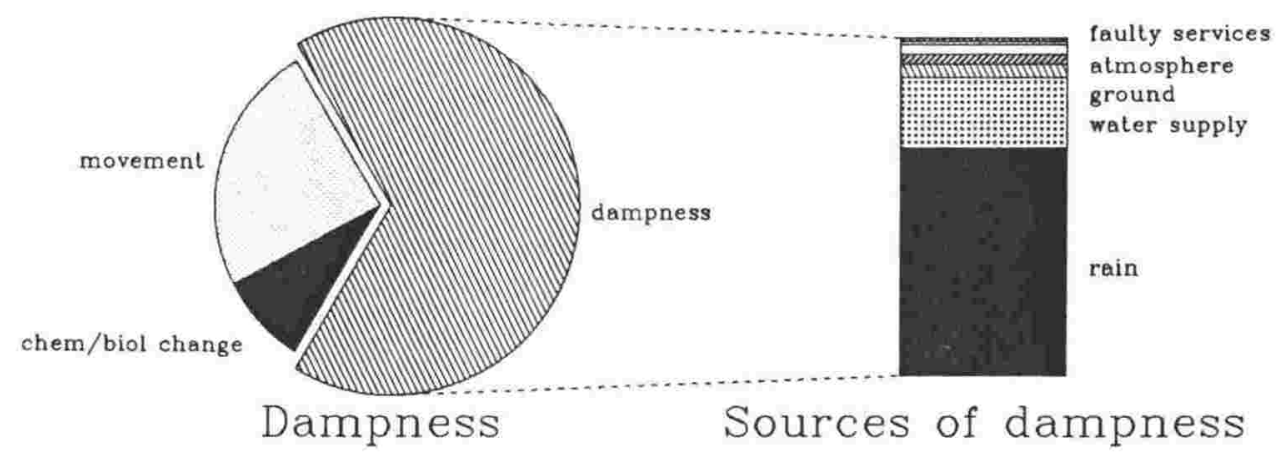

Fig 5.5 BPGC. Cause 'dampness' analysed by source.

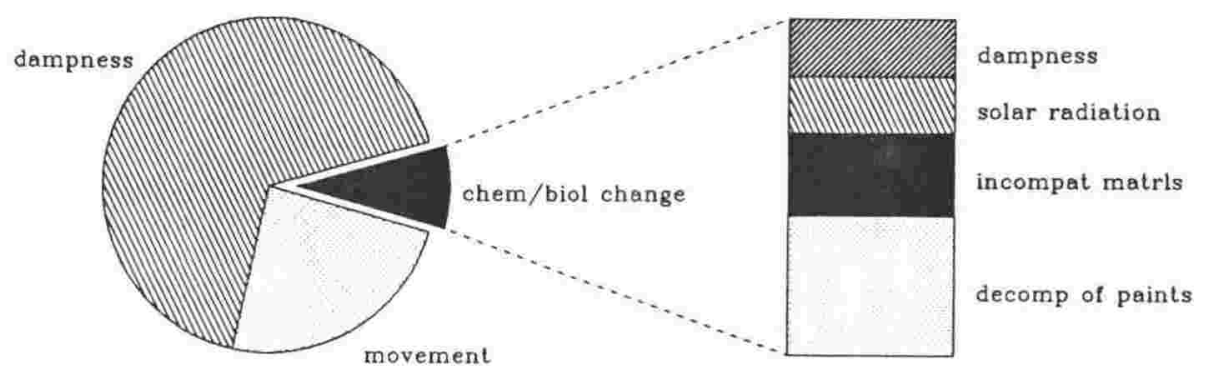

Chem/biol change Sources of chem/biol chan

Fig 5.6 BPGC. Cause 'Chemical/Biological change' analysed by source

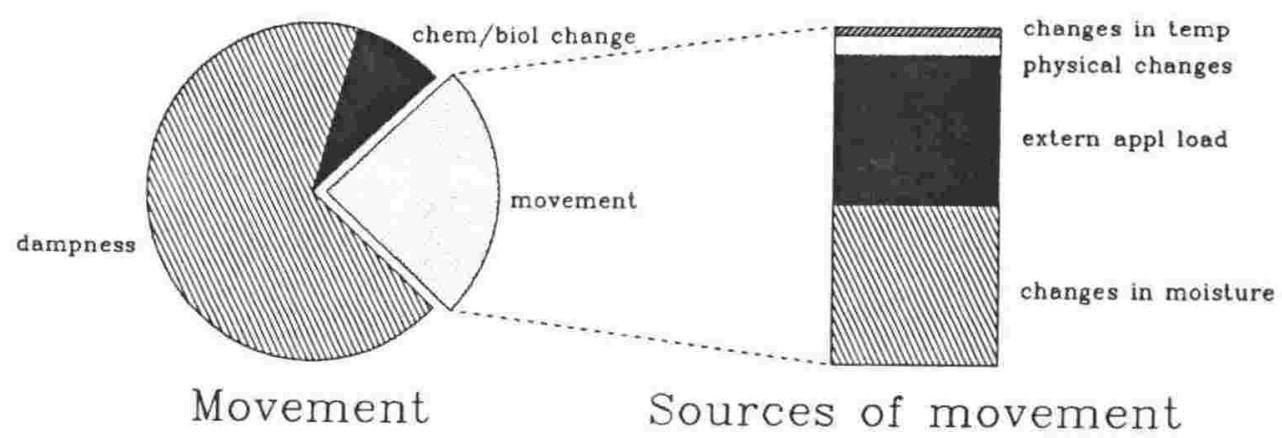

Fig 5.7 BPGC. Cause 'movement' analysed by source. 


\subsubsection{Time interval from completion to claim}

Examination of the BPGC claim files revealed information about the time interval between the completion of the dwelling and the lodging of the claim with the Corporation. For many house-owners the completion date is virtually the same as the occupancy date and gives an indication of the date after which the owner might first become aware of any building failures. Fig 5.8 indicates the number of claims made within $1,2,3,4$, or 5 years of completion of the dwelling. (The negative time span $(-1-0)$ allows for claims which were lodged before the dwelling was completed).

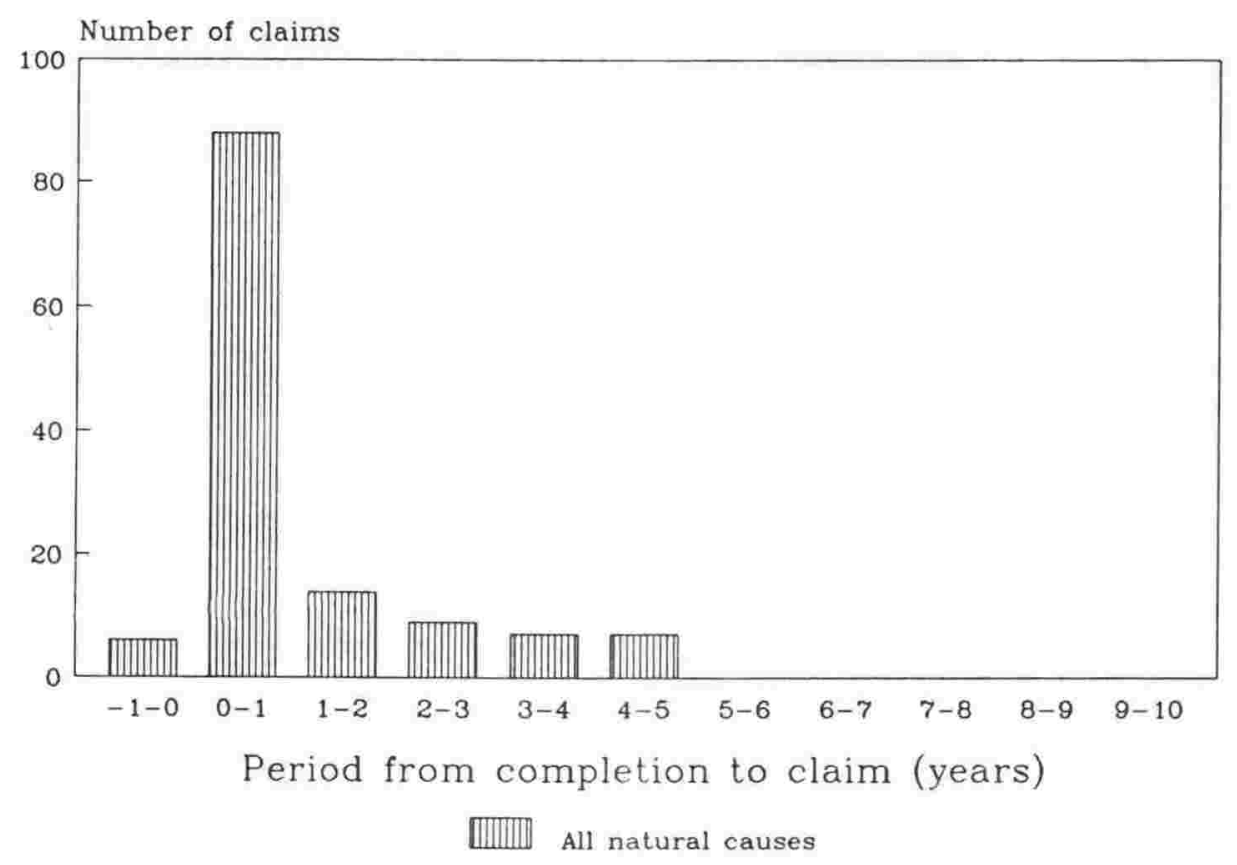

Fig 5.8 BPGC. Completion to claim time (years) (all natural causes). 
Analysis of the claims by natural causes reveals the early dominance of dampness as the most common natural cause. See Fig 5.9.

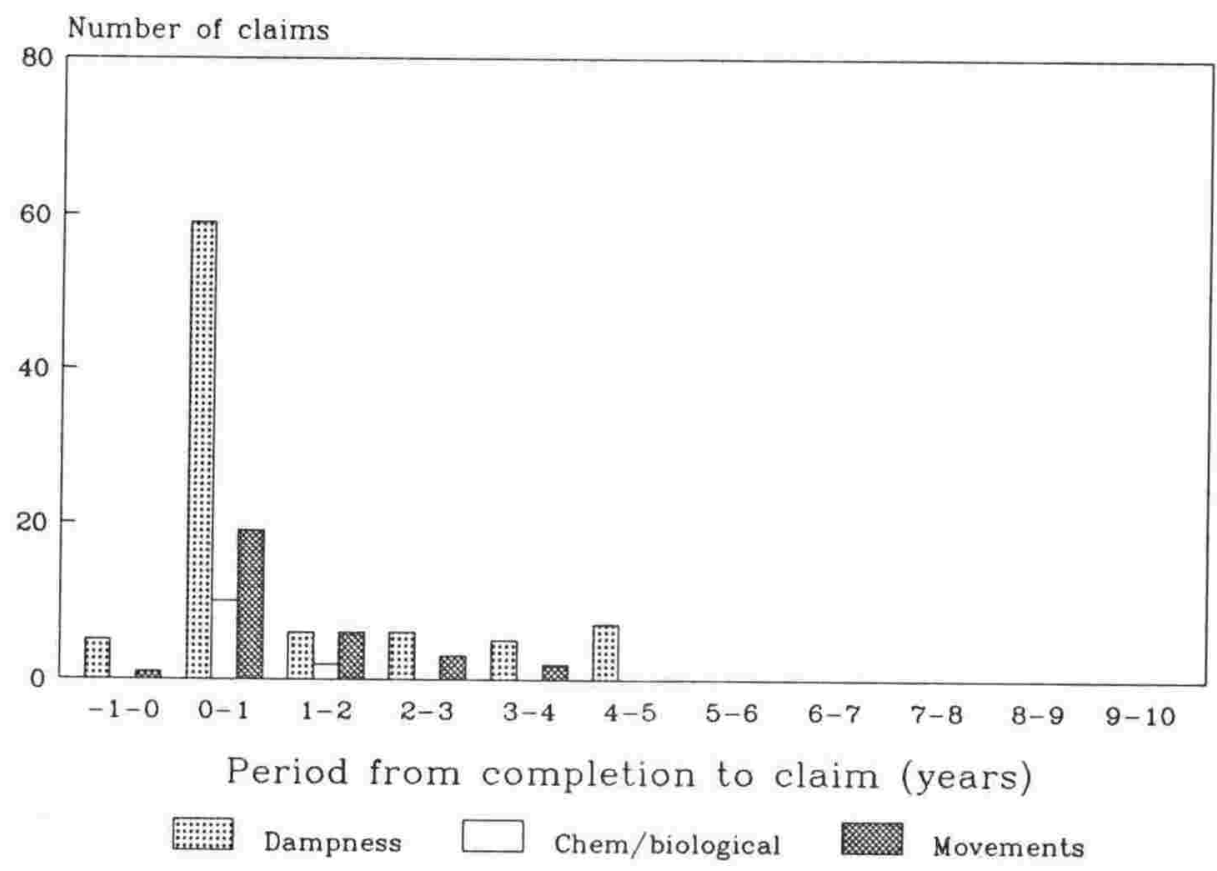

Fig 5.9 BPGC. Completion to claim time (years) (natural causes separately).

It is evident that by far the largest number or claims made in a 12 month period were made within the first 12 months after completion. As Fig 5.10 shows, the majority of these claims were made early in that first 12 month period. 


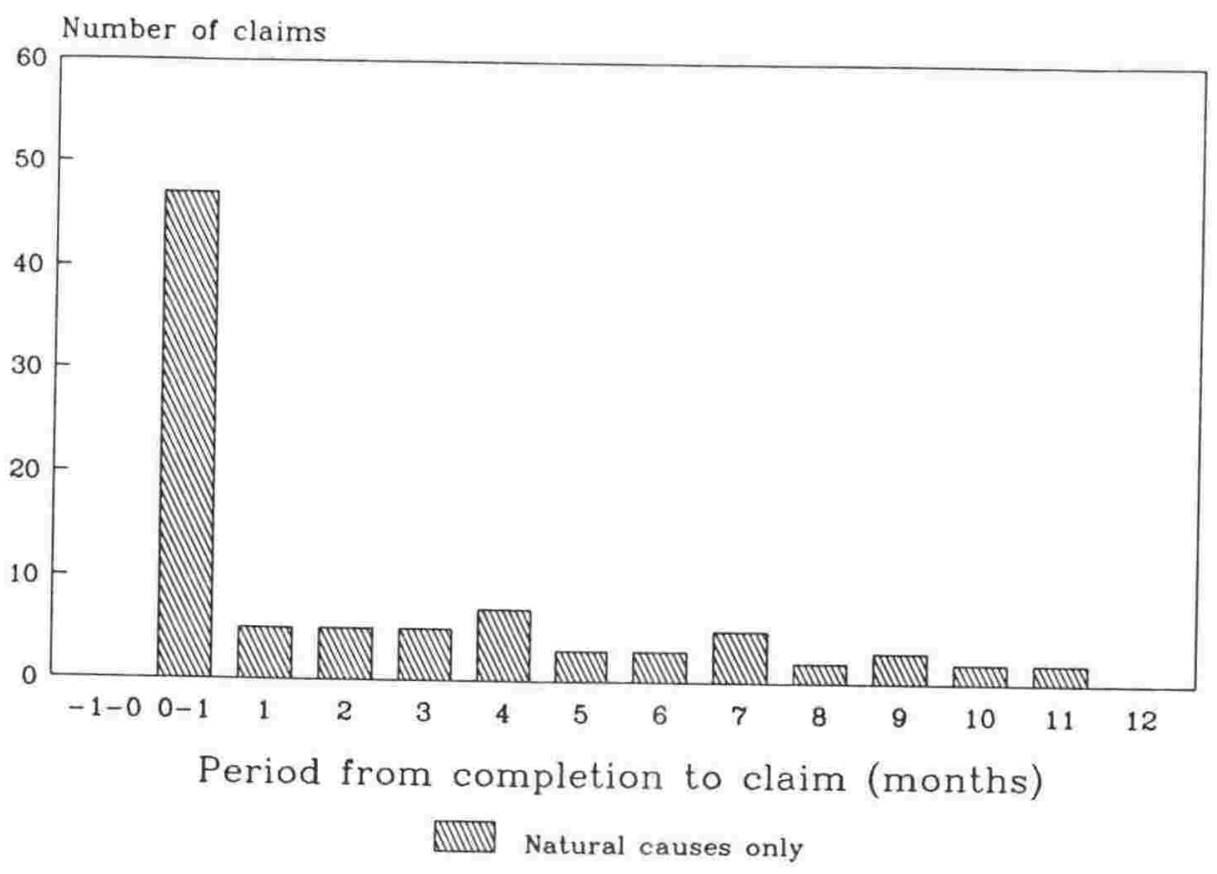

Fig 5.10 BPGC. Completion to claim time (months) (natural causes only).

Further analysis to investigate the relative frequency of the three natural causes as contributors to the claims made in the first 12 months is illustrated in Fig 5.11 in which dampness continues to be an influence in early claims.

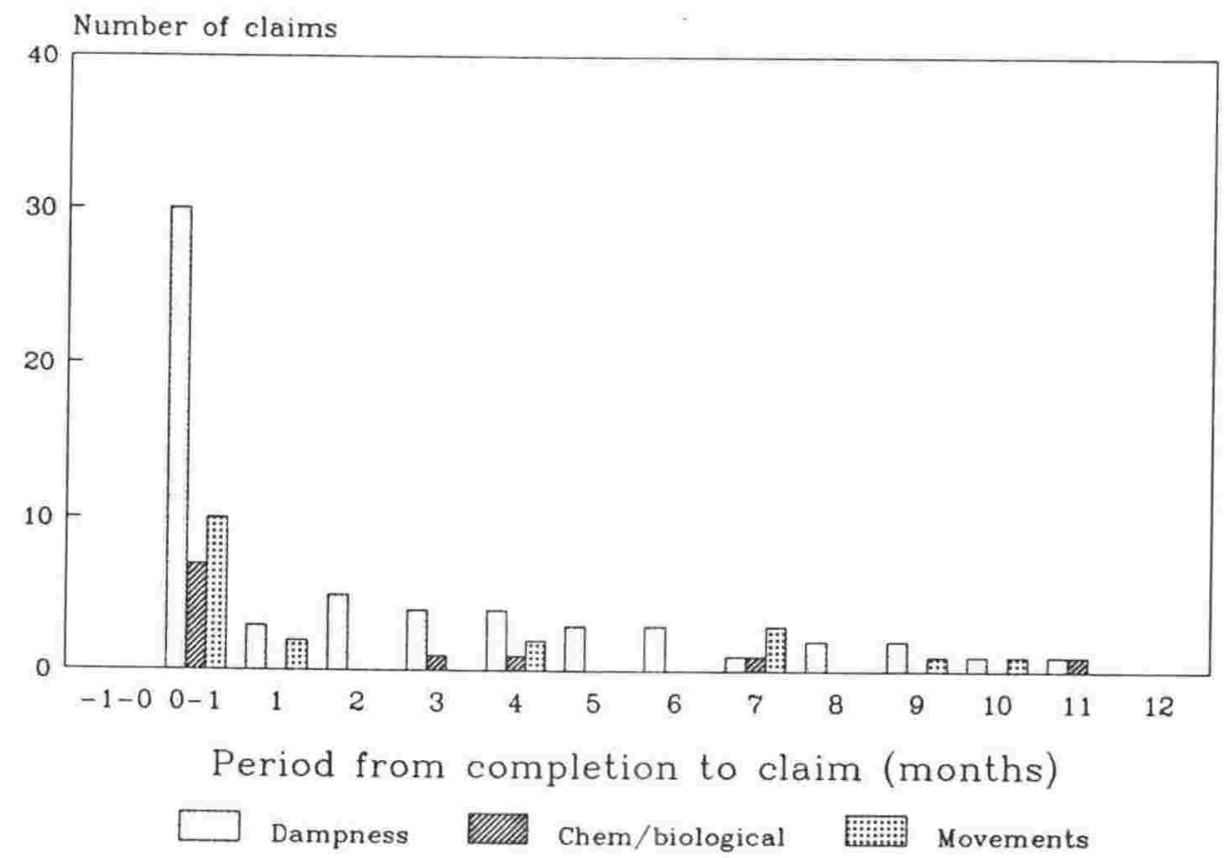

Fig 5.11 (BPGC). Completion to claim time (months) (natural causes separately). 
As Fig 5.2 shows a significant number of claims to the BPGC were the result of human error alone (ie there were none of the 3 natural causes present and contributing to the failure). Fig 5.12 shows the completion to claim time for BPGC claims due to human error only as compared with the times for claims caused by natural causes. (It must be remembered that of 198 BPGC claims only 6 (approximately $3 \%$ ) contained no element of human error while 8 claims (approximately) 4\%) revealed the presence of 3 types of human error. 78 claims (39.5\%) revealed the presence of 2 types of human error while the remaining 106 claims (53.5\%) reveal only 1 type of human error). See Fig 5.3 for illustration.

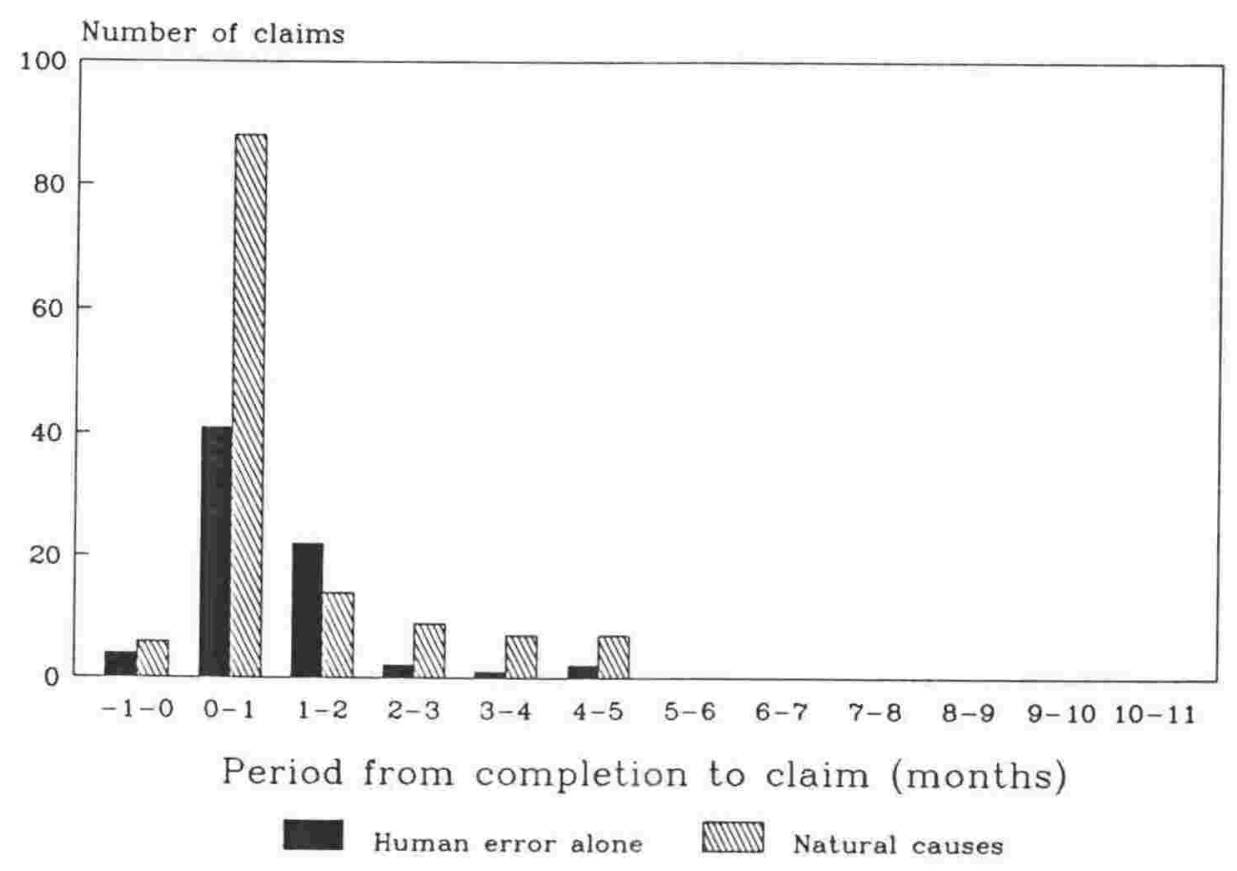

Fig 5.12 BPGC. Completion to claim time (human error alone and natural causes separately)

Again the preponderance of claims in the first year makes analysis of the first year necessary. Fig 5.13 provides this analysis and shows clearly that there is a difference between the patterns of claims arising from human error alone on the one hand and natural causes on the other. 


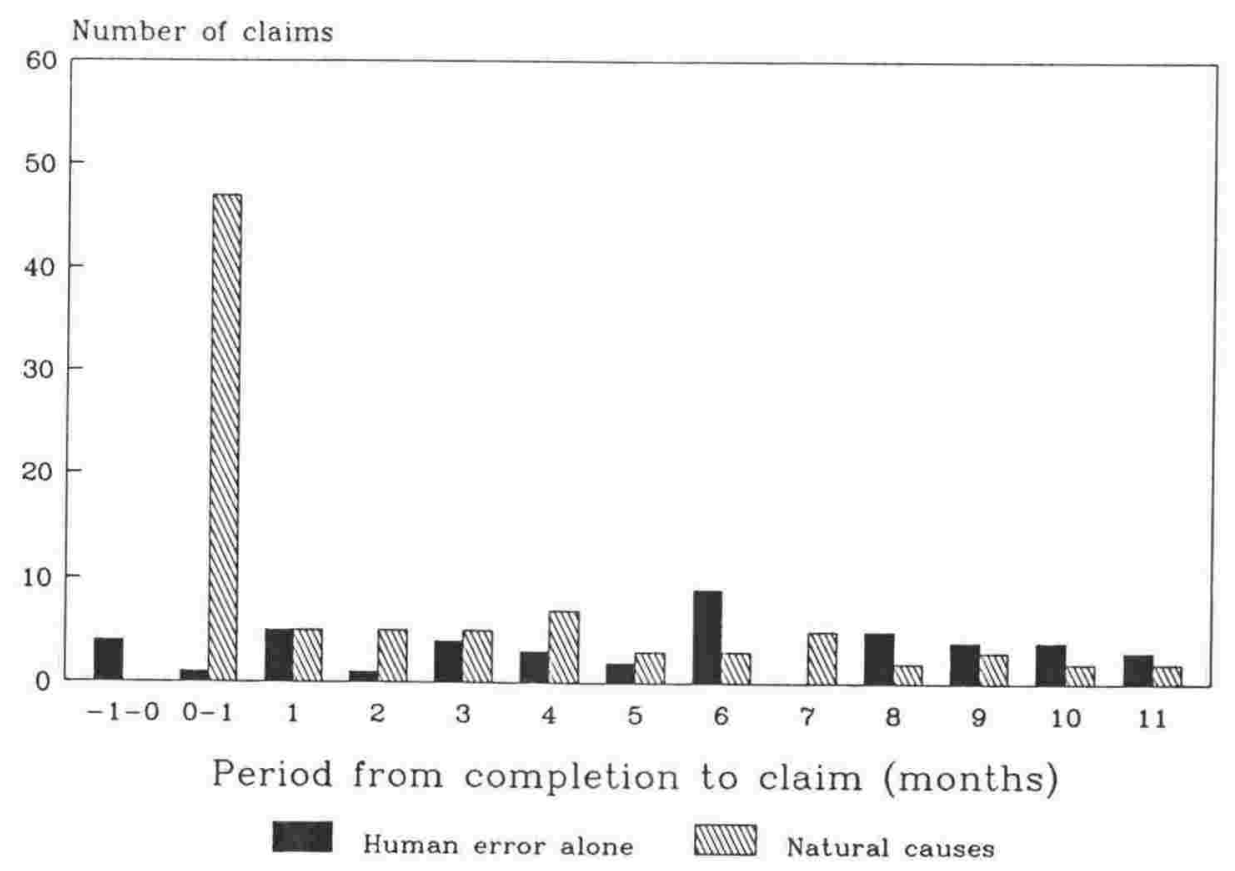

Fig 5.13 BPGC. Completion to claim time (months) (human error alone and natural causes separately).

The sum of claims arising from human error alone and from natural causes reveals a pattern in the completion to claim time which is shown, firstly, as the yearly pattern in Fig 5.14 and then, secondly, as the pattern over the first year after completion in Fig 5.15. 


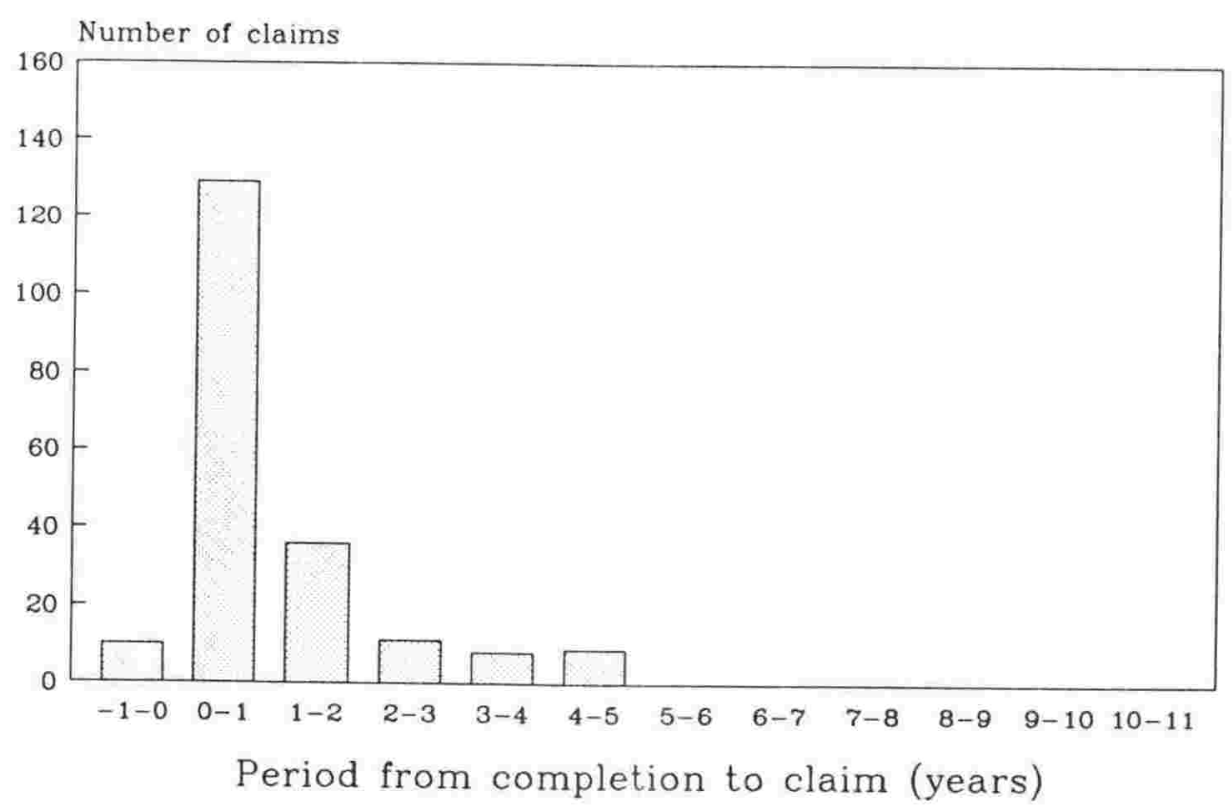

H/error \& natcas sum

Fig 5.14 BPGC. Completion to claim time (years) (human error alone and natural causes summed).

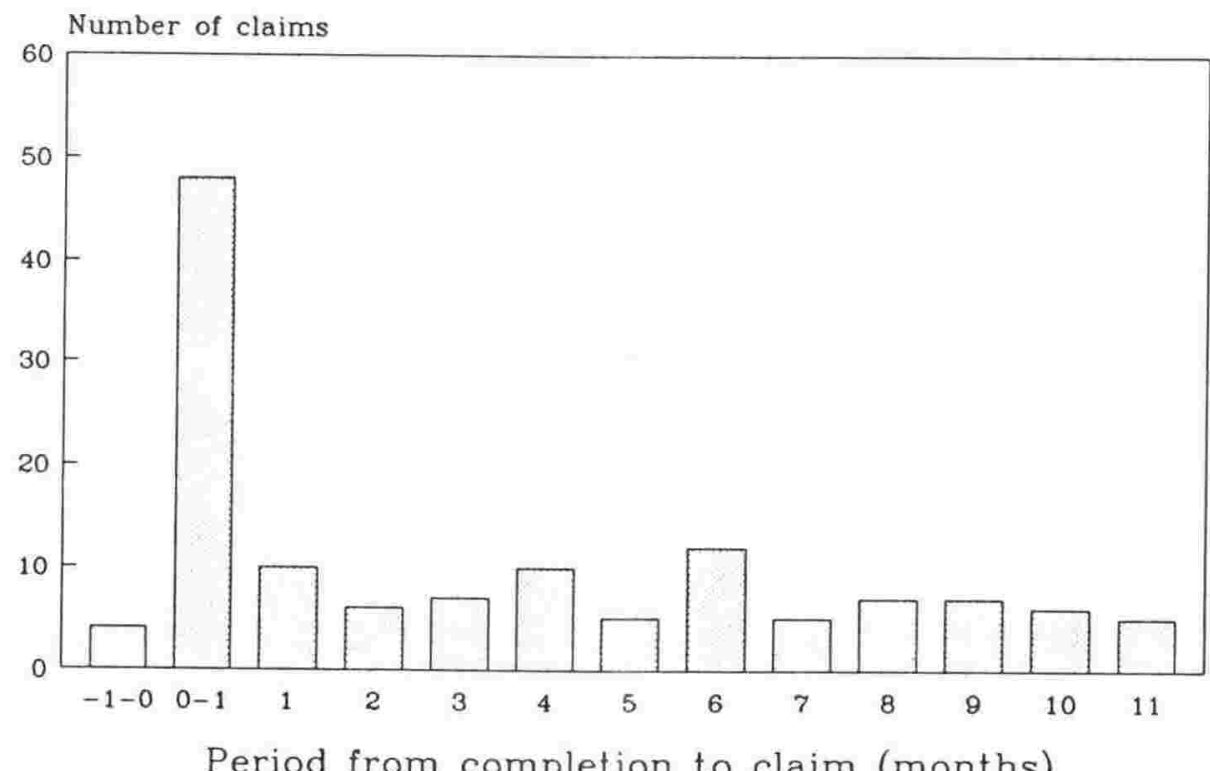

Period from completion to claim (months)

H/error \& natcas sum

Fig 5.15 BPGC. Completion to claim time (months) (human error alone and natural causes summed). 
Considering now the cost of the claims to the various claimants, there are two obvious ways to measure these. One is to measure the dollar cost of the claim. This method has only been used when a comparison between, say, the value of claims caused by dampness and those caused by movement is being made. Other than as a comparative measure the dollar values are of little use unless adjusted for inflation and adjusted to 1992 values. Even then the values would be subject to the criticism that they took no account of the variation in the cost of building materials and componentry over that period of time, a variation which owes as much to the deregulation of the New Zealand economy, closer economic relations (CER) with Australia, and alterations to import duty and tariff controls, as it does to inflation.

One useful measure of the cost of claims is a measurement of the claim sum as a percentage of the original contract price of the house. In all the BPGC claims considered in this report the period of time from completion until the claim was lodged was no more than 5 years, and the bulk of the claims were lodged within 1 year, so the effects of inflation on the claim cost to contract price ratio could be expected to be minimal. Fig 5.16 shows the pattern of claims arising form all natural causes when analysed by the claim sum/contract price ratio expressed as a percentage.

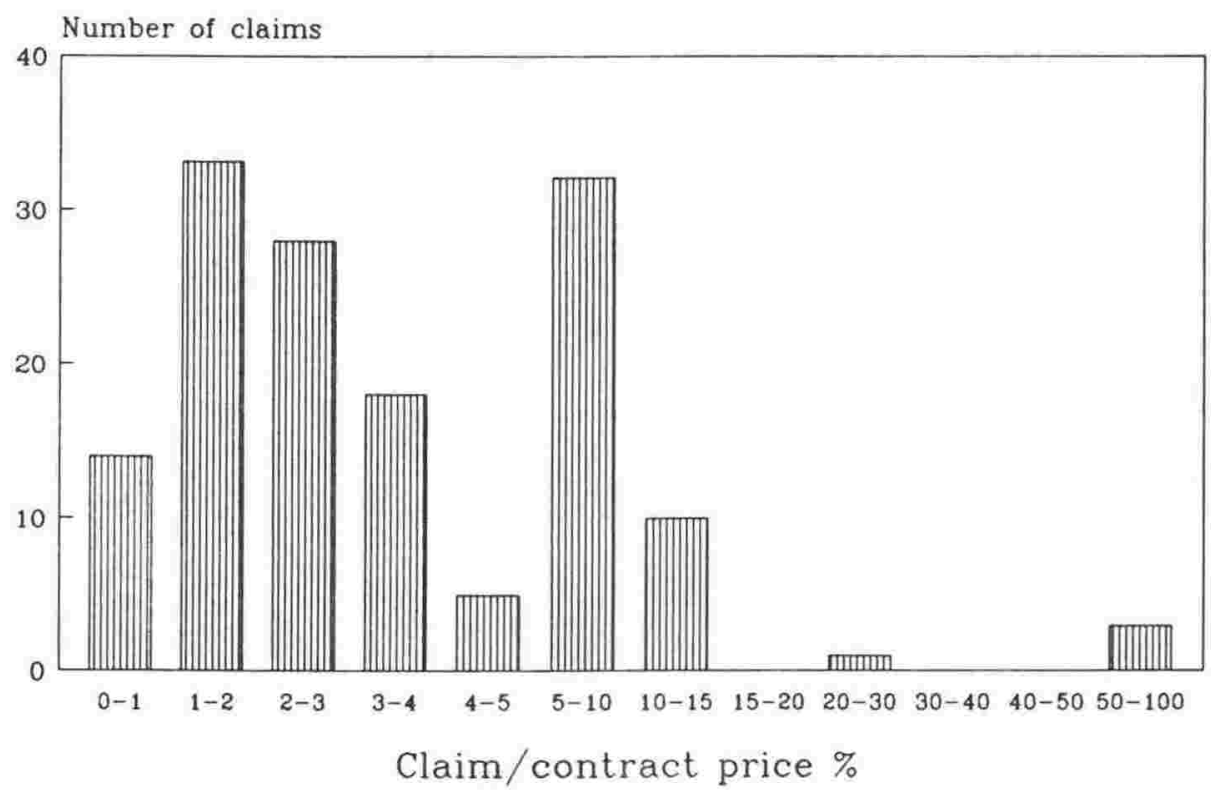

Fig 5.16 BPGC. Claim as \% of contract price. (all natural causes). 
The pattern of the claim/contract price ratio broken down by each of the three natural causes is illustrated in Fig. 5.17.

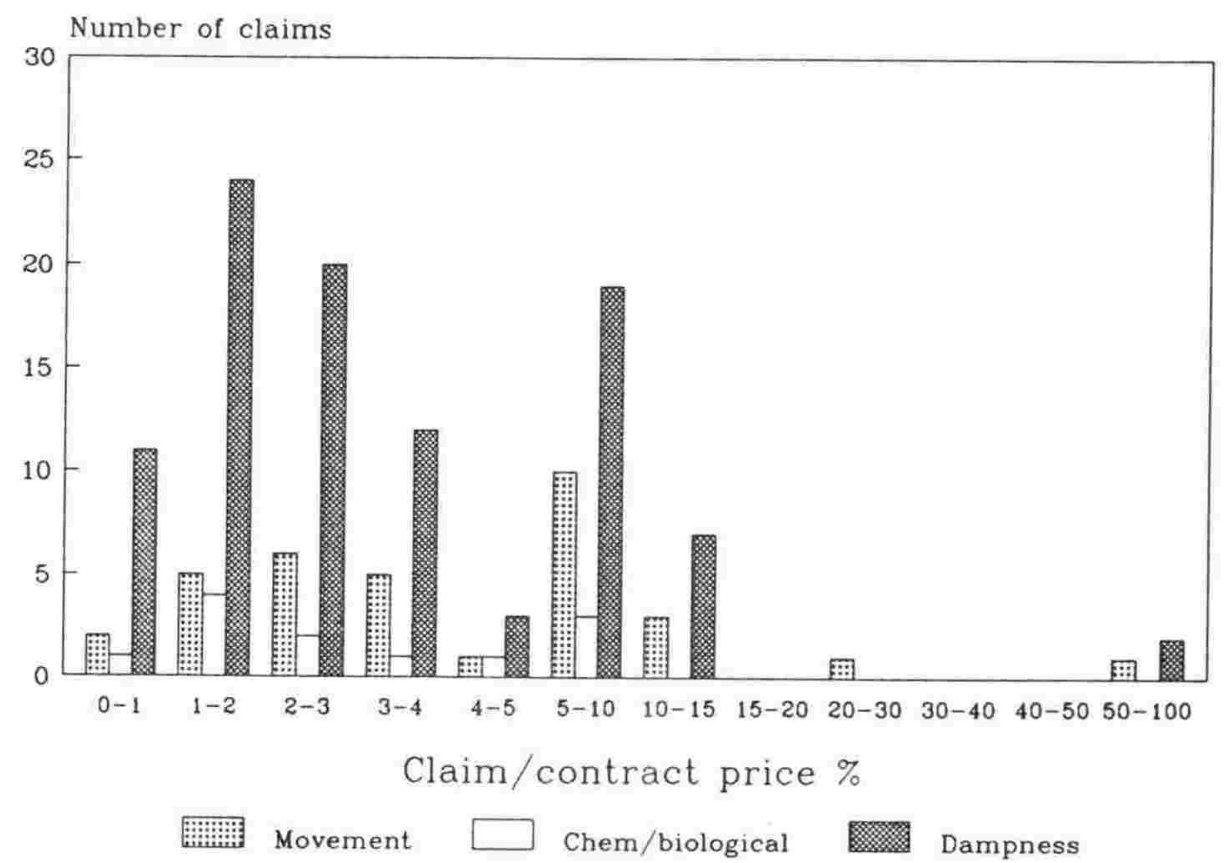

Fig 5.17 BPGC. Claim as \% of contract price (for each 'natural cause'). 
The relative impact of human error alone as compared with that of all the natural causes is shown in Fig 5.18.

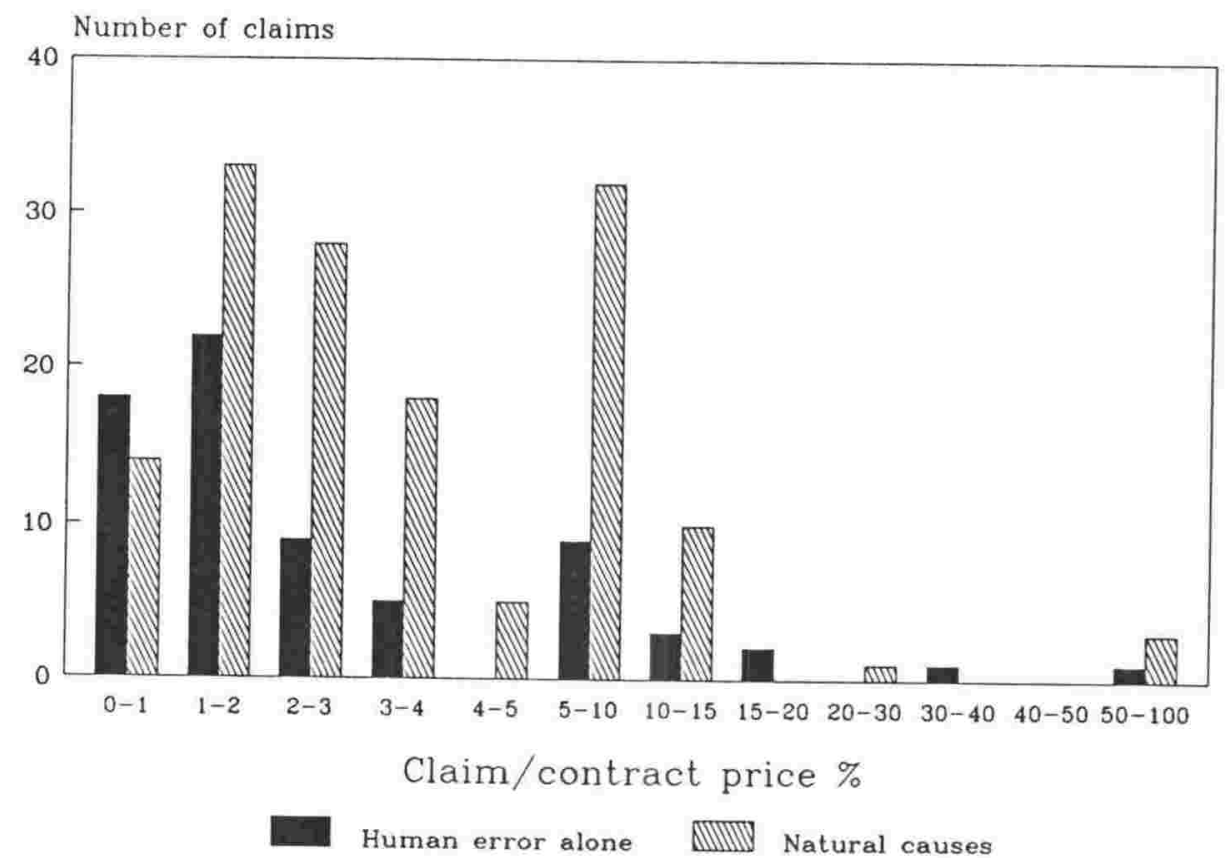

Fig 5.18 BPGC. Claim as \% of contract price. (human error alone and 'natural causes'.)

The three natural causes' contribution to the cost of building failures was shown in Fig 5.17. In the following figures these three natural causes are shown analysed by the source of the dampness, chemical/biological change, or movement in each case. 
Thus Fig 5.19 shows the distribution of the cost of the claims caused by dampness while the accompanying Fig 5.20 shows the same distribution broken down by the various sources of the dampness. This latter Figure makes apparent the significant contribution of rain as a source of dampness as compared with the other sources such as ground atmosphere and faulty services.

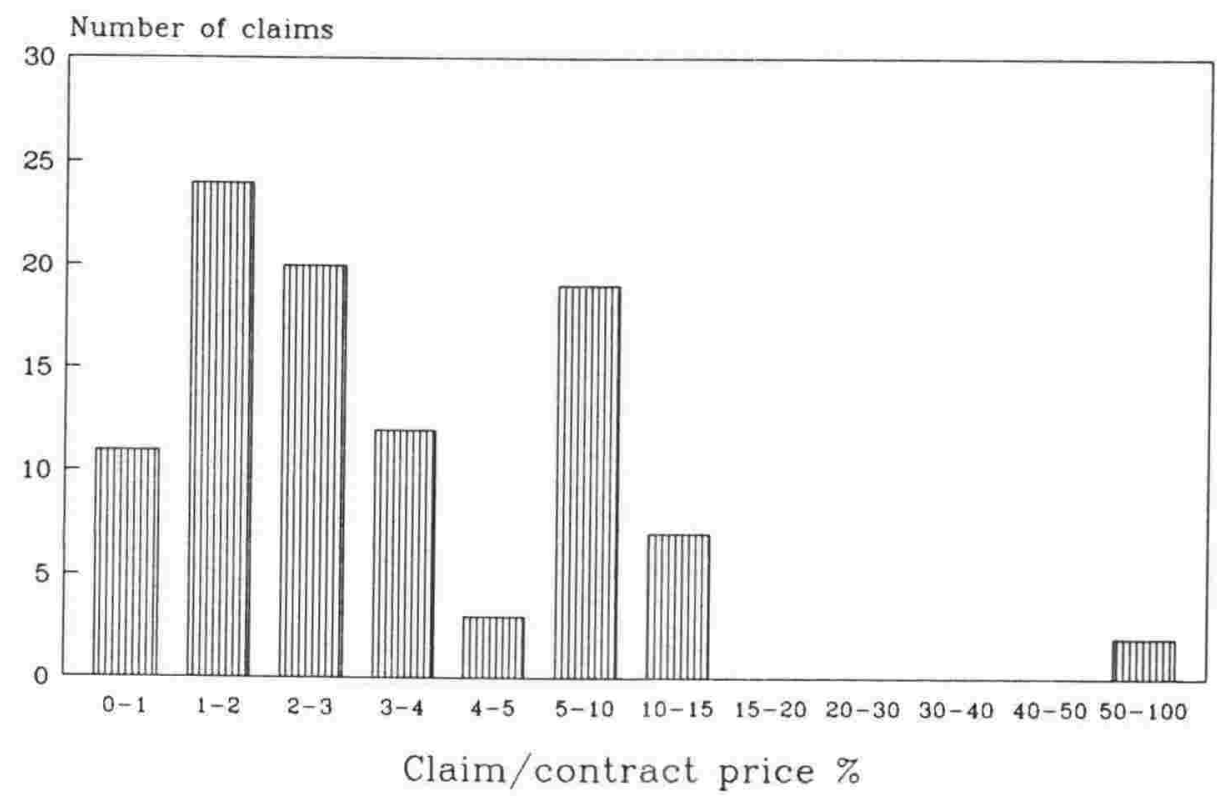

Fig 5.19 BPGC. Claim as \% of contract price. (cause 'dampness'.)

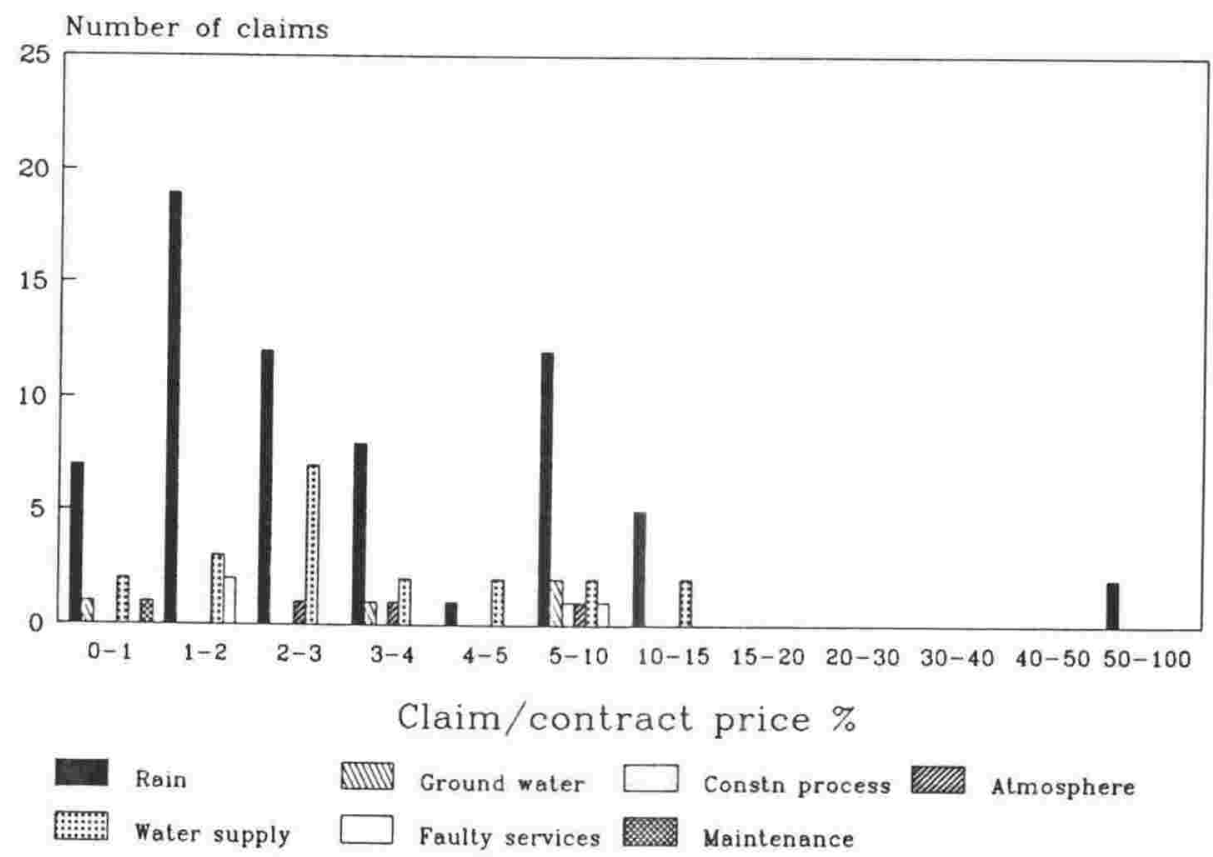

Fig 5.20 BPGC. Claim as \% of contract price. (Cause 'dampness' analysed by source.) 
The corresponding illustrations for Chemical/biological change and Movement now follow:

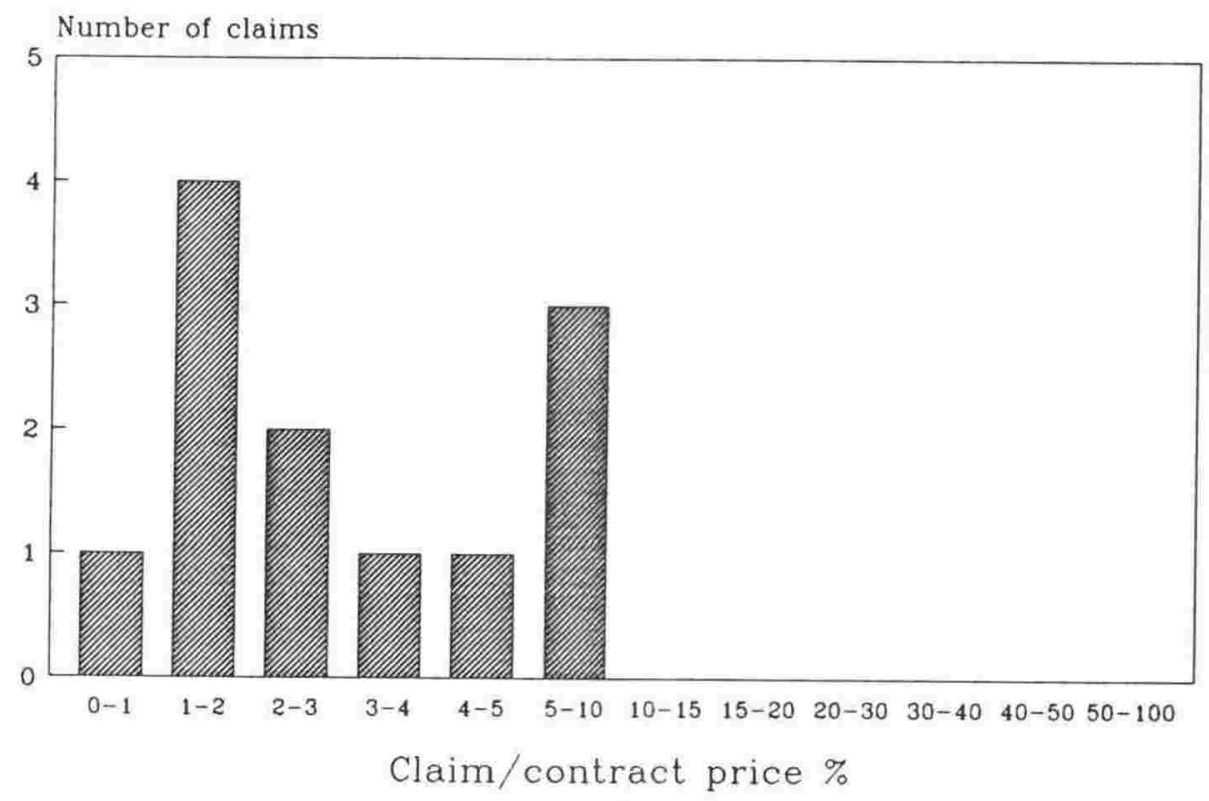

Fig 5.21 BPGC. Claim as \% of contract price. (Cause 'chemical/biological'.)

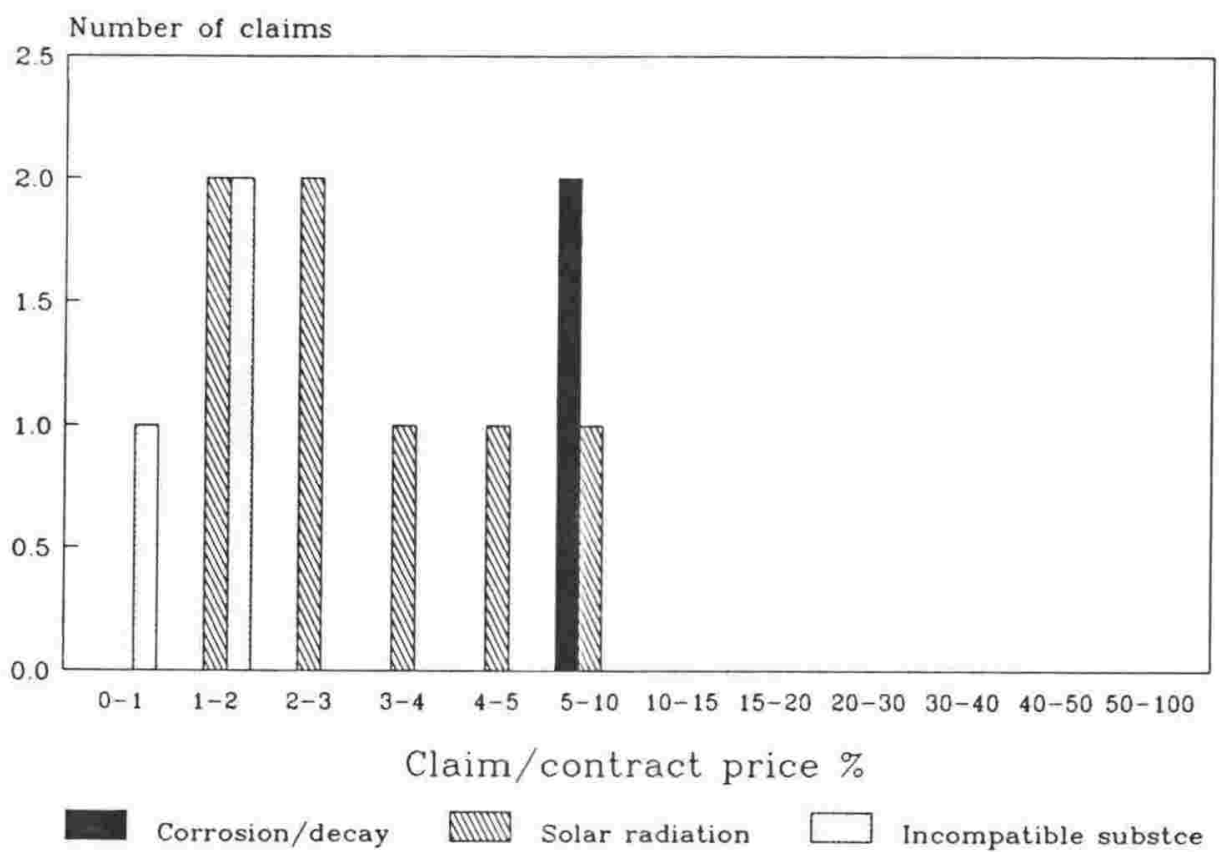

Fig 5.22 BPGC. Claim as \% of contract price. (Cause 'chemical/biological analysed by source.) 


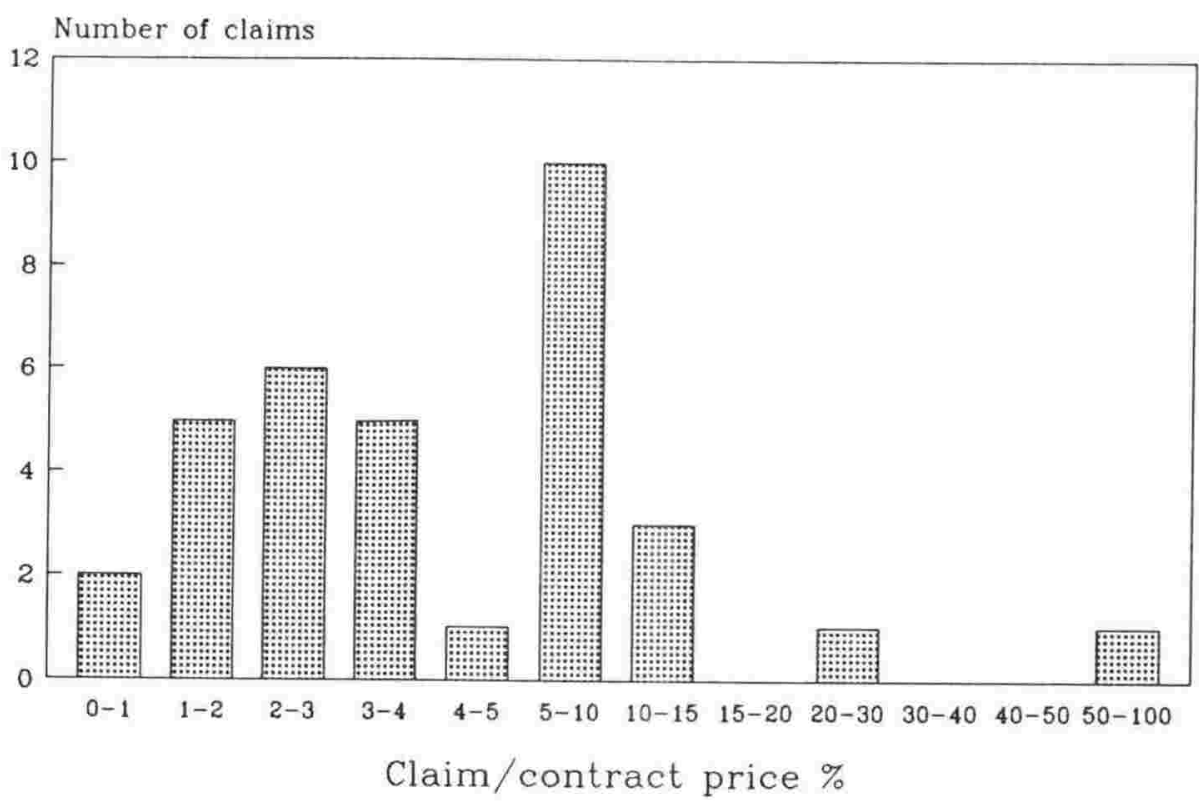

Fig 5.23 BPGC. Claim as \% of contract price. (Cause 'movement'.)

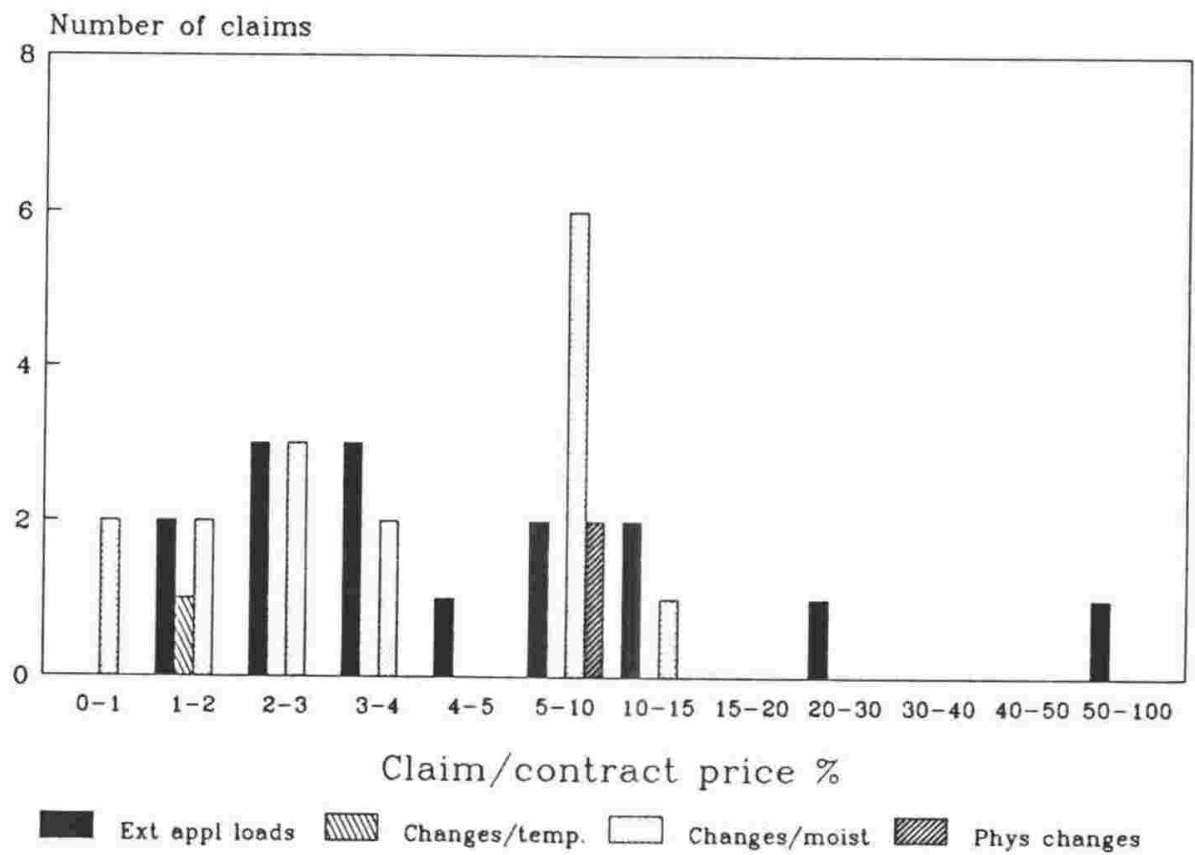

Fig 5.24 BPGC. Claim as \% of contract price. (Cause 'movement' analysed by source.)

\subsubsection{Claim sums}

When the claim sums are considered in dollar terms alone, with the cost of the claim stated in the dollar value at the time of claim, the pattern of claim 
value is as shown in Figs 5.25 and 5.26. The former shows the distribution of dollar value for claims caused by human error alone, while Fig 5.26 shows the distribution for claims caused by natural causes (with an element of human error present in most cases as previously discussed).

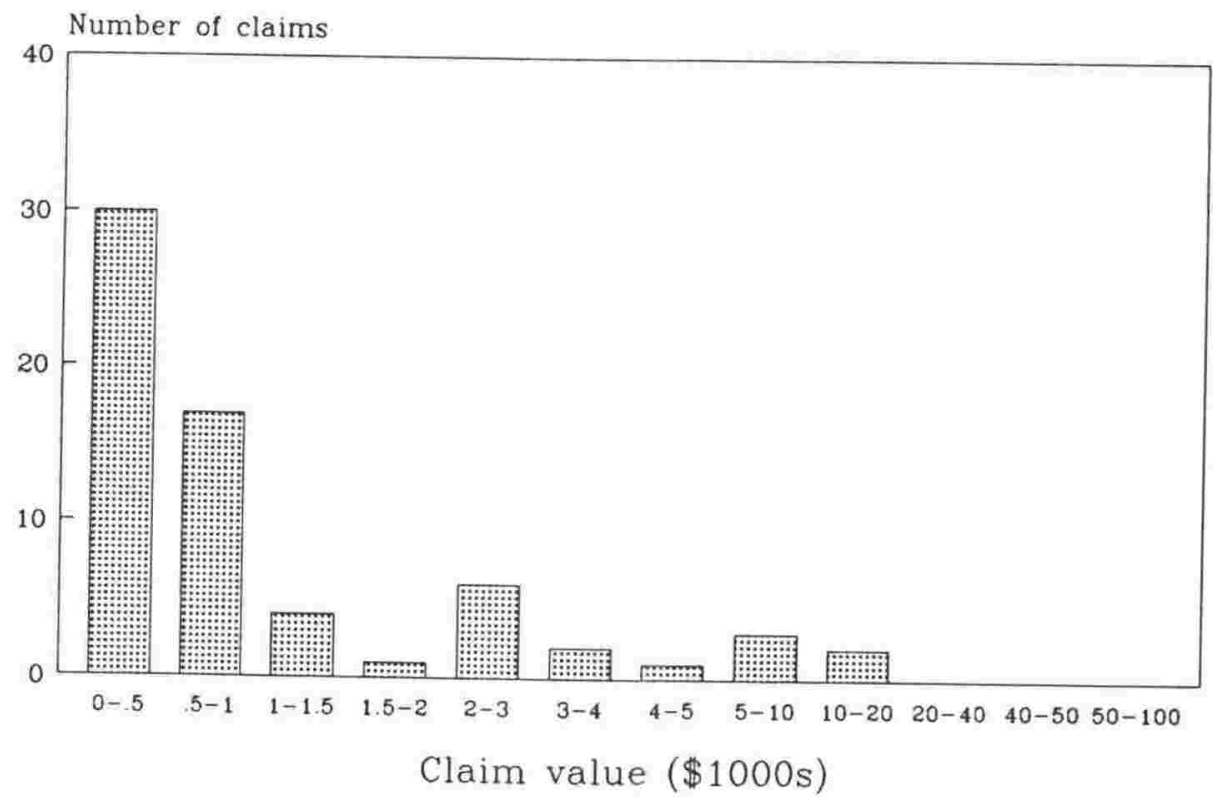

Fig 5.25 BPGC. Claim sums ( $\$ 1000$ s) (human error alone.)

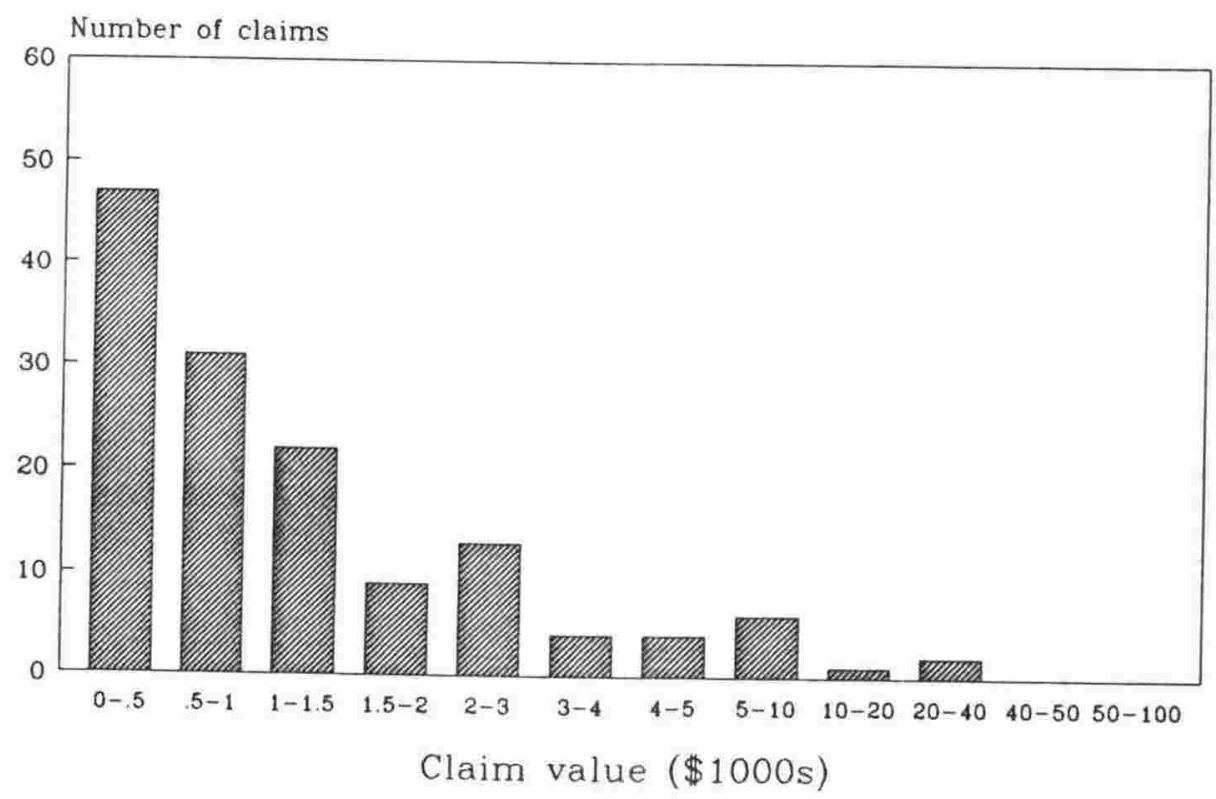

Fig 5.26 BPGC. Claim sums (\$1000s) BPGC natural causes summed.) 
The breakdown of 'natural causes' claims by cause to indicate the dollar value distribution of claims is shown in Fig 5.27.

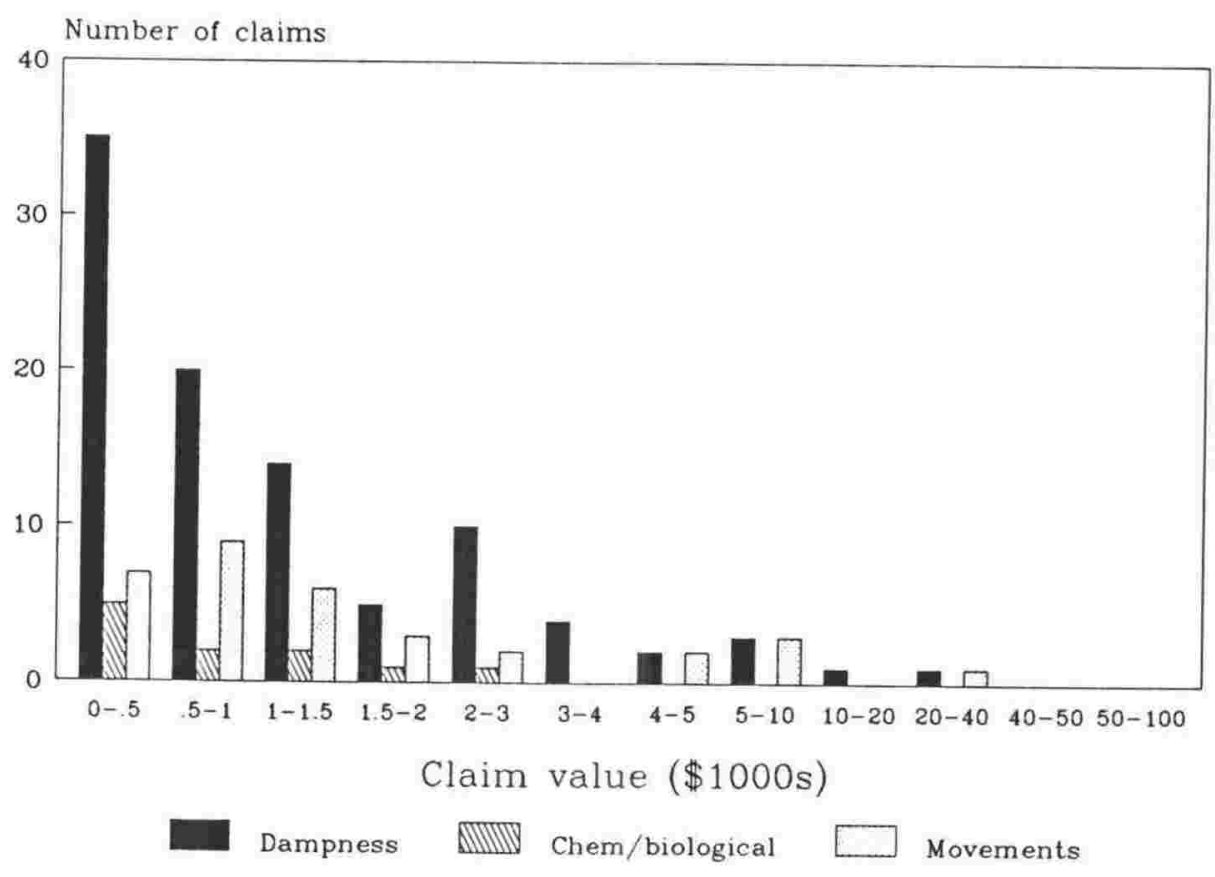

Fig 5.27 BPGC Claim sums ( $\$ 1000$ s) (by natural cause.)

The distribution of claims analysed by natural cause and then by the sources of those natural causes now follows, providing an alternative indication of the relative costs of claims to that provided by Figs $5.19-5.24$ which expressed the claim cost as a percentage of the contract price.

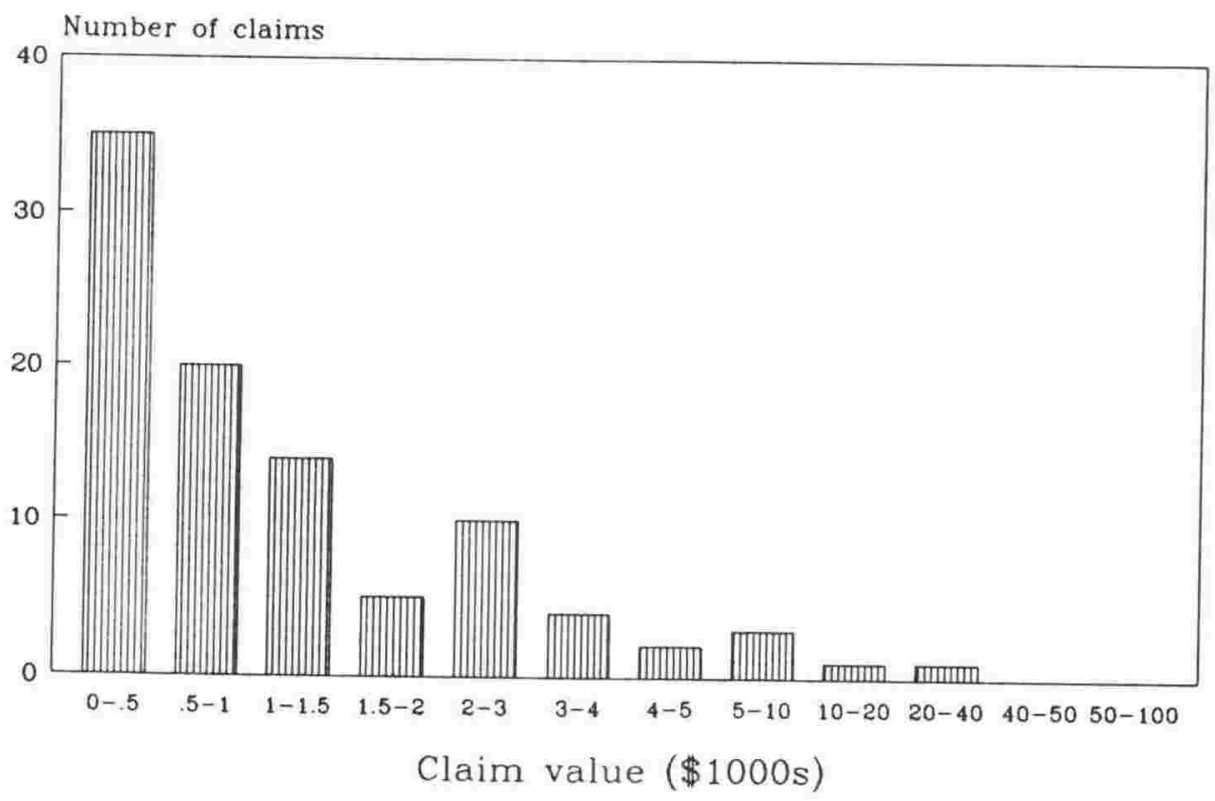

Fig 5.28 BPGC Claim sums (\$1000s) (Cause 'dampness'.) 


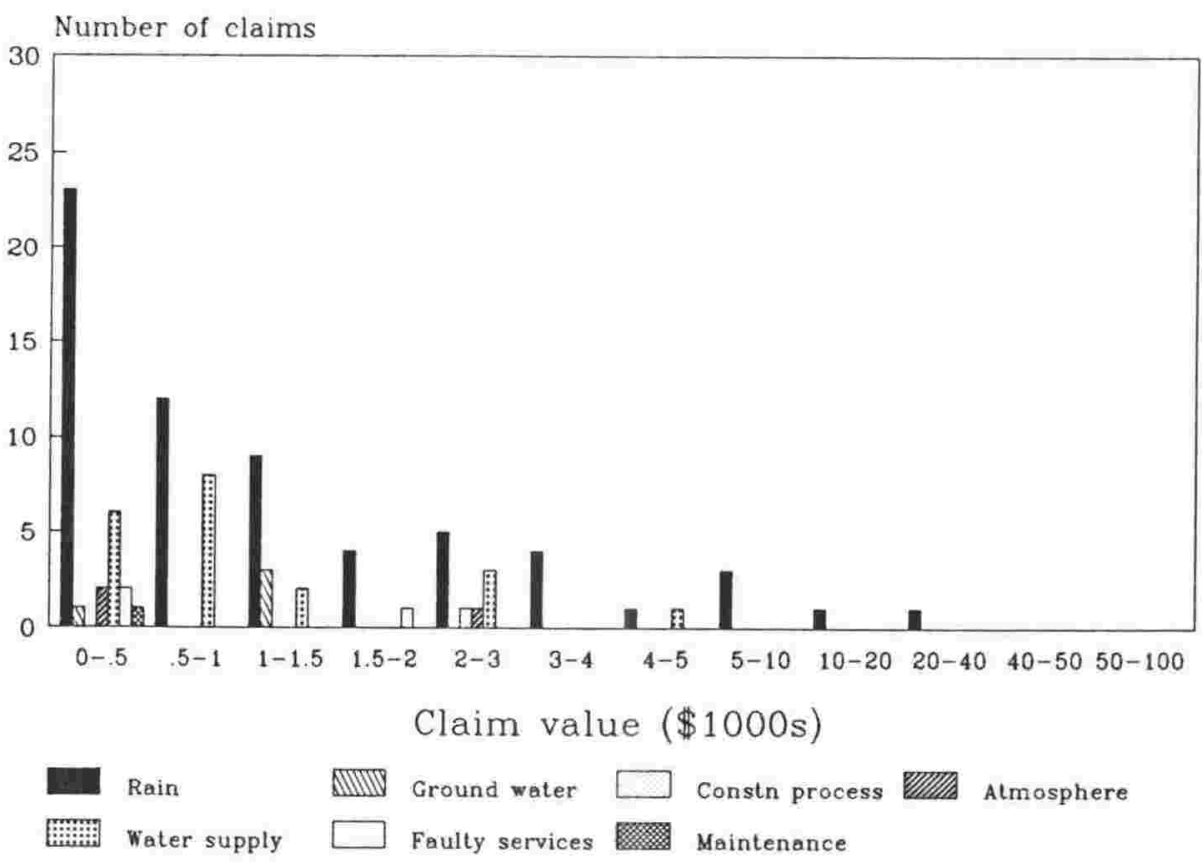

Fig 5.29 BPGC Claim sums (\$1000s) (Cause 'dampness' analysed by source.)

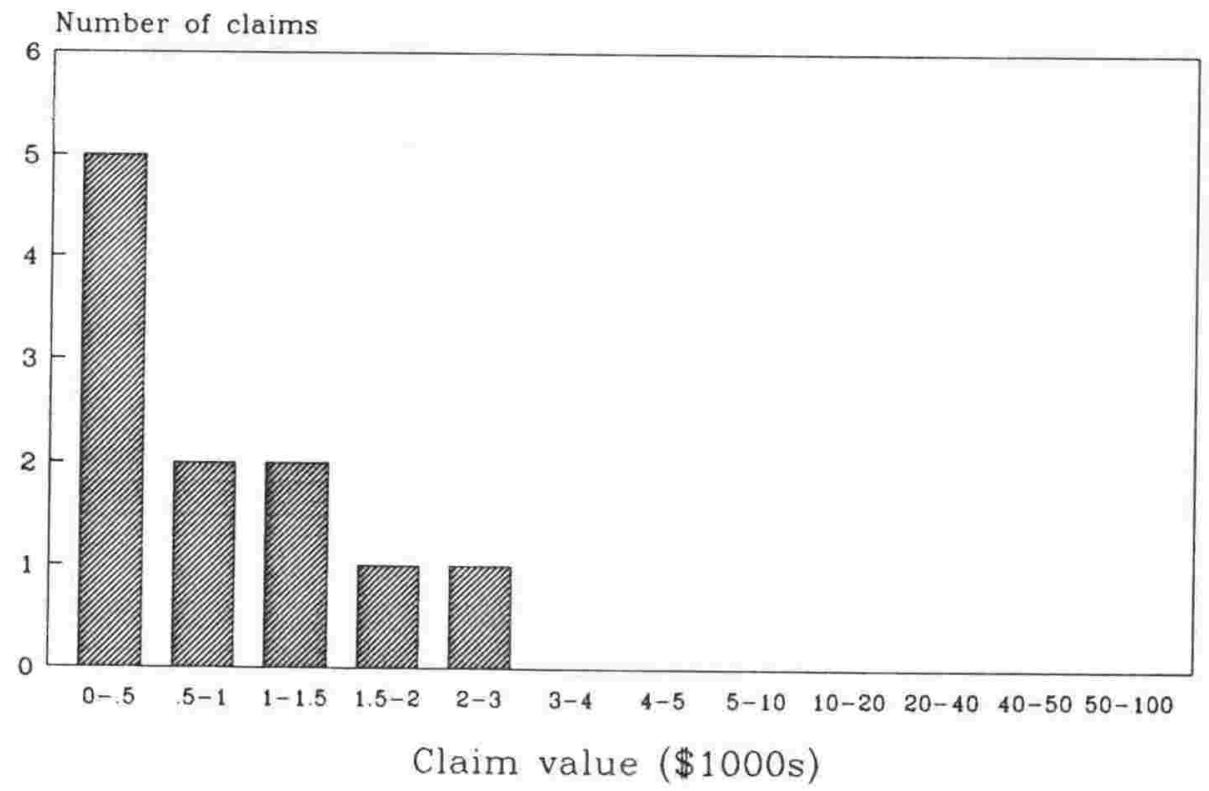

Fig 5.30 BPGC Claim sums (\$1000s) (Cause 'chemical/biological change'.) 


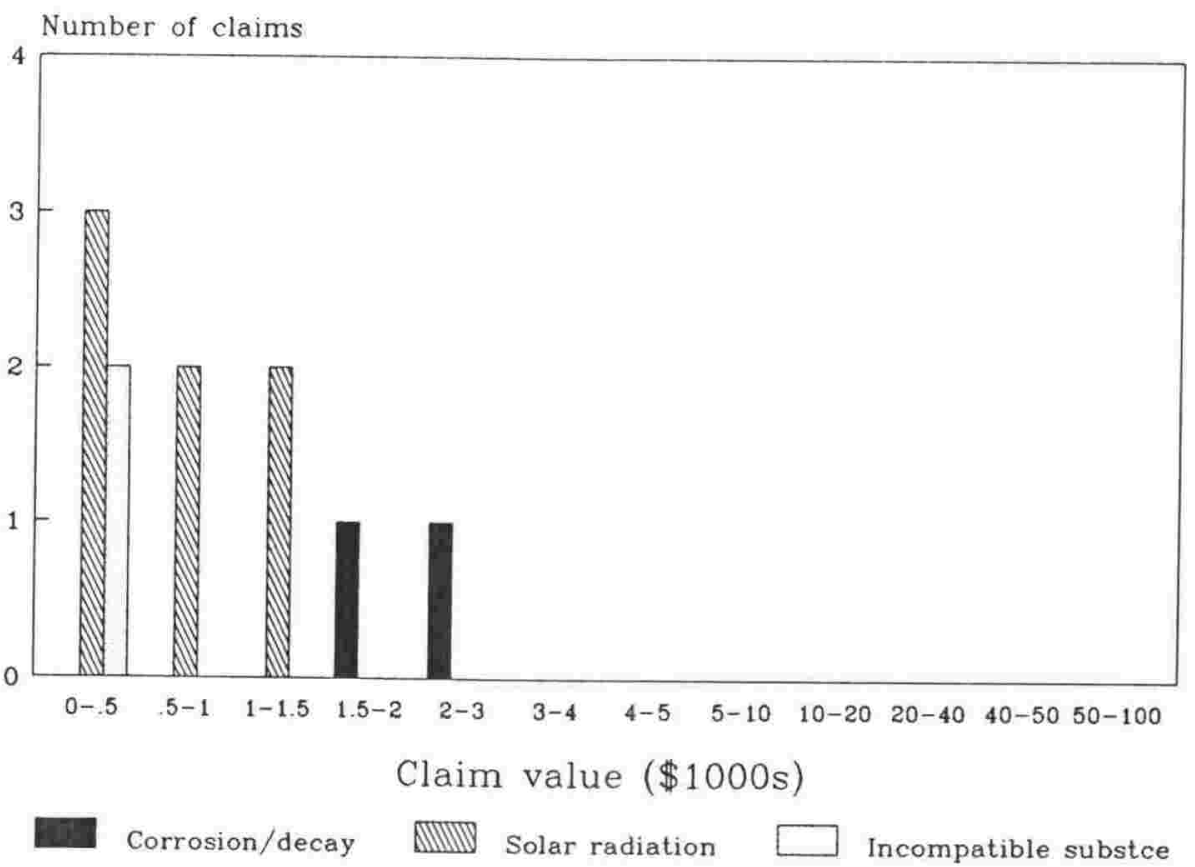

Fig 5.31 BPGC Claim sums (\$1000s) (Cause 'chemical/biological change analysed by source)

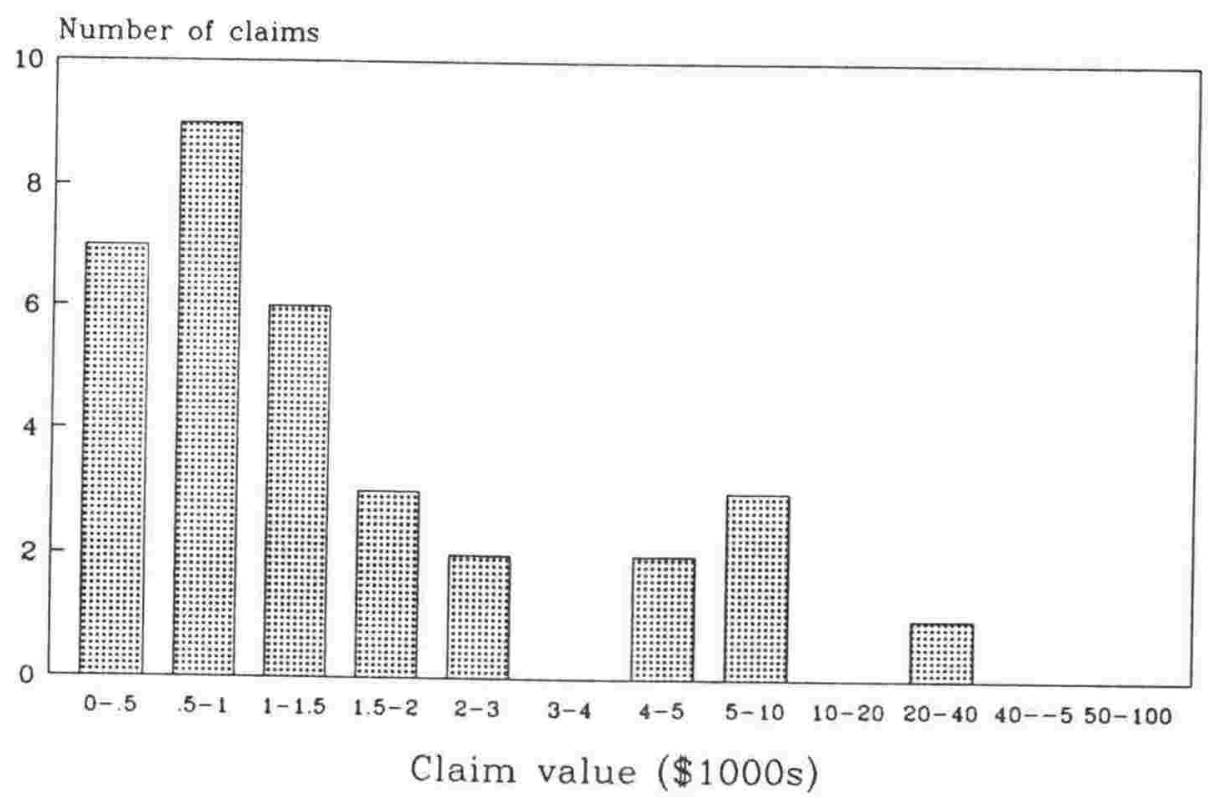

Fig 5.32 BPGC. Claim sums (\$1000s). (Cause 'movement'.) 


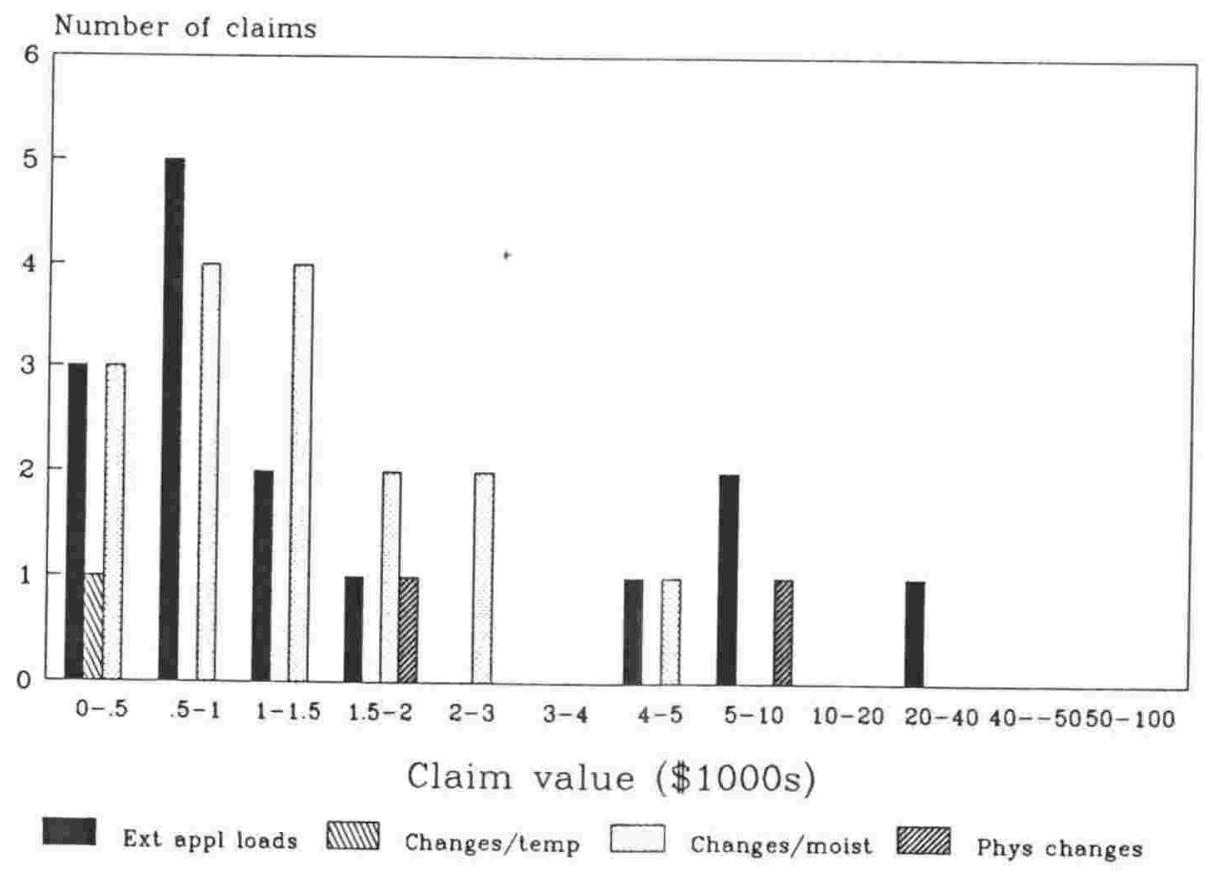

Fig 5.33 BPGC. Claim sums (\$1000s). (Cause 'movement' analysed by source.)

\subsubsection{Contract prices of BPGC sample houses}

To determine whether claims arose from any particular range of dwelling contract prices, the contract prices of the dwellings which gave rise to claims were compared with the average price of dwellings admitted to the BPGC scheme in a particular year. For example Fig 5.34 shows the average price of houses admitted to the BPGC scheme through the Wellington office (a curved line connects the average values shown in the middle of each yearly interval) together with the contract price of all the dwellings which gave rise to claims, shown in the year of completion. (each dot indicates the completion date and contract price of one dwelling.

Comparable data for Auckland, Hamilton, Christchurch and Dunedin are shown in Figs 5.34 - 5.38 which follow.

The data for Auckland and Christchurch (respectively the most populous cities in the North and South Island of New Zealand) have had added to them a line showing the average new dwelling price each year for the region as 
supplied by the Department of Statistics. Note that this average price is based on all new dwellings whether or not they were admitted to the BPGC scheme. As Fig 5.35 and Fig 5.37 show, there is a tendency for dwellings indemnified by BPGC to have a lower average price than the average of all houses in the region. This tendency cannot be explained by any BPGC policy.

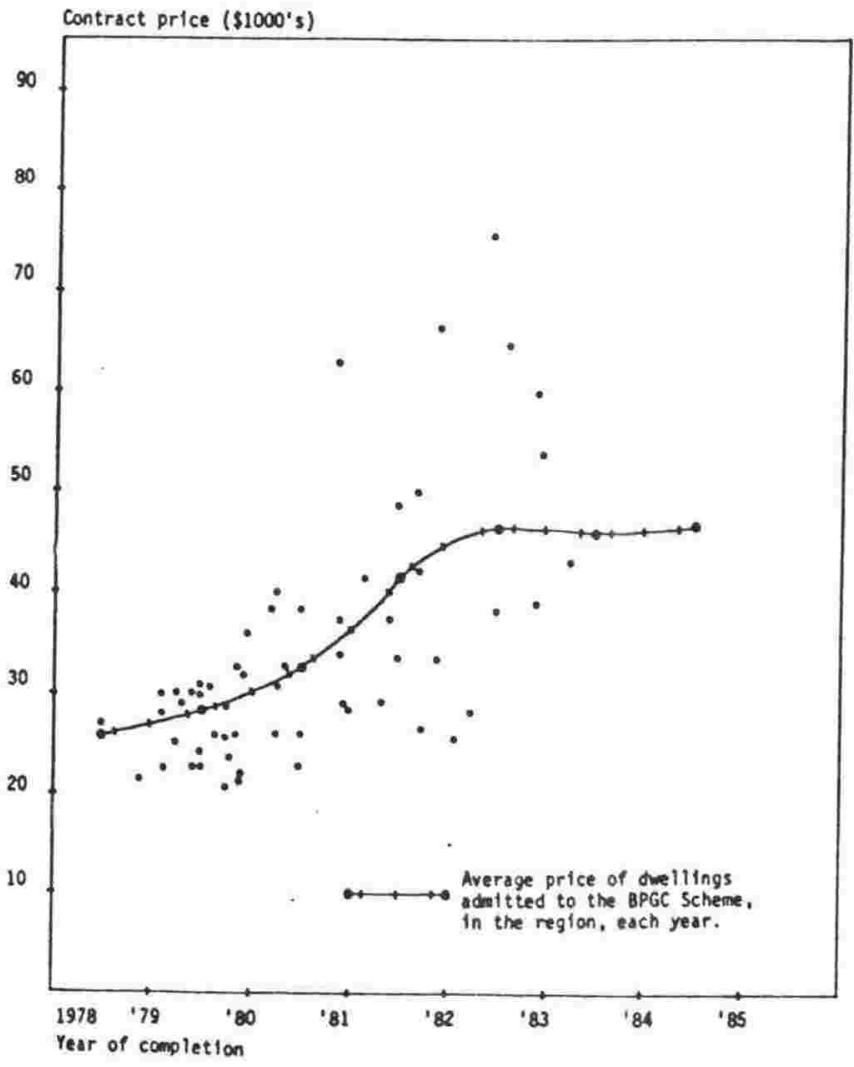

Fig 5.34 BPGC. Wellington. (Average prices of dwellings.) 


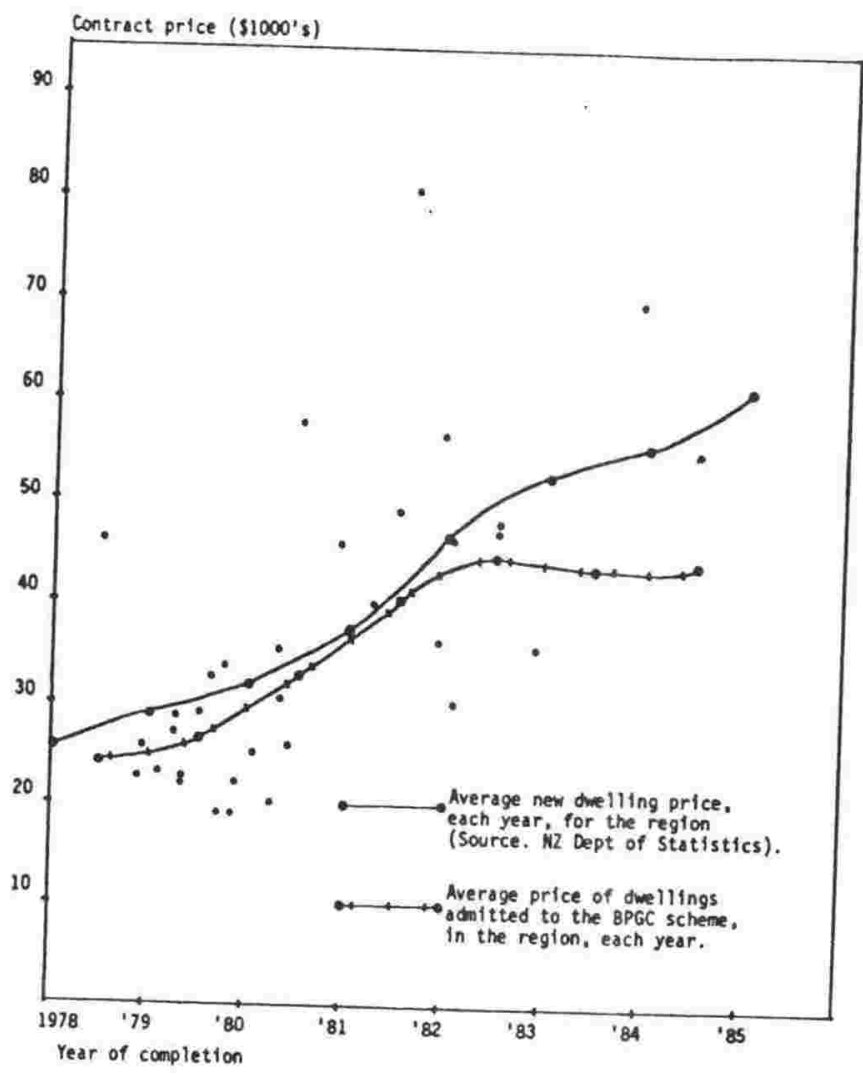

Fig 5.35 BPGC. Auckland. (Average prices of dwellings.)

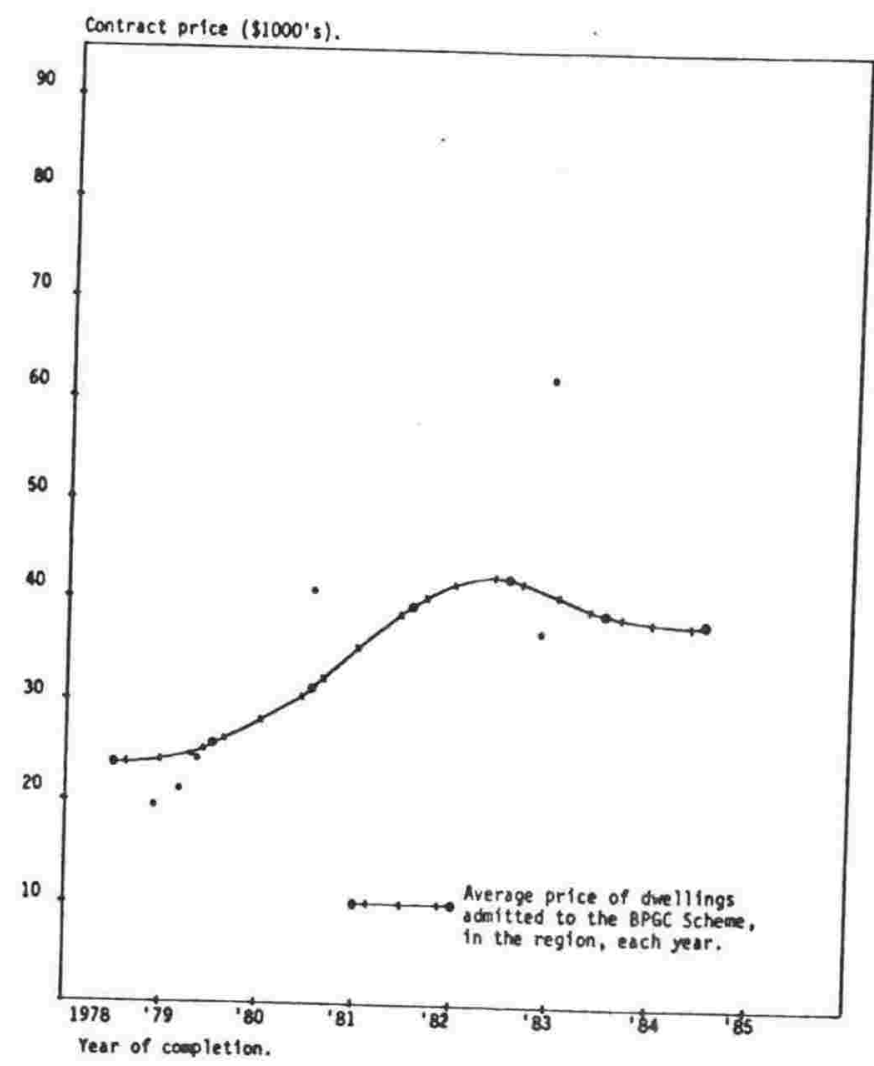

Fig 5.36 BPGC. Hamilton. (Average prices of dwellings.) 


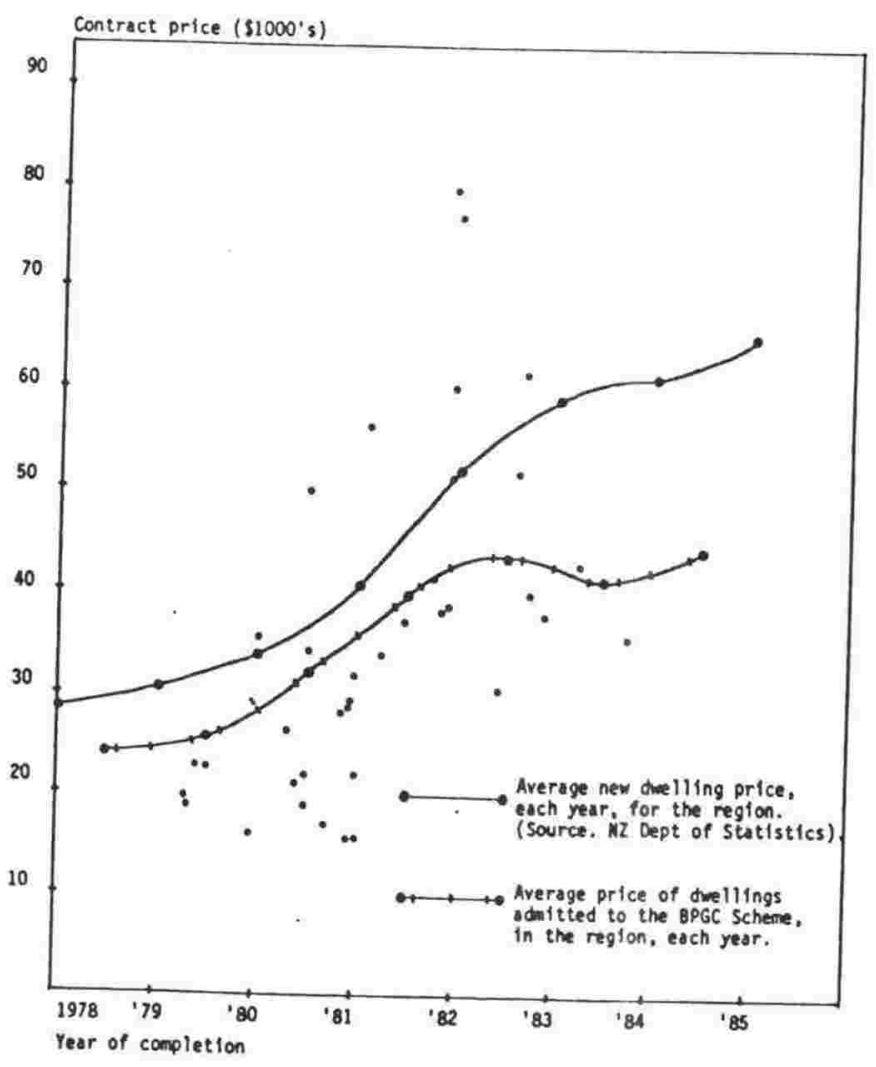

Fig 5.37 BPGC. Christchurch. (Average prices of dwellings.)

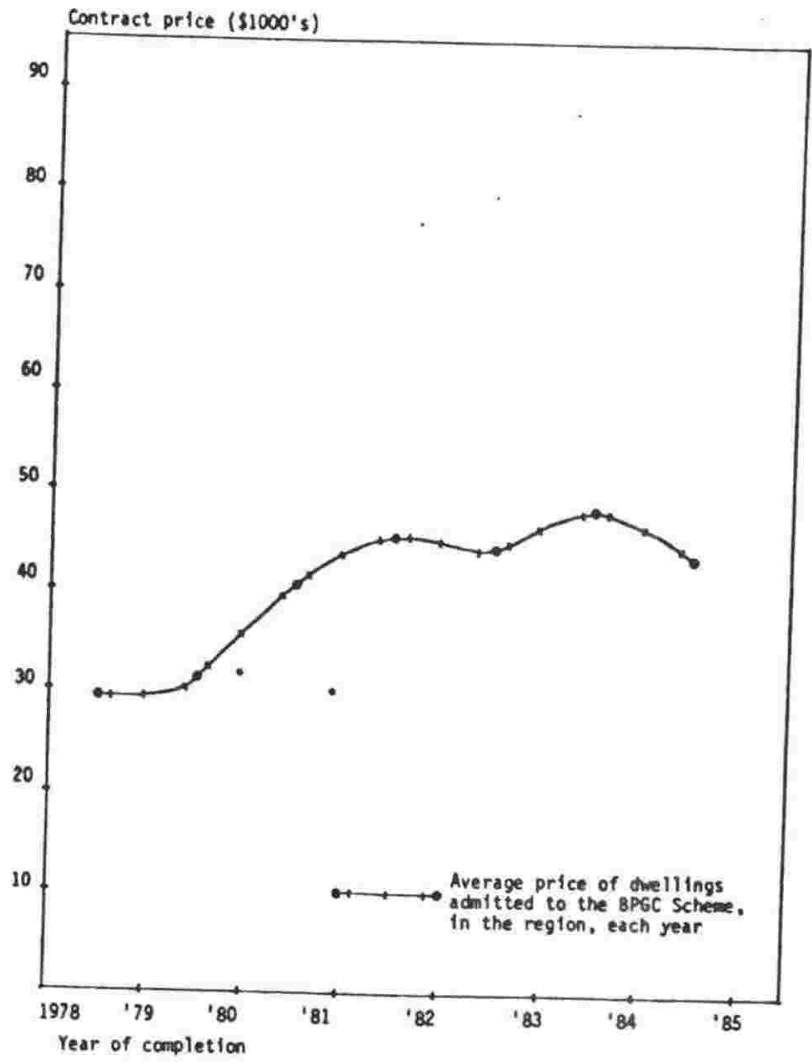

Fig 5.38 BPGC. Dunedin. (Average prices of dwellings.) 

(NZACS)

\subsubsection{Access to the NZACS claim files}

The Claim Files of the New Zealand Architects Co-operative Society Ltd (NZACS) concern architects' claims under their Professional Indemnity insurance contracts.

With the approval and assistance of the Claims Director of NZACS and of the NZACS Board, access to files concerning claims notified to NZACS since it inception in 1972 was obtained. The files relating to claims concerning dwellings were extracted from the records system by the Claims Director and made available for scrutiny. An undertaking was given to the NZACS Board that no information obtained from NZACS which might identify any architect or client would be published. It was also agreed that no files would be removed from the custody of the NZACS Claims Director and that no photocopying of any part of the files would be done.

\subsubsection{NZACS claim procedure}

Each of the claims files held by the Director is given a Claim number. The Claim Numbers are issued consecutively so that were it not for a very few numbers which have never been allocated the latest number corresponds closely to the running total of claims notified to the Director. It is important to understand that not all "possible claims" notified to the Director become actual claims against the professional indemnity policy. It is required of all architects who belong to the Society that they notify the Claims Director immediately the possibility of a claim arises. This requirement exists so that the Director and the insurers can give advice to the architect as to the steps to be taken in dealing with the problem in a way designed to contain or minimise the claim. 
Fundamental to the process of handling a possible claim is the insurer's requirement that the architect must never under any circumstances admit liability, because to do so may immediately render impossible a negotiated out-of-court settlement whether by arbitration or otherwise.

As a consequence of this requirement to deny liability, there is rarely any correspondence on the Director's Claim file which directly imputes legal liability. As this research was concerned with the reasons for building failures, their causes and characteristics, the absence of evidence concerning legal fault was of no consequence.

\subsubsection{NZACS claim data categories}

By reading the claim notification papers and other correspondence between the architect and the Claims Director and from examination of claims analyses carried out by the Director, the following data relative to each claim was amassed:-

A. From the Director's analyses:

$1 \quad$ NZACS Claim Number.

2 The area in New Zealand in which the architect was domiciled.

3 The period during which the possible claim was notified. The Director used the following key for recording the period:-

PERIOD

$S \quad$ Sketch stage of production

WD Working Drawing stage of production

C Construction stage

R Retro-active stage (ie where the claim arises after the building was completed).

$4 \quad$ Whether the file was closed or open.

5 The Director's own view as to the fault lying behind the claim. For this purpose the Director used the following alpha-numeric coding system:-

MEMBER FAULT INDEX

A TECHNICAL FAILURE

1 Poor detailing

2 Lack of understanding of material

3 Lack of understanding of method

4 Inadequate supervision

5 No supervision 
1 Mechanical

2 Structural

3 Surveying

4 Other

C PROCEDURAL CAUSES

1 Exceeding authority

2 Departure from brief

3 Defective brief

$4 \quad$ Failure to perform

5 Negligent certification

6 Administration defects

7 Inadequate survey or site information

8 Negligent advice

9 Negligent estimating

10 Incomplete or ambiguous documentation

11 Failure to comply with regulations or acts

12 Failure to co-ordinate consultants

D LACK OF COMMUNICATION

1 Client

2 Contractor

3 Consultants

4 Architect's staff

E TRY ON (Author's note: This term describes those cases where no basis for a claim exists, but the pretence is being maintained by one party that a well-founded claim can be made).

1 Owner

2 Contractor

3 Consultant

4 Insurance company

F UNSATISFACTORY PERFORMANCE

1 Contractor

2 Sub contractor

G FEE PROBLEM

$\mathrm{H}$ LOSS OF DOCUMENTS

I LIBEL AND SLANDER

\section{3 .4}

\section{Analysis of NZACS claims data}

Analysis of the NZACS claim files from 1972 (when the NZ Architects Co-operative Society Ltd was established) until the end of 1984 revealed the following facts:

1 Total number of claims (of all varieties A-I above) related to completed dwellings notified to NZACS as at end December 1984

$$
=52
$$


2 Total number of claims (of all varieties A-I above) related to completed NZ dwellings notified to NZACS as at end December 1984 and classifiable (as a building failure or otherwise) as at February 1985

$$
=45
$$

3 Total number of claims related to NZ dwellings notified to NZACS as at end December 1984, classifiable as at February 1985 and indicating building failure

$$
=19
$$

\subsubsection{Distribution by locality}

The 19 building failure claims originated from centres all over New Zealand. Figure 5.39 shows the distribution of claims by locality.

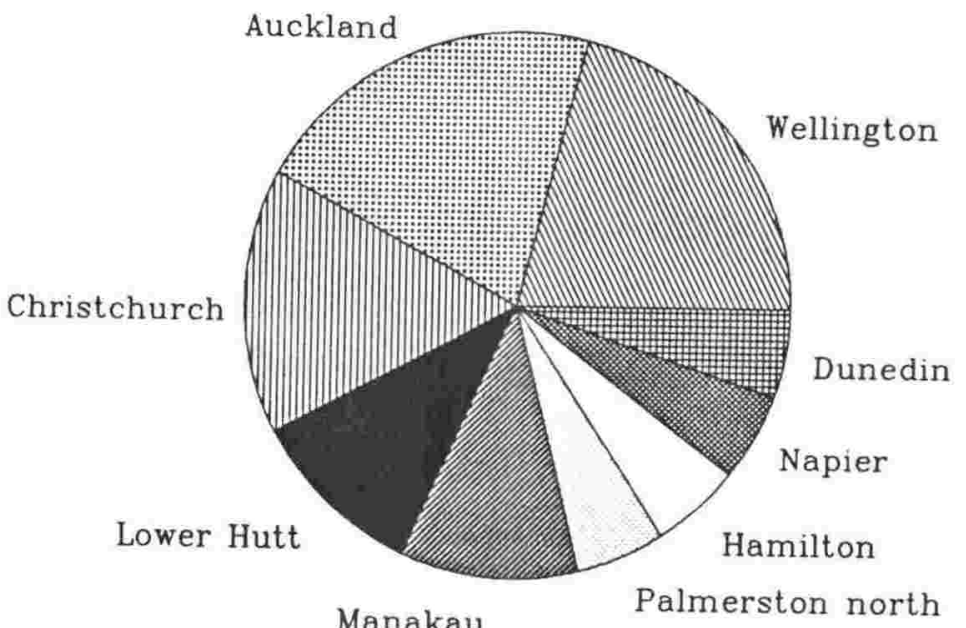

Fig 5.39 NZACS. Claims by location. 
Each claim is given a code number by NZACS and this is used in the following list showing the number of building failure claims in each centre. The code numbers are shown in parenthesis and have been used to preserve the confidentiality of the claimants in each case.

$\begin{array}{llr}\text { Ak } & (1)(16)(23)(24) & 4 \\ \text { Manakau } & (36)(3) & 2 \\ \text { Hm } & (12) & 1 \\ \text { Napier } & (39) & 1 \\ \text { Pn } & (8) & 1 \\ \text { Lh } & (9)(15) & 2 \\ \text { Wn } & (14)(25)(26)(30) & 4 \\ \text { Ch } & (4)(29)(41) & 3 \\ \text { Dn } & (33) & 19\end{array}$

Table 5.2 NZACS. Analysis of claims by locality

It is apparent that building failure claims are not confined to one or more geographical zones, and that, not surprisingly the larger population centres produce a greater number of claims. Given that the number of claims investigated was the total for about 12 years during which time building activity would have flowed and ebbed in all the centres it is reasonable to suppose that the number of claims is proportional to the number of new houses being designed and built in each centre over that time-span. After all, if there was no design or building going on in a particular centre there would be no building failure claims emanating from that centre. 


\subsubsection{Examination of claims to identify cause(s)}

Examination of the 19 building failure claims to identify the cause or causes was carried out using the list of causes identified in Chapter 4:

dampness

movement

chemical/biological change

and

human error (Table 4.2)

It must be remembered that more than one cause may operate to create a building failure. Fig 5.40 shows the relative frequency with which a given cause was found to have been a factor.

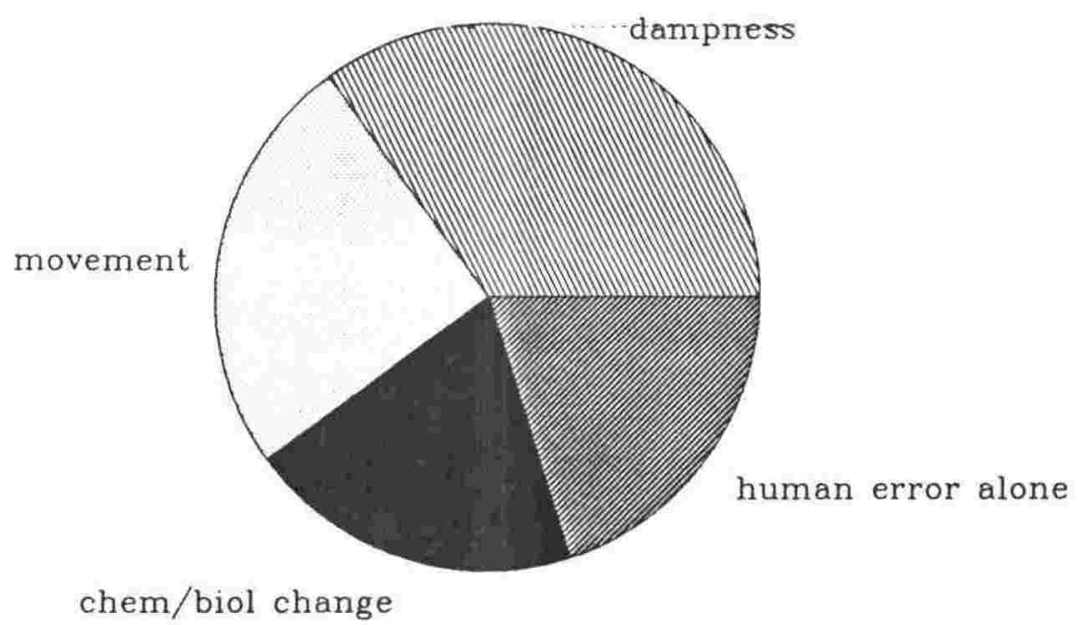

Fig 5.40 NZACS Causes of failure

The predominance of the cause 'dampness' is immediately obvious. The cause "human error alone' is obviously also a prominent contributor to building failures in NZACS claims. In fact, as the Table 5.3 shows, human error of one of more varieties was present in every one of the 19 claims. 
Claim No. Sources

(1)

(3)

(4)

(8)

(9) dampness

ground

dampness

externally applied loads

externally applied loads

rain

dampness

pure human error

pure human error

externally applied loads

construction process + atmosphere

rain atmosphere

pure human error

rain, also human error

rain, faulty services

pure human error

faulty

services

changes in moisture

dampness

externally

applied loads
'Natural Cause'

Classification of human error

chemical/

1,9

biological change

dampness

2, 9

chemical/

6, 9

biological change

movement

2

movement

4,8

dampness

9

chemical/

biological change

3, 9

9

6, 10

movements

dampness

3, 9

dampness

$2,3,8,10$

6,10

dampness

9, 10

dampness

5,9

dampness

9

movement

$1,6,9,10$

chemical/biological

change

movements

2

Table 5.3 NZACS. List of claims showing 'natural' cause and classification of human error. 
The contents of Table 5.3 is displayed in Table 5.4 in a format which indicates the frequency of occurrence of human error types.

Class of human error

1 Defective materials

2 Overlooked site conditions

3 Ignorance

4 Overemphasis on first cost

5 Defective documentation

6 Unanticipated consequences of change

7 Specialist contractor's lack of knowledge

8 Design too difficult to build well

9 Dereliction or negligence

10 Poor communication
Total

2

4

3

1

2

4

(14)(24) (25)

(9)

(3) (8) (25) (41)

e code no.

(1) (39)

(30) (33)

(4) (16) (26) (39)

2

(9) (25)
(1) (3) (4) (12) (14) (15) (23)

(24) (29) (30) (33) (36) (39)

(16) (25) (26) (29) (39)

36

Table 5.4 NZACS. Analysis of claims by class of human error. 
The relative incidence of the different classes or types of human error is illustrated in Fig 5.42 .

Some claim files revealed that more that one type of human error had occurred to contribute in the building failure.

1 No. of claim files revealing 1 Class of error $=6$

[(8) (12) (15) (23) (36) (41)]

2 No. of claim files revealing 2 Classes of error $=11$

[(1) (3) (4) (9) (14) (16) (24) (26) (29) (30) (33)]

3 No. of claim files revealing 3 Classes of error $=0$

4 No. of claims revealing 4 Classes of error $=2$

[(25) (39)]

The proportions of the number of claims revealing more than one class of human error as compared with those revealing only one are illustrated on Fig 5.41.

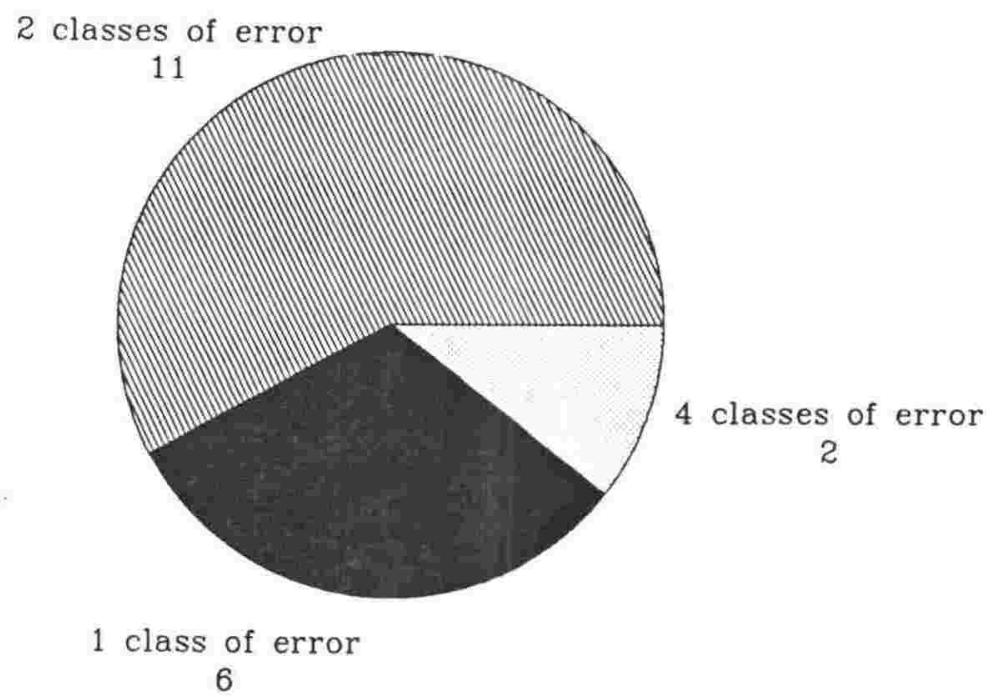

Fig 5.41 NZACS. Analysis of claims by number of classes of human error per claim. 
Key to type of human error:

1 Defective materials

2 Overlooked site conditions

3 Ignorance

4 Overemphasis

on first cost

5 Defective documentation

6 Unanticipated consequence of change

7 Specialist contractors lack of knowledge

8 Design too difficult to build well

9 Dereliction or negligence

10 Poor communication

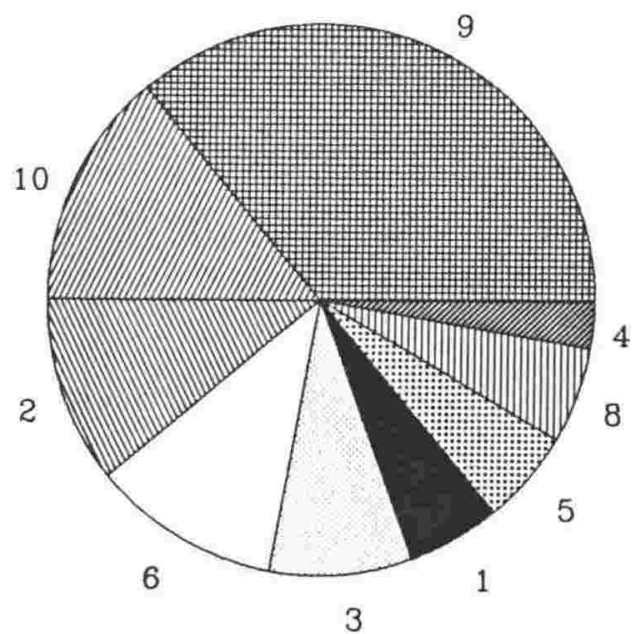

Fig 5.42 NZACS. Incidence of types of human error.

Table 5.5 displays 'natural causes' and the relevant 'source' in each case. Table 5.5 tabulates these according to the operating 'natural cause' in the NZACS claims. The 'sources' and 'natural causes' are taken, as explained in Chapter 4, from a modified form of a table developed by Lyall Addleson (Addleson, L 1977). 


\begin{tabular}{|c|c|c|}
\hline Natural Cause & Claim No. & Sources \\
\hline \multirow[t]{4}{*}{ chemical/biological change } & 1 & dampness \\
\hline & 4 & dampness \\
\hline & 14 & dampness \\
\hline & 39 & dampness \\
\hline \multirow[t]{10}{*}{ dampness } & 3 & ground \\
\hline & 12 & rain \\
\hline & 24 & $\begin{array}{l}\text { construction } \\
\text { process }\end{array}$ \\
\hline & & atmosphere \\
\hline & 25 & rain \\
\hline & & faulty services \\
\hline & 29 & rain \\
\hline & 30 & rain \\
\hline & & faulty services \\
\hline & 36 & faulty services \\
\hline \multirow[t]{8}{*}{ movements } & 8 & \multirow{2}{*}{$\begin{array}{l}\text { externally } \\
\text { loads }\end{array}$} \\
\hline & & \\
\hline & 9 & externally \\
\hline & & loads \\
\hline & 23 & externally \\
\hline & & loads \\
\hline & 39 & $\begin{array}{l}\text { changes in moisture } \\
\text { content }\end{array}$ \\
\hline & 41 & $\begin{array}{l}\text { externally applied } \\
\text { loads }\end{array}$ \\
\hline
\end{tabular}

Table 5.5 NZACS. Analysis of causes by sources 
The analysis of the sources of the three natural causes is illustrated in Figure 5.44, 5.45, and 5.46, which follow. Figure 5.43 shows the relative incidence of the three natural causes in the claims.

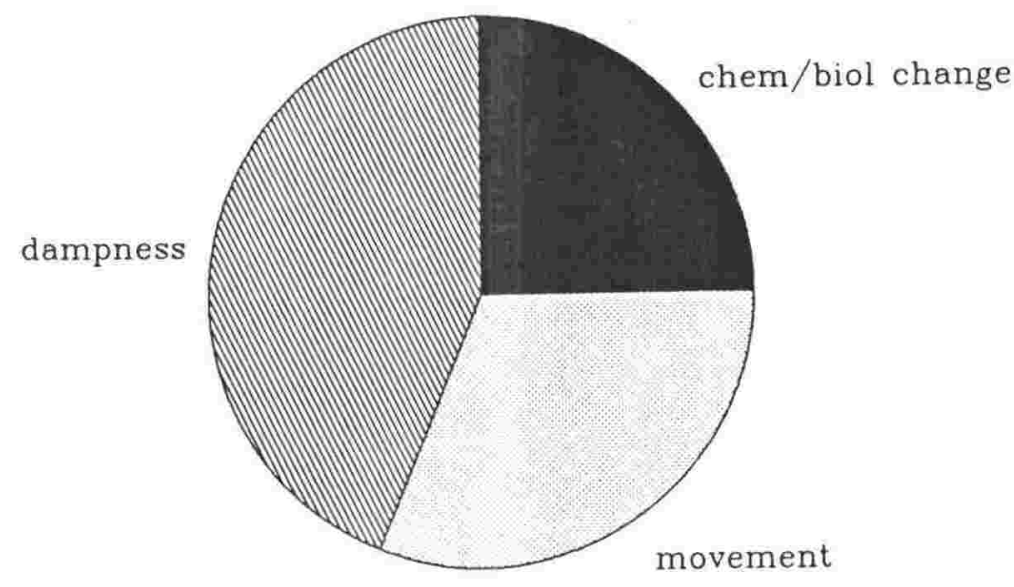

Fig 5.43 NZACS. Natural Causes

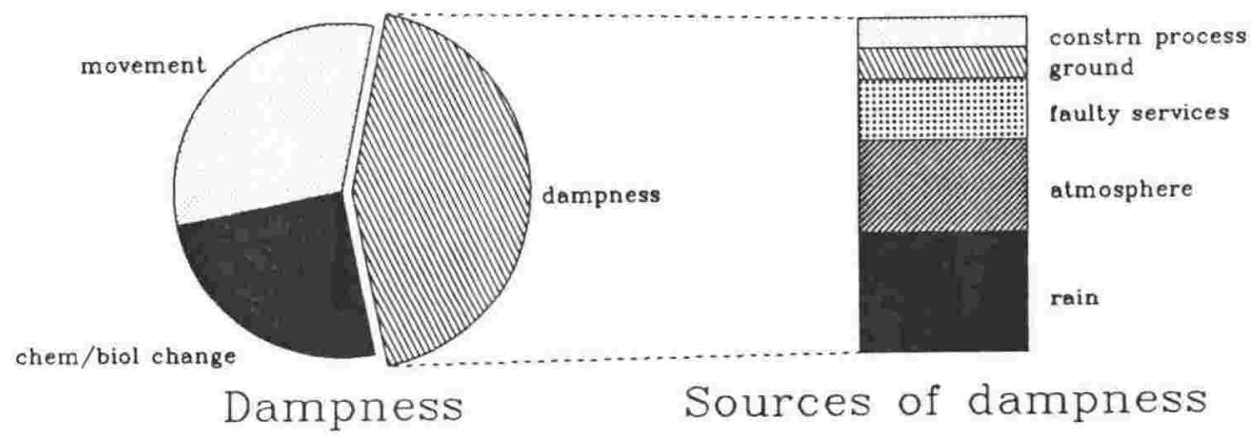

Fig 5.44 NZACS. Natural cause 'dampness' analysed by source.

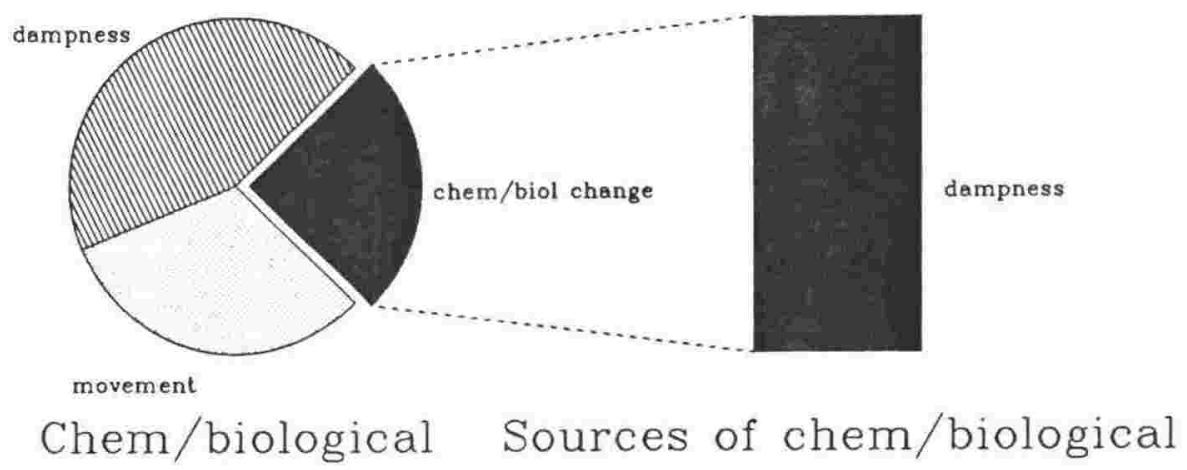

Fig 5.45 NZACS. Natural cause 'chem-biol' analysed by source. 


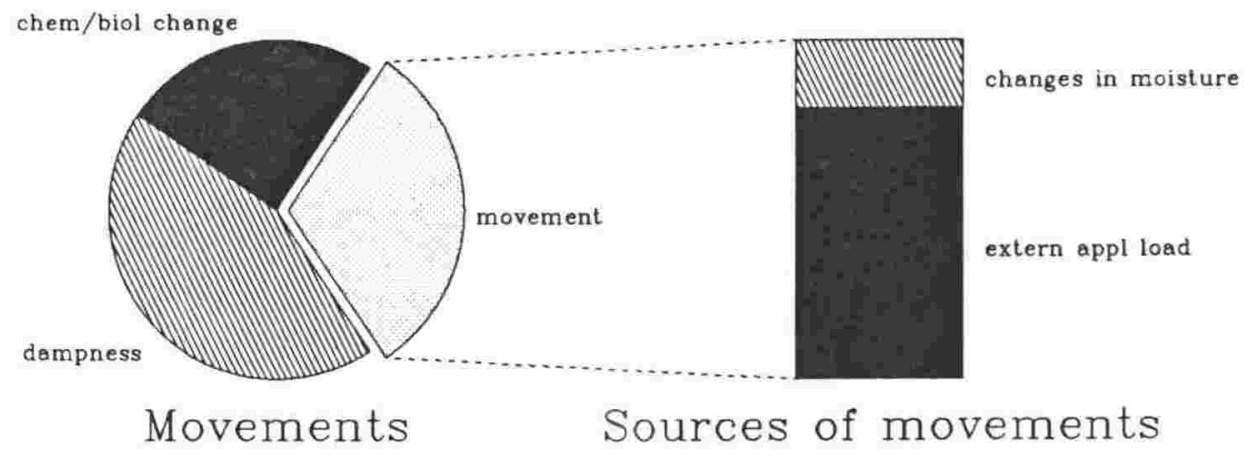

Fig 5.46 NZACS. Natural cause 'movement' analysed by source.

\subsubsection{Time interval from completion to claim}

A further piece of information obtained form the NZACS claims date was the time interval between the completion of the dwelling and the lodging of the claim with the insurers. Fig 5.47 shows the relative number of claims lodged at various time intervals, measured in years, after the dwellings were completed.

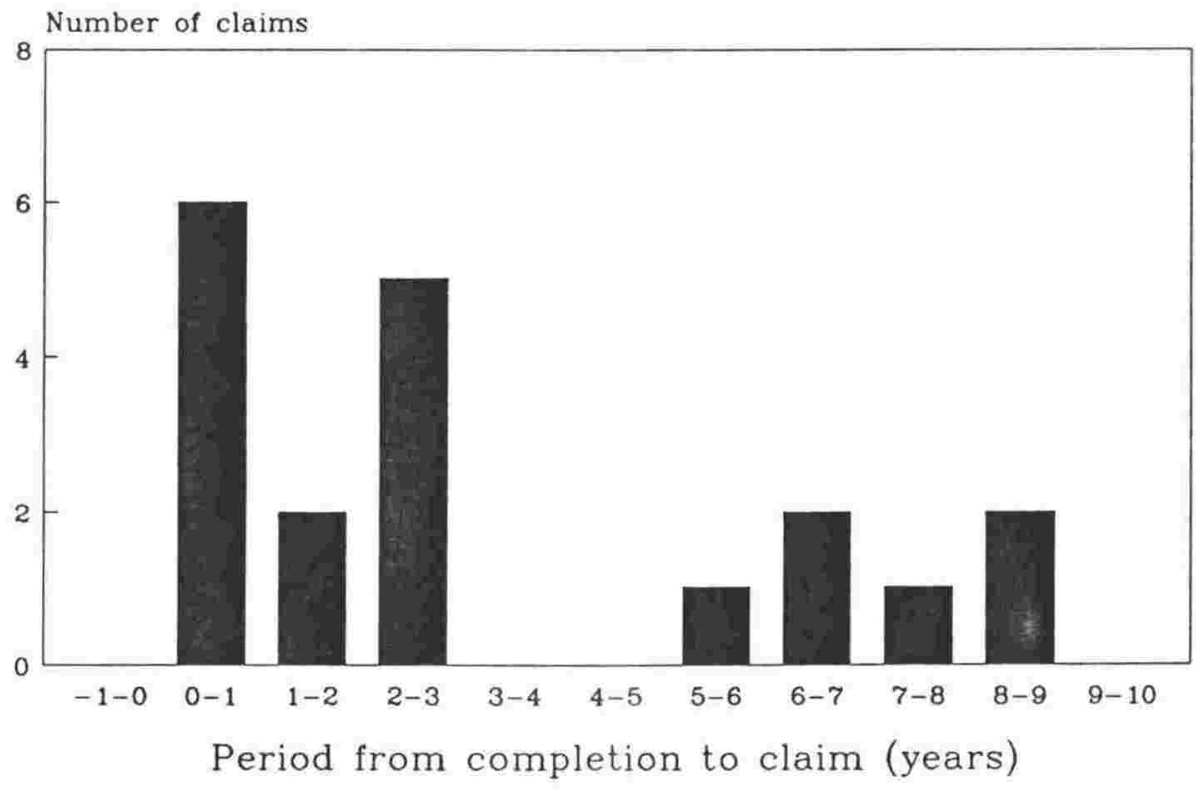

Fig 5.47 NZACS. Completion to claim time (years) (all causes.) 
It is apparent from Fig 5.47 that the largest number of claims in a given 12 month period occur within the first year after completion. Further analysis of this first 12 months postcompletion is shown in Fig 5.48 in which it is evident that as many claims were lodged within the first month post-completion as were lodged in the seventh month post-completion.

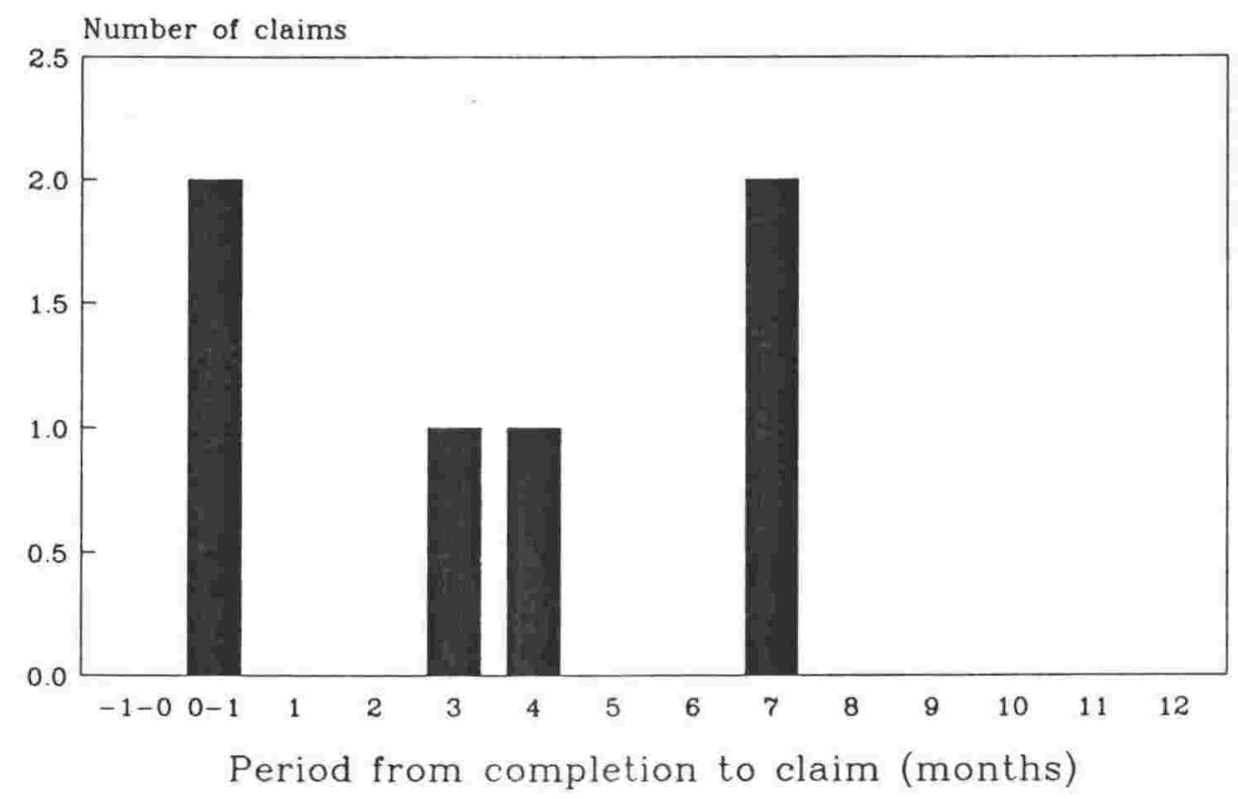

Fig 5.48 NZACS. Completion to claim (months) (all causes.)

The relative significance of the three 'natural causes' in the analysis of the completion to claim date interval is shown in Fig 5.49 which breaks down Fig 5.47 by natural cause. 


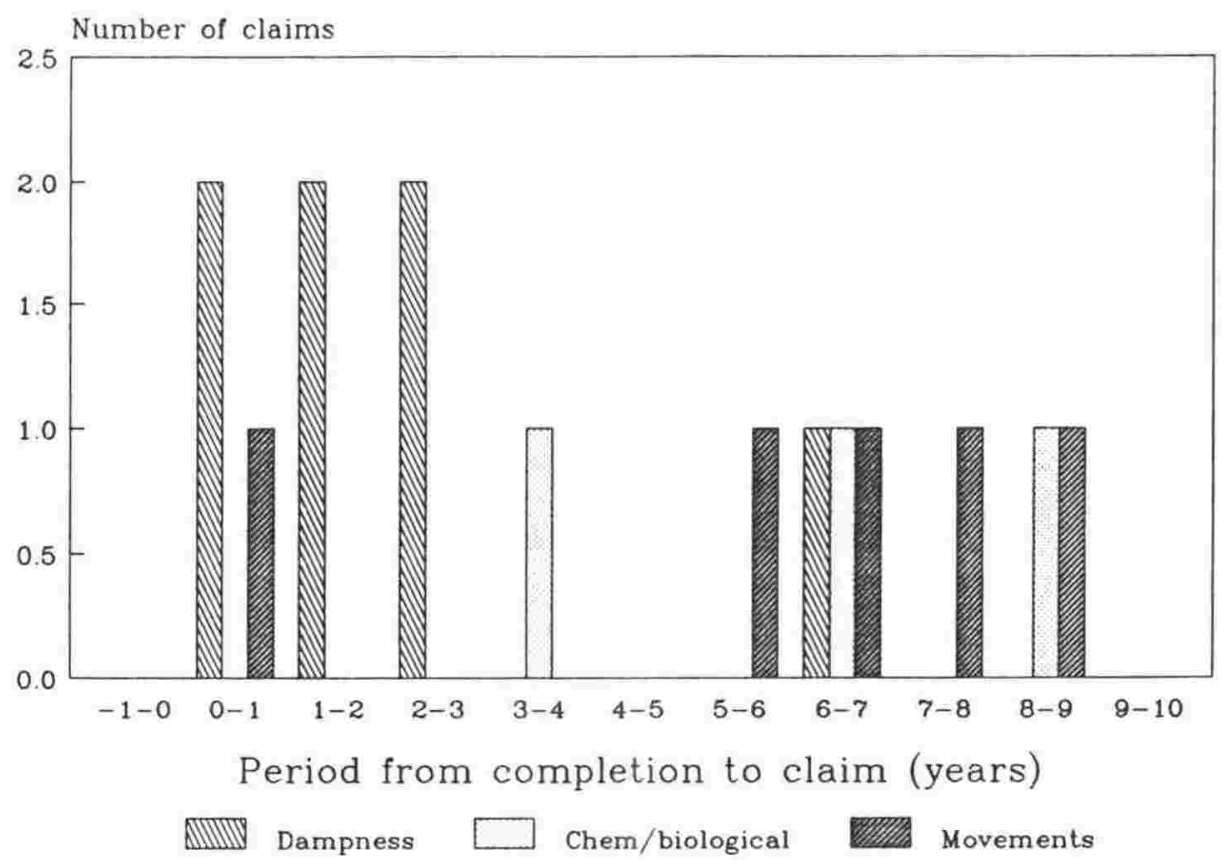

Fig 5.49 NZACS. Completion to claim time (years). (natural causes.)

Further analysis of the first 12 month period in Fig 5.48 is shown in Fig 5.50 in which the significance of the natural cause 'dampness' is evident.

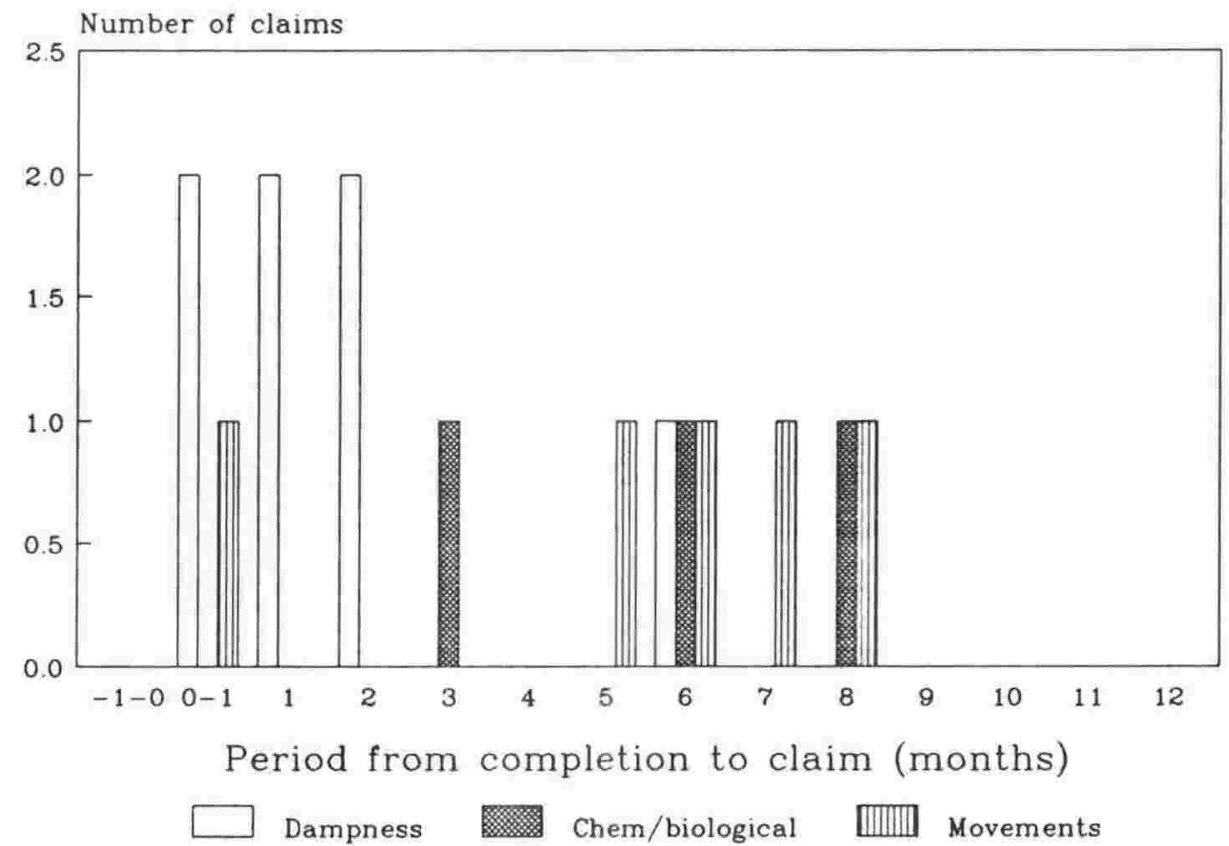

Fig 5.50 NZACS. Completion to claim time (months). (natural causes.) 
Analysis of the 4 'human error only' cases in the NZACS claim record reveals a spread of completion to claim periods as shown in Fig 5.51.

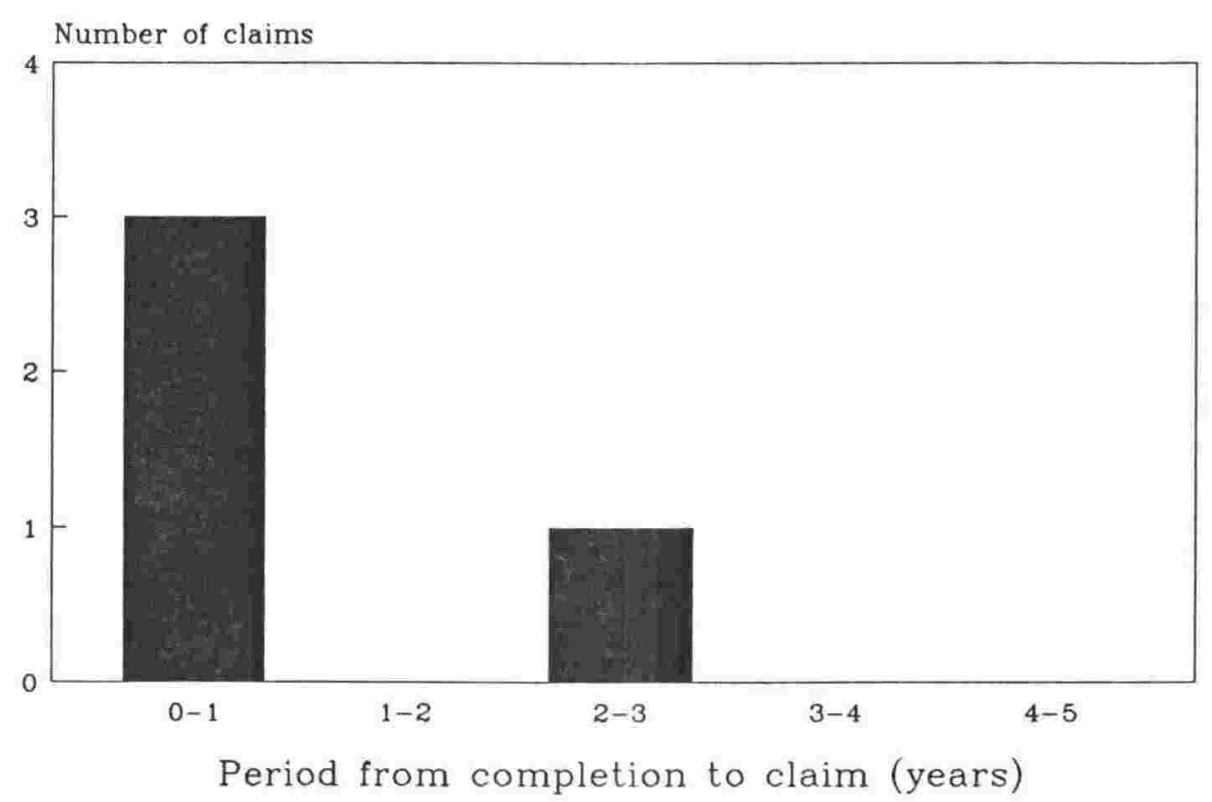

Fig 5.51 NZACS. (Completion to claim time (years). (human error only.)

Again the predominance of claims in the first 12 months is evident and has been further analysed in Fig 5.52 .

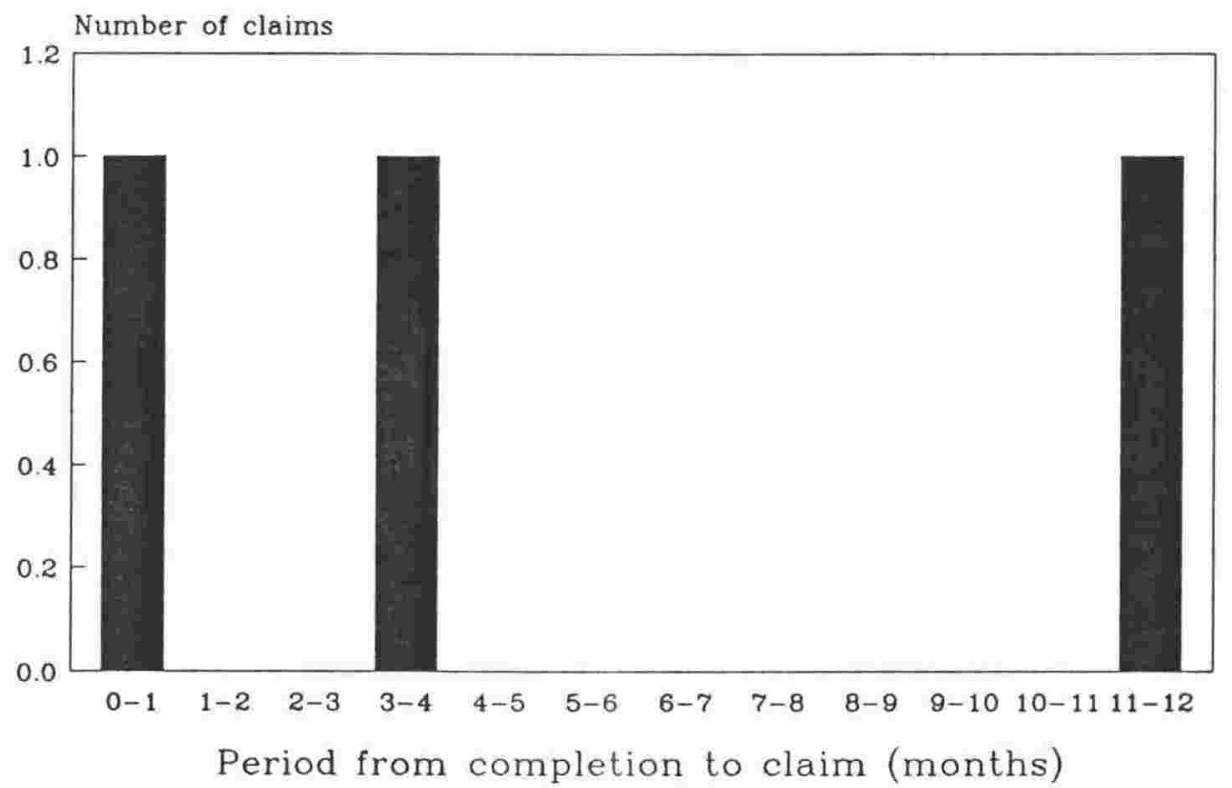

Fig 5.52 NZACS. Completion to claim time months). (human error only.) 
It is not possible to show the relationship of the claim sum to the original contract price of each dwelling involved in a NZAC's claim because the claim files did not indicate the contract price in each case.

It is possible to illustrate the number of claims made within a range of claim values. Fig 5.53 shows the distribution of claim values for all NZAC's claims (except those 6 out of the 19 claims for which no claim value was discoverable from the claim file) across a value range from $\$ 0-40,000$.

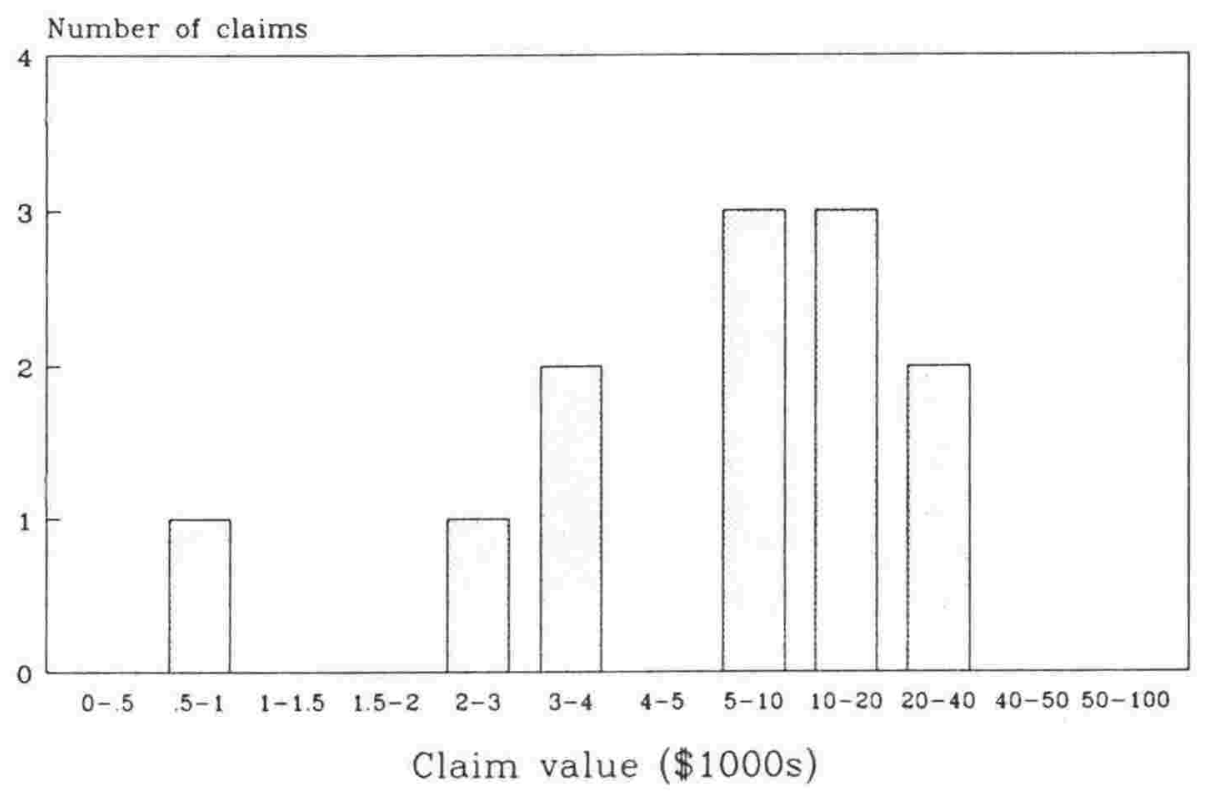

Fig 5.53 NZACS. Claim sums ( $\$ 1000$ s) (all causes.)

When the claims are separated into the two categories of 'natural causes' and 'human error alone', the distribution of claim values is as shown in Fig 5.54 


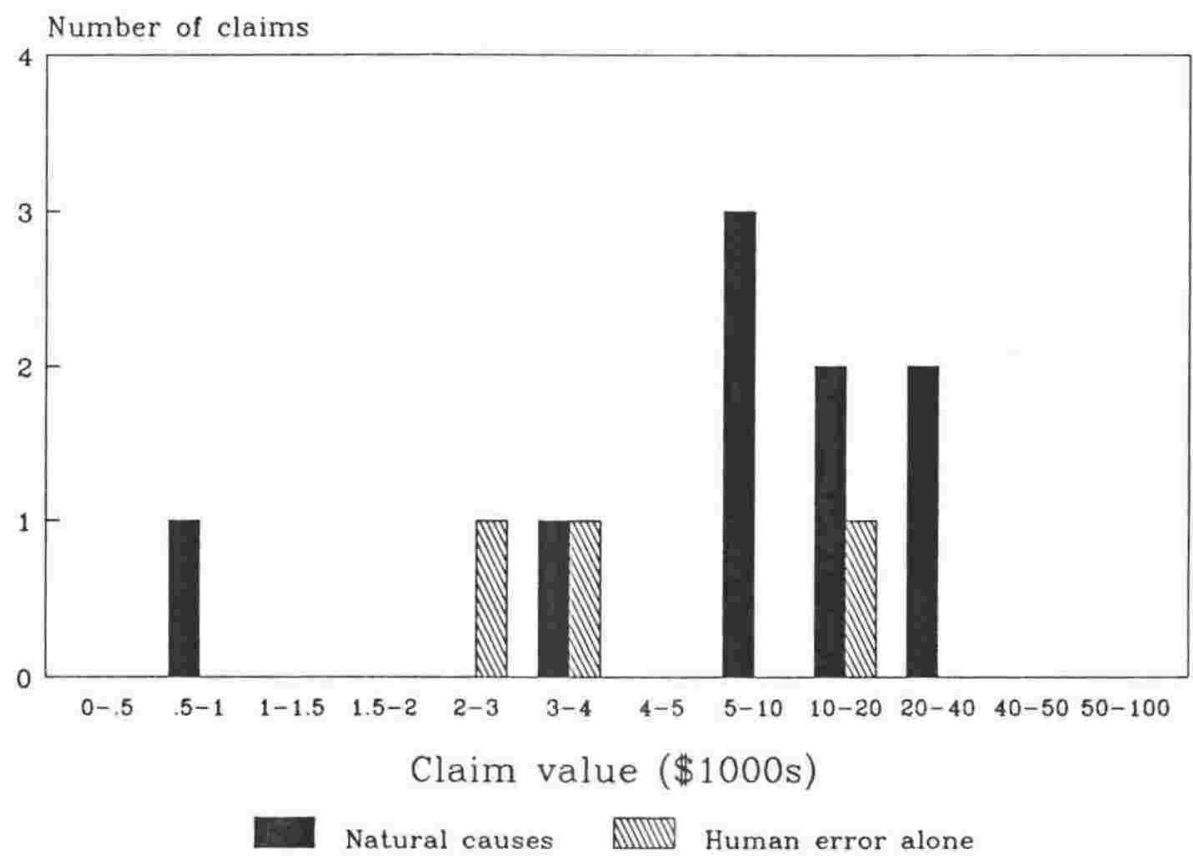

Fig 5.54 NZACS. Claim sums (\$1000s) (human error alone and natural causes.)

\subsection{INSURANCE LOSS-ADJUSTERS}

\subsubsection{Function of loss-adjusters}

The function of insurance loss-adjustors is to act as the impartial investigator of insurance claims made by a policy-holder under the terms of an insurance contract intended to compensate the policy holder for certain types of loss. Generally loss-adjusters work independently of any particular insurance company but take their instructions to investigate a claim from the company which issued the policy to the claimant. Because loss-adjusters have a professional knowledge of insurance contracts and specialised expertise in claims settlement their engagement by an insurance company is intended to reassure the claimant that the claim is being objectively and impartially investigated. The loss-adjusters report their findings to the client insurers together with a recommendation for a basis of settlement.

A typical example of the loss-adjustor's work in a dwelling-related claim is the adjustment of a claim resulting from carpet damage following a washing- 
machine overflow. The options available to compensate the policy holder include:

1 lifting, drying and re-laying the carpet

2 drying and shampooing the carpet to remove water stains

3 a lump sum payment to the policy-holder amounting to the value of the carpet as at the date of the claim, allowing for depreciation of value due to age and wear. (Assuming the policy provides for compensation for the value of the asset at the time of loss)

4 a lump-sum payment to the policy-holder amounting to the value of a new replacement carpet (assuming the policy provides for replacement of an asset which is ruined).

The loss adjuster's experience ideally ensures a fair balance between the natural wish of the insurers to minimise the cost of the claim and the equally natural wish of the claimant to benefit to the maximum permitted by the terms of the policy.

\subsubsection{Impartiality and skilled judgement}

The example of the carpet damage claim is intended to demonstrate that there is a degree of impartiality and skilled judgement in the work of lossadjusters which makes their observations on the cause of the claims worthy of note. The loss adjusters are not, of course, as well versed in building matters as the inspectors who investigate BPGC claims, but often the information recorded in the loss-adjuster's report is sufficient for a confident identification and classification of a building failure to be made by someone who is knowledgable about building failures.

It is important to keep it in mind that the loss-adjusters are primarily interested in investigating and adjusting claims and have no intrinsic interest in building failures. In that regard they reflect the position of the insurance industry generally in taking no interest in analysing the causes of the damages which generate claims on dwelling and dwelling contents policies. 
There are several firms of loss adjusters operating in New Zealand, of which some operate under a more or less loose national organization with offices (which are often autonomous) in several centres throughout the country. One such organisation to which the writer was referred by sources within the insurance industry was MBS Loss Adjusters (NZ) Ltd. In return for assurances that client confidentiality would be preserved the management of four branches of the MBS organisation generously allowed access to their claim files.

As the MBS organisation sorts its claim files by an identifying number and a brief, often cryptic, entry in a log of claims handled, a large number of claim files had to be examined in the search for building failure claims. The total number of claims handled by each of four MBS offices in 1982, for example, was as follows:

$\begin{array}{ll}\text { Auckland } & 1679 \text { claims } \\ \text { Wellington } & 1538 \text { claims } \\ \text { Christchurch } & 1250 \text { claims } \\ \text { Dunedin } & 1795 \text { claims }\end{array}$

\subsubsection{Building failures as a proportion of all claims}

The MBS Loss Adjusting group handle insurance claims of all types including motor vehicle, marine, cargo as well as householder's claims for damage to houses and contents. The extent to which building failure claims form part of their workload can be seen in Figures 5.55 and 5.56 which show the annual total of claims of all sorts handled by the offices in Auckland, Wellington, Christchurch and Dunedin and the relatively small number of building failure claims made to each office. 


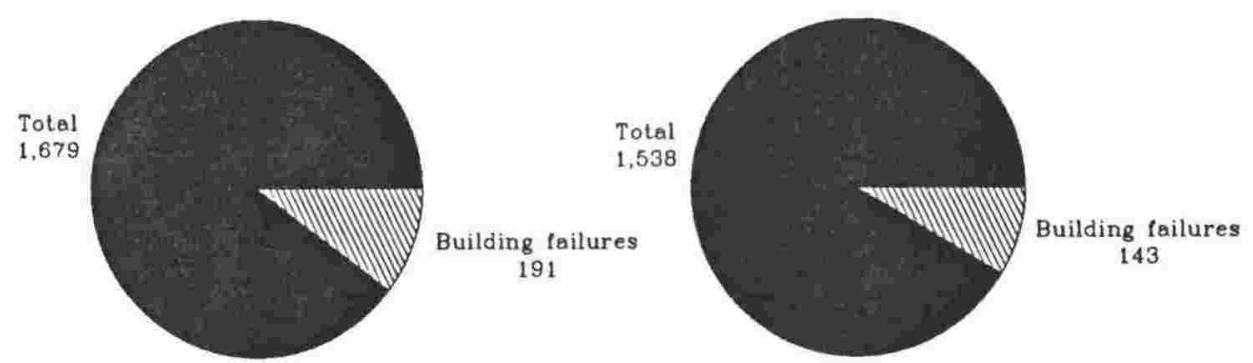

MBS Auckland 1982 MBS Wellington 1982

Fig 5.55 MBS Proportion of building failures, Auckland and Wellington.

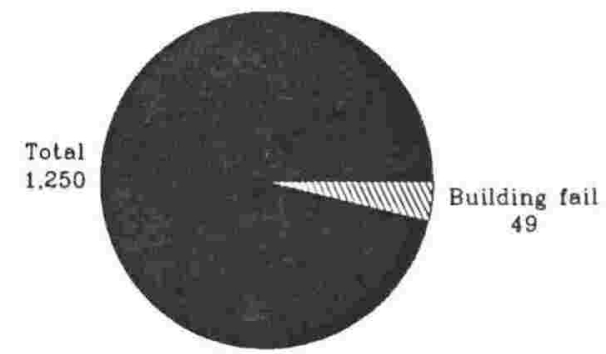

MBS Christchurch 1982

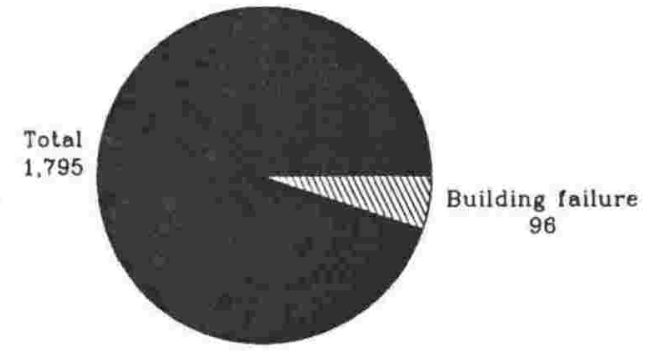

MBS Dunedin 1982

Fig 5.56 MBS Proportion of building failures, Christchurch and Dunedin.

The householder's insurance policies are not intended to protect their dwellings against the builders' human error or even against the effects of natural weathering and aging, but they do provide for compensation for the consequences of water and fire damage. All the building failure claims examined related to fire or water damage arising from causes other than flood, tempest, earthquake or Act of God.

The relative proportion of water to fire claims adjusted by the four offices are shown in Figs 5.57 and 5.58 . 


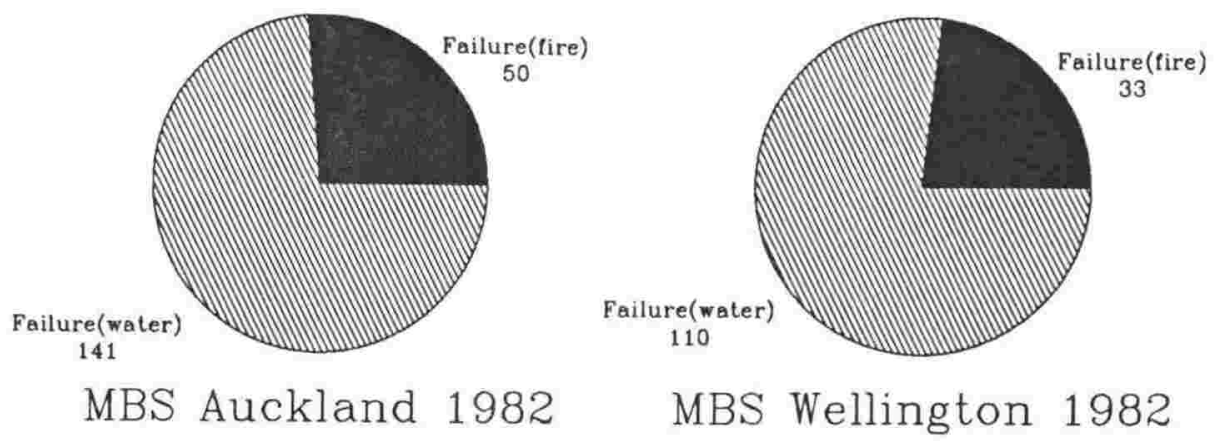

Fig 5.57 MBS Failure by fire and water, Auckland and Wellington

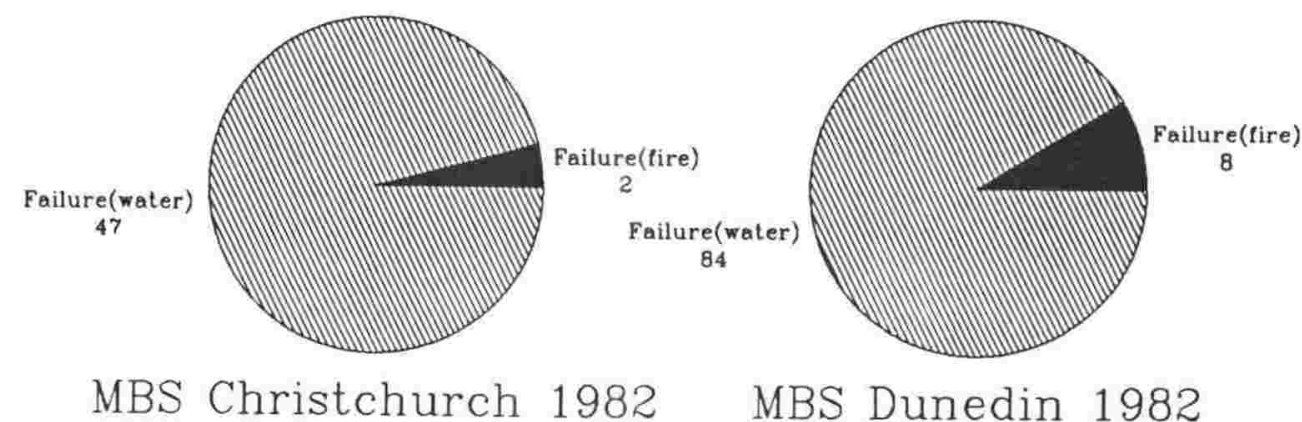

Fig 5.58 MBS Failure by fire and water, Christchurch and Dunedin.

Remembering that examination of a full year's claims in each office amounts merely to a sampling of the range and number of claims adjusted by MBS and its competitors during that year throughout New Zealand, no significance can be attached to the total number of such claims handled by one office as against another. What may be significant is a comparison between the numbers of claims of various types adjusted each year. Figures 5.59 and 5.60 illustrate such a comparison by showing the numbers of fire and water claims arising from building failure alongside the numbers of claims arising from accidental events. The most common overflow accidents arise from automatic washing machines discharging into blocked laundry tubs, while cooking fires frequently originate from an overheated 'fry-up'. 


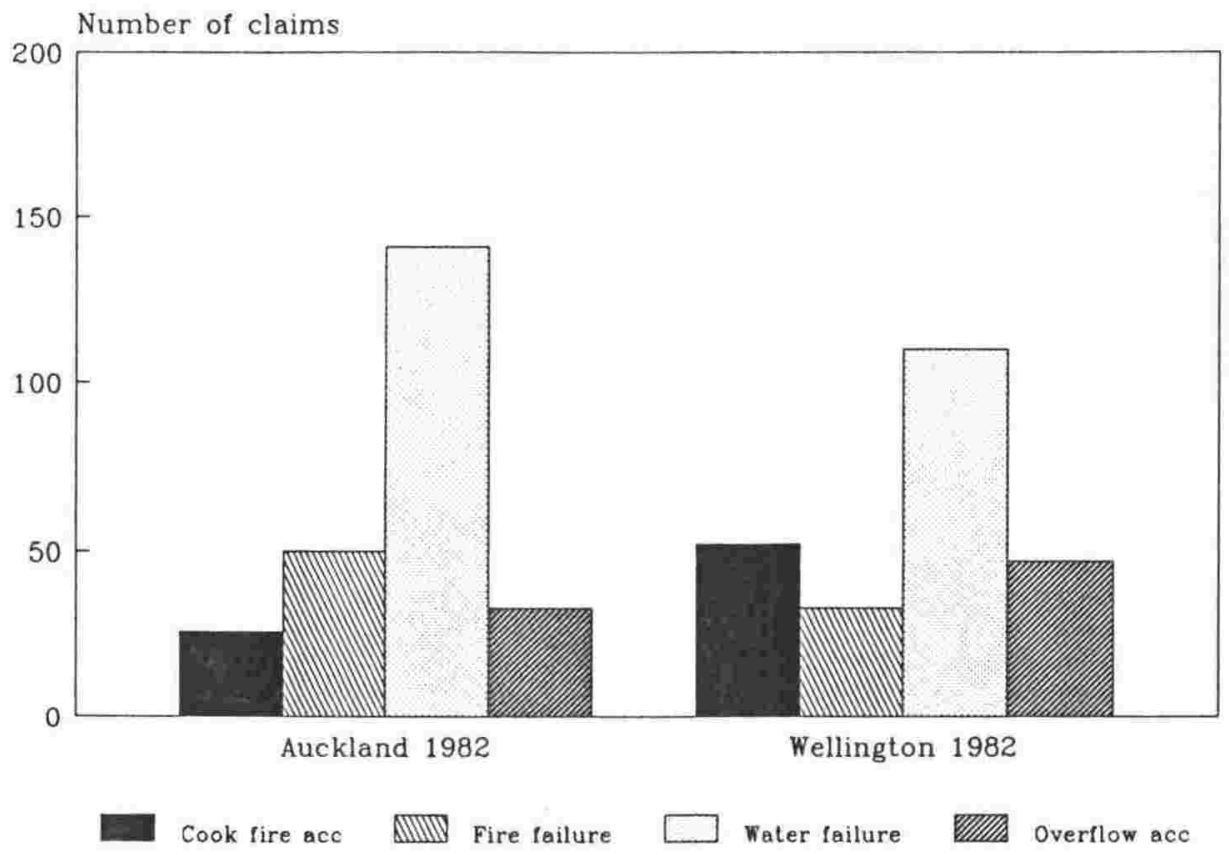

Fig 5.59 MBS Failures and accidents in Auckland and Wellington (1982).

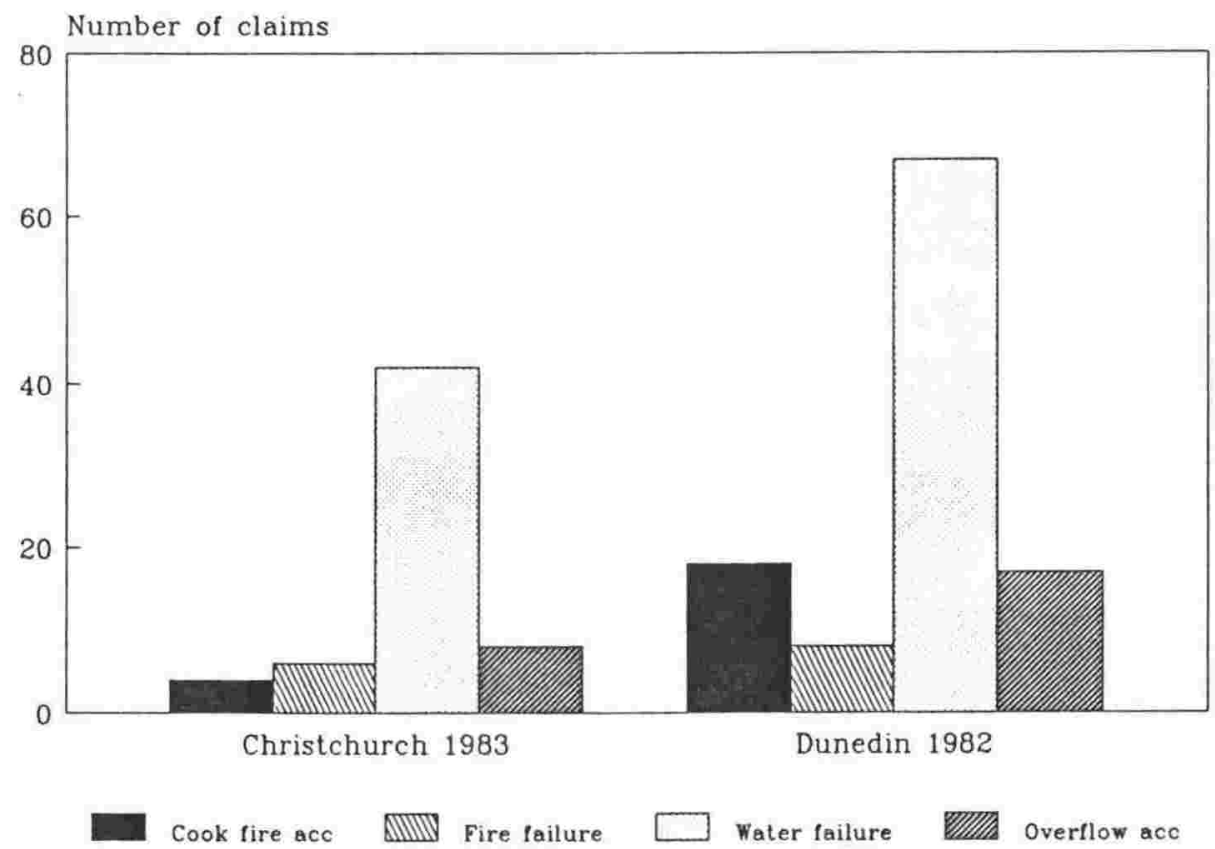

Fig 5.60 MBS Failures and accidents in Christchurch (1983) and Dunedin (1982).

In the case of the Wellington office it was possible to obtain a full two years of data (for years 1982 and 1983). The two years are compared in Fig 5.61 
to illustrate differences and similarities between the claims adjustment experience of the two consecutive years.

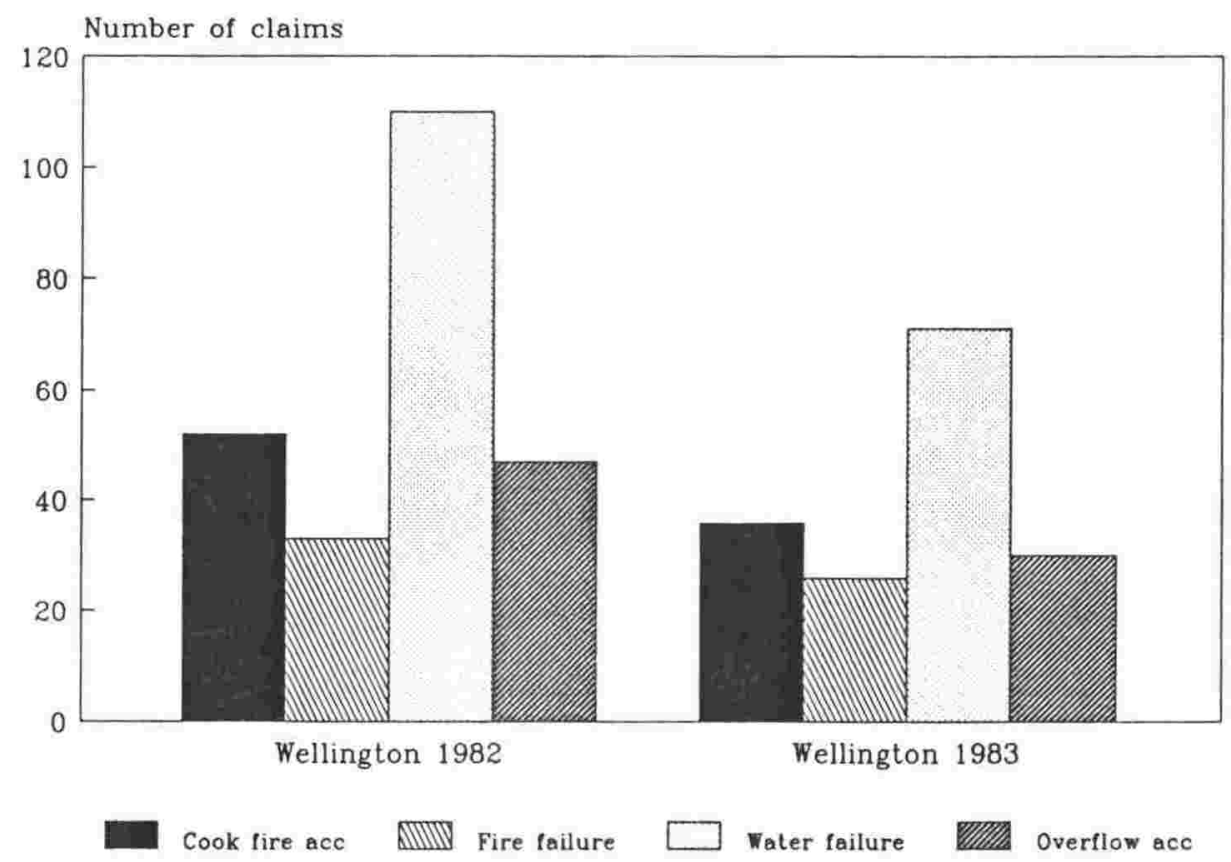

Fig 5.61 MBS Failures and accidents in Wellington in 1982 and 1983.

\subsection{SUMMARY}

This chapter introduced the data sources which were sought in order to test the usefulness of the system of classification of building failures proposed in Chapter 4. The classification system in turn had been developed to facilitate the practice of identification and technical evaluation of buildings proposed in Chapters 2 and 3 . The results of the analysis of the data are reported and explained. The patterns of the results are discussed in Chapter 6. 


\subsection{REFERENCES}

BUILDING PERFORMANCE GUARANTEE CORPORATION OF NEW ZEALAND. Report of Building Performance Guarantee Corporation of New Zealand for the years ending 31 March 1982, 1983, 1984, 1985 and 1986. 


\section{CHAPTER 6}

\section{PATTERNS FROM THE FAILURE DATA}

\subsection{INTRODUCTION}

This chapter draws together the results of the various analyses of data presented in Chapter 5. It prefaces its commentary on the patterns which emerge by drawing attention to the differences between the business objectives of the various data sources. None of the sources, it is pointed out, recorded data with the knowledge or intention that it would be subjected to analysis and classification in the course of research into building failures. Consequently the nature of the data recorded tended to reflect the administrative requirements and convenience of the recording organisation rather than the preferences of a researcher. Nonetheless it proved possible to extract from the records enough information about cost, dates, and causes, to allow aggregation of data to be carried out sensibly. Had the data contained more information, consistently recorded, more analysis would have been possible.

Some more or less consistent trends or patterns do emerge from the analysis of the claims files located in the study. These patterns, the results of aggregating the data from individual claims, provide interesting and factual insights into the timing of claims, their cost and, of course, their causes. It is also possible, from the results of the research, to estimate the total number of claims in a year in New Zealand. 


\subsection{VARIED USEFULNESS OF THE DATA}

\subsubsection{Variation in data-collection habits}

It will be apparent from Chapter 5 that the sources of building failure data for this research are widely varied in their business objectives and therefore in their data-collecting habits. Closest to the ideal source was the New Zealand Building Performance Guarantee Corporation (BPGC), which was established to indemnify dwelling owners against, inter alia, building failures, and had a formal independent inspection and reporting system to handle claims. It was the use of the independent expert evaluator that made the BPGC the best source of material for the technical evaluation discussed in Chapter 2. The BPGC was also actively involved in arranging the rectification of building failures which were reported to it.

The NZ Architects Co-operative Society (NZACS), on the other hand, was established to ensure that architects who joined the scheme could tell their clients that they were adequately indemnified professionally. NZACS is not actively involved in organising the rectification of building failures. Its function is to be ready to pay for the legal consequences of an architect's client claiming monetary compensation for the architect's professional shortcomings. As a consequence some of the NZACS claim files contain only brief information about a claim which might or might not actually be pursued by the client. These 'notional' claims arise out of the insurer's requirement for the earliest possible notification of an impending possible claim. Few of the claims files contain a formal report by an independent person qualified in building, but many files contain lawyers' statements of the legal technicalities. The researcher is forced to apply a higher level of interpretive judgement and more intuition to NZACS claim files than to BPGC files.

The loss-adjusters' data is different from both the NZACS and BPGC data. While it is often recorded by people with some training in the technologies and arts of building (and is therefore not totally unlike the BPGC data) it is recorded only for the purpose of determining whether the conditions 
necessary for a valid claim within the relevant policy conditions have been met. Those policy conditions are more concerned with compensating for the value of the loss sustained by the claimant than in contributing to the cost of prevention. Thus, in the event of water damage to wallpapers and carpets resulting from a defective ball-valve in a supply tank in the ceiling the insurance policy will generally provide for some or all of the cost of repair or replacement of wallpapers and carpets damaged by the water but not for the cost of repair of the ball-valve. Even if the water damage occurred because normal trade practice (such as the installation of a 'safe tray' beneath the tank to catch overflows and drain them clear of the building) had not been followed, the insurers are not required by the policy conditions to contribute to bringing the installation up to standard. That is a fundamental difference between the BPGC and the ordinary insurance companies. Unlike the NZACS and BPGC data, the loss adjusters' claim files concerned dwellings of all ages, not merely those up to six years old (BPGC) or slightly longer for the NZACS cases.

\subsubsection{Drawbacks and possible gains from variety of data sources}

The fact that all these data sources are different from each other in these various aspects is not, of course, ideal from the research point of view, in that the data cannot be manipulated as one homogenous mass of claims all made according to the same rules. While that is a draw-back, unavoidable because there are no better data available, it is still possible to detect common trends in the claims experience of the three different organisations. It may even be argued that the very diversity of the three viewpoints on claims gives these common themes more significance. 


\subsection{PATTERN OF CLAIMS}

\subsubsection{Time lapse between completion and claim}

The evidence is clear that the bulk of BPGC failure claims are lodged within the first 12 months after completion and that after the first 24 months postcompletion, the incidence of claims in each year remains much lower. This pattern is illustrated in Fig 6.1 which also shows that the trend is the same whether the cause of failure was human error alone, or natural causes and human error combined.

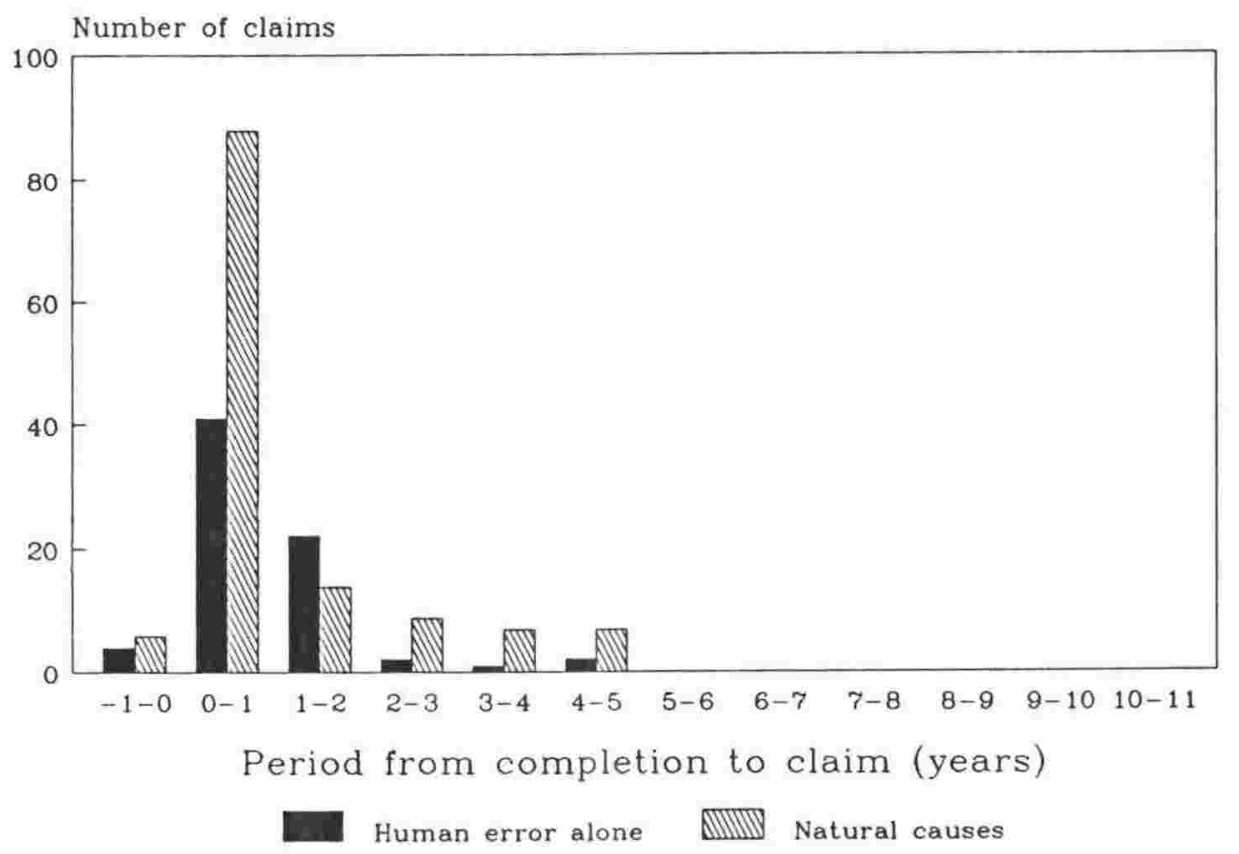

Fig 6.1 Completion to claim time lapse (years) for BPGC claims from all causes. 
If the claims are analysed by natural cause the resultant pattern is shown in Fig 6.2 which makes apparent the predominance of dampness as a cause of claims within the first 12 months. Dampness is also predominant in claims lodged before completion and in the 2-5 year period. The cause 'movements' is obviously apparent in the first 2 years as well, rising to a frequency equal to 'dampness' in the 1-2 year period.

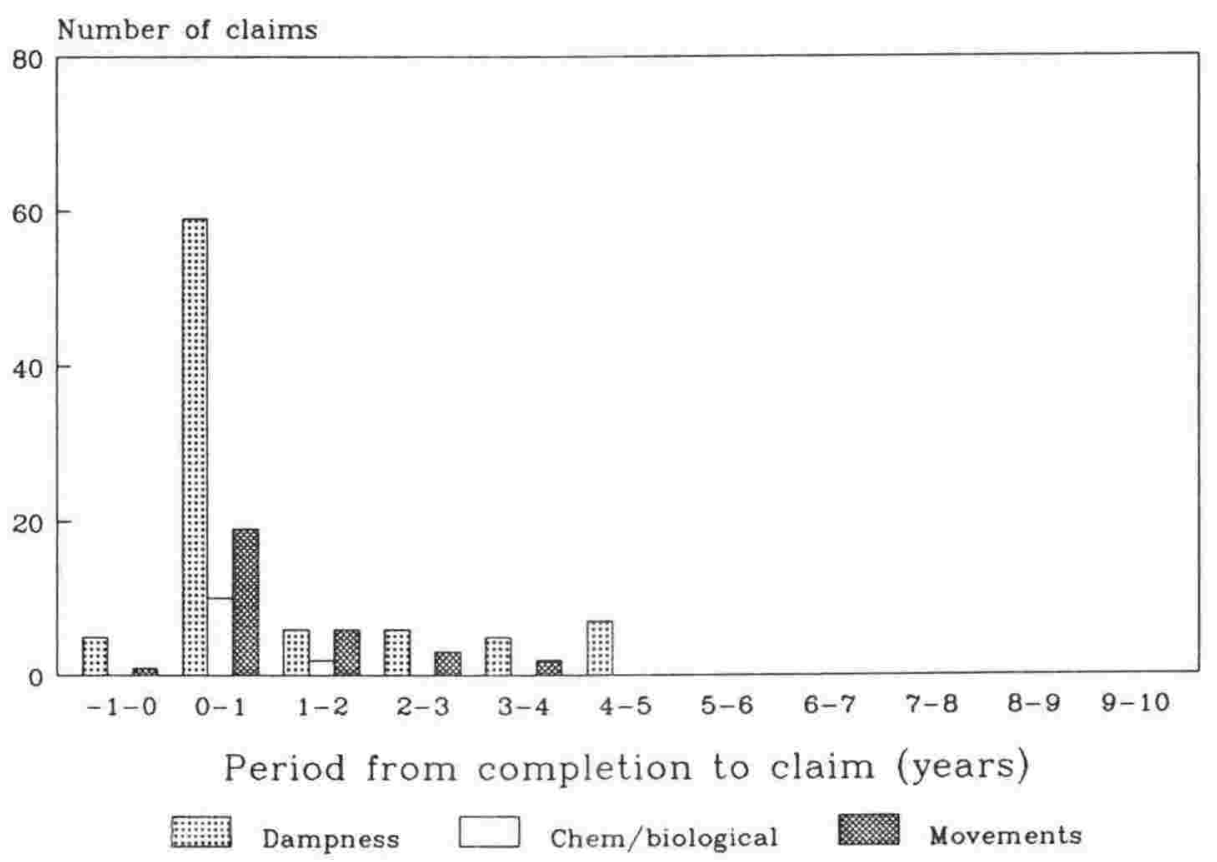

Fig 6.2 Completion to claim time lapse (years) for BPGC claims from 'natural causes'. 
When the NZACS claims are considered the same early incidence of claims is evident, but there is a second bulge in the 2-3 year period, followed by a quiet period of two years before more claims are lodged in the 5-9 years period. Fig 6.3 illustrates this pattern in the 20 claims investigated.

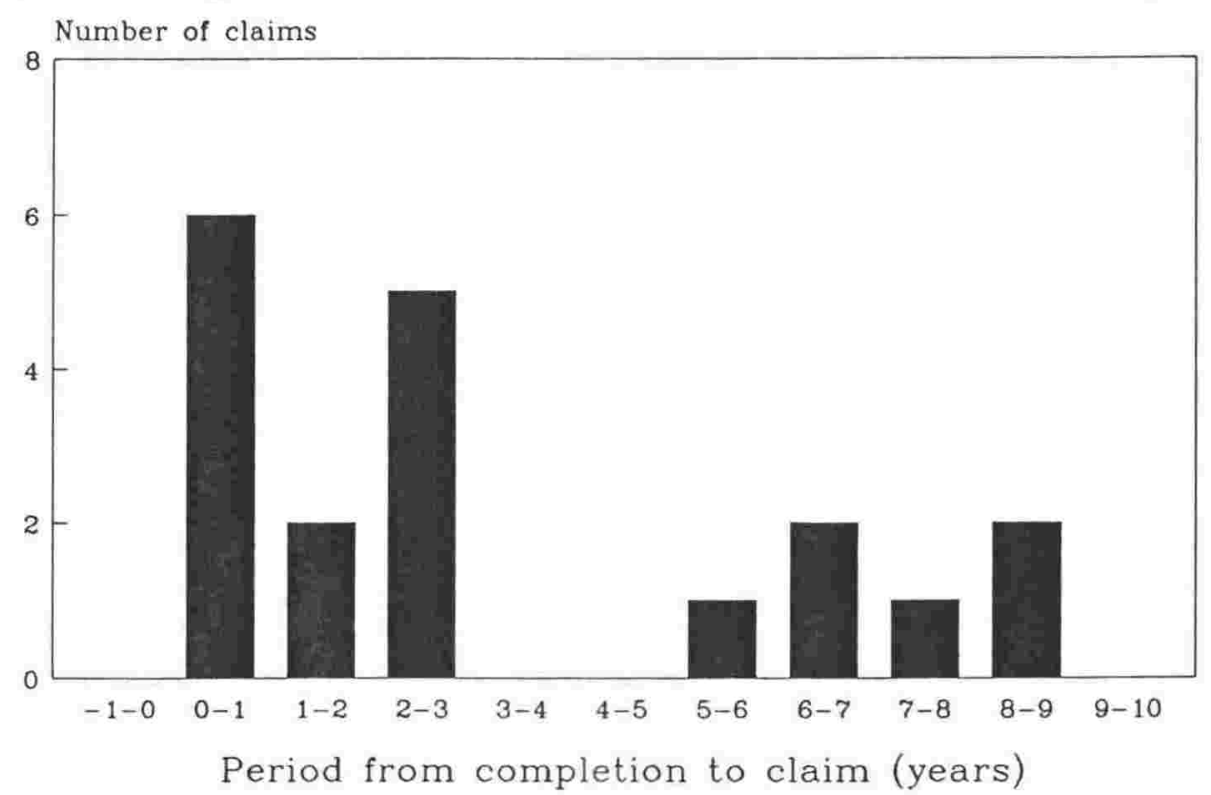

Fig 6.3 Completion to claim time lapse (years) for NZACS claims from all causes.

A comparison of the completion to claim time lapse for BPGC and for NZACS claims from all causes is shown in Fig 6.4. The tendency for BPGC claims to be made earlier than NZACS claims is clear.

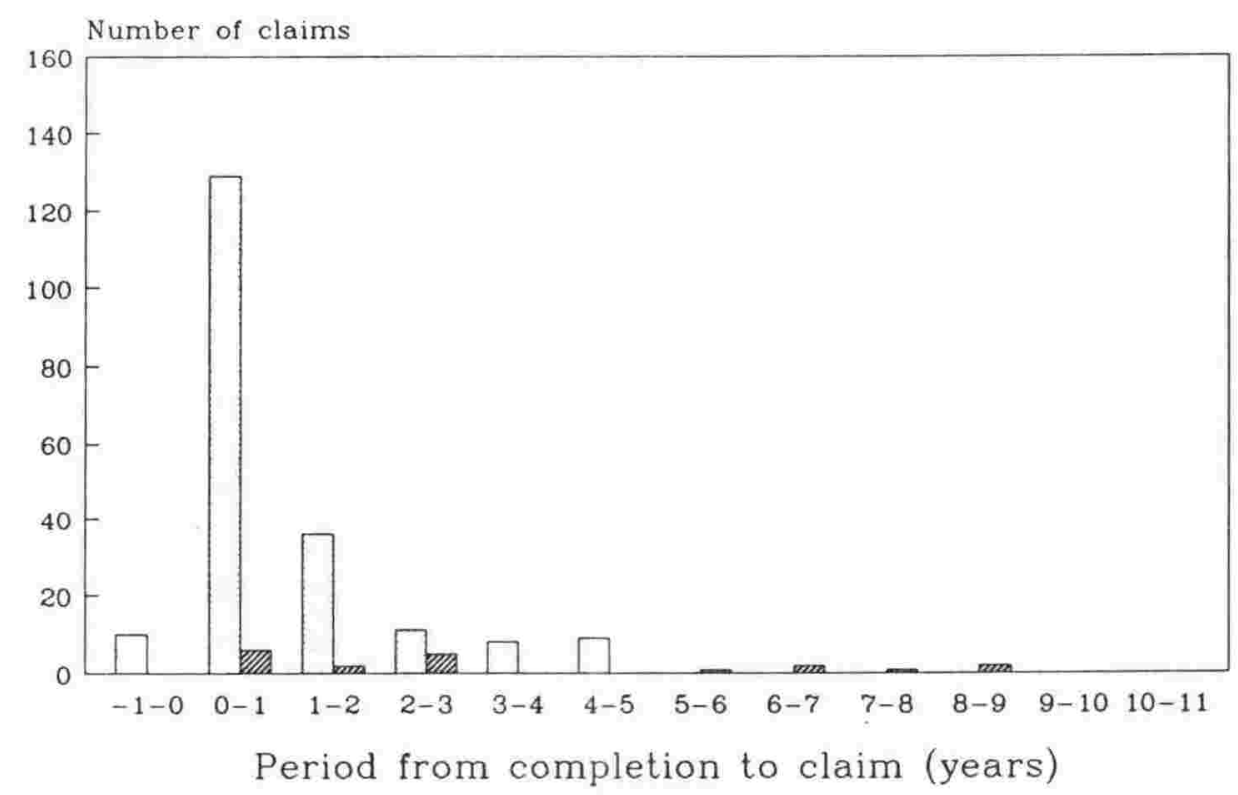

Fig 6.4 Comparison of completion to claim time lapse (years) for BPGC and NZACS claims from all causes. 
Analysis of the NZACS claims by natural causes reveals the considerable contribution of 'dampness' to the claims lodged in the 0-3 year period. The other natural causes ('chemical/biological' change and 'movement') became more significant in the 5-9 year interval. The small number of claims in the sample available make it unwise to read too much significance into the trends shown in Fig 6.5.

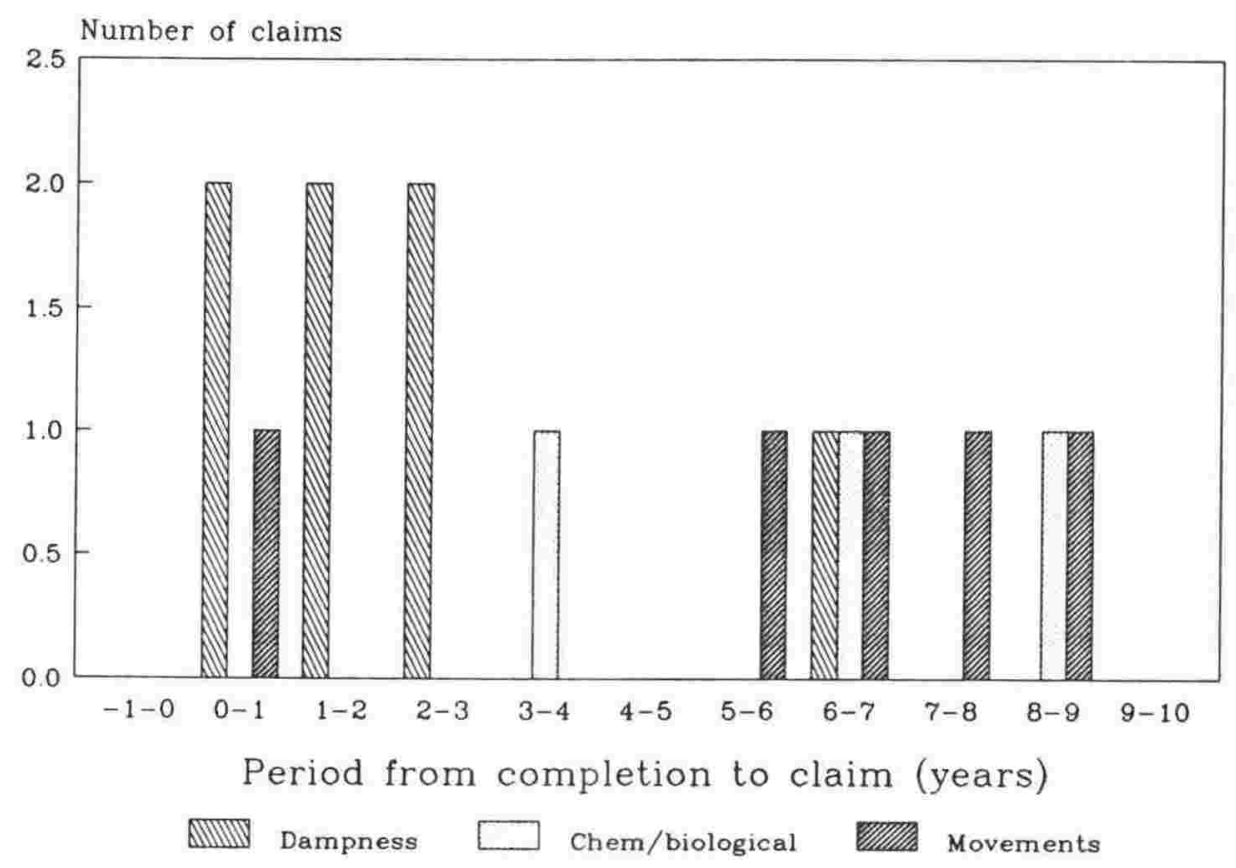

Fig 6.5 Completion to claim time lapse (years) for NZACS claims from 'natural causes'.

Closer examination of the claims lodged with BPGC in the first 12 months after completion of the dwelling shows that the highest rate of claims per month occurs within the first month after the stated completion date. This means, in most cases, that the claim was lodged during the maintenance period. On the face of it such early lodging of the claim may seem precipitate but it may be that the early lodgement reflects the lack of confidence on the owners' part that the identified building failure was going to be rectified by the builder during the maintenance period. 
The pattern of claims lodged with BPGC within the first 12 months of completion is shown in Fig 6.6.

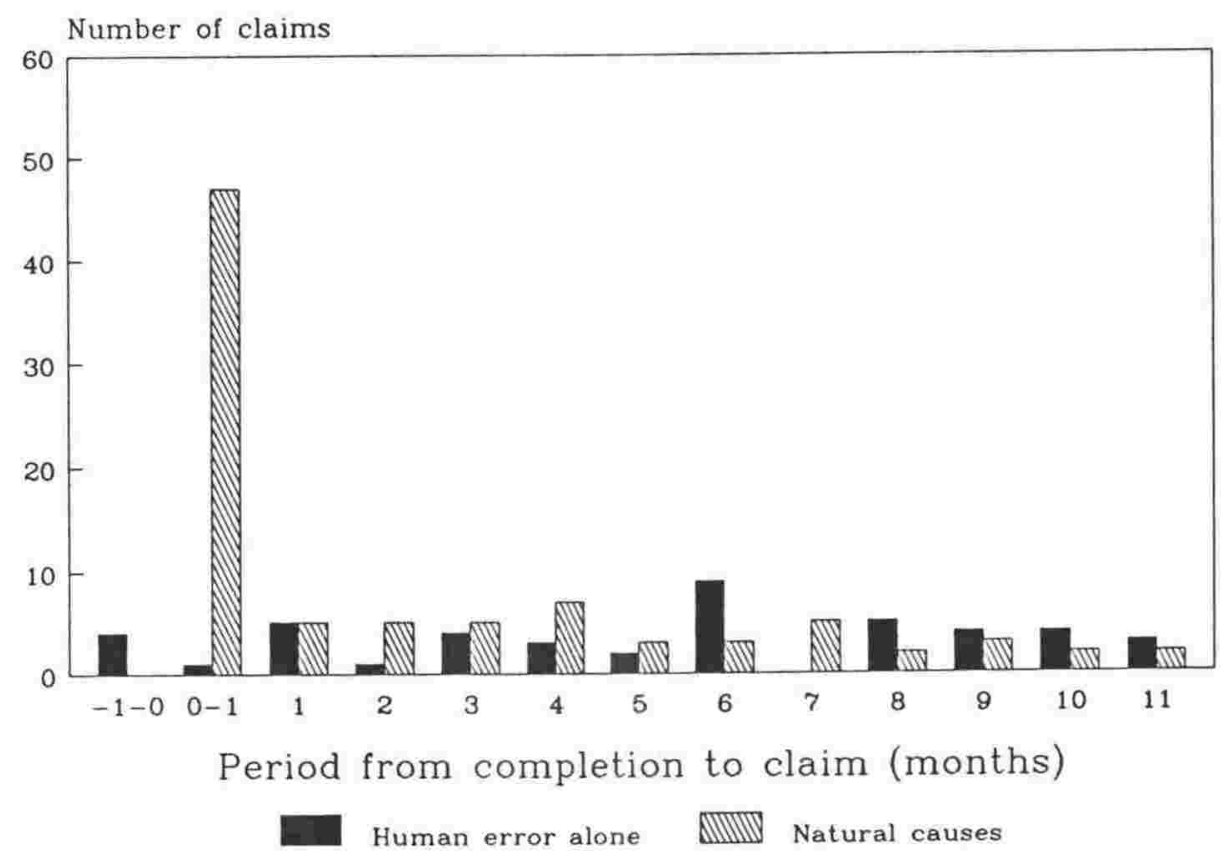

Fig 6.6 Completion to claim time lapse (months) for BPGC claims from human error alone and 'natural causes'. 
When these first year claims are broken down by natural causes the pattern of early dominance by 'dampness' is apparent as is the persistence of 'dampness' as a significant cause over most of the year - see Fig 6.7.

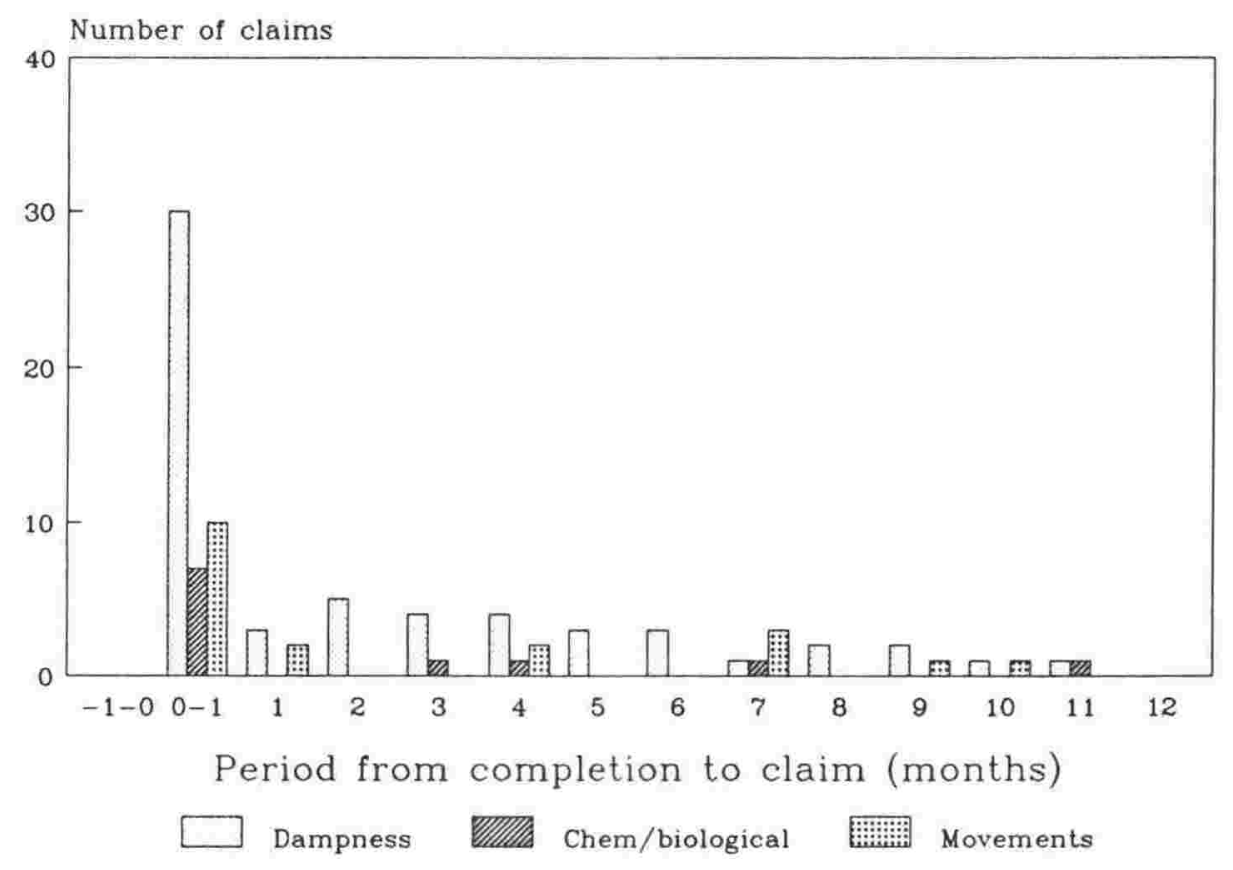

Fig 6.7 Completion to claim time lapse (months) for BPGC claims from 'natural causes'. 
The admittedly small number of claims made to NZACS and analysed here provide some similarity with the BPGC claims in that there is a peak of claims within the first month, but quite dissimilar is the second peak in the 7th month, shown in Fig 6.8.

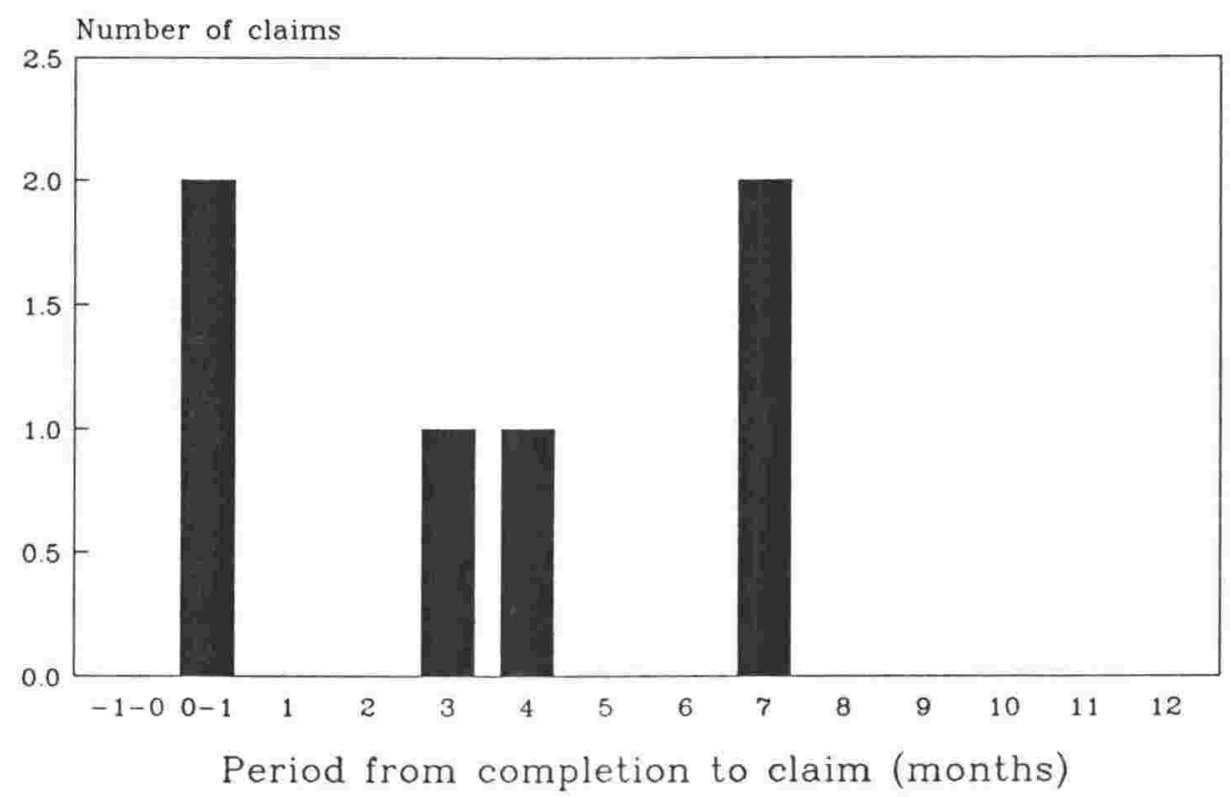

Fig 6.8 Completion to claim time lapse (months) NZACS claims.

Analysis of the NZACS claims by natural causes again demonstrates clearly the predominance of cause 'dampness' in the first 2 months. By the 3rd month the incidence of 'chemical/biological' and movements begins to match or exceed that of dampness as shown in Fig 6.9. This may be an indication of a trend for leaks and water damage to became apparent before a movement or chemical/biological change, but while everyday experience suggests that leaks do tend to appear before settlement or premature paint decay becomes apparent, the small number of claims makes it difficult to be certain. The BPGC experience (Fig 6.7) is obviously not the same, with early chemical/biological and movement claims. 


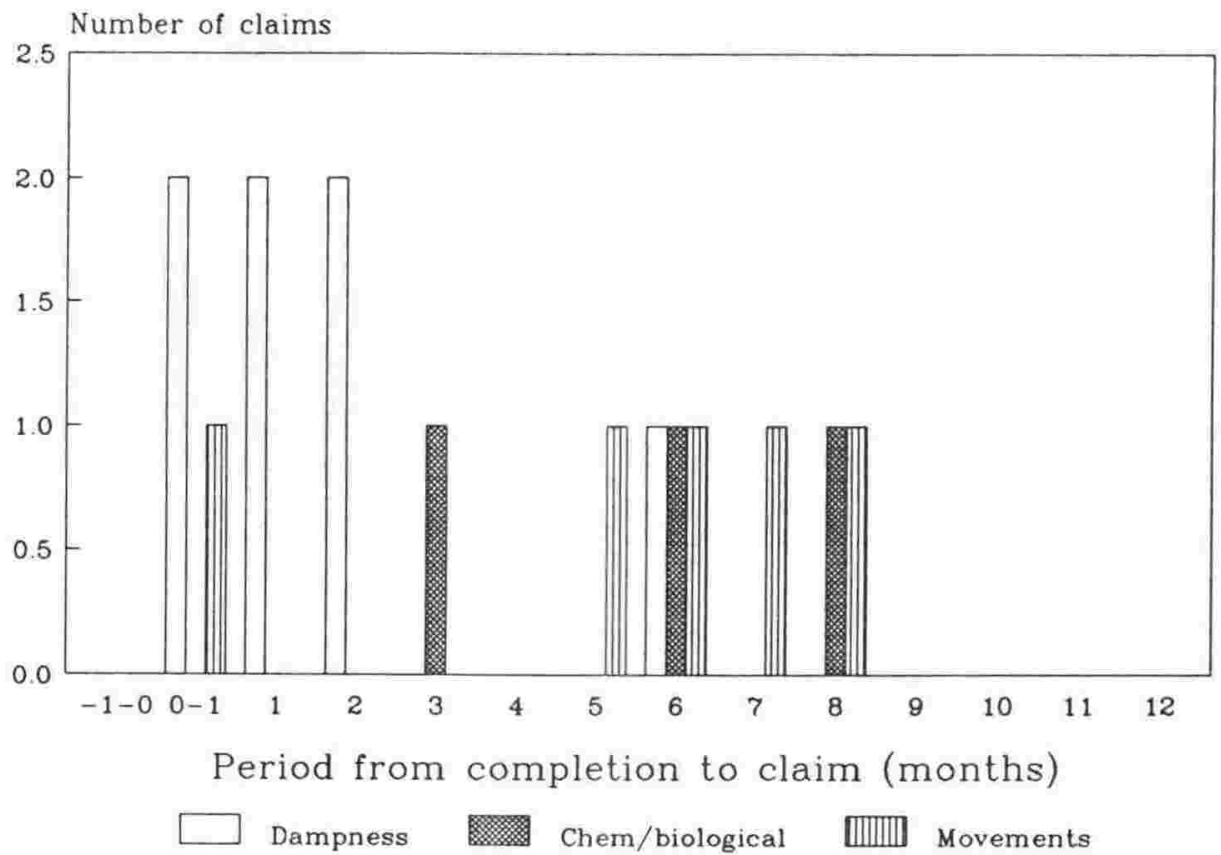

Fig 6.9 Completion to claim time lapse (months) NZACS claims from 'natural causes'.

A comparison of the claim time lapse, within the first year, for BPGC and for NZACS claims from all causes is shown in Fig 6.10

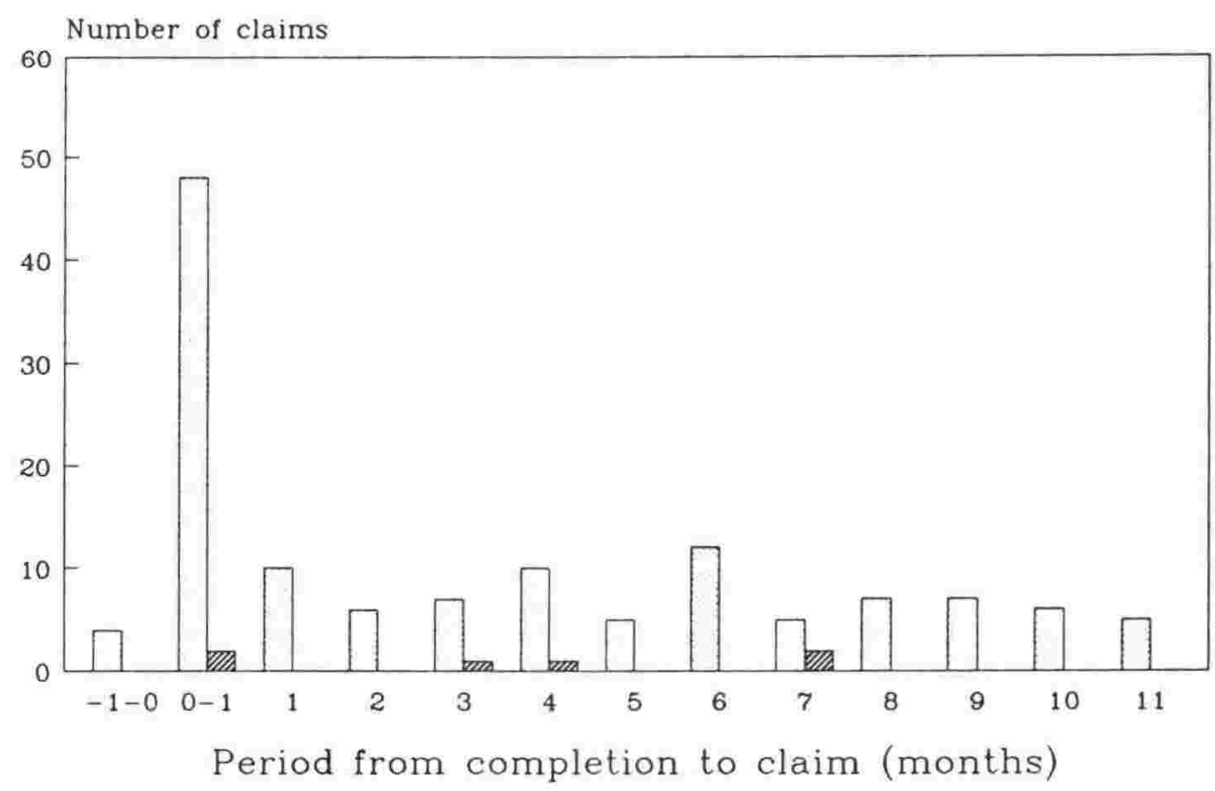

BPGC claims

NZACS claims

Fig 6.10 Comparison of completion to claim time lapse (months) for BPGC and NZACS claims from all causes. 


\subsubsection{The cost of claims as a \% of the contract price}

As discussed in Chapter 5 one basis of comparison of the cost of claims which minimises the influence of annual inflation is the cost of the claim as a percentage of the contract price of the dwelling. As the contract prices were not available for the NZACS claims the claim/contract \% figure could not be calculated, but for the BPGC claims the information was available. Fig 6.11 illustrates the number of claims which fell into each band of claim/contract price\%.

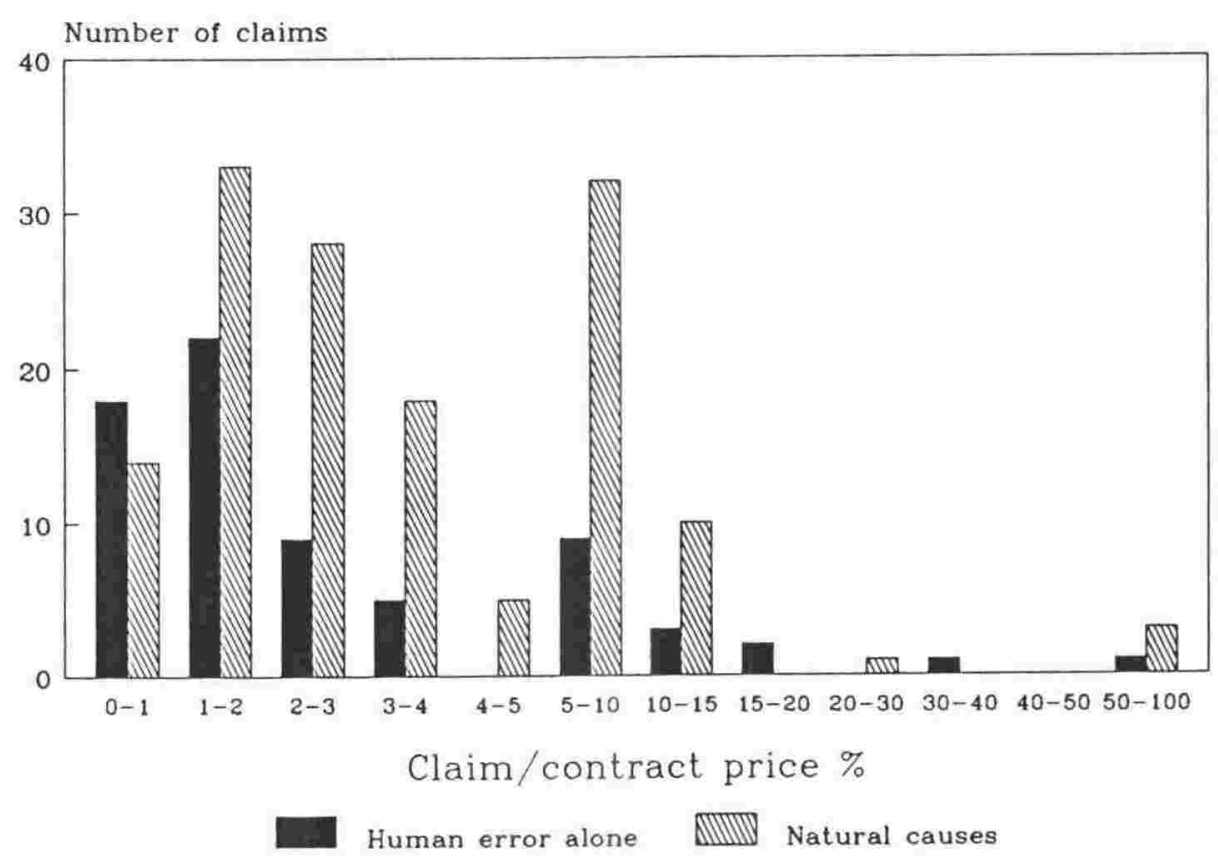

Fig 6.11 Claim as \% of contract price for BPGC claims from all causes.

From Fig 6.11 it is apparent that building failure claims involving human error alone tend to fit a pattern very similar to that of failure claims arising from natural causes. While a small number of claims may cost more than $50 \%$ of the original dwelling contract price to fix it is unusual for the claims cost to exceed $15 \%$ of the contract price and by far the bulk of claims cost less than $10 \%$. Of 198 BPGC claims approximately 140 cost no more than $4 \%$ of the original contract price. 
The detailed information provided by the BPGC claim files enabled the 'natural causes' claims of building failures to be broken down by the three natural causes. The result of the analysis is shown in Fig 6.12 where the impact of dampness as a cause of building failures is yet again evident, with movement in second position well behind. Dampness and movement are prominent causes over the whole spectrum of claim/contract price percentages.

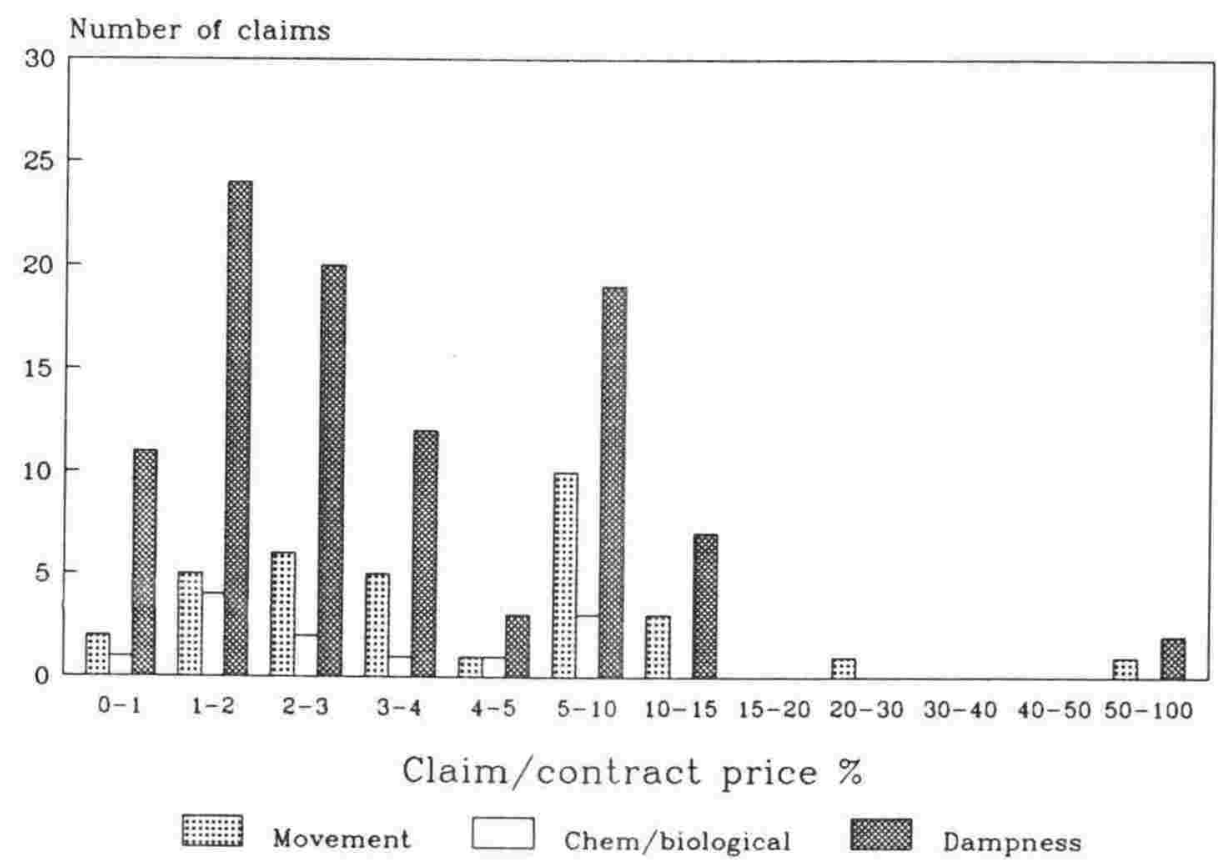

Fig 6.12 Claim as \% of contract price for BPGC claims from 'natural causes'. 
Analysis of the three natural causes to establish the source of each cause reveals the patterns which now follow. The first to be considered is the cause 'movement'. Fig 6.13 shows how externally applied loads and changes in moisture tend to dominate the pattern with changes in moisture contributing heavily to movement claims in the $5 \%$ to $10 \%$ range. Externally applied loads can also cause some of the most expensive claims at the right hand end of the cost spectrum.

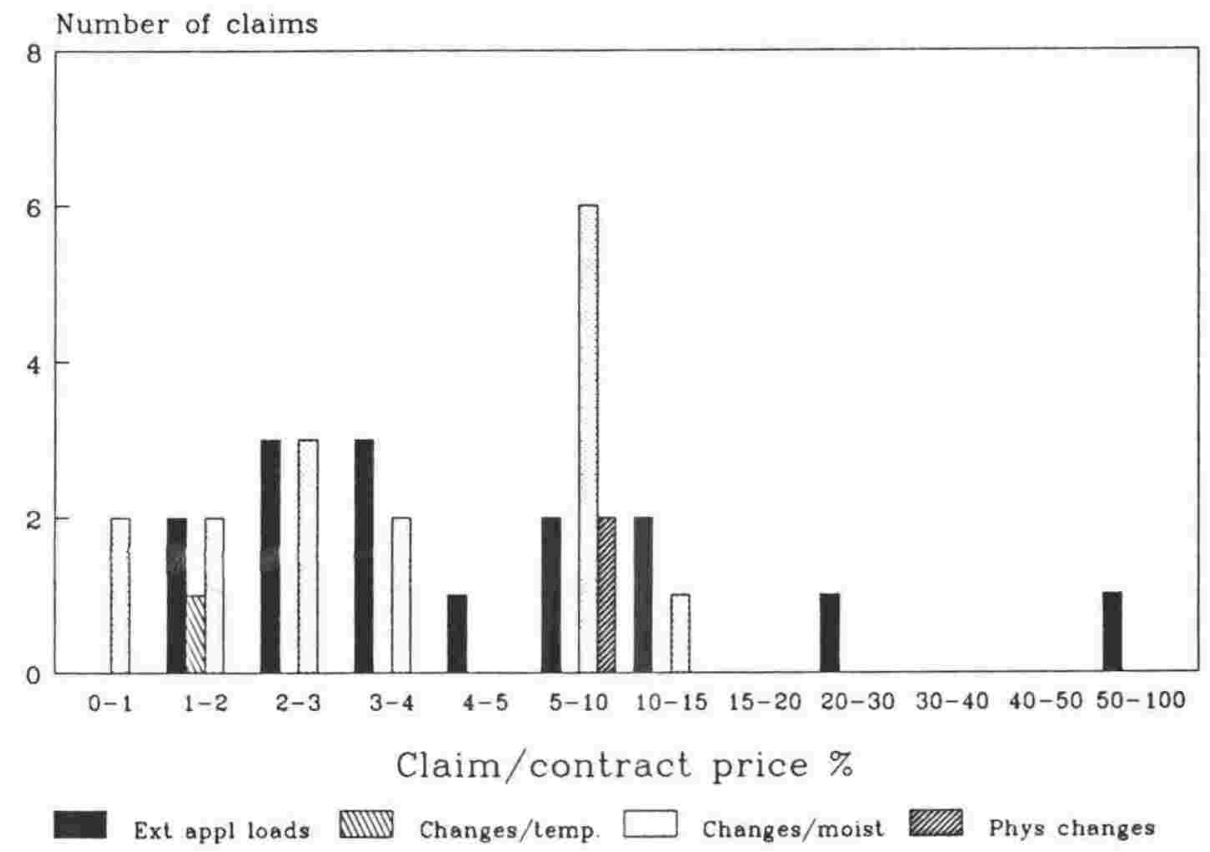

Fig 6.13 Claims as \% of contract price for BPGC claims caused by movement, showing sources. 
Analysis of cause 'chemical/biological' makes clear the relatively expensive impact of corrosion and/or decay as a source of claims used by chemical/biological change, while the high incidence of solar radiation across the $1-10 \%$ band indicates the pervasive influence of solar radiation in the cause chemical/biological change. Incompatible substances, on the other hand, appear to be involved in the lower cost end of the failure cost spectrum. (See Fig 6.14)

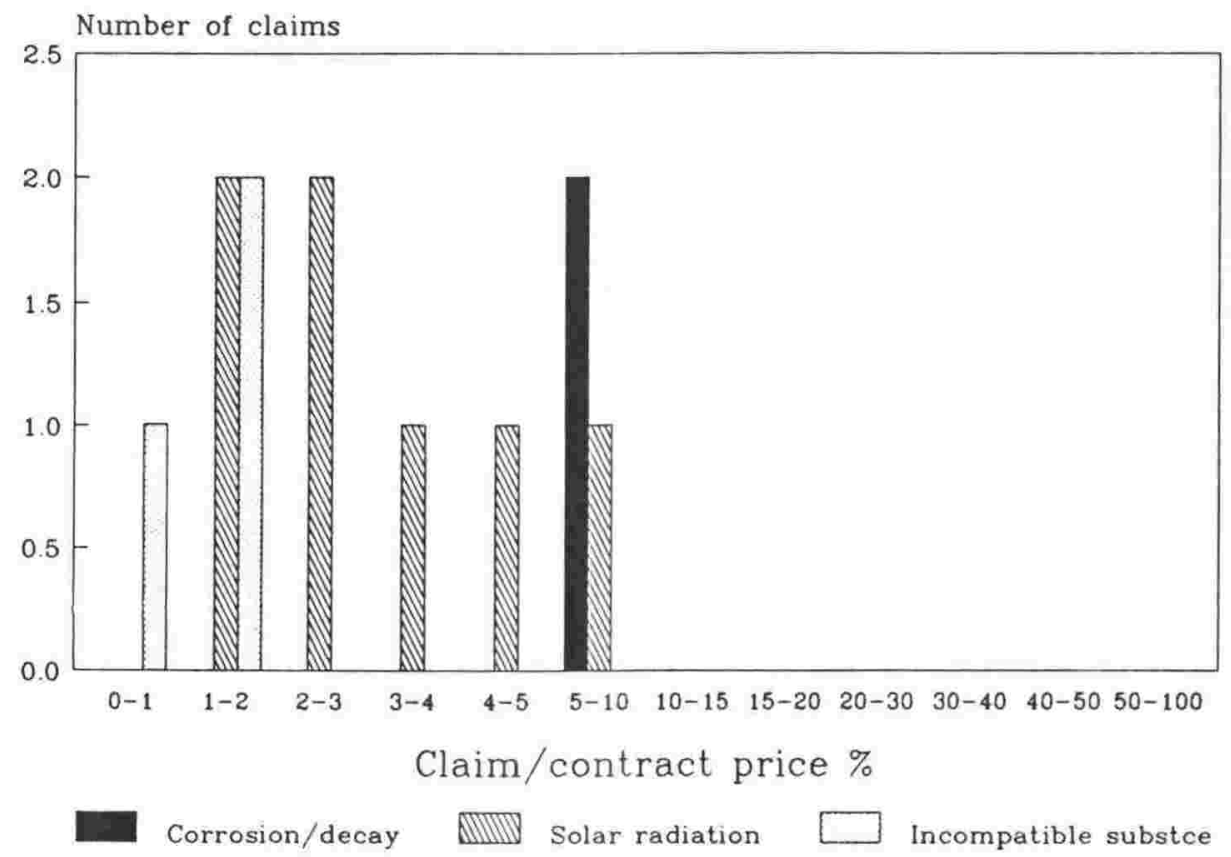

Fig 6.14 Claim as \% of contract price for BPGC claims caused by chemical/biological change, showing sources. 
The cause 'dampness', wheri analysed by source, is found to arise predominantly from rain, with the water supply system as runner-up both in number of claims affected and in the spread of influence across the cost spectrum. Given that rain is a well-known phenomenon and that one of the primary purposes of a dwelling is to keep the occupants and their belongings protected from the rain, the pattern of contribution rain makes to the most common cause of building failure (dampness) is noteworthy.

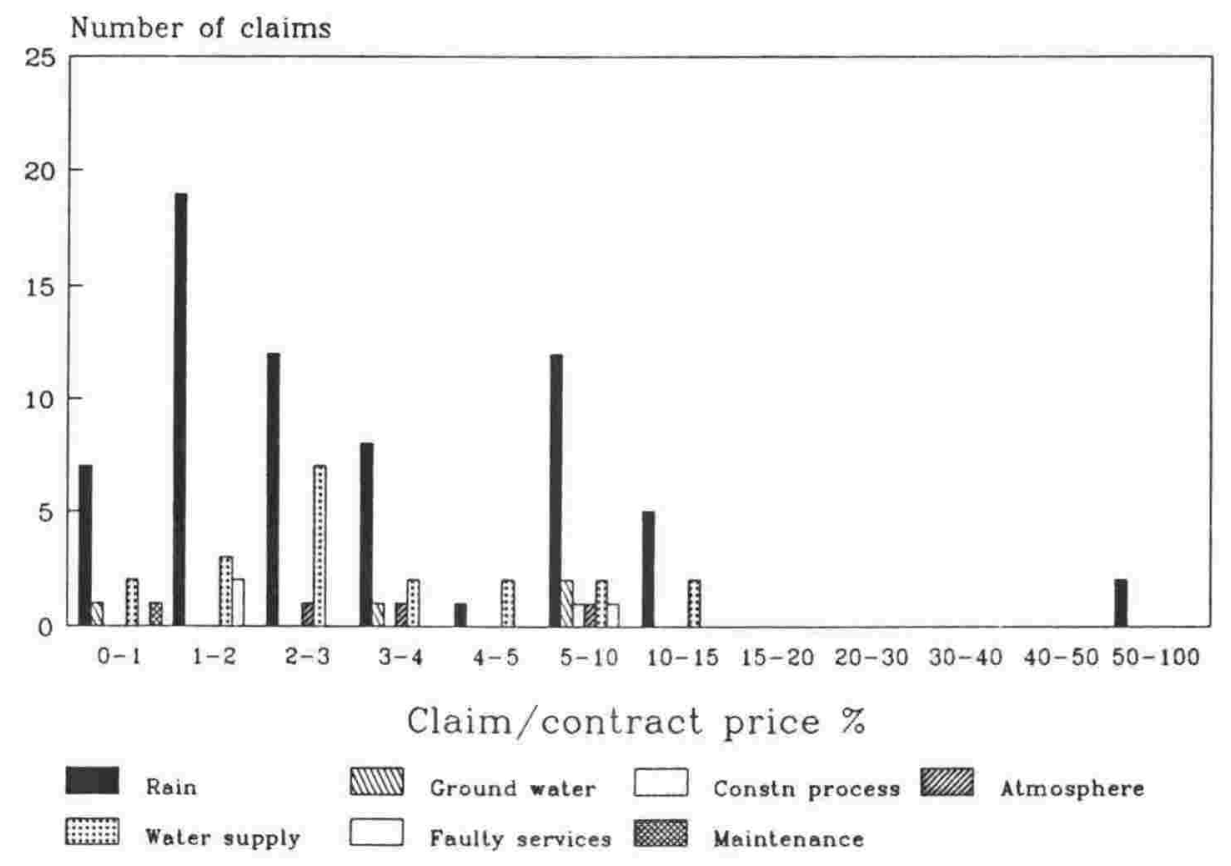

Fig 6.15 Claim as \% of contract price for BPGC claims caused by dampness, showing sources.

\subsubsection{The cost of claims in dollar terms}

When the cost of building failure claims is measured simply in dollar value as at the date of the claim it may be argued that, because of inflation, a more recent claim will appear to cost more than the same claim made a few years earlier. 
Given that inflation may be increasing the value of later claims as compared with earlier ones, it is interesting to look at the claim sums distribution for all building failure claims made to NZACS and BPGC over several years. As Fig 6.16 shows the dollar value of most of the claims is less than $\$ 1500$ for BPGC claims while the NZACS claims have a tendency to be a great deal more expensive.

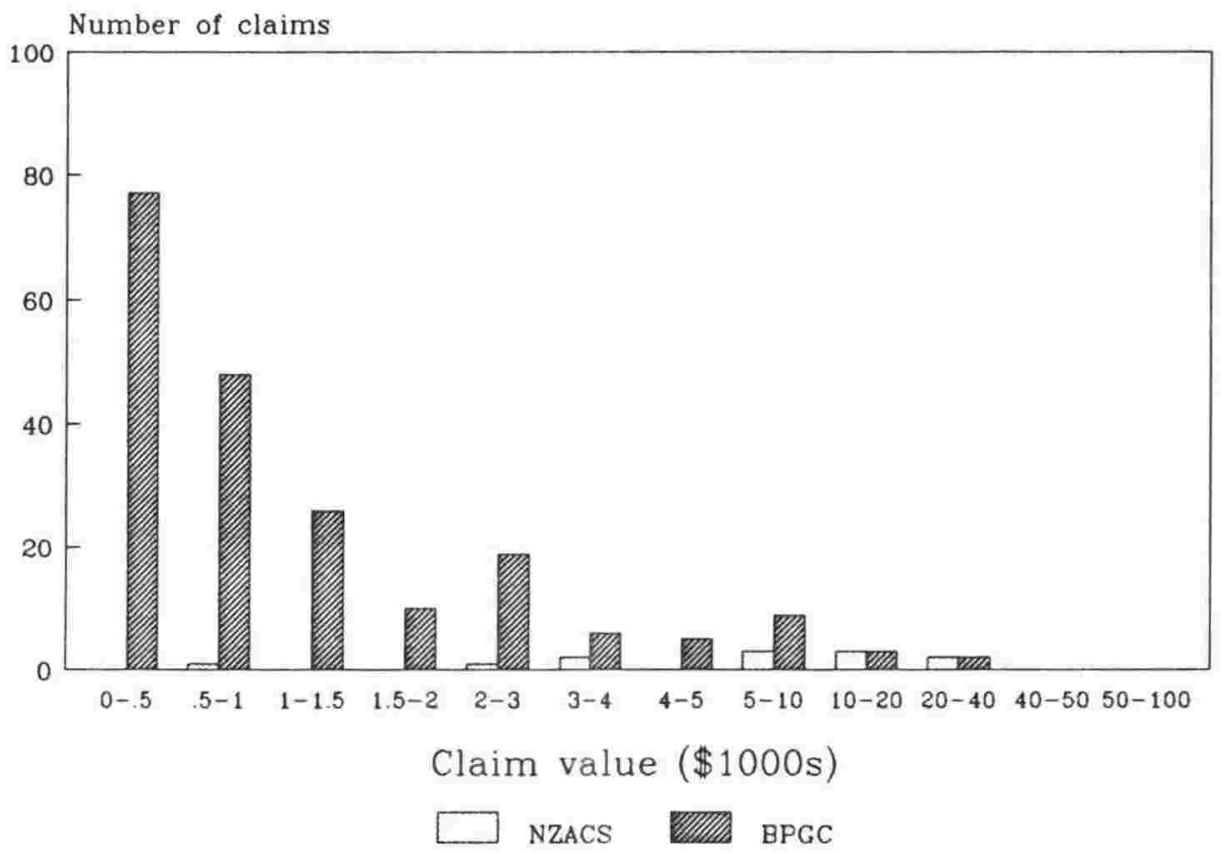

Fig 6.16 Claim sums ( $\$ 1000$ s) for NZACS and BPGC claims. 
When the BPGC claim sums are analysed by 'cause' the trend for most claims to cost less than $\$ 1500$ is just as marked. As Fig 6.17 shows, the cause 'dampness' is predominant but only a few dampness-caused claims cost more than $\$ 4000$ to fix.

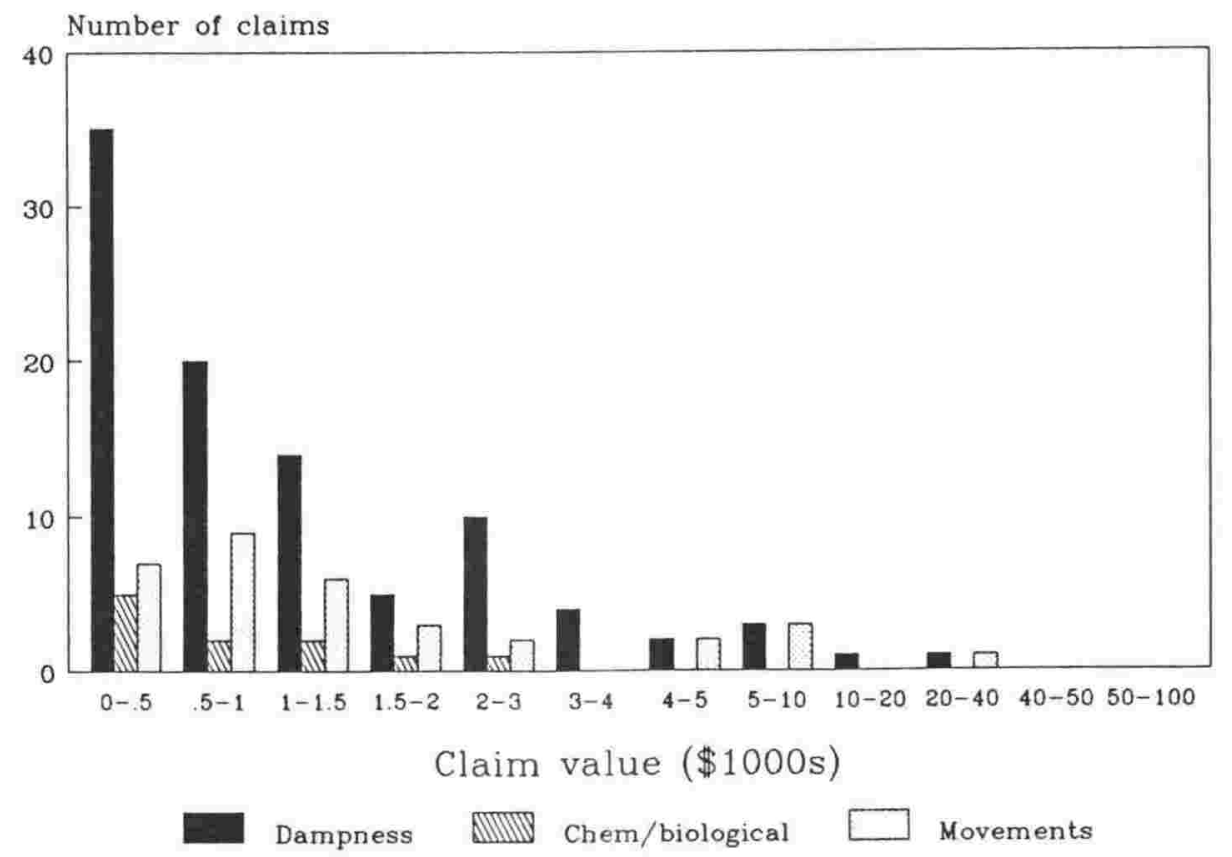

Fig 6.17 Claim sums ( $\$ 1000$ s) for BPGC claims by 'natural causes' 
The impact of human error on the dollar cost of claims is shown in Fig 6.18 in which claim sums for claims caused by natural causes on the one hand, and by human error alone on the other, are illustrated for all BPGC claims. The similarity in the pattern is clear.

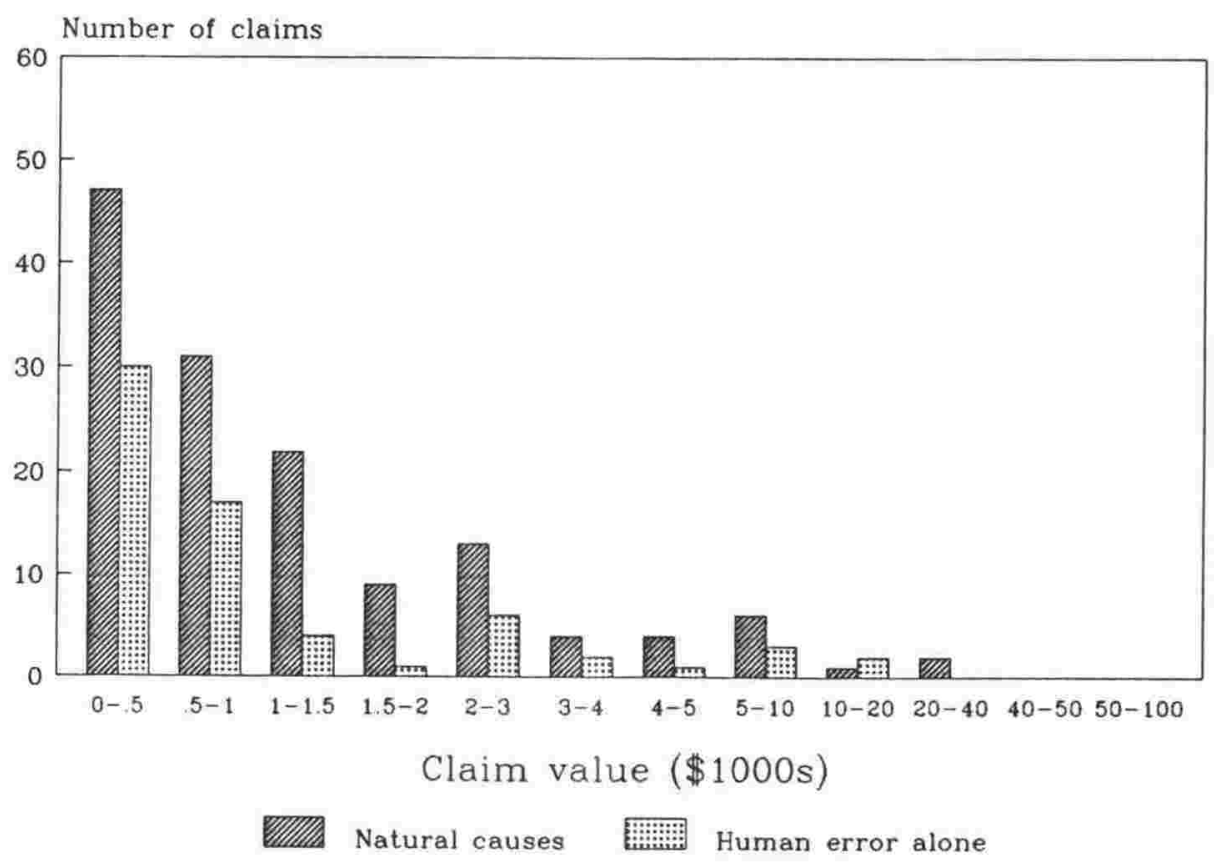

Fig 6.18 Claim sums ( $\$ 1000$ s) for BPGC claims by 'natural causes' and human error alone. 
The effect of inflation on the cost of claims and on the spread of those costs is indicated in Fig 6.19 in which the distribution of claim sums for each of 3 two year intervals is shown. It is apparent that over the six year period there is no obvious overall tendency for more claims to occur in increasingly higher cost brackets. (ie for a larger proportion of claims to appear at the right of the graph.)

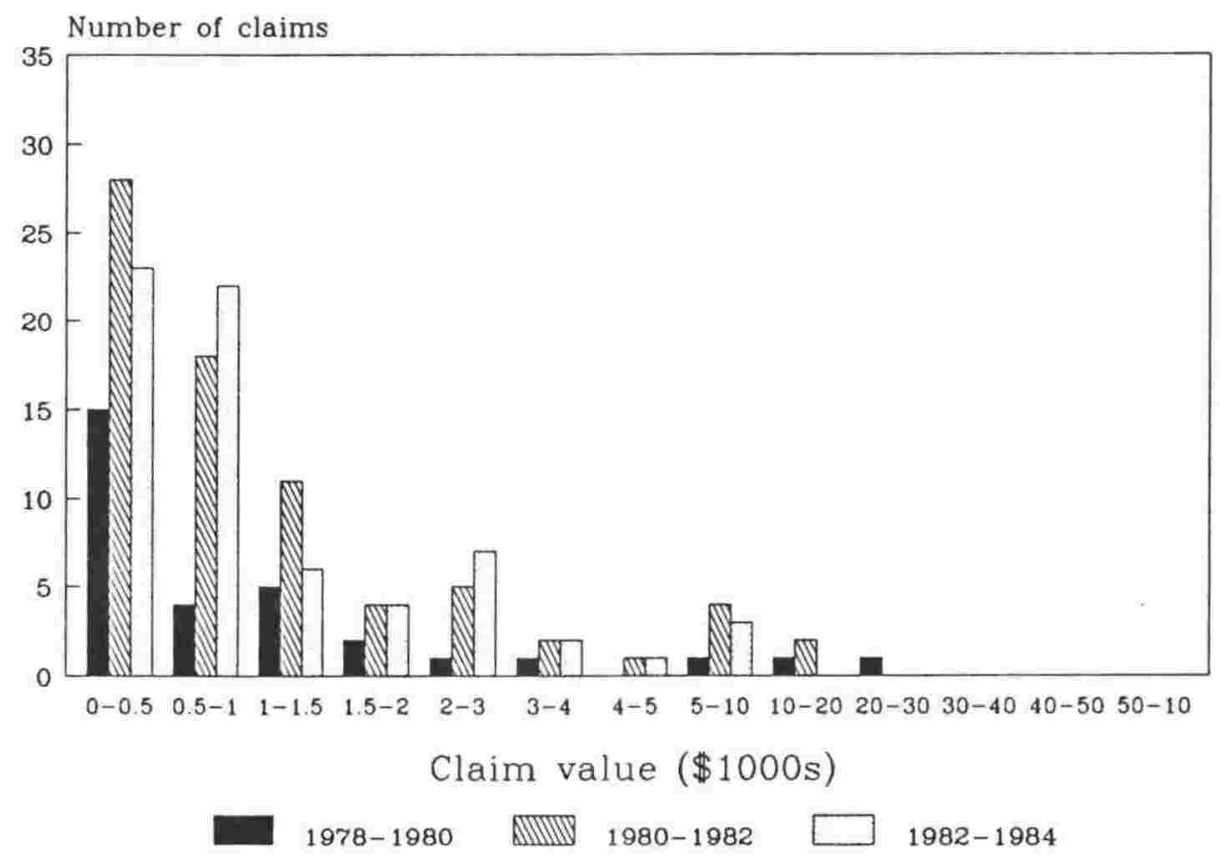

Fig 6.19 Claim sums ( $\$ 1000$ s) for all BPGC claims in period $1978 / 80,1980 / 82$ and 1982/84.

\subsubsection{The loss adjusters' data}

The loss-adjusters claim files did not provide information to the same extent of detail as the BPGC files. Information about the estimated cost of repairing the defect (as distinct from the consequential damage), the date of the dwelling construction, the contract price or the time elapsed between the completion of the building and the claim was not stated. What the claim files do provide, en masse, is a sample of the relative number of claims 
arising from water and fire in dwellings and made by house-owners or occupiers who were appropriately insured. The data provides evidence that building failures caused by dampness not only dominate the claims pattern in the first six years of a dwelling's life but continue to figure prominently in the claims pattern in dwellings of all ages. It also provides evidence that while building failure claims may contribute to the frequently publicised risk of fire in dwellings they also contribute to the far more common water damage risk.

\subsubsection{The incidence of building failures in dwellings}

The data source which best provides some basis for estimating the incidence of building failure in New Zealand dwellings is the BPGC.

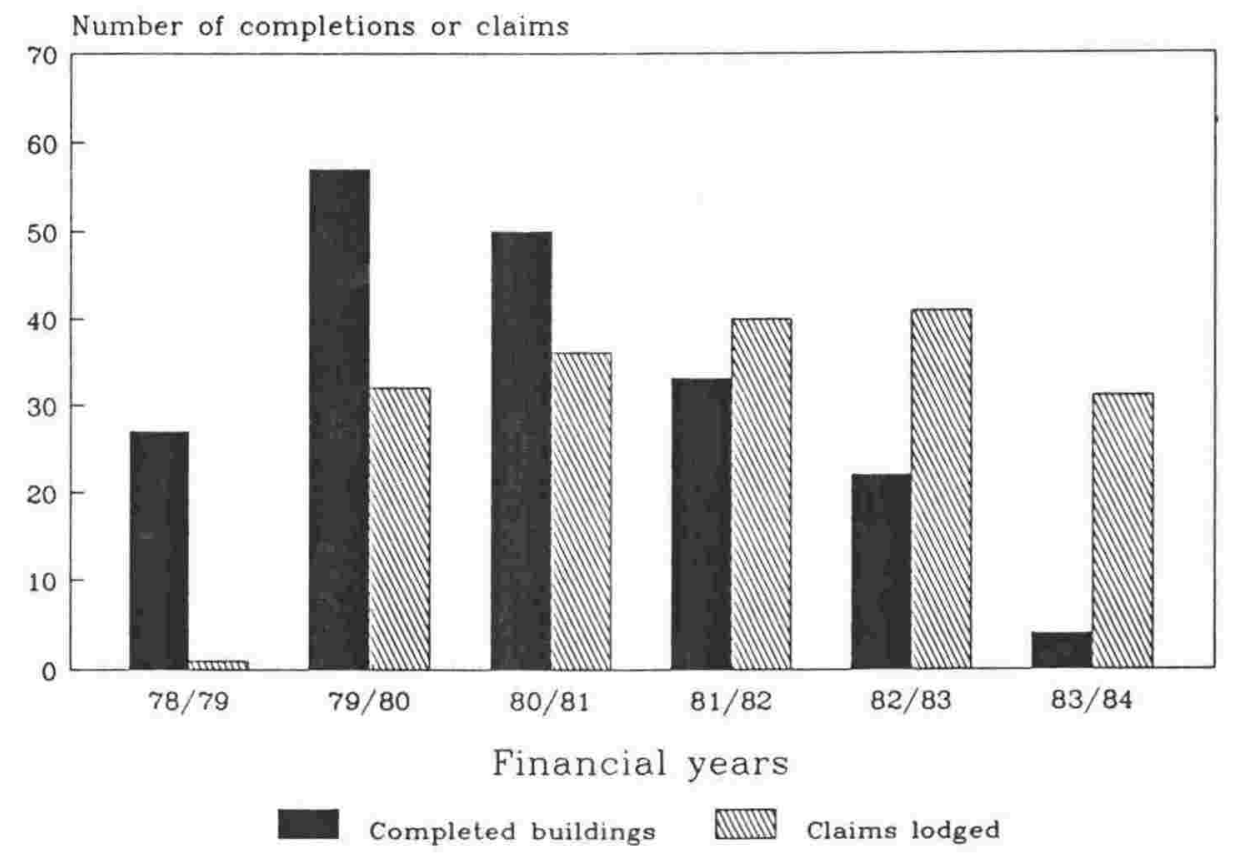

Fig 6.20 Dwelling annual completions and annual BPGC claims.

Fig 6.18 shows the number of 'failure' dwellings completed and the number of building failure claims lodged within each financial year from 1st April 
1978 to 31 March 1984. (A 'failure' dwelling is one which became the subject of a claim in the period from 1st April 1978 until 31 December 1984, being the period for which the claim files were available for examination for this study.) The graph demonstrates yet again that for a given sample of claims (in this case claims in the period specified) the majority of claims are lodged within the first 2 years after completion of the dwelling (see Fig 6.1) reflected in the larger number of 'failure' dwelling completions at the start of the period as compared with the end. The number of claims lodged each year is naturally affected directly by the number of completions in the preceding years.

The following table sets out the number of new house permits issued in New Zealand each year, the number of BPGC guarantees issued, and the number of building failure claims lodged in those same years, and accumulative.

\begin{tabular}{|l|c|c|c|c|c|}
\cline { 2 - 6 } \multicolumn{1}{c|}{} & 1981 & 1982 & 1983 & 1984 & TOTAL \\
\hline New Zealand New House Permits No's & 14442 & 19006 & 15999 & 20266 & 69713 \\
\hline BPGC Guarantees issued & 4015 & 5592 & 2479 & 3546 & 13632 \\
\hline BPGC market share in each year & $27.8 \%$ & $18.9 \%$ & $15.5 \%$ & $17.4 \%$ & \\
\hline Annual claims lodged with BPGC & 36 & 40 & 41 & 31 & 148 \\
\hline Cumulative claims lodged with BPGC & 69 & 109 & 150 & 181 & \\
\hline
\end{tabular}

The years 1979 and 1980 are excluded from all but the accumulated claims on the grounds that the first two years of operation of the BPGC would be atypical because of the effects of launch publicity in the first year (and the obviously small claim numbers as shown in Fig 6.20) and the observed pattern of most claims being lodged in the first two years after completion. Thus 1981 is arguably the first year which may be free of any distortions arising from the introduction of the BPGC scheme.

Considering the years 1981 to 1984 inclusive the following may be calculated from the Table above: 
Total New Zealand permits issued

Total BPGC Guarantees issued

BPGC market share
$=69713$

$=13632$

$=\frac{13632}{69713} \times \frac{100}{1}=19 \%$

Total Failure claims lodged

with BPGC

$=148$

If it is assumed, as observed, that the bulk of claims are lodged within 2 years of completion of a dwelling, and that by far the majority, say conservatively $70 \%$, are lodged in the first year, then a rough indication of the number of dwellings, guaranteed by BPGC, which become building failure claims

$$
\begin{aligned}
& =\frac{148}{13632} \times \frac{100}{1} \\
& =1.09 \%
\end{aligned}
$$

Since, as has been argued elsewhere, the BPGC scheme is open to all comers this low rate of failure could be extrapolated to apply to the national total of new houses for the four-year period (69713), whether BPGC guaranteed or not. In that case the expected number of building failure claims, of a severity similar to those which BPGC attracts, would be

$$
\begin{aligned}
& 69713 \times 1.09 \% \\
= & 759 \quad \text { nationally }
\end{aligned}
$$

\subsection{SUMMARY}

This chapter began by commenting on the varying usefulness of data obtained from the three sources presented in Chapter 5, having regard to the business objectives of each source and the method and detail of the recording process used by each. 
The pattern of claims, including such aspects as the timing, cost and causes of claims was then presented graphically. An estimation of the annual number of building failures in New Zealand was made. From the syntheses of claims patterns it is possible to draw conclusions which are discussed in Chapter 8.

Apart from the conclusions which may be drawn from the data considered in this chapter there is also the tantalising glimpse it gives of the potential value of aggregated building failure data, if only such data could be located.

In the next chapter are considered the processes and procedures by which the method used to identify and classify building failures in the sample of dwellings so far discussed, could be applied to buildings in general. Also examined are ways in which various interest groups in the industry (architects, insurers, contractors etc) could contribute to and benefit from the use of the method. 


\section{CHAPTER 7}

\section{WIDER APPLICATIONS}

Earlier chapters have explained how building failures might be defined and how, once defined, they might be classified according to their cause or causes. In Chapter 5 the data obtained from the only sources available in New Zealand were reported, while in Chapter 6 the few patterns or trends discernible in the data were presented. The limitations of the amount of data and of the data sources themselves strongly suggest the need to examine ways of generating larger and purposefully designed databases.

In this chapter the processes and procedures by which existing industry organisations might contribute to a nation-wide pool of building failure data are suggested, as are the benefits which those industries might expect to gain in return. Possible repositories for databases are suggested.

Other important issues such as confidentiality, ownership of the data, the method of storage, future uses of the database, and the variable standard of diagnoses in the failure reports are traversed.

Finally the requirement for building diagnosticians is considered with suggestions made as to what educational and training background is appropriate for such people, and what personal qualities they need to work effectively. 
The ideal data source was first described in 5.1.1 as a standard against which the existing available data sources could be compared. The criteria for the ideal data source for future use are no different. They may be listed as follows:

1. A building failure report destined for entry into a failures database must be as accurate and objective as possible. Generally this precludes reports written by, for example, the constructors of the failed buildings who, while well qualified to be accurate reporters, might have their objectivity affected by legal or economic considerations. Similarly, reports written by lay people without experience of building technology are precluded on the grounds that the accuracy of the information must be suspect. (In Chapter 3 the necessity for both the user and the 'objective expert evaluator' to identify a failure was justified on the grounds that the interests of the user were thus fairly protected and objectivity and accuracy assured.).

2. A building failure report destined for entry into a failures database must be written in a format which meets the needs of researchers. The most reliable research results are likely to emanate from the most reliable data. The more researchers have to interpret from obscure reports the less reliable the extracted data becomes, despite the expertise and objective intent of the interpreter. As a simple illustration, a report attributing water entry to 'a faulty flashing' leaves the way open for the interpreter of the report to suppose that the flashing was either poorly sized, or poorly fixed, or poorly shaped, or decayed, or a combination of all these possibilities. 
A suggested format for a building failure report is appended (See Appendix B).

Some potential sources of reliable failures data, the processes and procedures each would need to adopt, and the incidental benefits each might gain are discussed in the following sections.

The building industry in New Zealand, as in many other economies, contains a mixture of large development and construction companies, a much greater number of smaller companies whose number and individual size varies according to the economic state of the country, a variety of professional consultants, and a continually changing host of materials suppliers and manufacturers. There is no central organisation to which all these participants in the industry could belong. Some building companies belong to the New Zealand Master Builders Federation and some do not. There is no licensing or registration of builders to encourage membership of a national body. The professionals may belong to Institutes of Valuers, Architects, Building, Professional Engineers, or Quantity Surveyors, while the manufacturers and suppliers may belong to the Manufacturers Federation or the Plastics Institute, for example.

Outside the universities, research into building is largely confined to the Building Research Association of New Zealand (BRANZ), an organisation funded partly from a levy on building consent fees paid to Territorial Local Authorities. 
Enquiries made in the course of this research soon revealed that confidentiality is important to those engaged in the building industry. Information about building failures simply could not be obtained from industry sources other than BRANZ, despite guarantees of confidentiality, undertakings to render all data unidentifiable, and other precautions. The building industry is a very competitive one which explains, to some extent at least, its preoccupation with confidentiality.

\section{2 .2}

\section{Repository for failure reports}

The evident trust which the industry has in BRANZ, manifested in a willingness to allow BRANZ Technical Advisors to advise on problems on building sites and in the supply to BRANZ of new products for testing and appraisal suggests that BRANZ could be the best repository for building failure claim reports. BRANZ is demonstrably neutral, as befits a research institution, and could analyse the data to identify patterns and trends and report these in its publications.

Another possibility is that one or more of the Schools of Engineering or Architecture could separately, or in collaboration with BRANZ, maintain the database. The universities share with BRANZ the capacity to provide the necessary analysis, confidentiality of data, and objectivity in analysis.

\subsubsection{Failure reporting}

Ideally the building failure report would be written by someone unconnected with the contract in which the failure occurred. This will be difficult for smaller firms in which everyone may be involved with all current contracts. Nonetheless, given the emphasis that the report places on cause rather than simply on blame, it should be possible to have the report completed by someone in the organisation who was not physically associated directly with the failure or implicated in its cause. 
In every case the failure must be identified as such by both an objective expert evaluator and by someone who can reasonably be said to be representing the would-be owner's viewpoint. This ensures that technical failures which do not in themselves amount to failure in the eyes of a lay person are not added, incorrectly, to the database. (For example an unexpectedly uneven surface in a floor system using pre-cast concrete planks, which is readily repaired by the contractor when a topping is poured, should not be reported as a building failure. Similarly, blemishes which might offend a particularly fastidious layperson, but which are well within the range of tolerance normally achieved in construction, should not be reported.)

\subsubsection{Benefits}

The main benefit to the industry would be the collection of some factual data where none exists now. Supplied with reliable information about the weaknesses in current building design and practice the industry or its various sector groups would be able to:

1. concentrate training, supervisory and educational resources to overcome proven weaknesses

2. debate the value of professional and trade practices

3. argue to support regulatory controls which have a proven need and to oppose those that have not

4. measure reductions or increases in the incidence of buildings failures, from all causes, from year to year.

At present none of these benefits are available. The present position is little changed from that which applied in 1980 (Tippett, 1980) when a new requirement, impossible to meet, could be added to an existing 
mandatory code without the production of any evidence that it was necessary. That this is still possible is because there exists no evidence to produce.

\section{INSURANCE INDUSTRY}

\subsection{1}

\section{Nature of the industry}

The insurance industry is quite different from the building industry in several respects. One of these is the extent to which the participants in the industry agree to belong to one national organisation, the New Zealand Insurance Council, which represents industry interests at the highest level. Another is the extent to which the individual insurance companies compete with each other for new business while frowning upon unethical attempts to persuade clients to cancel existing insurance with one company in order to place their business with another.

Most importantly, the insurance industry differs by having a longestablished practice of independent investigation of claims, a practice not common in the building industry. Any insurer providing cover for the owners of buildings is inevitably going to become involved in investigation of building failures and their consequences.

\subsubsection{Repository for failure reports}

The New Zealand Insurance Council seems to be the most logical repository for building failure reports supplied to insurers. If the reports received from insurers are in the same format or contain the same information as those which, it is proposed, the building industry should produce, then researchers from either industry or from academia could aggregate the data from both sources with possible 
improvement in the reliability of the findings drawn from that data. It is theoretically possible that the insurance industry would be prepared, with suitable assurances of confidentiality, to supply failure reports directly to BRANZ or a university research unit.

\subsubsection{Failure reporting}

Loss-adjusters are already acting as investigators and reporters for insurance companies in many claims involving damage to buildings arising from building failure. As explained in Chapter 5 the lossadjusters are employed to act impartially between the interest of the property owner and the insurer. Frequently their level of expertise is such that they do indeed meet the ideal of the objective expert evaluator familiar with the usual standards of the building industry. The building failure reports prepared by such adjusters do describe building failures as recognised by the building user (the insurance claimant) and the objective expert evaluator (the loss-adjuster).

\subsubsection{Benefits}

The benefits to the insurance industry arising from the systematic reporting of building failure claims would include:

1. the ability to detect failure trends in new or existing building materials, components, and construction techniques, and hence

2. the ability to tailor premium rates to take account of the failure record of different construction, materials and component types.

At present, according to repeated enquiries made to the New Zealand Insurance Council, no aggregated data about types of claims is 
maintained by any insurer in the country. Insurance companies know how much they pay out in claims for fire, motor-vehicle, marine, and other policy types, but none apparently know how much claims resulting from water leaks (building failures) cost each year as compared with those resulting from accidents such as burst washing machine hoses or a sink overflow. The loss-adjusters data in Chapter 5 is the only national insurance data available showing some breakdown of the types of water and fire claims which arise. It was obtained not from an insurance industry database but by manual extraction from archived files. (At one location the 'archive' was a leaky garage full of limp cardboard beer cartons packed with files.)

\subsection{RESEARCH ISSUES}

For building failure reports to be most useful they need to be completely frank. For this to happen the reporters must be confident that, provided they have acted in good faith and to the best of their abilities, they will suffer no legal consequences from having written their reports. The best way to guarantee that confidence is for each report to have all information identifying a particular building (ie the address of the building and the name of the owner) erased before being entered into a database. This is not to say that the contributing organisation, be it an insurance company or a building company cannot retain all the information it requires for its own needs, but the aggregated database which others will use for research purposes must preserve confidentiality. 
It seems reasonable to restrict access to a database to those organisations which have contributed to it and to researchers who have the consent of all the parties. Thus if a national database of insurance and industry failure reports was established, all contributing organisations would expect to be granted access to the data, and, more usefully in many cases, the results of analysis of the data carried out by researchers.

\subsubsection{Method of data storage}

Ultimately, with the falling cost of computer storage it should become both practicable and economical to store electronically all the words, numbers, and images on a building failure report form. Until then a compromise method of storage would be to use a form-based database with fields which can be encoded to allow the data to be manipulated by researchers and analysis. The 'hard-copy' failure report forms, which would probably contain explanatory diagrams or sketches and extra words, could be filed under a unique number allocated to its entry in the database.

The number of fields in the database is a matter for conjecture. If reporting of building failures to a database is to be a voluntary task it is unlikely that the reporter will want to supply exhaustive details even on a well-designed multiple-choice format report form. The information sought in the proposed Report Form (Appendix B) is sufficient, it is suggested, to enable a researcher to use the database to select most of the useful combinations of input data. 
Further developments, once a reliable system of reporting is established, might include:

1. one or more experienced people bringing to bear their collective knowledge and experience in some systematic and objective way. At the moment the body of knowledge brought to bear is unlikely to be comparable with that on which lawyers and medical practitioners can call from a long line of precedents, (Duffy, 1991), but recent research suggests that establishment of a failures database is feasible, even when there is little data to form the nucleus of that database. (Davies and Hegvold, 1991)

2. some form of expert system which is kept up to date with the latest materials, techniques, and technologies and contains a detailed record of all the significant factors involved in a wide range of precedent failures. Reported work in Canada (Cornick, Ruberg, and James, 1989) summarises the difficulties which have dogged the numerous prototype expert systems which have been developed for the construction industry. Chief amongst these difficulties has been the highly 'personal' nature of the system which has meant that only the authors of the system have been able to add to the rule base. A new different approach being taken at the Institute of Research in Construction under the auspices of the National Research Council in Canada uses what is termed a rule authoring assistant', a system which allows many authors to co-operate in the building of a rule base, at the expense of some constraint on the form of reporting building faults. Clearly there is a need to treat 'expert systems' with caution until they are proven in building industry applications. 
3. some form of symptom list which tends to combine the skills of the human diagnostician in (1) with the logic and virtually infinite memory of the computer in (2),

\subsubsection{Standard of diagnosis}

The standard of diagnosis of building failures will depend heavily on the competence of the diagnosticians involved. That competence will vary because there is no formal standard of competence or qualification required for people who carry out building failure diagnosis. In the course of examining several thousands of insurance claims in the search for building failure cases (see 5.4.2) it became clear that some loss-adjusters' knowledge of buildings is quite thorough, while in others it was sketchy. It is reasonable to assume that in the absence of formal training in building science and building technology most loss-adjusters learn from experience.

In the case of the BPGC failure claims, the investigators appointed by the Corporation were builders or Clerks of Works employed by the Housing Corporation of New Zealand, and consequently well qualified to diagnose failures in dwellings.

One of the benefits of creating a large database of building failures is that generally the patterns and trends which emerge from analysis of the data will be less harmfully affected by the inclusion of a few faulty diagnoses than would be the case when the database is small. Where the faulty diagnosis occurs frequently in one type of relatively rare building failure the size of the database will provide no such smoothing effect on the data, and mistaken conclusions may start to be drawn. 
The quality of the building failure data available for inclusion in a database is clearly dependent on the skill of the diagnostician who reports on the failure. A barrier to progress in encouraging good diagnosticians is the lack of recognition of diagnosis as a skill in its own right. After all, the majority of builders and sub-contractors are trained to build using new material. Some may become involved with repair, demolition, and rebuilding but few if any are likely to obtain much experience in diagnosis of faults in buildings and none will have received any formal training in diagnostic techniques. (It should be noted that these people's skills in making good the damage resulting from building failures are not being denigrated here, but the point that diagnosis and repair are different skills needs to be made).

As a consequence most diagnosis is not done by diagnosticians but by people who are untrained and therefore resort, quite reasonably, to the trial and error type of remedy where guess work (often wellinformed guesswork) is substituted for a methodical analysis of the evidence presented. Such an approach may be acceptable when fixing the failure is all that is desired, but it is hardly the best approach to diagnosis of the original cause of failure.

This lack of diagnostic skill within the industry is a threat to the accuracy of failure claim records, and to the validity of analysis of those records.

\subsubsection{Existing tradition of diagnosis}

There is little history or tradition of diagnostic work in the building industry, which has tended to see itself as existing for the purpose of 
constructing new work, sometimes after demolishing a building to clear the site. There are few diagnostic instruments in use. Even plumbers and electricians have few diagnostic techniques and fewer instruments. In many respects the building industry's diagnostic tools compare with those of a medical practitioner deprived of access to Xray, laboratory, or specialist referral facilities. This means that diagnosis has to be based on experience and is only as good as that experience. Skill in diagnosis then improves with greater experience, preferably experience of some diagnoses which have been proven to be correct.

Ideally diagnosis should be dependent upon the diagnostician having a good grounding in the theory of building as well as experience gained in practice. It is the theory which gives an understanding of why building processes are carried out in particular ways. Many builders in New Zealand have no formal theory background to their often well-developed practical skills and knowledge of how to build. This lack of a theoretical base to their building experience must at least retard the development of diagnostic skills in such builders.

If the shortage of diagnostic skills is not in itself a great enough obstacle to the development of a tradition of skilled investigation and accurate objective recording of building failures, there is the fear of dire legal consequences hanging over many diagnosticians as they try to attribute blame fairly, on the insistence of lawyers. There can be few influences more likely to damage the objectivity of a diagnostician than the knowledge that one or more parties affected by the building failure are more concerned with the attribution of blame than with the analysis of cause. In such circumstances the diagnostician must be an independent person free of any real or imagined loyalty to any party to the failure. (In Britain, recent successful appeals against convictions for acts of terrorism have focused attention on the frailty of scientific evidence when objectivity is diminished. (Price, 1991). 
The consequences of error by diagnosticians of building failures and by diagnosticians of pathological evidence may be different, but the importance of total objectivity is the same.)

\subsubsection{Future diagnosticians}

If building failure diagnosis is to become a valued activity in the building and insurance industries, then diagnosticians will have to become recognised for their qualities of technical expertise, objectivity, and discretion. The best diagnosticians will exhibit the lawyer's cautious phrase when speaking or writing, the building contractor's appreciation of what is practicable in given circumstances, the technical knowledge of architects and professional engineers, and the physician's ability to diagnose from visible or palpable evidence.

Not all building failures need such people, any more than someone with an ordinary headache needs a doctor. Some building failures require no diagnostic skills for their cause(s) to be readily identified. Others are difficult to diagnose and should signal the need to consult a specialist diagnostician. To do so makes good sense since the repair of the failure, and of its consequences, is a cost which most building owners would prefer to outlay with some certainty that the cause has been found and remedied.

The practice of building failure diagnosis is one in which architects, building scientists and professional engineers, competent in the skills described above, could engage. 
This chapter described ways in which the method of identification and classification of building failures, developed in earlier chapters, could be extended more widely into the building and insurance industries. In doing so it suggested who might carry out investigations of building failure, diagnose the failure, and report it to a database.

The content of a building failure report form was suggested, and suggestions made as to the repositories for the databases which could be established.

This chapter also considered research issues such as confidentiality, ownership of the data, and methods of storing and using the data.

Finally the chapter drew attention to the importance of competent diagnosticians, the reasons for the present lack of diagnostic skills, the qualities a good diagnostician will exhibit, and what categories of building professionals might engage in diagnosis in the future.

In Chapter 8 the methods of building evaluation, identification of building failure, and the classification of those failures, all of which were developed and described in earlier chapters, are summarised in a statement of the methodology used in the research. The summary is followed by discussion of conclusions which may be drawn from the application of the methodology to the sample of failures considered in Chapter 5 and Chapter 6 and from the possibilities proposed in this chapter. 
CORNICK, S. M., RUBERG, K., and JAMES, K.A. Constructing a Diagnostic Knowledge Base for Building Faults in Proceedings of CIB International Congress. Paris, June 1989. Theme III, Vol 1, pp 457-466

DAVIES, V.F. and HEGVOLD, L.W. Building Faults Database - A pilot study. Centre for Architecture and Planning Research, Curtin University of Technology, Perth, 1991.

DUFFY, F. What Price Commodity? Evaluating Buildings. Architects Journal, 6 February 1991. pp 45-47.

PRICE, C. Forensic Science Needs Open Minds. New Scientist, 20 July 1991, p4. 


\section{CHAPTER 8}

\section{SUMMARY AND CONCLUSIONS}

8.0

INTRODUCTION

This chapter begins with a summary of the methodology used in the research, and explains the methods used to evaluate, identify, and classify building failures. It then describes how the methodology was tested.

The limitations of the findings are explained before the findings themselves are summarised. The findings are followed by the conclusions drawn from the research.

8.1 METHODOLOGY

8.1.1 Evaluation, identification, and classification combined

The methodology used in the research was a combination of a method of building evaluation, a method of identification of building failures, and a method of classification by cause.

8.1.2

Method of building evaluation

The modified evaluation technique is described in Chapter 2, where it is argued that both the users and producers of buildings should be involved in their evaluation if the evaluation is to discover and comment on all those aspects of the buildings' performance which affect the lives of those concerned with it. To some extent this 
technique was modified to be appropriate to the sample of buildings in the study. The sample comprised dwellings. For example, in the case of dwellings it is argued that a 'most knowledgable person' could be used to adequately represent the producer, in the absence (as is usually unavoidable) of the builder. The objective, experienced and qualified investigator of claims of building failure, as used by such organisations as the Building Performance Guarantee Corporation to act impartially between the claimant and the insurer is proposed as such a 'most knowledgable person' in this context. A further modification was necessary to overcome the lack of access to the failure sites resulting from privacy and confidentiality considerations, or from the impracticability of visiting all the failure sites before the defects had been repaired. Instead of analysing and classifying the failures on site, the task had to be done by careful examination of the confidential written records held in the offices of the various data sources.

\subsubsection{Method of identification}

A definition of building failure based on the largely coincident perceptions of the expert producers and the generally lay users of buildings was developed in Chapter 3 . This definition is a practicable means of identifying building failures from the usual evidence available when a claim of failure is made.

\subsubsection{Method of classification}

Classifying building failures according to the natural causes involved posed few problems. The work of Addleson required only the slightest modification (to allow for insect attack) to enable it to be transplanted from the United Kingdom to New Zealand. The classification by natural causes, adapted from Addleson's original, works as well in New Zealand as it apparently does in the United Kingdom. It makes little provision for catastrophic events leading to building failure but as this study deliberately excluded the, mercifully, 
rare cases of catastrophe in buildings, the absence of that provision is of no concern. There appears to be no reason why this classification should not be applied in other studies of this type.

The element of human error was another matter. While many commentators have written about various human tendencies to err, no single list of commonly-agreed types of human error which might complement Addleson's 'natural causes' appears to have been proposed in the literature. The list eventually assembled and used in this report is one of many different lists which might legitimately be drawn out of the reports of various commentators. The content of the list is important, but it is the use of a list as a classification tool that is paramount in the methodology of the research.

The test of the methodology proposed in this report was its application to such building failure data as could be obtained. It is evident from findings reported in Chapters 5 and 6 that the methodology does produce useful results which are not inconsistent with the experience of those involved with buildings from day to day.

In particular the division between the forces of nature and the errors people make appears to provide an objective way of acknowledging, if not apportioning, the contribution of each. This objectivity is enhanced by the use of failure records which contain both the building users' complaints of perceived shortfalls in performance and the reports of the 'most' knowledgable persons' representing the producers' unbiased assessment.

There also appears to be no difficulty in applying the methodology to all the building failure cases so far encountered. 
The classification of human error derived from the most frequently cited errors reported in the literature draws attention to the range of error types and to the unhelpfulness of the idea of 'negligence' when the aim of research is to find causes rather than to apportion blame for them. Use of the classification as part of the methodology focuses attention on the nature of the mistake rather than on the legal liability of its maker.

\subsection{LIMITATIONS OF THE FINDINGS}

\subsubsection{Limitations of the data}

If ever evidence was needed to illustrate how little is known about building failures the author's search for objectively recorded data would provide that evidence. A willingness to consider building failure data related to any class of buildings in New Zealand made no appreciable difference to the difficulty found in unearthing reliable data. That difficulty was, in fact, a result of the surprising failure of those organisations ostensibly concerned with maintaining and promoting building quality to record, in some systematic way, information about the building failures they have observed.

More disturbing than surprising, given the extensive system of Acts. regulations, bylaws, codes of practice, and other legal instruments promulgated to control the activities of the building industry, is the lack of easily accessible data to show whether the whole building regulatory system is working. There is obviously no evidence yet that the Building Act 1991 will be more relevant than previous legislation to the control or reduction of the incidence of building failure.

It is certain that limited information about the incidence of building failures of various types in New Zealand caused by various agencies, can be obtained from existing records. Those records were never 
designed and have never previously been used as a source of information about building failures.

It should be noted that the information unearthed for this research did not come from records in which the failures were classified by natural cause or human error (or both) but was based on the author's interpretation of whatever apparently factual statements had been written into the record. None of the records had been kept by organisations which envisaged that they would be used for the purpose to which the author put them. From this it must be concluded that the results and findings in this report must be taken as indicative rather than absolute. The fact that the interpretation of the data was performed by the same person in each case should be some guarantee of consistency. The potential value of reliable results and findings are the justification for arguing that the systematic approach to classifying building failures, described and tested in this report should be used as often as possible by all those involved in the investigation of perceived building failures.

\section{Limitations of the data sources}

Various promising information sources were investigated during the research, but in the end this report is based on an analysis of one source of building failure records, available in New Zealand. Each of the three promising sources has its limitations:

Building Performance Guarantee Corporation (BPGC) - recorded * objective information with a view to accepting or rejecting a claim for building defect or non-completion, but is more concerned with how the defect can be fixed, by whom, and at what cost, than in analysis of cause. It deals with buildings up to 6 years old. 
New Zealand Architects Cooperative Society (NZACS) - an organisation providing professional indemnity insurance to architects. The number of claims records found in that source was much smaller than from other sources. This reflects the small proportion of dwellings designed by architects rather than any inherent lower incidence of building failures in those dwellings.

Insurance Loss-Adjusters - record objective information as to what happened to cause a claim to arise, but are not interested in the cause of building failure. They deal with buildings of all ages.

\subsection{FINDINGS ABOUT RISK OF FAILURES}

\subsubsection{Low incidence of failures}

As the previous chapter reports the incidence of reported and confirmed building failures in dwellings is low - about $1 \%$ of new houses appear to exhibit a building failure in the first 6 years after completion. Common knowledge suggests that there are often multiple defects in a new dwelling when first occupied but it is evident from the research that all but a few of these are remedied, by the builder or a sub-contractor, sufficiently quickly and efficiently to avoid the need for a formal building failure claim. The incidence of failures in other categories of buildings, or in buildings in general, may be quite different from the incidence in dwellings.

\subsubsection{Inevitability of some failures}

That there should be teething troubles with a new building is not surprising. The entire process of procuring a new building, from choice of site through design, selection of materials and all the myriad activities which must occur before the building is complete, entails risk 
(Starbuck and Milliken, 1988). The risk is present because in one or more ways every such process of procurement is unique. No new building has a precedent identical in every respect. Change one aspect of the procurement process and the unforeseen can, and probably will, happen. The Auckland builder (see 4.3.5) who constructed building after building on ground-supported concrete floor slabs with no waterproof barrier between the soil and the slab is a case in point. His luck held, the sites were all well-drained, the slabs were made of dense concrete and did not crack and no damp floors developed to alert him to the risk he had been running. Add to the need for luck the need to counter the 'forces of nature' and to avoid human error, and the risk becomes even more obvious.

\subsubsection{Management of risk}

Where there is risk the prudent turn to insurance against that risk. That is why fire insurance, earthquake, and contents insurance for buildings is so common. Few buildings burn down each year, (more are damaged) yet fire insurance of a building is almost universal. The risk is low but the consequences for the unlucky few owners or users are at least irritating and inconvenient and at worst disastrous. The same is true of building failure.

Forms of insurance against the risk of building failure in new dwellings are not expensive (generally well under $\$ 1000$ ) and in any event the 'one-off' cost can be included painlessly in the financial arrangements made to pay for the construction of the new building. It is therefore surprising that such a small proportion of all new house-construction is so insured (see 6.2.5), especially when it is considered that new house-owners are often rendered financially vulnerable by heavy borrowing to purchase the house and to equip it.

Until researchers gain access to information about building failures in commercial buildings, and can carry out the same sort of analysis that was applied to the sample of dwellings, it will not be possible to 
calculate the cost of insurance against building failures in those buildings on any other basis than guesswork. At the moment there appear to be no recorded data discoverable.

\subsubsection{Causes are proven}

The research clearly proves that the causes of building failures are varied and complex, frequently involving a mix of the effects of nature (which are referred to as 'natural forces') and of human error. Both are unpredictable in occurrence, intensity, and effect and obviously contribute to the extent of the element of risk always present when new buildings are being constructed.

\subsubsection{Learning from investigation of causes}

Attempting to analyse and hence to understand the causes of a building failure helps in the understanding of the many forms of building failure phenomena and adds to the precedent knowledge which can accumulate in the memory, if not the literature, of the building industry. The outcomes for the short-term (remedying the immediate fault), the medium term (improving the next building), and long-term (providing improved criteria for measurement of performance) were first mentioned in 2.4.1.

Adding each building failure episode to a database, complete with an analysis of how and why it happened, is a helpful constructive process that ensures that some good may come from the disappointment and cost of the failure itself. Quite apart from databases, which do not in themselves distribute new knowledge, the building industry could benefit from imitating the regular case-reporting that is a feature of the journals by which the legal and medical professions share new developments and experiences. 
Less constructive is the use of the lawyers' term 'negligence', an unhelpful and pejorative label to apply to human mistakes made in a risky activity like building, unless there is very strong evidence that the builder was careless or inattentive. It is easy in a relatively comfortable court room to attribute a lack of reasonable care and attention to a builder who, working in unpleasant conditions on a unique building on a unique site, makes a mistake in some aspect of his or her work. It is much harder, but more useful to posterity, to find out how the mistake was made.

If, as the research suggests, there is knowledge to be gained from the systematic identification, evaluation, classification, and recording of building failures, then the use of the term negligence is counterproductive. In fact the negligent use of the word "negligence" to describe the cause of building failures may well have the effect of

1. suppressing the truth by suggesting that the sole cause of a failure is a human failing, and/or

2. frustrating attempts to build up a local or national database by ensuring that cases are not reported, or are reported only in terms of legal issues and/or

3. impeding the establishment of a line of precedent knowledge on which fair arbitration, systematic diagnosis and even expert systems could depend.

\subsubsection{Drawbacks to legal procedures}

Failures are not necessarily the result of negligence. Reliance on legal action for negligence may have the effect of 
1. concentrating attention on the legal niceties of measuring human actions against some almost arbitrary yardstick of negligence,

2. diverting attention from the particular combination of human error and natural causes which initiated failure,

3. adding further cost (by reason of delay and legal expenses) to the task of making good the building,

4. and adding to the long list of legal precedents, none of which are likely to be continually in the mind of builders and their subcontractors as they perform their daily work.

\subsection{CONCLUSIONS}

\subsubsection{Dealing with the causes of failure}

The research has shown that the classification of building failures in dwellings according to the type of human error and or the 'forces(s) of nature' which have contributed to the failure, embraces all the factors which can cause building failures. Although the evaluated building sample consisted of dwellings there is no reason to limit this finding to dwellings only.

With this knowledge it is obviously possible to state confidently that building failures could be avoided by:

1. protecting buildings from the 'forces of nature' from the moment construction of buildings is commenced, and

2. perfecting human behaviour so that human errors are not made. 
These two objectives are likely to take some time to attain. Until then the building industry must conduct its affairs in ways which will minimise the impact of the known causes of building failure. The 'forces of nature', which are by definition virtually omnipotent in their effect on inanimate objects (such as buildings), yield only slowly to the advance of science and technology, but human error is easier to anticipate and to counteract in various ways. That is why Quality Assurance attracts greater interest in the commercial world than earthquake or meteorological predictions. Quality Assurance seeks to organise human processes in error-proof ways, while earthquake or meteorological predictions can, at best, forecast probabilities in uncontrollable systems.

This report does not pretend to be an authoritative treatise on methods of altering peoples' tendency to err, but it does argue that reduction of human error shows the most immediate promise for a reduction in the incidence of building failures.

The incidence of failure in larger buildings is unknown. It may be as low as for dwellings in New Zealand, but until research is encouraged by the providers and users of such buildings, the building industry must remain ignorant of the facts.

\subsubsection{Dealing with the risk of building failure}

There will always be a risk of building failure when a new building is constructed. This report shows that the risk of a particular dwelling developing a significant failure in the first six years after completion is low (about $1 \%$ ) even in a country with no licensing or registration of builders. The data used to show this low incidence of failure came from an insurance organisation which took no account of the qualification, experience, or previous record of a client's proposed builders before agreeing to indemnify the owner against building failure. 
That the risk of failure is low is no consolation to the unlucky few victims of building failure, for whom the shortfall in building performance may be expensive, stressful and disruptive. This risk should be properly recognised and managed by prospective new building providers and users and their advisers. The risk may be low, but is real, and insurance schemes are an obvious method of management.

\subsubsection{Evaluating 'at arm's length'}

The original investigation set out to test whether benefits might be gained by enfranchising building users in the technical evaluation of their own buildings. Commonly, evaluations of building failures have been conducted entirely by experts whose sage pronouncements take no account of the users' expectations of the building. In this research the bulk of the data used was extracted from a source (claim files) in which the users' indications of a shortfall in building performance were recorded along with the report of an independent technicallycompetent evaluator who represented the viewpoint of the ordinary builder. Thus the user was accorded the same consideration as the 'expert' when the existence of a building failure was confirmed and analysed.

The technique yielded useful and sensible results, despite the fact that the claim records had never been intended for the post-claim analysis to which they were subjected. It seems likely that the evaluation technique would produce more certain results if it could be carried out not 'at arm's length', but on the failure site, when the evaluation would benefit from all parties being able to see the evidence at first hand and to agree on what should be written into the building failure report. Identification of the cause of failure could be carried out on site, even while the failure persists, giving greater certainty of accuracy than is obtainable from the 'at arm's length' review of the written record of another observer. As with many other aspects of the identification, diagnosis and recording of building failures there is 
scope for much improvement in the practice of this new approach to identification building failures in search of truth rather than blame.

\subsection{REFERENCES}

STARBUCK W and MILLIKEN, F. Challenger : Fine-tuning the Odds until something breaks, Journal of Management Studies. Vol 25, July 1988. 


\section{BIBLIOGRAPHY}

ABBOTT, W.W. Quality costs in building, The Quantity Surveyor, June 1977, p1935.

Managing for Quality in Building, National Builder, September 1977, p 349.

ADDLESON, L. AJ Guide to Building Failures. Technical Study 1. Introduction, Architects Journal, vol 165, no 7, 16 February 1977, pp 23-25

AJ Guide to Building Failures. Technical Study 3. Diagnosis: Principles and Procedures. Architects Journal, vol 165, 2 March 1977, pp 415-419.

ALBRECHT, R. Building Damage. Prevention, Investigation, Rectifying, Bauverlag Gmb H. Gesamtherstellung: Wiesbadener Graphische Betriebe, Berlin 2nd Ed. 1977.

ALLEN, Bill. Building Defects - What Went Wrong?, Architects Journal, London, 14 December 1983. pp 63-66

ALLEN, W. Letter to the editor, Building, vol 232, no 6974 Issue 8, 25 Feb 1977, p 81.

ALLEN, William and ANDERSON, Jack. Expert Evidence in Construction Litigation in The International Construction Law Review. Pps 247-258.

ALLEN, D.E. AEPIC Computerised Database on Failures. Personal Communication with Division of Building Research Council, Canada, December 1983.

ALLEN, D.E. Structural Failures Due to Human Error - What Research to Do? in Proceedings of a Symposium on Structural Technology and Risk, University of Waterloo, 16-21 July 1983. Division of Building Research, National Research Council Canada. DBR Paper No 1311. pp 127-136.

ANDERSON, W.F. Assessing the Risk, Building Defects - (Supplement to Chartered Surveyor), April 1981.

ARMSTRONG, L.D. Inhibiting Dampness in Buildings, Architectural Science Review, vol 23, no 1, March 1980, pp 4-6.

ASHLEY, S. A Catalogue of design faults Building, 17 Dec. 1976, p 31.

ASSOCIATION OF METROPOLITAN AUTHORITIES (AMA). Defects in Housing Part 2: Industrialised and System Built Dwellings of the 1960's and 1970's. AMA, London, March 1984, 60pp.

ATKINSON, G. Once the dust has settled Building, vol. 238, 11 April 1980, pp 47 48.

Attention to details, Building, vol 240, 8 May 1981, pp 60 - 61. 
ATKINSON, I. Back to the drawing board, Contract Journal. vol 251, no 4873, 1973, pp 34 - 36.

Checking out structural failures, Contract Journal. vol 278, no 5107, 21 July 1977, p 23.

BALLANTYNE, E.R. Walls and weather, Architectural Science Review, vol 21, no's 1 \& 2, March - June 1978, pp 19 - 23.

BAMPTON, E., BOWYER, J.T. and ARMSTRONG, R.W. Building better buildings Maintenance at the design stage. Three contributions, in Institute of Building Maintenance Information Service Paper No. 3, Ascot, Berks, U.K. 1978.

BARNETT, Right or Wrong? Review of G. Scott's 'Building Disasters and Failures', Surveyor, 147, 16 April 1976, pp 15 - 16.

BAYAZIT, Nigan. A study on the Diagnosis of Building (in use) failures in Design Methods and Themes, Design Methods Group, Californian Polytechnic State University, San Luis Obispo, USA, 1985, pp 268-280.

BECHTEL, Robert, B. Advances in POE Methods: An overview in Building Evaluation. Preiser W.F.E (Ed). Plenum Press, New York 1989, p202.

BECK, V.R. Failures of wall claddings and finishes: a survey. Record 448, Experimental Building Station, Department of Housing and Construction, NSW, February 1979.

BENTLEY, M.J.C. Quality control on building sites. Information Paper IP 28/81. Building Research Establishment, U.K. 1981. 3 pp.

Quality control on building sites. Current Paper CP $7 / 81$. Building Research Establishment, U.K. 1981. 10 pp.

BERRY, F. ... and the walls came tumbling down, Municipal Review, vol 49, no 588, Jan 1979, pp 210 - 212.

BESSEY, G.E. Avoiding faults and failures in buildings, in BRE Overseas Building Notes, no 177, Building Research Establishment, Garston, Watford, U.K. Dec 1977.

BICKERDIKE, ALLEN, RICH AND PARTNERS in Association with Turlogh O'Brien. Building failures, Building. vol 221, 24 September 1971, p 107.

Design failures in Buildings - First Series, George Goodwin Ltd, London, 1971.

Design Failures in Buildings, Second Series, George Goodwin Ltd, London, 1974.

BIGNELL, V. PETERS, G. and PYM, L. Catastrophic failures. Milton Keynes, Open University Press, 1977. 
BINGHAM, Tony. Turning back the clock on negligence, Building, 3 June 1988. p31

BLOCKLEY, D.I. and HENDERSON, J.R. Structural Failures and the Growth of Engineering Knowledge. Proceedings of Institution Civil Engineers, London, November 1980.

BONSHOR, R. Low rise housing, design and construction, Architects Journal, vol 171, no 18, 30 April 1980, pp 881 - 885.

BONSHOR, R. and HARRISON, H.W. Traditional housing: a BRE study on quality, Building Research Establishment Information Paper 18/82, September 1982. 3 pp.

BOURKE, J. Cracks in external walls, Building progress, vol 6, no 2, March/October 1979, pp 1 - 2.

BOWYER, Jack. Guide to Domestic Building Surveys. The Architectural Press, London, 2nd Ed. 1973.

BROMILOW, F.J. (Editor) Building Maintainability and Efficiency Research and Practice. Division of Building Research. Commonwealth Scientific and Industrial Research Organisation. Victoria, Australia. pp53.

BUILDING National House-builders Registration Council research into preventing defects in new houses. 28 August 1970, p 59.

BUILDING DEFECTS: WHO IS TO BLAME? in Building Trades Journal, 6 July 1979.

BUILDING FAILURES, Architects Journal, vol 154, no 30, 28 July 1971, pp 187-88.

BUILDING FAILURES, Building Technology and Management, vol 20, no 4, April 1982.

BUILDING PERFORMANCE GUARANTEE CORPORATION OF NEW ZEALAND Indemnity Agreement. Published by the Corporation, Wellington, 1980.

BUILDING PERFORMANCE GUARANTEE CORPORATION OF NEW ZEALAND. Report of Building Performance Guarantee Corporation of New Zealand, for the years ending 31 March 1982, 1983, 1984, 1985, and 1986.

BUILDING RESEARCH ESTABLISHMENT. Failure patterns and implications. Digest 196. HMSO, U.K. April 1975.

Building research series, Vol. 5, Building failure. Practical Studies from the BRE. Construction Press, Lancaster, 1978.

-- Building defects and maintenance - essential information from the BRE. Construction Press, Lancaster, 1978. 
Common Defects in Low-rise Traditional Housing. BRE Digest No. 268. Watford, UK. December 1982. 8 pp.

BUILDING SCIENCE FORUM OF AUSTRALIA (BSFA) Defects in buildings. Proceedings of the 29th Conference of the N.S.W. Division, BSFA NSW Division, 3 November, 1977.

BUILDING SCIENCE FORM OF AUSTRALIA (BSFA). Building Science Passed or Failed? Proceedings of BSFA Seminar Nov 13, 1986. BSFA NSW Division, 1986.

BUILDING TRADES JOURNAL. Let builders beware, the Defective Premises Act, Building Trades Journal, vol 165, no 4956, 25 August, 1972, p 6.

BYRNES, Anne. Business leaders slate building standards. National Business Review, Auckland, May 22, 1987, p 54.

CAN WE MASTER TECHNOLOGY? Architects Journal, vol 165, no 19, 11 May 1977, pp 864-5.

CARRUTHERS, J.F.S. Classifying the Performance of Components by Usage. in The Performance Concept in Building - Proceedings of the 3rd ASTM/CIB/RILEM Symposium, March/April 1982. pp 161-172.

CAULFIELD, Robert. Surviving the Recession - Minimising Claims. Paper presented to NZIA International Conference, Auckland, November 1991.

CECIL, Raymond. Raymond Cecil on liability in Royal Institute of British Architects (RIBA) Journal, September 1983 p43, October 1983 p 39 November 1983 p 43, November 1983 p 27, January 1984 p 35, February 1984 p 41, April 1984 p 44, May 1984 p 42, June 1984 p 42, September 1984 p 42, October 1984, p 41.

CHAPMAN, M.D. and BEATON, R.G. The Architect and Claims of Professional Negligence. Practice Division. The Royal Australian Institute of Architects. Melbourne. $59 \mathrm{pp}$.

CHEETHAM, D.W. Defects in modern buildings, Building Part 1, vol 225, no 6805, 2 November 1973, pp 91 - 94. Part 2, vol 225, no 6807, 16 November 1973, pp 175 - 176, $179-180,182,187-188$.

CIB Working Commission W60. The Performance Concept in Building. Working papers presented at a Symposium on Performance Over Time/Durability, University of Strathclyde. International Council for Building Research Studies and Documentation. August 1982.

COHEN, Marshall. Practice Law - Professional Liability, Architects Journal. 11 June 1986 pp 75-76

COAD, JR AND ROSAMAM, D. Site-applied adhesives - failures and how to avoid them. BRE Information Paper 12/86 Building Research Establishment Watford UK. 1986. 
CONSTRUCTION INDUSTRY RESEARCH AND INFORMATION ASSOCIATION (CIRIA) Serviceability of buildings. in Development and Materials Bulletin of Greater London Council, vol 63, March 1973, pp2/1 - 2/8.

CONTRACT JOURNAL. Bringing failures into focus (BRE \& CIRIA). vol 295, no 5254, 26 June 1980, pp $26-27$.

CONTRACT JOURNAL. Learning the lesson of failure, vol 262, no 4971, 12 December 1974, pp $24-25$.

COONEY, R.C. The Te Aroha storm of 19 July 1978. Damage to buildings. BRANZ Technical paper No. P29. BRANZ 1980 Porirua, N.Z.

CORNICK S.M, RUBERG, $\mathrm{K}$ and JAMES K. A. Constructing a Diagnostic Knowledge Base for Building Faults in Proceedings of the CIB '89 11th International Congress, Paris, June 1989, Theme III, vol 1 pp 457-466.

CORNISH, James. Three Further Court Decisions, New Zealand Engineering, November 1, 1984 pp 22-23.

COTTERELL, G.P. and FREEMAN, I.L. Quality in the Construction of Buildings, Building Technology and Management, November 1979, pp 36-39.

CROOME, Derek J. The role of feedback in building design. Building Services Engineering Research and Technology, vol 1, no 1, 1980, pp1-9.

CROSS, Nigel. Design III: Design Failures. Open University Press, Bletchley, Bucks, 1972.

CULVER, Charles G., H.S. LEW (and others). Natural Hazards Evaluation of Existing Buildings. Nat. Bureau of standards, Washington, 1925.

DAISH J, GRAY J, AND KERNOHAN D. Post-Occupancy Evaluation of Government Buildings, Victoria University of Wellington. 1980.

DAVIES, J. with HAYWOOD-FARMER J., and McCORMACK, P. Technology transfer in the building industry: The research reports and technical papers of the Building Research Association of NZ - a case study. NZ Journal of Business, 1982. pp 93-121.

DAVIES, V.F. AND HEGVOLD, L.W. Building Faults Database - A Pilot Study, Centre for Architecture and Planning Research, Curtin University of Technology, Perth 1991.

DEPARTMENT OF THE ENVIRONMENT, UK. The future of building control in England and Wales. Consultation papers prepared for circulation to local authorities and interested parties in England and Wales, June 1980.

DESCH, H.E. Structural Surveying. Charles Griffin \& Co. Ltd., London 1970.

Di PASQUALE, R.A. Bridging catastrophe: understanding why failures occur. Concrete Construction, USA, April 1982. pp 345-348. 
DONALDSON R. Construction Faults in Housing Located in a Mining Town in North Western Australia, Architectural Science Review, vol 25, no 2, June 1982. pp 29-36.

DOUGLAS, B.J. Latent Defects - Some Legal and Insurance Considerations. Technical Information Service Paper No. 41, 1984. The Chartered Institute of Building, U.K.

DOWNEY E. Weathertightness and Water Penetration of Buildings, Seminar paper, Paisley College of Technology, 5 November 1980.

(with McLEOD I.A.) Serviceability Failures due to Structural Movements. Paisley College of Technology, 1981.

Condensation Problems: Possible Solutions to the Problem, Seminar Paper, Paisley College of Technology, 28 November 1979.

Building defects. Construction News, vol 3, no 9, October 1977, pp 72 73.

DORTER, John. Defects and Negligence in Proceedings of BSFA Seminar on Building Failures and Forensics, Building Science Forum of Australia Sydney, March 1989, pp 71-110.

DRURY, C.A. The Effects on Investment of Major Defects, Chartered Surveyor, (Supplement) April 1981 pp 10-11.

DUELL, J. Variations on a theme, Architects Journal, 5 January 1983, p 32.

DUFFY, Francis. What Price commodity? Evaluating buildings, Architects Journal, 6 Feb 1991. pp 45-47

ELDRIDGE, H.J. Common defects in buildings. London, HMSO, 1976.

Common defects and their diagnosis. in Proceedings of Joint Building Research Establishment/Institute of Building Seminar on building defects and failures. 29 November 1974, IOB, Ascot, Berks, U.K. 1974.

ELLIOTT, K. and NEWLOVE, J. Site inspection of buildings, Building, 14 January 1972. pp 110, 113-114.

EMERY, R.W. Common Faults in Modern Domestic Construction, South Australian Builder, August 22, vol 57, no 16, pp 19-20.

ENTWHISTLE, E. Building failure: why it is a modern phenomenon, Building Maintenance, vol 7, no 3, May/June 1973, pp 22 - 27.

EVIDENCE OF FAILURE. Architects Journal, 1 June 1983, pp 60-44. 
FAGG, A.J. Building Condition Survey. in Proceedings of CIB W70 Seminar on Systems of Maintenance Planning. Heriot-Watt University, Edinburgh, 21st 23 March 1983. $11 \mathrm{pp}$.

FAILURES - A NEED FOR UNDERSTANDING, Architects Journal, 31 October 1979.

FANTL, K. Building defects: The Clients Viewpoint, Building Research and Practice, Jan/Feb 1974, pp 23 - 26.

FAULTS IN NEW BUILDINGS, A Report in Architectural Surveyor, vol 18, May/June 1973, pp 9-12.

FELD, J. Construction failure. Wiley, New York. 1968.

FELL, W.L.F. Building design and those costly waterproofing problems, Building Materials and Equipment, no 141, Feb/March 1982, pp 22 - 26.

FISHER, Bill. Quality Control - A designers' view, Architects Journal, 21 May 1980 pp 1023-1024.

FORBES, Peter. The Sloppy School of Architecture, New Scientist, 12 December 1985, p 55.

FREEDMAN, B. Engineering Services: Environment for Productivity - Who Needs it? Building Research and Practice, Jan/Feb 1974.

FREEMAN, I.L Building failure patterns and their implications, Architects Journal, vol 161, no 6, 1975, 5 February, pp 303 - 308.

Failure Patterns and Implications. in Proceedings of Joint Building Research Establishment/Institute of Building Seminar on building defects and failures. 29 November 1974, IOB, Ascot, Berks, U.K. 1974.

Analysing failures. Building Maintenance, vol 9, no 2, February 1975, pp $15-17,19,21$.

Building failure patterns and their implications. Current Paper CP 30/75. Building Research Establishment, U.K. 1975.

Building better houses, BRE NEWS 58 , Winter, 1982. Building failures. in DOE Construction No. 14, June 1974, pp 14-19.

Building failures, Construction, no 14, Department of Environment, London, June 1974, pp 14-19.

GAMBLE, Sydney. Rectifications and Post Mortems - Two Case Studies in Proceedings of Building Science Forum of Australia Seminar on Building Failure and Forensics, BSFA Sydney March 1989. pp 51-55.

GARRATT, J. A long hard look at failures, Building, vol 285, no 33, 18 August 1978, p 30 
GRAHAM, H. Eliminating the defects of the 1970's, Municipal Building Management, vol 4, 1977, pp 31 - 32.

GREATER LONDON COUNCIL (GLC). Development and Materials Bulletin, vol 79, October/November 1974.

Development and Materials Bulletin, vol 81, January 1975.

GROVER, Reg. Failures in non-traditional housing, RIBA Journal, February 984, pp 36-37.

HANSEN, A T. The Regulation of Building Construction, Canadian Building Digest 237. National Research Council Canada Division of Building Research. Ottawa March 1985. 4pp.

HAPPOLD, E. Innovation in materials and technology makes a major contribution to defects and failures in building. 15pp (obtained in course of private correspondence).

HARDY, A.C. Opening address to symposium on Design Failures in building, Building, 24 may 1974, p 63.

HARPER, D. The Designer's Viewpoint. in Proceedings of joint Building Research Establishment/Institute of Building Seminar on building defects and failures. 29 November, 1974, IOB, Ascot, Berks, U.K. November 1974.

HARRIS, P. Sticking to the rules, Building, 29 April 1977, pp $70-71$.

HARRISON, H.W. Technical feedback and the defects prevention Unit. Building Technical File, no 2, Building Research Establishment, Garston, Watford, July 1983, pp 53 - 58.

(with KEEBLE, E.J.). Performance Specifications for Whole Buildings : Report on BRE Studies 1974 - 1982. Building Research Establishment. D.O.E., Garston, Watford.

Avoiding faults in traditional housing. BRE News, 58, Winter 1982.

Practical problems in estimating effective service life of components and elements in housing. Paper presented to CIB Seminar W60. (The Performance Concept), University of Strathclyde, Glasgow. June 1982.

HARTOG, Peter. Building Diagnostics - making choices amongst alternatives in the face of uncertainty in Proceedings of Building Science Forum of Australia Seminar on Building Failures and Forensics, BSFA, Sydney, March 1989, pp $9-30$.

HEAYES, N. Shoddy building - who takes the blame? Contract Journal, vol 274, no 5069, 28 October 1976, pp 30 - 31.

HIGBY, H.C. Defects in buildings: The client's viewpoint, Chartered Surveyor: BQS Quarterly, vol 2, March 1974, pp 52 - 54. 
HOLLAND, G. Misuse of Building Material - Design in Proceedings of 36th Conference of NSW Division of the Building Science Forum of Australia. BSFA NSW Division. Sydney June 1980.

HOLMES, Roy. A Methodology for assessing performance and quality in construction. in Proceedings of the CIB '89. 11th International Congress, Paris, June 19-23, 1989 Theme III vol I. pp 67-76.

HUGHES, T. Failures and remedial work in new buildings. Construction, no 25, London, March 1978, pp 8 - 10.

HUTCHINSON, B.D., BARTON, J. and ELLIS, N. Maintenance and Repair of Buildings. Newnes-Butterworths, London, 1975.

IN SEARCH OF QUALITY. Architects Journal, 31 October 1979, p 196.

INSTITUTION OF STRUCTURAL ENGINEERS. Stability of Modern Building. ISE, London 1971.

Structural failures in buildings. ISE, London July 1981.

JANNEY, J.R. Guide to investigation of structural failures. Report from ASCE Research Council on Performance of Structures. American Society of Civil Engineers, New York, 1979.

KAMINETZKY, Dov. Failures during and After Construction, Concrete Construction, vol 26, August 1981, pp 641, 643, 645, 647, 649.

KEEBLE, E.J. Performance values. Safety margins and risk of failure. in The Performance Concept in Building - Proceedings of the 3rd ASTM/CIB/RILEM Symposium, Lisbon. 1982. pp 113-124.

KERNOHAN D, GRAY J, AND DAISH J, WITH JOINER D. User Participation in Building Design and Management. Butterworth Architecture, ButterworthHeinemann, London, 1992.

KIMBER, K.G. Pathology of Building, Contract Journal. vol 225, no 4912, 25 October 1973, pp 38 - 39.

HUGHES, T. Failures and Remedial work in New Buildings. Construction, no 25 , Property Services Agency. London, March 1978, pp 8 - 10.

KUNZ, H. Defects and quality in building, Fibre Cement Review, vol 25, no 3, July 1980, pp $26-34$.

LATHAM, M. A Doomwatch for new construction, Building, 8 August 1975 pp 42 43.

LAW AND YOUR RESPONSIBILITIES, New Zealand Building Inspector, March 1975, pp 15, 17, 19. 
LEE, Reginald. Building Maintenance Management. Crosby Lockwood Staples, London, 1976.

LE GRYS, P. Damp and its consequences, Building Trades Journal, vol 178, no 5315, 24 August 1979, pp 19-21.

LITTLEMORE, David. Building Defects - who dunnit? in Proceedings of the 29th Conference of the N.S.W. Division of the Building Science Forum of Australia. Published by the BSFA, N.S.W. Division, Sydney, November 1977.

LUNN, B. Swedish Maintenance Planning. in Proceedings of CIB W70 Seminar on Systems of Maintenance Planning. Heriot-Watt University, Edinburgh, 21-23 March 1983.

MCDONALD, B. Defects - Who's to Blame? Developer, Architect, Government? or? in Proceedings of 29th Conference of the N.S.W. Division of the Building Science Forum of Australia. Published by the BSFA, N.S.W. Division, Sydney, November 1977.

MCDONALD, Willa. The Cancer That is Eating Our High-Rise Buildings, The Bulletin, September 4, 1984. pp 50-54.

MCDOWELL, I. Defects in Buildings - Feedback or foulups. in Proceedings of 29 Conference of the N.S.W. Division of the Building Science Forum of Australia. Published by the BSFA, N.S.W. Division, Sydney, November 1977.

McINNES, A. Who Pays if the Roof Falls In? in Proceedings of 29 Conference of the N.S.W. Division of the Building Science Forum of Australia. Published by the BSFA, N.S.W. Division, Sydney, November 1977.

McKAIG, T.H. Building failures. Case studies in construction and design, McGrawHill, New York, 1962.

McKINNEY, P. Pitfalls in house building, Building Trades Journal. vol 163, no 4910, 8 October 1971, pp $27-28,30,35$.

McNEILL, Joseph G. Principles of Home Inspection - A Guide to Residential Construction, Inspection and Maintenance. Van Nostrand Reinhold Company, New York, 1979.

MAGUIRE, P. Focus on the feedback system, Building Design, no 414, 22 September, 1978, p 4.

MARSH, Paul. Whither the buck? An analysis of blame, Concrete, vol 3, no 5, May 1979, pp 12 - 14.

MARSH, Peter. Why do Britain's Builders bungle the job? New Scientist, vol 78, no 1104, London, May 1978. pp 523-525.

MARSHALL, R.D. Reducing the risks of failure, Building Research and Practice, July/August 1982, p 210. 
MASON, W. Estates in decay, Building Design, no 379, 20 January 1978, p 7.

MARVIN, H. Using Experience and Publications in Building Design. Information Paper IP13/85. Building Research Establishment. Garston, June 1985.

MARVIN, H. Meeting building designers' needs for trade information. Information Paper 1P 14/214. Building Research Establishment. Watford. June 1985.

MATOUSEK, Miroslav. Measures against errors in the Building Process. Institute of Structural Engineering, Swiss Federal Institute of Technology Zurich. Translated by R. Serre for Canada Institute for Scientific and Technical Information. National Research Council, Ottawa, 1983.

MATSUMOTO, K. The new home warranty system in Japan. BRI Research Paper No 107 Building Research Institute, Ministry of Construction Tsukuba, Ibaraki, Japan. March 1984.

MELVILLE, Ian, A., GORDON, Ian, A. and BOSWOOD, Anthony. Structural Survey of Dwelling Houses, (2nd Enlarged Edn.), The Estates Gazette Ltd., London 1974.

MILLS, Denis and Associates. Building Defects: A Failure to Achieve Standards: Architects Report and Survey Analysis Report on the occurrence of defects with recommendations for avoidance and improving performance: Architects Report and survey analysis. Denis Mills Associates 1988. Maidstone, Kent.

MORISHITA, K, SATO, Y, FUSE, T. Deterioration Diagnosis and Repair Techniques for NTT Buildings in Proceedings of CIB ' 89 11th International Congress, Paris, June 1989. Theme III Vol 1. pp 167-176.

NATIONAL BOARD FOR CONSUMER POLICIES (SWEDEN). Single-family houses, defects and disputes, National Swedish Building Research Summary, S31:1978.

NATIONAL BUILDING AGENCY. Common building defects: diagnosis and remedy. Lancaster, Construction Press, 1979.

NATIONAL HOUSE BUILDERS REGISTRATION COUNCIL. (UK) Registered House builders foundation manual: preventing foundation failures in new buildings. NHBRC, London, 1977.

NATIONAL HOUSE BUILDERS REGISTRATION COUNCIL. The incidence, causes, and prevention of defects in private and public sector housing. NHBRC, London, June 1979.

NELSON, J. The nature of common defects in building, SAAT News, Society of Architects and Architectural Technicians, London, 28 August 1977, pp 7 - 8.

NEVILLE, A. and EVANS, R.W. Rethinking the professional role, Building, vol 232, No. 6972, Issue 6, 11 February 1977, pp $83-85,87$ 
NEW ZEALAND GOVERNMENT Building Performance Guarantee Corporation Act. 1977, NZ Govt Printer, Wellington 1977.

NEW ZEALAND INSTITUTE OF ARCHITECTS (NZIA) Members Play Leading Role in House of the Year Awards, NZIA Detail, Wellington, October 1992.

NEWLOVE, J. The achievement of quality in construction, Building Technology and Management, vol 16, no 1, January 1978, pp 6 - 10.

NICE, P.H. Building problems and failures, Building Technology and Management, vol 18, no 10, November 1980, pp 27 - 28.

NIELSEN, K. Attention to details, Building, vol 240, no 19, 8 May 1981, pp 60-61.

NIREKI, T. An Approach for Developing Maintenance Guidelines. in Proceedings of C.I.B. W70 Seminar on System of Maintenance Planning. Heriot-Watt University, Edinburgh 21-23 March 1983.

O'BRIEN, T.P. Quality control on site in Quality Control, 1970. Report on a conference organized by UK Ministry of Public Buildings and Works, HMSO, 1970.

OWENS, Ruth. Education for the 21st Century, Architects Journal. 30 October 1990. p 14.

OXFORD UNIVERSITY PRESS. Concise Oxford Dictionary of Current English, 6th Edition, 1976.

OXLEY, T.A. Causes and effects of rising damp, Building Trades Journal, vol 178, no 5326, 9 November, 1979, pp 30 - 32.

PALMER, J. Education in use or Misuse of Building Materials in Proceedings of the 36th Conference of the NSW Division of the Building Science Forum of Australia. Published by the BSFA NSW Division. Sydney, June 1980.

PARSEY, G. Condensation, a warning, Architects Journal, vol 170, no 29, 18 July 1979, p 117.

PATERSON, J. (with GOODACRE, P.). Strategic Maintenance in Proceedings of C.I.B. W70 Seminar on Systems of Maintenance Planning. Heriot-Watt University, Edinburgh, 21-23 March 1983.

PETTITT, R. Computer Aids to Housing Maintenance Management, in Proceedings of C.I.B. W70 Seminar on Systems of Maintenance Planning. Heriot-Watt University, Edinburgh, 21-23 March 1983.

PLATT, S.D., MARTIN, C.J., HUNT, S.M., LEWIS, C.W. Damp Housing, Mould Growth and Symptomatic Health State, British Medical Journal, vol 298, 1989, p 1673. 
POOT, Jacques and SCOTT, Alistair. A Data-base of Post War Construction Activity in New Zealand. Working Paper No. WP 83-16. School of Architecture, Victoria University of Wellington, New Zealand.

PORTEOUS, W.A. Building Failures. The Chartered Builder, vol 135, 1982. pp 5356

Perceived Causes of Building Failure. Unpublished Paper 1984.

Building Communication. in Proceedings of New Zealand Institute of Building/Australian Institute of Building Conference, Christchurch, March 1984.

Perceived Characteristics of Building Failure - A Survey of the Recent Literature. Architectural Science Review, vol 28, 2 June 1985 pp30-40.

Form and Failure in Proceedings of Australian and New Zealand Architectural Science Association (ANZAScA) Conference, Auckland, August 1986.

Proposal for the Classification and Minimisation of Building Failures. in in Proceedings of the 11th International Conference of the International Council of Building Research Studies and Documentation (CIB). Paris, 1989. pp 177-186

Human Fallibility - A Factor in Applying Architectural Science in Proceedings of the Australian and New Zealand Architectural Science Association (ANZASCA), Conference, Hobart, 1989.

Insurance Claim Data - A Potential Guide to Quality Assurance. in Proceedings of European Organisation for Quality Control (EOQC)/International Council for Building Research Studies and Documentation (CIB) Seminar. Copenhagen, 1989.

POWELL, M. The Incidence, Causes and Prevention of Defects in the Construction of New Houses. The Housing Research Foundation, U.K. 1971.

POWELL, M.J.V. The most frequent structural defect, The House Builder, Feb. 1972, vol 32, no 2, p 56.

Site supervision, The House Builder, 1972, vol 32, June, p 231.

Faults in new buildings - a report, The Architect and Surveyor, vol 18, May/June 1973, pp $9-12$.

Quality control in speculative house building. Institute of Building Occasional Paper No 11 1976. Institute of Building, U.K. 21 pp.

POWELL-SMITH, Vincent. Practice Law - Local Authority Liability, Architects Journal, 18 May 1986. pp 77-79. 
PREISER, WOLFGANG F.E. Towards a Performance-Based Conceptual Framework for Systematic POES in Building Evaluation, Preiser W.F.E (Ed). Plenum Press, New York 1989, pp 1-7.

PRICE, C. Forensic Science Needs Open Minds, New Scientist, 20 July 1991, p 4.

PRYKE, J.F.S. Cracked buildings: what constitutes design failure? Supplement to Chartered Builder, vol 113, no 9, April 1981, pp 14 - 15.

RABENECK, A. Facing up to failure. Diagnosing and preventing defects, Architects Journal, vol 173, no 15, 15 April 1981. pp 715-718.

RABINOWITZ, H.Z. Buildings in Use Study. Report R75-1 Center for Architecture and Urban Planning Research, University of Wisconsin - Milwaukee, 1975.

RABINOWITZ, Harvey Z. The Uses and Boundaries of Post-Occupancy Evaluation: An Overview in Building Evaluation, Preiser W.F.E (Ed) Plenum Press, New York 1989, p10.

RANALL, R.H. Building defects and feedback, Property Services Agency Institute of Building, 1978, Ascot, Berks. U.K.

RANKIN, I. Quality control and tolerances for internal finishes in building. Chartered Institute of Building Tech Info Paper No. 2, 1982.

RANSOM, W.H. Building failures: diagnosis and avoidance. E. \& F.N. Spon, London 1981.

RAVETZ, A. Nasty, brutish and short, Architects Journal, 1982, 5 May, p 38.

REIACH HALL BLYTH PARTNERSHIP. Failures In Building Construction - A General view. Department of Civil Engineering, Paisley College of Technology, UK, 18 March 1981.

RICHARDSON, Barry A. Remedial Treatment of Buildings. Construction Press, New York, 1980.

ROBERTS, W.G. Innovation in Materials and Technology Makes a Major Contribution to Defects and Failures in Buildings. Building Technology and Management. vol 20, no 5, May 1982. pp 16-19.

ROXBURGH, R.D. Use or Misuse of Material. in Proceedings of 36th Conference of the NSW Division of the Building Science Forum of Australia. BSFA NSW Division, Sydney, June 1980.

RUSH, R. Your solution or your leak, Progressive Architecture, vol 62, no 2, February 1981, pp $104-111$.

SAAT (SOCIETY OF ARCHITECTURAL AND ASSOCIATED TECHNICIANS) NEWS Avoidance of building failures. Extracts from Parts $4 \& 5$ reprinted with permission from the Greater London Council's Materials and Information Bulletins no's 79 and 80, July 1975, pp $16-19$. 
SCANDAL OF NEW FAILURES. Building Design, no 473, 23 November 1979, pp 19-26.

SCHILD, E. and others. Structural failure in residential buildings, vols 1 - 4, Granada, London, 1978 - 81.

SCOTT, DL. Rain leakage in wood frame walls: two case histories. Division of Building Research National Reserve Council of Canada, Ottawa April 1984.

SCOTT, Geoff. Building Disasters and Failures. Construction Press, London 1976.

SHARPE, R.W. The treatment of rising damp, Building Technology and Management, vol 18, no 11, December 1980. pp 31 - 33.

SINGH, J. Bibliography of structural failures 1850 - 1970. Building Research Establishment, Garston, 1976.

SKINNER, N.P. Local authority house maintenance - the variation in expenditure. Housing Review, May - June 1982. pp 92-96.

House condition. Standards and Maintenance. Housing Review, July Aug 1981. pp 106-109.

Feedback from building maintenance. BRE News 58, Winter 1982. pp 15-17.

SKINNER, N.P. \& KROLL, M.E. Maintenance feedback. Chartered Institute of Building (CIOB) Maintenance information service, 1981.

SKINNER, N.P. The Matching of Planning System to the Maintenance Work that is actually done. Proceedings of C.I.B. W70 Seminar on Systems of Maintenance Planning. Heriot-Watt University, Edinburgh, 21-23 March 1983.

SMILLIE, John. Compensation for Latent Building Defects, New Zealand Law Journal, September 1990. pp 310-340.

SMITH, A.C. Defects in building - a builders bane. in Proceedings of 29th Conference of the NSW Division of the Building Science Forum of Australia, BSFA, NSW Division, Sydney, November 1977.

SMOLIRA, M. Analysis of defects in concrete and brick structures during construction and in service. Department of Environment, London, March 1972.

SPEAIGHT, A. and STONE, G. Legal Report: Forever Liable?, Architects Journal, 20 January 1980.

SPRING, Martin. 1.25m Pounds Defects Found On Camden's Flagship Estate, Building, vol 244, no 7259, 17 September 1982, p11.

STANWOOD, L. Some perspectives on building failures, Construction Specifier, vol 36, no 4, May 1983. pp $24-27,30-31$. 
STARBUCK, W. AND MILLIKEN, F. Challenger: Fine-tuning the Odds Until Something Breaks, Journal of Management Studies, vol 25, July 1988.

STATENS INSTITUT FOR BYGGNADSFORSKRING. Inventory of Defects and Damage to Buildings. Statens Institute for Byggnadsforskring Rappart No. 13/66, 1966.

STRINGER, G.E. What is quality worth? in Quality Control. Report on a conference organised by UK Ministry of Public Buildings and Works, HMSO, 1970. pp 63-76.

TAYLOR, P.J. Four case histories describing why some buildings fail, Building Materials and Equipment, vol 21, no 6, April/May 1971, pp $50-51,53,55$.

THEN, D. The Public Sector Housing Maintenance Modernisation Process. in Proceedings of C.I.B. W70 Seminar on Maintenance Systems Planning. Heriot-Watt University, Edinburgh, 21-23 March 1983.

TIPPETT, $\mathrm{H}$ and PORTEOUS, W. Cost Impact of New Zealand Standards - A Pilot Study of Methodology Using NZS 4203: 1976 Clause 3.6.5. Suspended Ceilings. Report prepared for Ministry of Works and Development. Victoria University of Wellington, November 1980.

TIPPETT, $\mathrm{H}$ and RUNESON, G. Quality Evaluation of Residential Buildings, Research Paper 85/1. National Housing Commission, Wellington.

TIPPLE, Christopher. Defects and Cost Can be Kept down with Regular Inspection, Building Trades Journal, vol 183, no 5440. 1982. p28.

TODD, Stephen. Latent defects on property and the Limitation Act : A defence of the "discoverability" test. N.Z. Universities Law Review, vol 10, no 4, December 1983. pp 311-331.

TOLSTOY, Nikolaj. Field Investigations of Moisture in Buildings in Proceedings of the Third International Conference on the Durability of Building Materials and Components. Technical Research Centre of Finland, vol 2, 1984, pp 422432.

TOLSTOY, Nikolaj. The Design of Field Investigations in Proceedings for Estimating the Extent of Building Failures in proceedings of CIB '89 11th International Congress. Paris, June 1989, Theme II,I vol 1. p 187-196.

TRILL, J.E. Problems in building construction - a scientific method approach. Architectural Press, London 1972.

UNIVERSITY OF SYDNEY Department of Architectural Science. A method for measuring visible deterioration, General Report G.R. 14, Sydney, Australia, 1977.

VERRAL, A.F. Building decay associated with rain seepage, Technical Bulletin, No 1356, US Department of Agriculture, 1966. 
WALLACE, I.N.D. Cost of repair and inflation. The Australian Institute of Building, N.Z. Chapter, 1979.

WEBB, Chris. Working as an expert witness, Architects Journal, vol 190, no 21, 22 November 1989. p 127.

WEEKS, J. Planning for Growth and Change, Architects Journal, 7 July 1960.

WHEN WILL WE EVER LEARN? Chartered Surveyor (Supplement), London, April 1981, p 2

WIGGLESWORTH, G. Building defects. Who is guilty? Architects Journal, vol 164, no 11, August 1976, pp 252 - 253.

WILSON, Forrest. Building Diagnosis - Making Choices Amongst Alternatives in the Face of Uncertainty. in Proceedings of Seminar on Building Failures and Forensics, Building Science Forum of Australia, Sydney, March 1989, pp 930.

WISE, Douglass. The background to failure. Number 2 in a series of articles, Architects Journal, 8 June 1983, pp 69 - 71.

WYMOND, P.A. The incidence of building faults in dwelling construction in Victoria. Highett, Victoria Division of Building Research, CSIRO, 1977.

YAO, J.T.P. Performance of low rise buildings - existing and new. National Science Foundation, Washington. 1980. 


\section{APPENDIX A}

\section{PERCEIVED CAUSES OF BUILDING FAILURES}

PORTEOUS, W.A. Perceived Causes of Building Failure.

Unpublished paper, 1984.

This unpublished paper was written, in the course of research into building failures, with a view to recording the findings of a survey of the literature from 1969 to 1983.

The survey sought the opinions of various commentators as to the causes of building failures and the nature of the human errors which can contribute to those failures.

\section{INTRODUCTION}

As previously noted ${ }^{23}$ a survey of the literature concerned with building failures leads one to the conclusion that 1970 saw the beginning of both a growing interest in building failure within the building industry and efforts to define the phenomenon of building failure in some universally acceptable way.

It should, therefore, be borne in mind that while the various opinions as to the causes of building failures are described in chronological order in this paper there was a concurrent development of the definition of building failure. It is thus possible that the earlier opinions about reasons for building failures may have been expressed by people whose concept of a building failure differs from that of more recent commentators.

The occupations of those whose opinions have been recorded in this paper have been clearly stated wherever possible in order to illustrate the range of expertise on which it has drawn, and to enable the reader to form a personal view of the relative significance of the various commentators' opinions. 
Once the more than 70 bibliographical references to reasons for building failures were located, it remained only to assemble those in chronological order. Chronological order was chosen because it was considered that some commentators might, by publishing their views, have influenced subsequent writers.

\section{EARLIER OPINIONS}

One of the earliest observations about the causes of building failure was made by G.E. Stringer ${ }^{5}$ then Solicitor to the Royal Institute of British Architects, in an address to a two day conference held in 1969 during the International Building Exhibition at Olympia.

In the course of his address Stringer noted -

"...I think the problems of leakage are becoming more important nowadays with component development than they ever were in the past with the traditional building methods ...

I suppose the component has always been with us, but it's now becoming much more important and is in fact a basic method of constructing the entire building, whereas previously they were bits and pieces."

As far as can be ascertained this was the first time component-building had been put forward as a cause of building failure.

At the same conference T.P. O'Brien ${ }^{24}$ from the Research and Development Group, Ove Arup and Partners, and Lecturer in Building Materials at the Bartlett School of Architecture, University of London, spoke about quality control on site. In his concluding notes O'Brien makes a number of assertions, from which the following selection is relevant to a study of causes of building failure:

1. Specifications often include too much about 'how' to do something, and not enough about 'what' must be achieved.

2. Designs too frequently call for site operations which, due to their difficulty, are unlikely to be done well. 
3. Materials and component manufacturers often do not pay sufficient attention to site conditions, and the effects of these on the use of their products.

4. Transfer of work from site to factories does not necessarily result in better quality control, and, without new techniques, site staff have less control than before as they do not see all stages of the work.

5. Construction is involving an ever increasing number of specialist operations, carried out by specialist contractors, but this trend is not matched by the emergence of supervisors with corresponding specialist knowledge.

Commenting on the content of letters and articles concerning building failures published in the Architects Journal| ${ }^{25}$ early in 1971 that Journal said:

"... What emerges from these and other letters is that there appears to be no categorical answer to many building problems. Sound detailing and construction are still too much matters of opinion, too little based on effective feedback from site. Many failures occur through changing one small detail or material from a standard detail and specification which has always worked well in the past. Architects do not always realise the cumulative effects of making slight changes in a group of materials used in a particular way in a certain context. Change the balance, and failure can be the results."

In September 1971 the building industry journal Building introduced a fortnightly series of information sheets on building failures prepared by Bickerdike, Allen, Rich and Partners, architects, with Turlogh O'Brien, ${ }^{26}$ structural engineer, as materials consultant. In the introduction to the series it is stated:

"... Therefore in various cases and to various degrees it may be the designer, specifier, assembler or user of the 'machine' not to mention the supplier of the materials used, who is responsible for the failure of part of it to function ...

Usually failures occur as a result of either ignorance, dereliction or both. Sometimes, however, the reason is almost a motive and is almost wilful." 
October 1971 saw the production by the UK Housing Research Foundation of a report 'The Incidence, Causes and Prevention of Defects in the Construction of New Houses $^{\prime 27}$. This publication is an abridged report of an investigation carried out by one Michael Powell MSc, A.I.O.B. for the National House-Builders Registration Council in conjunction with the University of Aston in Birmingham.

In the 'Summary of Main Findings' the report states:

"Designers and site supervisors were considered to be responsible for the most costly defects. Numerically, the most defects seemed to be attributable to bad site supervision and bad workmanship. $30 \%$ of all defects complained of could easily have been prevented by systematic check before the house was handed over to the purchaser."

While the report acknowledges that there are defects primarily attributable to material behaviour and manufactured goods, it found that such defects constitute a very small proportion of the total number of defects costing $£ 100$ Stg or more to remedy.

The Construction Industry Research Information Association (CIRIA) in the UK produces the Development and Materials Bulletin. In March 1973 a report on serviceability of buildings appeared in the Bulletin ${ }^{28}$. As a general comment on performance problems in buildings the report notes:

"In most cases, the problems continue not through lack of the technical knowledge of how to counter them but more because, where there is a division in the responsibilities for design, specification or construction, the detailed consequences of the one stage are not properly communicated, appreciated and provided for in the subsequent stages."

Some of the general comments made by organisations which responded to the CIRIA survey add reinforcement to the views expressed by others in the building industry. 
(Respondent) P - "Until all participants in building gear their actions more positively to serviceability and reliability as long-term concerns, these problems will remain ... according to a BRS report, $20 \%$ of all maintenance expenditure is attributable to mistakes by designers and builders. A reduction in mistakes will come more quickly from a change of approach to serviceability than from new solutions to specific technical problems."

(Respondent) G - " "... the relationship between first cost and subsequent maintenance cost has a direct effect on the serviceability of buildings. The fact that one sum comes out of capital and the other out of revenue seems to have been the justification for the system over many years, but if we are going to improve the quality of our buildings then this problem must be resolved sooner or later."

To these comments the CIRIA report adds the following, based on the results of the survey of building organisations:

"Frequently, despite good pre-contract work (drawings, specification etc) the serviceability of buildings suffers because of poor and indifferent supervision."

and

"The 'state of the market' influences the future serviceability of buildings. When the economy is at a low ebb, contractors may have to put in tenders which are too low but needed to keep themselves afloat. Then, if the economy improves during the course of the contract, the work will suffer in consequence."

In the same month as the CIRIA Bulletin carried the report on its building problems survey, a seminar entitled 'Faults in New Buildings' was held at Shirecliffe College of Further Education at Sheffield. The content of the seminar was subsequently reported in The Architect and Surveyor ${ }^{29}$. The final speaker in the seminar was $\mathrm{E}$. Wadsworth F.R.I.C.S., Chief Land and Building Surveyor to the Sheffield Regional 
Hospital Board. He made suggestions as to ways in which maintenance costs could be reduced. Those of his suggestions which are directly linked to perceived causes of building failure include:

1. extending the period during which the contractor was responsible for remedying faults.

2. designers paying more attention to maintenance records in order that faults could be designed against.

3. adequate performance standards for building components.

4. the inclusion of the cost of maintenance over the first ten years as part of the capital cost.

Wadsworth also commented that in his opinion:

"... one of the troubles was due to the fact that craftsmen were very often not fully informed of the aim of the job. If they could be more fully informed they very often were able to produce a much more suitable result."

It is also reported that he felt:

"... at present many builders were taking on too much work at one time and as a result were not able to give the attention to each job, and further there was a great need for technical supervision during the construction process."

In the course of his summing up the seminar, the Chairman, J. Hall FIOB, MBIM, MRSH, Principal of Shirecliffe College said he felt:

"... that to some extent it was a criticism of modern education in the construction industry, as a lot of the faults seemed to be traceable to the fact that designers do not seem to comprehend basic technical education. This also applied to the education of craftsmen and operatives." 
He also felt:

"That the decisions with regard to the relative costs of the various parts of buildings were often made by people not qualified to do so and there seemed to be a fault at the political level in that there seemed to be a willingness to provide insurance against faults rather than to educate against faults. It was important to be able to diagnose the cause of a fault but it was even more important to be able to design against the fault happening."

He went on:

"There was also a need for increase in the quality of supervision and management in the construction industry. It would seem to be necessary to harness the evidence available on the extreme costs of maintenance and appeal both to the politicians and the consumers for action to reduce this. The standing of the Clerk of Works also ought to be considerably increased and he should be put into the category of a quality control engineer. He also felt that it was a great pity that there were not more people from the design and construction side of the industry present at seminars on the lines of the present one and perhaps this indicated one of the reasons why maintenance ran at its present level in that the interests of the design and construction sides were not in maintenance and until this was remedied we should not see a great improvement."

In October 1973 an address on 'Pathology of Building' by K.G. Kimber, partner in the R. Harry H. Stanger consultancy, was reported'. In Kimber's view,

"... Deficiencies pertain to design, specification, materials or workmanship. There are four primary causes of defects: inadequate briefing, inadequate design, errors in construction or defects in materials and components..." 
A month later an issue of Building carried an article by D.W. Cheetham, lecturer at the Lanchester Polytechnic, entitled 'Defects in Modern Buildings' ${ }^{6}$. As Cheetham saw it,

"... The occurrence of defects in the fabric of a building can result from many unrelated design decisions: poor material specification; inadequate assessment of loads; inadequate appreciation of conditions of use and inadequate assessment of exposure ..."

He went on to stress,

"... Many defects may occur for reasons which are outside the control of the designer. Poor workmanship manifests itself in inadequate protection of materials, inadequate quality control and just plain carelessness! Poor maintenance often results from insufficient budgeting on the part of corporate clients ..."

The views about human error disclosed by the literature survey to the end of 1973 are summarised in Table 1.

HUMAN ERROR

Defective materials

Overlooked site condition

Ignorance

Over-emphasis on first cost

Defective documentation

Unanticipated consequence of change

Specialist contractor's lack of knowledge

Design too difficult to build well

Dereliction or negligence

Poor communication

YEAR: '69-73

1

3

3

2

4

1

5

3

3

4

Table 1. No of references to human error causes of failure by year of publication (to the end of 1973). 
Early in 1974 Karl Fantl, Director of the Austrian Institute for Building Research discussed the role of building research in relation to building defects ${ }^{10}$. Fantl wrote,

"In the wider meaning of the term, a building defect or building flaw occurs when, as a result of poor workmanship in the erection of a building or because of faulty design, there arise avoidable costs during its construction ..."

Fantl's views appear to have been endorsed by H.C. Higby, Estate and Development Officer for the University of Liverpool in a paper produced a few weeks later ${ }^{8}$.

Higby began with a discussion of the conflicts within the building process, such as that between durability and low initial cost, or architectural awareness (sic) and 'sheer utility', and went on,

"I ought to talk a bit more about defects caused by design and construction because such defects result from the conflicts I have outlined and the remedies lie, to some extent, in the answers."

The May 1974 issue of Building carried a report on a symposium on design failures in buildings, held in Newcastle. The opening address was given by A.C. Hardy, ${ }^{30}$ Professor of Building Science, University of Newcastle upon Tyne. As reported in Building,

"Opening the Newcastle symposium, Professor Hardy said that in his view failures had their roots in poor design, inadequate knowledge of new materials, unsatisfactory workmanship, and materials which, when used together, caused unusual and unexpected chemical reactions. He accused architects of trying to be too clever, 'too unique' in attempting new forms of construction."

In November 1974 a joint BRE:IOB Seminar on Building Defects and Failures provided an opportunity for the results of some of the first objective research into 
the subject to be published. Among the researchers who delivered papers were $\mathrm{H}$. Eldridge $^{31}$ a former BRE employee and now an author and consultant in his field.

Eldridge, commenting on defects in general, noted early in his paper that,

\begin{abstract}
"Defects occur for a very wide range of reasons, but far too often they are ascribed to poor workmanship, bad luck or settlement. It is doubtful whether it is possible to construct a building without a defect being present in view of the fact that the majority of buildings are constructed of a number of materials, produced under a wide range of conditions and having different properties, and that the buildings are exposed to many different climatic and occupancy conditions, which can act individually or together in adversely affecting the materials."
\end{abstract}

He goes on to group building defects according to their causes and produces the following list:
a. Faults arising from incorrect design and construction
b. The incorrect use of sound materials
c. Faulty materials
d. Poor workmanship
e. $\quad$ Defects caused by dampness
f. Defects caused by other agencies

Another speaker at the Seminar was I.L. Freeman, ${ }^{9}$ then Head of Advisory Services Division at BRE, who delivered a paper 'Failure Patterns and Implications'. Freeman produced a table of causes of defects and listed the causes, with definitions, thus:

\footnotetext{
"Faulty design: all cases where the defect could reasonably be attributed to a failure to follow established design criteria, whether in Codes or Standards or in accepted good practice. The design fault would often lie with the main designer, but could also be in a boughtin component (such as a window unsuited to a severe exposure condition for which it had, knowingly, been supplied) and in a subcontracted service (for example granolithic flooring). A design was
} 
also considered to be at fault if it was clearly so complex that the probability of it ever being properly executed seemed very low;

Faulty execution: defects attributed to the failure on the part of the contractor, or sub-contractor, effectively to carry out a design which was satisfactory in itself, and properly specified;

Faulty materials components or proprietary systems: failure of these elements to meet their advertised or otherwise accepted performance levels;

Unexpected user requirements: defects caused by the user expecting more from the design than the designer anticipated at the time of design;"

Freeman went on to note

"Faults in design or in execution, or in a substantial minority of cases in both, could effectively explain most defects investigated."

Not all the Seminar speakers were associated with BRE research. D. Harper, ${ }^{32}$ then Professor of Building, University of Manchester, Institute of Science and Technology, former Chief Architect to Corby New Town from 1952-57, and a Past President of the Institute of Building, spoke from "The Designer's Viewpoint'. He spoke at length of the risks of innovation in relation to building failures.

"... Many of the risks of defects and failures start at 'programme conception' (what is required) which largely involves a management role and continues into 'design conception' (what to build) which involves an art/technology role. When both these roles involve innovation - and in many modern projects, they do, then there may be conflict between an understanding of requirements and of technical solutions, which could lead to increasing (untried) innovation on too many fronts at once. Thus we may find new untested proposals in the use of space, the structure, in comfort standards and the way they are obtained and the eventual building may well be used and serviced in 
unexpected ways. It must be true that while innovation within a limited field can be carefully analysed, simultaneous innovations across all the above fronts, produce interfaces much too complex for analysis in a limited time, and thus the risks taken are very great. An accumulation of defects leads to failure."

Continuing the 'risk' theme Harper went on to discuss the effect of fashion in building.

"... In general real risks of failure are taken when particular design fashions are insisted upon at an early stage, and they may well include the selection and use of new 'wonder' materials, covered by sales jargon. Add to these hazards - a complex geometry and continuing efforts to save money - and we can face a design situation where nothing of the new project format has been seriously tested ..."

The end of 1974 saw the appearance of further comment on building failures in the G.L.C. Development and Materials Bulletin ${ }^{33}$. In classifying various types of failures the Bulletin goes close to classifying failures by causes, as follows,

"It may be convenient to classify and consider various types of failures under the following headings

(a) Catastrophic failures

(b) Planning failures

(c) Detailed design failures

(d) Failures resulting from aesthetic decisions

(e) Failure to withstand 'normal' and 'robust' use

(f) Failure to discourage vandalism

(g) Failures of general construction

(h) Failures of workmanship and supervision.

In an effort to expand on 'Catastrophic failures' the Bulletin asserts, 
"... In most cases, catastrophic failures can be traced back to erroneous assumptions on the part of their designers. Fortunately such failures are rare and receive sufficient publicity without any contribution from the author, who would prefer to dwell on the multitude of failures and the means by which some of them may be avoided."

The Bulletin for January $1975,{ }^{34}$ continuing the theme of avoidance of building failures includes under a heading 'Safeguards against failure' a list of ways of avoiding causing building failures. As the Bulletin puts it,

"An examination of the 'problems' referred to the Scientific Branch for investigation shows that the following safeguards are needed if genuine failures are to be avoided:

(a) The building must be correctly designed and detailed.

(b) Possible alternative forms of the component and the materials used in its production must be correctly evaluated and a suitable component approved.

(c) The approved component must be correctly specified.

(d) The component must be correctly manufactured.

(e) The component must be correctly stored prior to installation.

(f) The component must be correctly installed and subsequently correctly protected after installation.

(g) The component must be correctly maintained."

Referring to the installation of building components later in the Bulletin, the author goes on,

"The product is now available for assembly and many feel, no doubt, that it is at this point that detailed design and careful planning are nullified because of inadequate workmanship and supervision. Whilst this may certainly be true in some cases there are mitigating circumstances where some failures are almost bound to result unless suitable preventive measures are taken. For instance, does the work force have an adequate opportunity of learning to handle and install 
unfamiliar products before it is called upon to perform its tasks in earnest? Many industries feel it necessary to have 'dummy runs' yet, all too often, the work force on a building site is expected to be able to handle new forms of component with little prior warning and with inadequate information about the procedure to be used. It must now also be questioned whether the supervisory staff is not being called upon to do too much, in relation to new materials and components, with inadequate tools at their disposal."

The work of I.L. Freeman, previously discussed, ${ }^{9}$ appeared in the Architects Journal early in 1975, marking the recognition of building failure as a serious subject for the architectural press. In the same month a leader in Building was devoted to a discussion of ways of avoiding building failure ${ }^{35}$.

In April 1975 Freeman's work appeared in a BRE Digest ${ }^{12}$ adding further to the respectability of building failure as a subject for serious scientific study. Then in July 1975 SAAT News ${ }^{11}$ reprinted some of the GLC Bulletin material already discussed ${ }^{33,34}$ for the benefit of its readers.

So seriously was building failure now being treated that in August 1975 a British MP who also happened to be a director of a building company and a former director of the House Builder's Federation was moved to write in Building, ${ }^{36}$ with reference to BRE,

"It would surely be desirable to appoint an additional deputy director specifically and solely responsible for initiating and co-ordinating all work on preventive research into possible faults into new techniques, components and materials, and with sufficient powers to insist that a new material is not used until he is fully satisfied with its safety from all angles - a lot to ask, certainly, but then it costs a lot to put them right." 
By the end of 1975 the opinions surveyed could by summarised by Table 2 .

HUMAN ERROR

Defective materials

Overlooked site condition

Ignorance

Over-emphasis on first cost

Defective documentation

Unanticipated consequence of change

Specialist contractor's lack of knowledge

Design too difficult to build well

Dereliction or negligence

Poor communication

\section{YEAR: ‘69-73 7475}

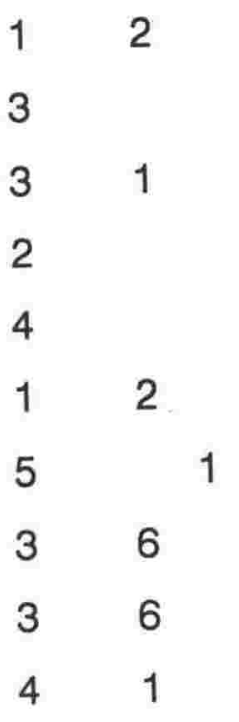

\section{Table 2. No of references to human error causes of failure by year of publication (to the end of 1975).}

About a year later Gordon Wigglesworth, a GLC housing architect, writing in the Architects Journal, ${ }^{37}$ said,

"It is easy to point a finger and attach blame, but to understand what has happened since the war we have to remember that building has been through a period of exceptional innovation. Traditional methods have been set aside to make way for new materials, products and techniques, generally exposed to no more than simulated test procedures, if that.

There has been unprecedented intervention by central government in building matters. Its agents, the ministries, have exercised control which was intended to give better value for money by the introduction of cost limits. But these limits have been concerned only with first or capital cost and have explicitly excluded revenue costs. The ministries have also promoted the use of systems of construction, principally for schools and housing, without a corresponding investment in the 
development of performance standards, testing methods and testing facilities.

There has also been an immense increase in the number of estates and buildings owned and managed by local authority education and housing departments with barely adequate resources to maintain them properly. To this must be added poorly organised feedback from maintenance organisations to design teams. Summarising, there has been:

1. exceptional innovation in building materials and techniques since the war:

2. intervention by Government in local authority building programmes by the use of cost limit systems based on capital cost only;

3. inadequate investment in the development of performance standards, testing methods and equipment;

4. a large increase in local authority owned and managed estates without a corresponding review of maintenance and feedback arrangements."

In defence of innovation and the risk innovation may entail Adam Neville, Professor of Civil Engineering at the University of Leeds was moved to assert, ${ }^{14}$

"... As I see it, the best modern design must include an element of risk if it is to be rationally based on economic criteria and possibly even if it is not but is to be new and imaginative. Yet the risk must be acceptably small, although to discuss what is acceptable and who determines what is acceptable is a large enough topic for another note.

This is not necessarily to say that we always follow this rational principle, that we all eschew other than safety considerations in making decisions in the construction industry. Departures occur, fortunately rarely ..." 
Neville's contribution was part of an on-going series of contributions to what Building called "our current debate 'Rethinking the Professional Role'", and was followed by a letter to that journal from William Allen ${ }^{38}$ of Bickerdike, Allen, Bramble in London. Allen raised the problem of inadequate specialist sub-contractors,

"... The so-called specialist sub-contractors have displayed some serious deficiencies in their understanding of the chemistry and physics of their specialisms and in our experience have been major contributors to contemporary problems. When architects lean on them for advice about products and techniques, they are often leaning on weak reeds ..."

In February 1977 Lyall Addleson ${ }^{39}$ began his technical studies under the title 'A.J. Guide to Building Failures' in the Architects Journal. Commenting on the lessons which could be learned from earlier failures, Addleson referred to the 'pressure of economics' and cited the following,

"The weaknesses of well tried materials are known and allowed for in good design; but even the best designer may have to use materials with known shortcomings because, for a particular purpose, there exists at the time no economically acceptable alternative'. (NBS Special Report 33 A qualitative study of some buildings in the London area. London, HMSO. 1964. pl.)"

Addleson went on,

"... With hindsight it is now patently obvious that, during the post-war period, far too many new materials and building techniques, most of whose shortcomings were not necessarily understood, have been used mostly because no economically acceptable alternatives seem to exist. The building industry has been under intense pressure (the social, economic and political forces alone have not been inconsiderable) to produce without adequate resources an unprecedentedly large number of buildings with quite different performance requirements from those previously encountered ..." 
The phenomenon of building failure provides, in Addleson's view, some lessons for architects. Some of those lessons may have more validity in the U.K. than in New Zealand but they are now listed, in Addleson's own words, for consideration:

1. Use of materials

(Architects) should understand the discipline that the combined use of materials, especially in modern multi-layer constructions, imposes on design solutions; or, more creatively, use this discipline as a motivation in design.

2. Determination of risk

They should recognise that modern building is not risk-free and that the best available techniques should be used to determine the risks in particular circumstances. These risks, together with the criteria on which they have been based, should be made known to (and understood by) their clients.

3. Limits imposed by cost

They should be realistic about the limitations that cost-limits or yardsticks impose on the standards that can be achieved, and resist the temptation of trying to get too much out of too little.

4. Intended life-span

The significance of the sixty-year economic life of buildings should be reappraised because, if taken too literally, buildings could be beyond economic repair after sixty years.

5. Building regulations not enough

It should be recognised that conformity with the requirements of building regulations and by-laws does not guarantee a successful building in all respects - condensation risk, for example, may be greatly increased because permanent ventilation is no longer required, and because standards of thermal insulation are in no way related to usage of the building.

6. Site craftsmanship lacking

Architects should recognise that the disappearance of the craftsmen on site, who used to be able to sort out detail difficulties, imposes on them the need 
for closer three-dimensional examination (including making models if necessary) of proposed details and the subsequent need to communicate the details chosen, clearly and explicitly, to those who will be responsible for their assembly on site. ... In addition to carefully thought-out and clearly-drawn details, rigorous specification and site supervision are required to ensure that the designer's intentions are carried out. Site personnel should be given an unmistakable indication of the quality of execution which will be insisted upon.

\section{Low safety factors}

It should be understood that the understandable tendency to reduce, as much as possible, factors of safety without a sound quantitative (or sometimes reliable empirical) basis leaves the building with very little, if any 'fat' with which to counteract unknowns - the technological imbalance is usually so fine that it does not need much to alter it, with deleterious result. it is almost true to say 'the better the science, the smaller the safety factor' and the less leeway for faulty workmanship and abuse of the completed building.

8. Use of quantitative data

Architects should learn to use and interpret quantitative data, to understand that empiric and science-based approaches cannot be mixed (except with great insight), and to accept the need for a more rigorous engineering approach to those problems that used to be solved satisfactorily by empiric means (for example, fixings and wind loading especially, and provision for differential movements, both of which have structural implications).

9. Repair of modern construction costly

Finally, they should recognise that modern types of construction are extremely costly to repair if failures occur, due partly to their greater rigidity, partly to the greater use of adhesives and partly to the greater use of mastics. As regards the latter, there is a strong case for architects to stop having such unparalleled faith in mastics to fill each and every gap in a building. They have their uses, but must be used appropriately and it must be remembered that no mastic will last the life of a building. 
In a discussion about the diagnosis of causes or sources of building defects Addleson ${ }^{4}$ had this to say:

"... One of the most difficult aspects of any diagnosis is that very often more than one cause may be responsible for the defect, although in most cases it is possible (and indeed necessary) to identify the primary cause. For example, movement may have initially been responsible for the cracking of part of an element. The crack(s) would then make rain penetration possible and the water penetration would manifest itself as dampness. In this case there would have been no dampness if there had been no cracking. But equally important, the existence of a crack and the appearance of dampness does not necessarily mean that the crack has provided the means of ingress for the water. In some cases the two defects are not related, although both will have to be remedied. Nothing can be taken for granted ...

... It is important at the outset to distinguish clearly between the cause(s) of a defect, and the agency or factor ('source' may be more descriptive) that has so to speak activated the cause(s). The cause(s) of a defect may be identified fairly easily as there are really only three basic causes of defects, namely:

dampness

movements

chemical/biological change."

In a report (author unknown) in the Architects Journal ${ }^{40}$ in May 1977 on a one-day seminar organised by the RIBA, the Association of Consulting Scientists and the Council for Science and Society, and attended by senior representatives of BRE, DOE, GLC, BSI and others, the following key ideas were said to have emerged:

1. Improved design competence can make the greatest contribution (to improved technical performance of buildings). Execution on site is the next most important area. Faulty materials or products are a comparatively minor problem. 
2. Lack of design competence is rooted fundamentally in an education system run largely by theoreticians rather than practitioners; in the lack of any accepted master/pupil training relationship in offices; and in the fiction that the newly qualified designer is as competent as the highly experienced. There should be a ladder of progression via recognised grades of increasing competence, based on experience as well as education.

3. At the level of design procedures, the greatest need is for improved checking systems, to pick up mistakes and omissions before building commences. An increased fee to allow for independent checking would be money well spent. (It is accepted without fuss in Belgium).

4. Site supervision, and the checking of materials and workmanship for compliance with the specification, must be improved. In view of the complexity of modern building technology, specialist assistance may in many cases need to be called in.

5. Possibly the greatest difficulty faced by the designer is that of information proliferation. And even if that is overcome, there remains the secondary problem of incentive to find the information.

6. It has to be made easy and presented in a way which suits the user's needs; and there must be sufficient sanctions against not using information such as liability for future defects.

7. Finally, there is too much unnecessary innovation, and not enough reliance on standard, tested solutions of known reliability. 
The report included a diagram (the source was not stated) which is reproduced below

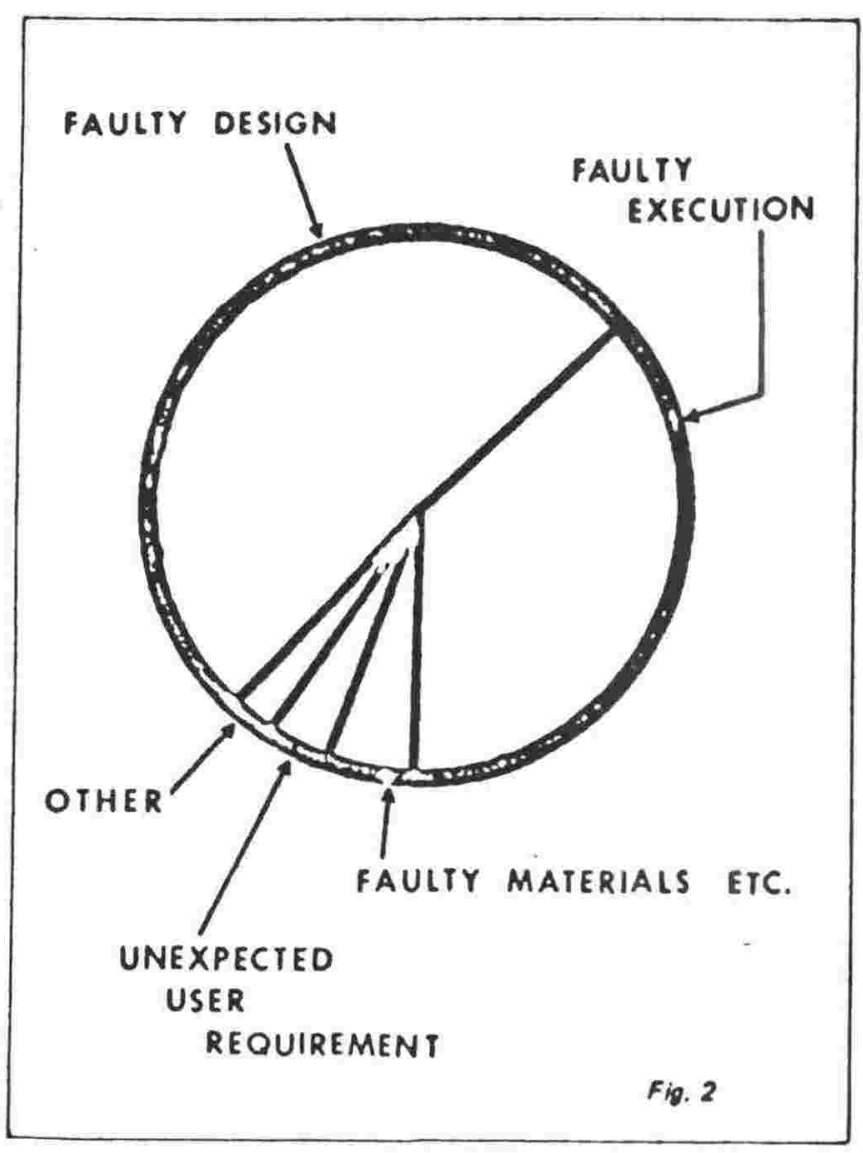

The mystery of the source of this diagram could not remain so for long. In SAAT News in August 1977, an article by J. Nelson ${ }^{16}$ from the BRE Advisory Division established that the diagram was based on an analysis of BRE Advisory Division investigations over recent years. In a paragraph headed 'The Causes of Failure' Nelson writes:

"One important conclusion we are forced to make from our analysis of failures, and indeed from our continuing daily workload is that many happen because existing, authoritative guidance, for example in BS Codes and BRE Digests, is not followed.

Failures originating in the design process appear to fall into two main categories. First, there is a neglect either through ignorance or error of well established properties of new materials before employing them. Thus either the wrong material is selected for the job or an acceptable material is used in a way which almost ensures failure. 
In the latter case the fault lies in the detailing. The properties most often disregarded concern thermal and moisture movement, water absorbency and the behaviour of the material when wet. Using a material outside the context in which it has been tested can lead to misfortune.

Secondly, designers or their detailers misjudge or ignore the conditions under which a material or an element will have to perform. Externally this applies most to the severity of exposure to wind and rain, or the heat of the sun; internally, to humidity levels and. temperature fluctuations.

A further cause of failure is the poor standard of communication between the design team and the builders. An apparent lack of appreciation on the part of the detailer of the information needs of the operative, particularly when new materials or methods are specified, leads to much uncertainty and makeshift solutions. This is matched on the builders' part by a failure to assess at an early stage what information will be needed, while there is still time to acquire it. Building operations should not become experiments.

One consequence of the information problem is that the clerk of works spends his time seeking design solutions on the ground or enquiring about the designer's intentions, and neglecting his proper role of supervision. For the same reasons there is a lack of close supervision on the part of the builder.

Builders' failures also originate from neglect of good building practice, from a failure to adhere to specification, from the use of sub-standard materials, or more likely, from a failure to store, handle properly or protect materials on site. Mention must also be made of the effect on workmanship of operative labour which either has not the appropriate skills or is poorly motivated or supervised." 
Another view of the causes of building failures was offered by $H$. Graham ${ }^{41}$ F.I.Mun.B.M, MIOB writing in Municipal Building Management late in 1977.

"... My architectural colleagues both in private practice and in the public sector claim that the causes of current bad building are stringent financial constraints; they are forced to design down to comply with cost yardsticks or tight financial restrictions with the objective of keeping initial costs down to a minimum regardless of subsequent maintenance costs. The fact is that buildings up and down the country are being erected within the financial constraints, but many are producing defects both in construction and in installation of services where urgent and costly remedial work is necessary to keep the properties habitable.

These defects which may be subdivided into basic design defects and those arising during construction on site, are now estimated to be costing building owners throughout the UK over $£ 400$ million per annum in remedial work. More care and technical competence is necessary from all levels of staff, professional, technical and artisan, to eradicate the mistakes of the last decade.

The problems are found to be resulting from incorrect detailing, poor choice of materials, defective construction techniques and workmanship and failures of innovation requiring urgent attention to protect the structure. They are quite distinct from cyclical maintenance of the normal day to day requirements of buildings in use ..."

In September 1977 W.W. Abbot, ${ }^{42}$ Principal Lecturer in Building at Lanchester Polytechnic at Coventry, reported on the results of the national survey of the opinions of four independent groups:

1. Managers in large and medium size general contracting firms.

2. Architects in medium size private practice.

3. Clerks of works employed by local authorities. 
4. Craftsmen directly employed by medium size general contractors.

The purpose of the survey was "to obtain an overall view of the relative importance of the various causes of substandard quality (in building)". Abbott found that:

1. Quality of operatives was generally agreed as the most important single factor.

2. Quality of supervision was the second most important single factor in the opinion of contractors, architects and clerks of works.

In Abbott's view, if establishing priorities for improvement of building quality is an objective, it should be remembered that the "total cost of quality" consists of three elements:

\section{Prevention}

Expenditure on preventing the occurrence of defects, such as time spent on selection and checking the previous experience of operatives, checking the quality of materials before use, specifying correct methods of working, establishing priorities, planning the allocation of supervisory time and arranging special training for operatives.

\section{Inspection}

Supervisory time spent on the assessment of quality of work during progress or on completion, related to the standards required by the specification.

\section{Failure}

Expenditure and loss caused by substandard workmanship and defective materials which have not been eradicated by prevention or inspection including materials which have to be scrapped, additional replacement materials, remedial work time, extra supervision, delays, arguments, disputes, loss of future business by failure to complete on time, reduction of client goodwill, loss of productivity due to low morale, and friction between individuals and departments. 
Abbott believes there is some evidence to indicate that, on average, total "quality cost" consists of about five percent prevention, 30 percent inspection and 65 percent failure.

A claim that negligence is the main cause of the cost of correcting defects in modern buildings was made by Eric Downey ${ }^{43}$ a director of the Macdata (Material and Components Development and Testing Association) Unit of Paisley College, in an article published in October 1977. Downey recognises that dangerous and costly disasters on the scale of Ronan Point do occur but points out that,

"... the largest part of the annual expenditure on building faults lies in the mass of relatively small-scale remedial work. The need for much of this work arises out of the failure of many of those concerned in the construction of buildings to fully utilise information readily available, concerning materials and components and their method of application, in planning the form of construction to be used. Frequently, well documented and widely accepted standards of good building practice are ignored when detail drawings are prepared. Where new or untried materials and methods are used, or where doubts exist, regarding properties of materials, these should be thoroughly tested. 'Testing in advance of use must invariably be cheaper than remedial work which might be needed afterwards. Faulty workmanship is, of course, responsible for a great many defects, but even here those responsible for the selection of the design, method of construction, or materials, might often have been in a position to foresee the possibility of such shortcomings and to cater for these in their plan."

In November 1977 the 29th Conference of the Building Science Forum of Australia New South Wales Division, considered defects in buildings as its theme. The keynote address was given by Mr Bruce McDonald M.LA, ${ }^{44}$, Member for Kirribilli, a chartered civil engineer and urban planner. In the course of his address McDonald asserted,

"Much better links must be established between the researchers and architects and they in turn must move to eliminate the barriers between the expensive professional structure which they create and the proprietor/builder. 
With the rapid technological changes, consultants and architects in particular generally have less knowledge about materials than the builders who are closer to the new products.

The inbuilding of such safeguards and communication linkages (as suggested) will go a long way to minimising defects before they even arise."

David Littlemore ${ }^{17}$ Chairman of Directors of a firm of Architects practising in Australia and Papua New Guinea, and one time visiting lecturer in the Department of Architectural Science, University of Sydney, and at the University of New South Wales, was another speaker at the Conference. Commenting on the lack of hard evidence from which to draw conclusions about the causes of building failures, Littlemore notes:

"... Generally there is little available as useful feedback, case history records about defects in buildings, which overall would be so useful to us. For I think they would disclose that almost invariably the cause is broadly in the area of the phenomenon of human error.

The absence of case history material, the silence in this area, is due at least in part to the existing defamation law. Our Journals are perhaps reluctant to publish although I am sure that such exposure, perhaps explanation, would help us all to avoid repetition of failures and faults by others. I am not suggesting really that there is nothing available as feedback and case history records for I know that in certain privileged positions, and of course under wraps, there is a record ..."

Arguing that the training for the building industry should include a larger content of 'practical' in relation to 'academic' in the programme, he goes on:

"It will be obvious that I am pretty sure that much of the blame for the defect situation lies in adequate and narrow preparation acquired in at least partial ignorance and out of insufficient exposure to the realities 
of life/work in a complex industry. Technology is rapid in development. Materials, techniques are more and more sophisticated but the fundamental truth remains unaltered and unchanged. I would never reject development and change, part of technology, nor would I object to the avant garde ideas man. There must be no inhibition or restriction, just guidance and vigilance. I insist that I welcome controlled innovation, but I want to see that it is tested and understood before any of it is put into use..."

These themes and others were picked up in the address to the same conference by A.C. Smith ${ }^{45}$ President of the Master Builders Association of NSW. He listed the following causes of building failure:

1. Poor design and documentation

2. Ineffective communications within and between the many sections of the industry, and the undercurrents of its hierarchial structure.

3. Bad workmanship,

to which he proposed the following - "relatively recent additions".

4. The building boom of the last decade.

5. Rapid technological changes, affecting both design and construction method.

6. Inadequate knowledge of the multitude of new materials and techniques.

7. Influx of migrant labour.

8. Inadequate training both on the job and in the education institutions.

9. The rapid expansion of sub-contracting.

10. Consumer awareness and protective legislation.

As would be expected at such a conference, there was a lawyer speaking on the subject. In an address entitled "Who Pays if the Roof Falls In?" A. McInness, ${ }^{19}$ a Barrister-at-Law practising in Sydney and experienced in building disputes, had this to say about defects in buildings:

"Defects in buildings almost always result from one or two causes.

The first is a design or supervision defect caused by the architect or engineer or a mistake made by a surveyor. The contracts in such 
cases are often of an informal nature, often oral and made without any thought of an error being made.

From a lawyer's viewpoint, when such a mistake occurs, it is in most instances easy to prove. Experience tends to suggest that, indeed, the author of the mistake admits to the error and the only question left is how the error is to be rectified and how much is it to cost.

The second, and far more frequent defect arises from poor workmanship by the builder or the use of poor or unsuitable materials."

One other speaker who expressed a view about the cause of building defects was I. McDowell, ${ }^{46}$ Head of the Technical Information Branch of the Commonwealth Department of Construction. Alluding to the need to transfer information from its source to where it is needed, he said:

"... Defects and failures in buildings are more often due to the failure to apply known information than to lack of information in any absolute sense. The message I wish to get over to you is to select critically and then study thoroughly, an amount of information which is appropriate to your role and responsibility in the construction industry."

In December 1977 the Overseas Division of BRE published a paper by G.E. Bessey $^{47}$ a former employee of BRE who later became an independent consultant concerned with building materials manufacturing problems and feasibility studies for new buildings as well as with the performance of materials in existing buildings. In "Avoiding Faults and Failures in Building" Bessey refers to the RIBA Seminar held earlier in the year, ${ }^{40}$ and goes on to list the following causes of "unsatisfactory building performance, defects and failures":

1. Inadequate provision of money in relation to the indicated requirements of the building.

2. Design in relation to choice of materials.

3. Inadequate consideration of environmental factors. 
4. The control of work on site.

5. Control of materials.

6. Inadequate maintenance.

7. Misuse, or alteration of use, of a building.

Writing in Building Technology and Management in January 1978, J. Newlove, ${ }^{48}$ Construction Management Consultant to the UK National Building Agency with an earlier career in civil and structural engineering and architecture, commented on what he saw as "the causes of defective design". He wrote:

"The causes of defective design can be found in the management system. Design faults arise from errors of judgement, misunderstandings and lack of care and are evidence of deficiencies in staff selection and supervision. They ought to be avoided or remedied by normal office procedures and it should be impossible for a serious design error to escape detection before completion.

In addition to any earlier controls which are applied, adequate safeguards necessitate some control of information just before it leaves the design office. It needs to be checked before it is used by quality surveyors, other consultants, or contractors. How is it, then, that such information rarely bears a checker's signature? Notwithstanding this neglect, the fact that major design faults get built would seem to imply some criticism of subsequent users of the information (or at the very least lack of awareness on their part)."

By the end of 1977, the opinion expressed by the various commentators can be summarised by Table 3 . 
Defective materials

12

Overlooked site condition

Ignorance

$\begin{array}{lll}3 & 1 & 5\end{array}$

Over-emphasis on first cost

$2 \quad 13$

Defective documentation

Unanticipated consequence of change

$\begin{array}{lll}1 & 2 & 4\end{array}$

Specialist contractor's lack of knowledge

Design too difficult to build well

$\begin{array}{lll}3 & 6 & 3\end{array}$

Dereliction or negligence

36

4

Poor communication

41

6

Table 3. No of references to human error causes of failure by year of publication (to the end of 1977).

Tom Hughes ${ }^{49}$ lately regional works officer in the UK Property Services Agency (PSA) South East Region, discussed failures and remedial work in an article in Construction in March 1978. Advocating improvement of the "interface between design and maintenance" Hughes asserts:

\begin{abstract}
"The cause of many failures in the building industry generally, is often due to there being little contact between the designers/providers of new buildings and those who use, operate and maintain them. It is easier in the PSA because all these facets are embraced by the one organisation, but even so, more needs to be done to ensure that design staff get early enough advice on the maintenance implications of their proposals."
\end{abstract}

April 1978 saw publication of a paper by E. Bampton ${ }^{50} \mathrm{FIOB}$, in the Institute of Building (IOB) Maintenance Information Service series. Examining the causes of defects or failures in buildings, Bampton comments:

"It is difficult, for a number of reasons, in most cases to establish the absolute cause of failure, if indeed there is one. In general terms, 
however, they can usually be regarded as being initiated from one of the following:

(i) The client either did not provide a brief or provided one which was inadequate.

(ii The client changed his mind during construction.

(iii) The site investigations were not satisfactory.

(iv) The design team failed to provide, on time, the necessary detailed drawings.

(vi) The design team's details did not allow for differential expansion, or for proper damp proof coursing, or for weatherproofing.

(vii) The contractor/subcontractors interpreted instructions incorrectly.

(viii) The contractor/subcontractors used the materials incorrectly or used wrong jointing materials.

(ix) The contractor/subcontractor's lack of proper site supervision or poor craftsmanship.

It is clear that all three parties involved - the client, the architect and the contractor - can contribute to failure but the main factor would appear to be that of communication. It is in the interests of all parties to exert their efforts in resolving the problem and thereby improve efficiency and reduce costs."

An article in New Scientist in May 1978 probably crystallised some of the issues involving building failures and their cost to the industry. Peter Marsh ${ }^{2}$ began his report on events with an estimate of the cost of failure:

"Some maintenance (of buildings) is, of course, to be expected - just as humans need a dose of medical care once in a while - but repairs and improvements nowadays account for about £3.5 billion of the industry's annual output of $£ 12$ billion. An estimated fifth of this maintenance is due to construction errors. The industry is becoming increasingly concerned because the number of mistakes coming to light appears to be growing every year. 
The injection of more scientific thinking - the job of organisations like the BRE - might be expected to improve matters. But science is not an easy discipline for the industry to take on board. The basic activities of the building industry - job such as mixing cement or laying bricks - have little likeness to laboratory processes, especially when carried out on a dirty, chaotic building site."

After describing the complicated structure of the UK building industry, Marsh goes on:

"Superimposed on this welter of human activity is a mass of regulations bombarding the builder from almost every conceivable angle. First there are the official Building Regulations, statutory documents applying to every new building. These are so wrapped up in legal jargon that they are incomprehensible to most people including many of the architects and council officers who have to interpret them. There are planning rules laid down by both central and local government which cover everything from maximum densities, expressed in fractions of people per acre, to the number of outside drains a structure can have. Add to this approximately 2000 certificates and codes of practice from organisations such as the Agrément Board and the British Standards Institution - covering recommended ways of going about the minutiae of construction - and it is a wonder anything gets built at all."

Marsh points out that a quarter of the BRE's budget is spent on disseminating information about the fruits of its research, but notes:

"The BRE has estimated that 90 percent of design errors arise because of a failure to apply existing knowledge. Many of the defects that have come to light over the past few years had eminently avoidable causes."

He goes on:

"Ironically, many of the faults showing up today are the results of the 'high technology' era of the 1960s when the construction industry flirted with 'system' building. In theory this approach had much to 
offer. The assembly on site of factory-made components - such as concrete slabs to form the basic building blocks of walls and floors seemed much more efficient than the old fashioned use of bricks and mortar. However, the industry failed to come to terms with the high precision demanded by the new techniques. The concrete panels which should have slotted neatly into place often didn't; the seals between the panels were sometimes of incorrect material and let in water. Simple things - for example, the concrete in the slabs expanding after drying and pushing out adjacent brickwork - were not allowed for".

"... There has been no clearer indictment of these 'innovative' building methods than the Greater London Council's report, published two years ago, which blamed the methods almost totally for $£ 38$ million worth of design problems on council estates barely ten years old. Today, system building is scorned because of the maintenance problems and the fact that it lent itself to the high-rise buildings methods in favour in the 1960s which are so roundly condemned on social grounds."

Writing in Technical Record 448 published in February 1979 by the Experimental Building Station, Department of Housing and Construction, in New South Wales, V.R. Beck ${ }^{51}$ recorded that in a survey of failures of wall claddings and finishes there were some common aspects. Usually at least one of the following was listed as a reason for the failure:

1. During the design there was a failure to recognise fully the significance of differential movement (due to inherent material properties and/or different load and exposure conditions) between the various materials used.

2. Contract documents failed to provide details of construction techniques to be adopted in critical areas, or omitted to highlight the relative importance of certain aspects of the design for the guidance of builders and supervisors. In some cases reliance was placed on "accepted practice" without an assessment of its adequacy. 
3. Critical requirements were not faithfully carried out during construction.

4. Adequate resources were not provided for the supervision of critical aspects of the construction.

Analysing the question of blame for building defects, Paul Marsh' ${ }^{52}$ Chief Architect for a construction company and a visiting lecturer at Surrey University suggested:

"The blame sequence goes like this. First the material of construction is blamed. Something must be wrong with it, or the particular form it takes in this particular building. As the material is inert and voiceless unless it is a proprietary material backed by a large commercial organisation, this is easy game - and the buck may prematurely come to rest there. If it passes on, it moves inexorably to the builder. Imputations of bad workmanship are made. Cavities are peered down, as though for the first time, the client's architect forgetting that that was what his clerk of works was supposed to be doing during the process of the works. Whoops of joy are emitted over the discovery of a dirty wall tie, but let's face it, there is not one building in the world where there is not at least one minor lapse of workmanship. This is the sort of game building is; and basic building design should be able to cope with the occasional slight lapse. The very last thing to be blamed is the design; and yet the design is more likely to contain the fundamental weaknesses from which, maybe with contributions from the other two buck stages, the failure originated.

With the best will in the world, the architect will look for weakness first in the materials of construction, then in the standard of workmanship before (if he ever gets around to it) questioning his own detailing.

The problem is that too little respect is given by designers to the less tangible aspects of providing a weathertight building shell, such aspects as the site exposure, linked with building height and the relationship of one building to another. In addition, they are curiously unaware that a lot of the techniques they have rushed to use in the last twenty years are relatively untried and without historic evidence of 
survival. These they force into evermore demanding climatic locations, often with a personal experience which does not - could not - allow them to assess the validity of what they are doing. ..."

He concludes

"The lesson to be learnt is that if failure occurs, it is most important to investigate all three aspects of the operation - materials, workmanship and design. Do not let the buck stop prematurely, even if shortcomings are discovered. You may still have not found the real culprit."

In the summary to a report on building defects in private and public sector housing prepared by the UK National House-Builders' Council ${ }^{3}$ in June 1979, it was recorded:

\footnotetext{
"Subjective judgement by NHBC inspectors is that recognition of bad ground, simple design and good site supervision are all crucial factors (in the incidence, causes and prevention of defects)."
}

Looking to the future, the report says:

"The evidence, both from Scotland, and from the comparison of defects in public and private sectors, suggests that fewer defects occur where design is simple, and where traditional methods are used. In both public and private sectors no evidence has been produced which shows any correlation between the incidence of defects and the scale on which local authority building control is provided ..."

A plea for deeper understanding of the properties and limitations of building products, not solely by the architect, was made by Bill Allen ${ }^{53}$ of Bickerdike, Allen and Partners, a former senior architect at the BRE, at a seminar on failures and defects in modern council housing. Allen claimed no-one was to blame for building defects which arose from the unforseen consequences of changes in the characteristics of building materials or building use. 
A report in the November 23, 1979 issue of Building Design ${ }^{54}$ was less reluctant to attribute blame. Under the bold headline "Scandal of New Failures" the publication reports on Building Design's survey of 22 local authorities in England and Wales, dealing with nearly 50 estates housing 30,000 people. The report claims:

"Poor workmanship, faulty design and shoddy materials on local authority housing completed since 1974 will cost millions of pounds to remedy ...

... The investigation claims that none of the horrors of the 60s have caused mistakes to be rectified in the late 1970s despite increased technical knowledge ..."

After the literature survey has covered a period of 10 years since the first opinion considered, the opinions about the types of human error can be summarised in Table 4.

HUMAN ERROR

YEAR: ‘69-73 747576777879

Defective materials

Overlooked site condition

Ignorance

Over-emphasis on first cost

Defective documentation

Unanticipated consequence of change

Specialist contractor's lack of knowledge

Design too difficult to build well

Dereliction or negligence

Poor communication

\begin{tabular}{|c|c|c|c|c|}
\hline 4 & 2 & & & \\
\hline 3 & & 1 & 2 & \\
\hline 3 & 1 & & 5 & \\
\hline 2 & & 1 & & \\
\hline & & & 3 & 1 \\
\hline & 2 & & 4 & 1 \\
\hline & 1 & & & 1 \\
\hline & 6 & & 3 & 1 \\
\hline & 6 & & 4 & 2 \\
\hline & 1 & & & 3 \\
\hline
\end{tabular}

Table 4. No of references to human error causes of failure by year of publication (to the end of 1979). 
In the course of a paper on the role of feedback in building design, Derek $\mathrm{J}$ Croome ${ }^{20}$ Senior Lecturer at the School of Architecture and Building Engineering, University of Bath, wrote:

"The causes of failure in building design are various - an inadequate brief and specification; a genuine lack of data on certain aspects; poor communication between the client and the design team, and between the members of the design team, themselves; inadequate analysis or synthesis of solutions; unpredictable quirks of human behaviour resulting in poor installation or maintenance may each or all contribute."

The Architect's Journal of 30 April 1980 carried a report from R. Bonshor ${ }^{55}$ on interim results from a survey of faults in traditional low rise housing. Bonshor reported:

"This interim report has covered only the most frequently occurring and readily explained faults revealed by limited site inspection. Inspections could not cover every stage of construction on a site and yet each site typically yielded between 100 and 150 faults.

Analysis shows that those faults are about equally distributed between design and construction errors. And they occur despite - or perhaps in part because of - the prodigious quantity of information, recommendations and mandatory requirements that already exists."

The Building Science Forum of Australia (NSW Division) selected the subject 'Use or Misuse of Building Material' for its 36th Conference in Sydney. One speaker at the Conference was Graham Holland ${ }^{56}$, Senior Lecturer in Architecture, University of Sydney, who dealt with the sort of education (on the selection and behaviour of building materials) required by consultants in general and architects in particular.

He began:

"It is important that this education should concentrate on the principles of materials and their behaviour rather than just transmit current industry lore. That is, it should concentrate on the way materials are 
made, their characteristics such as density, strength, thermal, acoustic, electrical and optical properties, colour, texture, ease of cleaning, deformations caused by applied loads, temperature and moisture changes and so on, rather than merely describing the materials and the way they are used. It needs to be explanation and not just description."

\section{Later he says:}

"The behaviour of materials in their assembled form is also fairly well documented, but as the situations in which materials are used will vary greatly, it is not possible, and as I have suggested earlier, nor desirable, to try and describe recipes for every situation, but rather ensure that the appropriate principles are known and applied ...

It is not really possible to educate designers about materials, without dealing with the way in which materials are put together. This includes methods of handling materials, assembling them on site, and workmanship."

On the subject of 'short cuts' for cost-saving purposes, Holland comments:

"Some of the short cuts with materials taken by designers are the result of pressures to reduce costs, sometimes for clients who don't seem to realise, or care about the long term consequences, particularly in cost, of taking risks with materials and their assembly.

Design decisions also involve risk taking, a nervous process at the best of times. The risks may result from pressure to reduce costs, or they might result from a desire to innovate, to try something new, and hopefully better. Designers need to assess very carefully the information available to them, and unfortunately some of the information, particularly about new materials, leaves much to be desired." 
Another speaker was R.D. Roxburgh ${ }^{57}$ an architect and Associate Director (Projects) in the NSW office of the Commonwealth Department of Housing and Construction. Starting with the premise that:

"Defects arise from a number of sources most of which are interrelated and some of which are the result of the selection and utilisation of inappropriate materials, ..."

he went on to mention the following factors contributing to materials misuse and consequent building defects.

1. The abundance of information from thousands of sources upon which the designers and builders base many of their decisions in selecting systems and materials, the availability of sophisticated materials and the wide range of associated literature which is part of the marketing process, is not matched by effective information on the performance of some of these materials in practice.

2. Most materials produced by reliable and well established firms are satisfactory in themselves if properly selected for the purpose, and it is generally in the installation or application of them that difficulties arise, particularly as a result of the interaction between materials installed by different trades groups.

3. The difficulty with trade or technical information which is readily available from many sources is deciding which is the most appropriate for each purpose. Until designers are experienced enough to rely on their practical experience to determine the effectiveness of particular materials or systems they constitute something of salesman's dream.

4. It is a point of conjecture whether there is reasonably widespread industry knowledge of the results of research on particular problems associated with buildings.

5. The fundamental problem is not that there is a shortage of information but that there is an overabundance of it, which is generally not effectively used 
throughout all levels of the industry. If this is not so, then why do the same problems occur?

John Palmer ${ }^{58}$ Director of an Australian company specialising in building maintenance and waterproofing also delivered a paper to the Conference. On the subject of building materials failure he commented:

"It is significant that the company for which I work, spends more of its resources on investigating and providing solutions for maintenance on 'new' buildings than it does on buildings of our heritage. And that is because of an ever-increasing need to 'prop up' our highly technical construction systems, to interpret failure mechanisms in new materials and technology which are sometimes on the part of the designer the failure of practicality rather than of material performance."

Later he goes on:

"However, an understanding of the fundamentals of material types helps to relate the interaction and possible areas of failure. Knowledge and use of regulations do not excuse impractical design or construction systems and very often the excuse of warranties or guarantees or performance specifications, call them what you will, offer building owner or clients very serious maintenance problems well within the periods prescribed."

At a seminar on weathertightness and water penetration of buildings held in November 1980 , E. Downey ${ }^{59,43}$ suggested that building defects are the result of bad design, which manifests itself in one of the following ways:

1. The designer has not given sufficient thought to specific details.

2. The designer has relied upon a standard of workmanship and adherence to tolerances which are not normally achievable.

3. New materials or processes have been adopted in the design which are incompatible with other features. 
In November 1980, P.H. Nice ${ }^{60}$ a consultant on matters of building failures and defects, contributed an article to Building Technology and Management, reporting on the experiences of his organisation. He wrote:

\begin{abstract}
"Most of the failures we have investigated were due to a combination of bad design and specification, incorrect choice of materials and deviations from good practice. It would appear that on occasion too much is expected from new materials which, although subjected to vigorous testing, have not yet been proven over a number of years in service. Testing in accordance with specification involves standard samples tested on standard machines in standard conditions which do not and cannot claim to stimulate service conditions.
\end{abstract}

We have also found that compatibility of materials is often a problem. Different materials with different properties (eg thermal, creep, strength, resistance to exposure) behave in ways which may be detrimental to the adjoining material or component."

Nice's views appear to be endorsed to some extent by W.H. Ransom ${ }^{61}$ in his book Building Failures. In his introduction he writes:

"Most building defects are avoidable; they occur, in general, not through a lack of basic knowledge but by non-application or misapplication of it. Knowledge seems to become mislaid from time to time. Those with long memories, and those whose business it is to make a particular study of building defects, are often struck by the reemergence of problems which have been well researched and documented."

Interestingly, Ransom takes up a theme first developed at the 36th Conference of the NSW Division of the Building Science Forum ${ }^{56}$ which is that of the appropriate training for people entering the building industry.

"Current training in design tends to concentrate on what to do rather than what not to do. A similar situation exists in training in 
constructional techniques, where the craftsman is instructed how best to undertake a particular operation but, to a lesser extent, in the dangers of deviation from an accepted technique. Understanding of the likelihood of defects through inadequate design or construction is taught implicitly rather than explicitly. The level and nature of defects in building construction currently encountered suggests that more guidance is required on the avoidance of failures. A need is seen, too, for such guidance to be a positive part of a training curriculum. Indeed there a good arguments for suggesting that, as the first essential in design and construction is to ensure that the structure provided is stable and durable, specific education in the avoidance of failure should be a major part of any design and construction syllabus."

After citing the results of BRE studies of building failure, Ransom goes on to write about reasons for failure.

"There seems little doubt that a major reason for failure in construction is the complex structure of the building industry. Despite the calls for closer integration of design and construction, made many times over the years, these two vital roles are still essentially separate."

Commenting on changes in the construction industry:

"The loss of craft skills has been matched at a more professional level by a reduction in the number of those able to comment sensibly on the likely interactive effects of changes in materials, components and procedures. Many of the problems which have beset so-called industrialised building systems have stemmed directly from the general inability in the construction industry to understand these interactions, together with inadequate matching of site skills to the new technology."

On technical recommendations:

"In some cases, the technical recommendations, although available, are not readily available, and while they do state 'the truth and nothing 
but the truth' it is, sometimes, 'not the whole truth'. Thus, some failures, though probably a relatively small portion of the whole, do stem from knowledge which is less than comprehensive."

On innovation:

"While innovatory pressures have been considerable, the requirement for adequate control and certification of these has lacked 'bite'. ... In the longer term, and at its most extreme, there is a possibility that innovation will make existing knowledge and skills redundant. If the innovation is enduring and valuable, this may be acceptable, but if not, the nation will be the loser. But, perhaps the biggest danger of all lies in the inadequate mechanism for control of the innovation to safeguard the user"

Editorial comment in the Chartered Surveyor $^{62}$ in April 1981 was trenchant in its criticisms of those whom it felt were responsible for building defects.

"Prime offenders are architects, many of whom have responded irresponsibly to the demands of their clients to cut costs. This is married to an inadequate training in building construction and maintenance and an emphasis on innovative design. The resulting absence of tried and tested prototypes means faults are not revealed before designs are built in large numbers. Contractors with an eye to low costs and high profits also share the blame; for instance, inadequate on-site supervision has contributed to the ineffectiveness of some system housing.

The Government will largely be footing the UK's building defect bill and the Government played a role in the creation of those defects by pressuring local authorities to build fast and inexpensively."

In the same issue, C.A. Drury ${ }^{67}$ a partner in a firm of chartered surveyors, categorised building defects and causes in the course of an article on the effects of major defects on investment in buildings. His categories were:

1. Defects in design 
2. Defects in workmanship

3. Defects in materials used

4. Defects in services

5. Defects through lack of maintenance

6. Defects through obsolescence

7. Defects through extraneous circumstances.

Andrew Rabenek ${ }^{1}$ a Director of Building Systems Development (UK) Ltd, was writing at about the same time as Drury, but in the Architect's Journal. By this time the problem of building failures was becoming so serious that Rabeneck was able to state, without exaggeration,

"Those closely involved with building defects - maintenance staff, investigators, insurance underwriters and managers of testing laboratories, not to mention occupants of new housing - are coming to believe that a high potential for failure is endemic in our system of design and construction. Defects happen because of, rather than in spite of, the way we go about getting the buildings we need.

... Naturally those failures which are discussed in the press tend to be spectacular, involving innovations that went wrong, and so on. As a result an impression could be gained that innovation is the root cause of failure, but that would be imprecise. It is truer to say that as the specifier's choice has broadened away from well understood conventions, so the scope for uncertainty and error has increased, and thus the probability of defects arising."

Rabeneck then goes on to suggest a list of causes of building failures, with examples of each.

1. Collective amnesia

2. Side effects of innovation

3. Lack of anticipation

4. Bureaucratic confusion

5. Misplaced optimism 
6. The false economy

7. The ignorant specialist

8. Sheer incompetence.

Similar causes of failures or defects were mentioned by G.Atkinson ${ }^{64}$ in an article on the subject published in May 1981. Commenting on the fact that failures persist despite existing knowledge of ways of avoiding them, Atkinson wrote:

"For one or more reasons - inexperience, carelessness, pressure of work, poor office organisation, ill-defined responsibilities, excessive enthusiasm for novelties, unquestioning acceptance of a supplier's claim - readily available advice had been ignored, or the seriousness of its neglect not appreciated".

A Current Paper from BRE published in 1981 reported on a study of quality control on building sites. The author, M.J.C.Bentley ${ }^{65}$ drew the following conclusions from the research.

1. In general, quality standards on site did not rely significantly on formal checking and acceptance or rejection of completed work. Instead they resulted from the clerk of works, together with the site agent, putting great efforts into creating an environment where good work could and was likely to take place.

2. For a disturbing number of problems, particularly the serious ones, identification of the problem on site did not result in effective remedial action being taken. Major reasons for this were that the clerk of works did not normally have the authority to press for effective remedial action and architects put too little effort into understanding and solving problems on site.

3. Tradesmen's lack of skill produced comparatively few faults, a much larger number being produced by lack of care. However, clerks of works and contractors' site staff seemed able to cope with most of these types of problems fairly well. 
4. The architect's contribution to quality was predominantly through the quality, completeness and accessibility of the project information ie drawings, specification, and bills of quantities. Poor project documentation could have a very detrimental effect on quality, both because of the errors and delays arising directly, and because of the depressant effect on site morale.

5. The clerk of works and site agent had key roles in determining the quality actually achieved. Deficiencies in one's knowledge could be made up by the other, at the risk of some blurring of their contractual roles. On balance, this willingness to work outside formal limitations, by allowing fuller pooling of available expertise, was beneficial.

6. Sites with acceptable quality standards tended to be characterised by a 'consultative' approach to problem-solving - anyone on site could raise questions and many individuals could contribute to solutions - whereas sites with low quality standards tended to be 'non-consultative' with only the clerks of works really concerned with quality matters.

The range of industry opinion revealed by the literature survey up to the end of 1981 in summarised in Table 5.

HUMAN ERROR YEAR: '69-73 $74 \quad 75 \quad 76 \quad 77 \quad 78 \quad 79 \quad 80 \quad 81$

Defective materials

Overlooked site condition

\begin{tabular}{|c|c|c|c|c|c|c|}
\hline 1 & 2 & & 1 & & 2 & \\
\hline ? & & 1 & 2 & & 1 & \\
\hline & 1 & & 5 & & & 1 \\
\hline & & 1 & 3 & & & 1 \\
\hline & & & 3 & 1 & & 1 \\
\hline & 2 & & 4 & 1 & 2 & 4 \\
\hline & 1 & & 7 & 1 & 2 & \\
\hline & 6 & & 3 & 1 & 3 & 3 \\
\hline & 6 & & 4 & 2 & 2 & 3 \\
\hline & 1 & & 6 & 3 & 1 & 4 \\
\hline
\end{tabular}

Table 5. No of references to human error causes of failure by year of publication (to the end of 1981). 
Any examination of the causes of building defects or failures must take account of the point made by $\mathrm{H}$ W Harrison ${ }^{22}$ from BRE in a paper prepared for presentation to a CIB Symposium in June 1982.

\begin{abstract}
"We need to distinguish carefully between a fault in design or construction giving an immediate risk of deficient performance, and a fault where initial performance is satisfactory, but which can be expected to deteriorate with time.
\end{abstract}

The immediate deficiency in performance can be illustrated with the fault, common in the survey, of gaps being left in the masonry of a separating wall between dwellings. That the wall will certainly fail from the point of view of both sound and fire is not in question. There are however different probabilities of failure with time for the different performance attributes. The first days of occupation of the dwelling will produce noise of a kind, which will be heard next door, whereas the risk of a major fire, exposing the lack of integrity of the wall, might be as little as once in one thousand years."

The degree of understanding of materials by designers was again alluded to in an editorial in the IOB Journal Building Technology and Management ${ }^{66}$ in April 1982. The editorial underlined points made by a consulting engineer at a 'failures' conference in London a month earlier, asking why, when the effects of rain, frost and wind are well-known, buildings have been constructed which let the elements take their toll. Also queried was the lack of understanding which resulted in composite structures failing through differential movement or incompatible materials. Was the science of materials sufficiently understood by builders and designers?

Writing in the same journal a month later, W.G. Roberts ${ }^{67}$ argues that innovation is not of itself a proven cause of building defects. Roberts argues,

"First of all, what constitutes an innovation? In the strictest dictionary terms an innovation is 'the introduction of novelties; the alteration of what is established'. To put it simply, I take this to mean a new product, material or technique which supersedes an existing method. 
Of course implicit in the word innovation is the hidden assumption that the 'new' is also superior. Within this broad definition the term innovation can be applied not only to a new product, material or technique but also to imported products and technology which have not been previously used in this country, the use of established products in a 'new' way - change of function or location; design solutions at variance with established practice - where, for example, an architect designs his own solution to a standard problem or detail.

Clearly, if the term is used in its widest sense then the proposal can be verified since almost all failures can be attributed to poor design, inappropriate use of materials or faulty workmanship. However, I do not believe this is the valid interpretation for the subject of this paper. For our purpose, innovation will be taken to mean strictly a new product, material or technique used in the construction of a building. It then becomes apparent that the statement 'innovation is a major factor ...' cannot be substantiated in the face of the available research evidence on failures and defects. This is one of industry's 'myths' originating from the media's pre-occupation with spectacular disasters like Ronan Point, HAC and more recently Bison Wallframe, all of which at one time or another have been attributed to innovation. Although innovation may be a contributing factor either on its own as a minor cause or, to a greater extent, in combination with other factors, it certainly cannot be classified as a major cause."

Research results published in Australia by R. Donaldson ${ }^{68}$ Lecturer in Construction and Technology and Design, Department of Architecture, University of Newcastle, NSW in June 1982, was based on the following categories of faults:

1. Faults in documentation.

2. Faults in construction including -

(a) workmanship

(b) quality control

3. Faults in occupied buildings.

In his conclusion, Donaldson wrote, 
"Many of the failures evident in the surveyed housing stock can be directly attributed to poor quality workmanship and the lack of close site supervision during the progress of the construction of the buildings. The need for proper site supervision is particularly important, when the nature of the site personnel and their building expertise is considered. This is especially so in remote areas where personnel may come as a result of high wages rather than building expertise. Too few works supervisors inspecting the work of many semi-skilled personnel can too often result in the poor standard of work and the wide range of faults described in this paper.

The economics of building in remote areas will very often demand that products be manufactured from local material on site rather than be transported thousands of kilometres by rail or road. When materials such as concrete and concrete blocks are manufactured on site, strict control is necessary to ensure that the end product conforms to the minimum conditions of quality established by the various building codes and the Standards Association of Australia. However, no amount of quality control kept on the materials or their assembly can produce a satisfactory building unless that building has been designed appropriately from the outset.

Houses which were intended for families in a temperate climatic setting have no place in the extreme climate of most Australian mining townships. Materials and components which are acceptable in more temperate climates simply do not behave as predictably under extremes of temperature, wind and moisture. Decisions, often made without an understanding of the technological or environmental problems of housing in hot dry regions, cause massive expenditure on the part of the building's owners and unnecessary inconvenience on the part of its occupants."

Meanwhile, discussion about the role of innovation in buildings defects and failures had not stopped. Professor E. Happold ${ }^{69}$ from the University of Bath, writing about the historical record of innovation in the building industry since 1751, comments: 
"The question to be answered is not whether innovation in materials and technology makes a major contribution to difficulties and failures in building but whether our existing organisation is well adapted to use innovation in materials and technology, not just for toaky but to serve efficiently the needs for the immediate future."

BRE News Winter Edition 1982 announced the completion of a three year study of nearly TOOS alifferent kinds of faults in low-rise traditional' nousing by R.B. Bonshor ${ }^{55}$ and H.W.Harrison ${ }^{70}$.

It was noted that few faults were related to innovation - only about 3 percent were related to new material or construction methods introduced since 1975. As the authors point out:

"When frequency of occurrence (and not simply type of fault) is taken into account, design faults - which were apt to repeat on all dwellings of the relevant type - tended to outnumber faults of site origin. Out of the total number of faults, 50 percent were attributed to design, 41 percent to site and 8 percent to materials."

The final optimistic word, for the moment, goes to John Duell ${ }^{71}$ a partner in a firm of British architects, writing in the Architect's Journal. While noting that building failures are still happening, Duell suggests that headway is being made in combating the various causes of failure, frequently by improvement in the communication of information. Duell believes:

"Building defects are rarely caused by a basic lack of knowledge in the construction industry as a whole. The problem is to ensure that the relevant information is available to the individual at the time a decision is made. The complexity of modern construction makes it impossible for the designer to retain all the information in his head." 
The opinions of the various commentators as to the types of human error which can contribute to building failure are summarised in the table below. The table shows the number of references to human error causes of failure in each year surveyed.

\begin{tabular}{|c|c|c|c|c|c|c|c|c|c|c|c|}
\hline HUMAN ERROR & $9-73$ & 7475 & 76 & 77 & 78 & 79 & 80 & 81 & 82 & 83 & Total \\
\hline Defective materials & 1 & 2 & & 1 & & 2 & & 1 & 2 & & 9 \\
\hline Overlooked site condition & 3 & & 1 & 2 & & 1 & & 1 & 1 & & 9 \\
\hline Ignorance & 3 & 1 & & 5 & & & 1 & & & & 10 \\
\hline Over-emphasis on first cost & 2 & & 1 & 3 & & & 1 & 2 & 1 & & 10 \\
\hline Defective documentation & 4 & & & 3 & 1 & & 1 & 2 & & & 11 \\
\hline Unanticipated consequence of change & 1 & 2 & & 4 & 1 & 2 & 4 & 2 & 1 & & 17 \\
\hline Specialist contractor's lack of knowledge & 5 & 1 & & 7 & 1 & 2 & & 3 & 1 & & 20 \\
\hline Design too difficult to build well & 3 & 6 & & 3 & 1 & 3 & 3 & 1 & 2 & & 22 \\
\hline Dereliction or negligence & 3 & 6 & & 4 & 2 & 2 & 3 & 3 & 2 & & 25 \\
\hline Poor communication & 4 & 1 & & 6 & 3 & 1 & 4 & 4 & 1 & 1 & 25 \\
\hline
\end{tabular}

Table 6. No of references to human error causes of failure by year of publication (to the end of 1983).

\section{REFERENCES}

1 RABENECK, A. Facing up to failure. Diagnosing and preventing defects. Architects Journal., vol 173, no 15, 15 April 1981.

2. MARSH, P. Why do Britain's Builders bungle the job? New Scientist, London, May 1978.

3. NATIONAL HOUSE BUILDERS COUNCIL (U.K.) The incidence, causes and prevention of defects in private and public sector housing. NHBC, UK, June 1979. 
4. ADDLESON, L. A.J. Guide to building failures. Architects Journal, London, 2 March 1977, pp 415-419.

5. STRINGER, G.E. What is Quality Worth? is in Quality Control. Report on a conference organised by U.K. Ministry of Public Buildings and Works. 1970. H.M. Stationery Office.

6. CHEETHAM, D.W. Defects in modern buildings. Building, Part 1, vol 225, no 6805, 2 November 1973, pp 91-94. Part 2, vol 225, no 6807, 16 November 1973, pp 175-176, 179-180, 182, 187-188.

7. KIMBER, K.G. Pathology of Building. Contract Journal, vol 225, 25 October 1973, pp 38-39.

8. HIGBY, H.C. Defects in buildings: The client's viewpoint. Chartered Surveyor: BQS Quarterly, vol 2 March 1974, pp 52-54.

9. FREEMAN, I.L. Failure Patterns and Implications. in Joint BRE/IOB Seminar on building defects and failures. IOB, Ascot, Berks, U.K. 1974.

10. FANTL, K. Building defects: The client's viewpoint. Building Research and Practice, Jan/Feb 1974, pp 23-26.

11. SAAT NEWS. Avoidance of building failures. Extracts from Parts $4 \& 5$ from the Greater London Council's Materials and Information Bulletins Nos 79 and 80 reprinted with permission, July 1975, pp 16-19.

12. BUILDING RESEARCH ESTABLISHMENT (BRE). Failure patterns and implications. Digest 176. HMSO, U.K April 1975.

13. NIELSEN, K. Attention to details, Building 240, no 19, 8 May 1981, pp 60-61.

14. NEVILLE, A. Not Guilty of Professional Failure, Building, vol 232. 11 February 1977, pp 83-87. 
15. ABвOTT, W.W. Quality costs in building, The Quantity Surveyor, June 1977, pp 193-195.

16. NELSON, J. The nature of common defects in building, SAAT News, 28 August 1977, pp 7-8.

17. LITTLEMORE, D. Building Defects - who dunnit? in Proceedings of the 29th Conference of the NSW Division of the Building Science Forum of Australia. Published by the BSFA, NSW Division, Sydney, November 1977.

18. FREEDMAN, B. Engineering Services: Environment for Productivity - who needs it? Building Research and Practice, Jan/Feb 1974.

19. McINNES, A. Who Pays if the Roof Falls In? Proceedings of the 29th Conference of the NSW Division of the Building Science Forum of Australia. Published by the BSFA, NSW Division, Sydney, November 1977.

20. CROOME, Derek J. The role of feedback in building design, Building Services Engineering Research and Technology, vol 1, no 1, 1980, pp 1-9.

21. ANDERSON, W.F. Assessing the Risk, Building Defects - Supplement to Chartered Surveyor, April 1981.

22. HARRISON, H.W. Practical problems in Estimating Effective Service Life of Components and Elements in Housing - Paper presented to $\underline{\text { C.I.B }}$ Seminar W60 (The Performance Concept) University of Strathclyde, Glasgow June 1982.

23. PORTEOUS, W.A. Perceived characteristics of Building Failure - a Survey of the recent literature, Architectural Science Review, vol 28, no 2, June 1985. 
24. O'BRIEN, T.P. Quality Control on Site, Quality Control. Report on a Conference organised by U.K. Ministry of Public Buildings and Works. 1970 H.M. Stationery Office, 82pp.

25. ARCHITECTS JOURNAL 28 July 1971, p 187. Building Failures, vol 154, no 30, 28 July 1971, pp 187.

26. BICKERDIKE, ALLEN, RICH AND PARTNERS in association with TURLOGH O'BRIEN, Building, vol 221, 24 September 1971, p.107.

27. POWELL, M. The Incidence, Causes and Prevention of Defects in the Construction of New Houses. The Housing Research Foundation, U.K. 1971.

28. CONSTRUCTION INDUSTRY RESEARCH AND INFORMATION ASSOCIATION (CIRIA). Serviceability of Buildings in Development and Materials Bulletin of GLC, vol 63, March 1973, pp 2/1-2/7.

29. THE ARCHITECT AND SURVEYOR. Faults in New Buildings - A Report. May/June 1973, pp 9-12.

30. HARDY, A.C. Opening Address to Symposium on Design Failures in Buildings, Building, 24 May 1974, p 63.

31. ELDRIDGE, H. Common Defects and Their Diagnosis. Paper delivered to a joint BRE:10B Seminar on Building Defects and Failures, 29 November 1974.

32. HARPER, D. The Designers' Viewpoint (as above).

33. DEVELOPMENT AND MATERIAL BULLETIN OF GLC. vol 79, October/November 1974, p 2/11.

34. DEVELOPMENT AND MATERIAL BULLETIN OF GLC. vol 81, January 1975, pp 2/1-2/3. 
35. BUILDING. Can Type Approval Stop Building Failures?

7 February 1975.

36. LATHAM, M. A Doomwatch for New Construction, Building, 8 August 1975, pp 42-3.

37. WIGGLESWORTH, G. Building Defects - Who is Guilty, Architects Journal, 11 August 1976, pp 252-253.

38. ALLEN, W. Letter to the Editor, Building, 25 February 1977, p 81.

39. ADDLESON, L. A.J. Guide to Building Failures, Architects Journal, 16 February 1977, pp 23-25.

40. ARCHITECTS JOURNAL. Can we Master Technology? 11 May 1977, pp 864-5.

41. GRAHAM, H. Eliminating the Defects of the 1970s, Municipal Building Management, vol 4. 1977, pp 31-2.

42. ABBOTT, W.W. Managing for Quality in Building, National Builder, September 1977, p 349.

43. DOWNEY, E. Building Defects, Construction News, vol 3, no 9, October 1977, pp 72-3.

44. McDONALD, B. Defects - Who's to Blame? Developer, Architect, Governments? Or? Paper delivered at 29th Conference of the NSW Division of the Building Science Forum of Australia. Published by the BSFA, NSW Divn, Sydney, November 1977.

45. SMITH, A.C. Defects in Buildings - A Builder's Bane (as above).

46. McDOWELL, I. Defects in Buildings - Feedback or Foul-ups (as above). 
47. BESSEY, G.E. Avoiding Faults and Failures in Building, Overseas Building Notes, no 177. BRE Overseas Division, December 1977.

48. NEWLOVE, J. The Achievement of Quality in Construction, Building Notes, no 77. BRE Overseas Division, December 1977.

49. HUGHES, T. Failures and Remedial Work in New Buildings, Construction No.25, PSA March 1978, pp 8-10.

50. BAMPTON, E. Building Better Buildings - Maintenance at the Design Stage, I.O.B. Maintenance Information Service No.3, Spring 1978, pp 1-3.

51. BECK, V.R. Failures of Wall Claddings and Finishes - A Survey. Technical Record 448. Experimental Building Station, Dept of Housing and Construction. NSW, February 1979.

52. MARSH, PAUL. Whither the Buck? An Analyses of Blame, Concrete, vol 3, no 5, May 1979.

53. ARCHITECTS JOURNAL. Failures - A need for Understanding. 31 October 1979.

54. BUILDING DESIGN. Scandal of New Failures. no 473, November 23, 1979.

55. BONSHOR, R. Low Rise Housing Design and Construction, Architects Journal, 30 April 1980, pp 881-885.

56. HOLLAND, G. Misuse of Building Material - Design. Paper delivered to 36th Conference of the NSW Division of the Building Science Forum of Australia. Published by the BSFA NSW Divn. Sydney June 1980.

57. ROXBURGH, R.D. Use or Misuse of Material. (as above).

58. PALMER. J. Education in use or misuse of Building Materials. (as above.) 
59. DOWNEY, E. Weathertightness and Water Penetration of Buildings. Seminar Paper. Paisley College of Technology. 5 November 1980.

60. NICE, P.H. Building Problems and Failures, Building Technology and Management, November 1980, pp 27-8.

61. RANSOM, W.H. Building Failures, E \& F.N.Spon Ltd., London 1981.

62. CHARTERED SURVEYOR. When Will we ever Learn? (Supplement) April 1981, p 2.

63. DRURY, C.A. The Effects on Investment of Major Defects. Supplement to Chartered Surveyor. April 1981, pp 10-11.

64. ATKINSON, G. Attention to details, Building, vol 240, 8 May 1981, pp 60-61.

65. BENTLEY, M.J.C. Quality Control on Building Sites. Current Paper CP $7 / 81$. BRE 1981.

66. BUILDING TECHNOLOGY AND MANAGEMENT. Building Failures, April 1982, p 2.

67. ROBERTS, W.G. Innovation in Materials and Technology makes a Major Construction to Defects and Failures in Buildings, Building Technology and Management, May 1982, p 16.

68. DONALDSON, R. Construction Faults in Housing located in a Mining Town in North West Australia, Architectural Science Review, vol 25, no 2, June 1982, pp 29-36.

69. HAPPOLD, E. Innovation in Materials and Technology makes a Major Contribution to Difficulties and Failures in Building. Paper prepared for delivery to I.O.B. 1982. 
70. HARRISON, H.W. Avoiding Faults in Traditional Housing. BRE News 58, Winter 1982

71. DUELL, J. Variations on a Theme, Architects Journal, 5 January 1983, p 32. 


\section{APPENDIX B}

\section{BUILDING FAILURE REPORT FORM - PROPOSED FORMAT}

Section A (to be completed in full)

Date of inspection:

Address of property:

Name of reporter:

Section B (to be completed only where relevant to the failure)

\section{Structure}

$\begin{array}{ll}\text { Roof Structure } & \text { - materials } \\ & \text { - horizontal elements } \\ & \text { - vertical elements } \\ & \text { - other elements } \\ \text { Wall Structure } & \text { - materials } \\ & \text { - horizontal elements } \\ & \text { - vertical elements } \\ & \text { - other elements } \\ \text { Floor Structure } & \text { - materials } \\ & \text { - horizontal elements } \\ & \text { - vertical elements } \\ & \text { - other elements }\end{array}$

Roof

Exterior description:

- main roof materials

- other roof materials

Eaves

- materials

Gutters

- pipes materials

- penetration materials (e.g. pipes, flues)

Walls

External materials

Finish

Decoration 


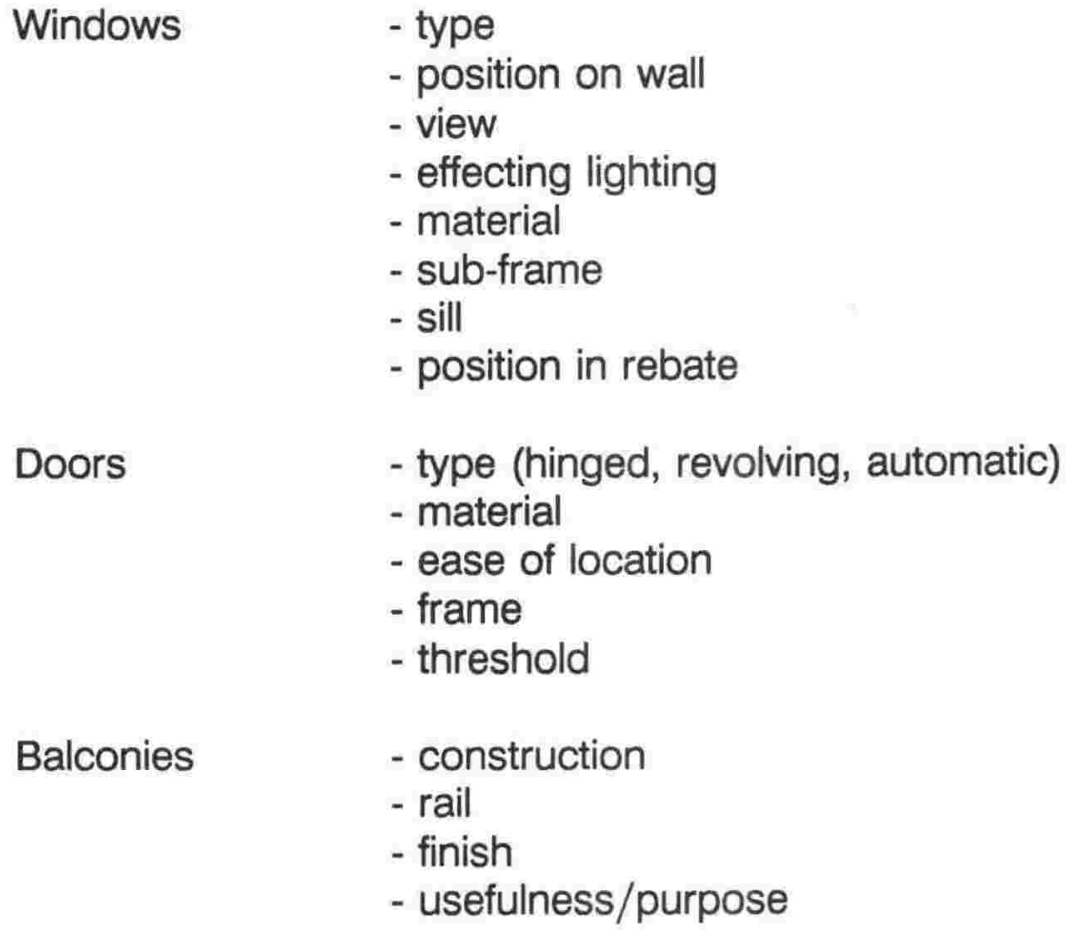

Doors

- type (hinged, revolving, automatic)

- material

- ease of location

- frame

- threshold

Balconies

- construction

- rail

- finish

- usefulness/purpose

\section{Internal finishes}

\begin{tabular}{|c|c|}
\hline Ceilings & $\begin{array}{l}\text { - materials } \\
\text { - tiles } \\
\text { - sheet } \\
\text { - other } \\
\text { - finish }\end{array}$ \\
\hline Walls & $\begin{array}{l}\text { - materials } \\
\text { - tiles } \\
\text { - sheet } \\
\text { - other } \\
\text { - finish }\end{array}$ \\
\hline Floors & $\begin{array}{l}\text { - materials } \\
\text { - tiles } \\
\text { - sheet } \\
\text { - other } \\
\text { - finish }\end{array}$ \\
\hline Trims & $\begin{array}{l}\text { - materials } \\
\text { - tiles } \\
\text { - sheet } \\
\text { - other } \\
\text { - finish }\end{array}$ \\
\hline Hardware & $\begin{array}{l}\text { - handles } \\
\text { - hooks } \\
\text { - hinges } \\
\text { - other fittings }\end{array}$ \\
\hline
\end{tabular}




\section{Other}

\section{SECTION C (to be completed as fully as possible)}

1. Record the evidence which is visible or detectable by touch, smell or hearing.

2. Record the evidence of others with knowledge of the failure site. (Include occupations of witnesses and comment on their apparent level of expertise).

3. Record you conclusion as the cause of failure. 
SECTION D (to be completed on the basis of your observations, the evidence available, and your professional judgment).

1. Human error. This failure was caused wholly or in part by the types of human error ticked below:

( ) 1. Defective materials

( ) 2. Overlooked site condition

( ) 3. Ignorance

( ) 4. Over-emphasis on first cost

( ) 5. Defective documentation

( ) 6. Unanticipated consequence of change

( ) 7. Specialist contractor's lack of knowledge

( ) 8. Design too difficult to build well

( ) 9. Dereliction or negligence

( ) 10. Poor communication

2. Natural causes. This failure was caused wholly or in part by the natural cause ticked below:

( ) 1. Movement

( ) 2. Dampness

( ) 3. Chemical/biological change

Cost of repair: $\$$

Cost of all consequences of failure: $\$$

(fees, consequential damages etc)

Signed:

Dated: 